2010

\title{
Cavitation erosion resistance of NiTi thin films produced by Filtered Arc Deposition
}

Limei Yang

University of Wollongong

\section{Recommended Citation}

Yang, Limei, Cavitation erosion resistance of NiTi thin films produced by Filtered Arc Deposition, Doctor of Philosophy thesis, School of Mechanical, Materials and Mechatronic, University of Wollongong, 2010. http://ro.uow.edu.au/theses/3220 


\section{Cavitation Erosion Resistance of NiTi Thin Films Produced by Filtered Arc Deposition}

A thesis submitted in fulfilment of the requirements

for the award of the degree

Doctor of Philosophy

from

University of Wollongong

by

Limei Yang B. Eng., M. Eng.

School of Mechanical, Materials and Mechatronic

February 2010 


\section{Declaration}

I, Limei Yang, hereby certify that the work presented in this thesis is original and was carried out at the School of Mechanical, Materials and Mechatronic Engineering, the University of Wollongong, New South Wales, Australia. To the best of my knowledge and belief this thesis contains no material previously published or written by another person, except where otherwise acknowledgement and references have been made in the thesis. This work has not been submitted previously, in part or in whole, to qualify for any other degree.

Limei Yang 


\section{Acknowledgements}

First and foremost, I would like to thank my principal supervisor, Professor A. Kiet. Tieu., for providing timely and insightful advice, financial and spiritual support. My supervisor's implicit trust in my research abilities not only allowed me to freely pursue my goals, but also gave me an opportunity to learn how to manage time and allocate resources. Special thanks go to Professor Druce Dunne, for his insightful instruction and for all the generous attention and time he devoted to my research work.

I would also like to express my appreciation to Dr. Shaowei Huang and Associate Professor Huijun Li. Without their invaluable assistance and guidance, I would never have finished this work. I thank my co-supervisors, Associate Professor Zhengyi Jiang. Special thanks go to Dr. David Wexler, who put a lot of time and work into my research work.

I would also like to thank Greg Tillman and Andrew Scobie. Without their genuine help in the lab work I would have not possibly finished my work. Thanks to other staff members, Mr. Keith Maywald, Mr. Bob De Jong, Mr. Jose Gonzalez, Mr. Nick Mackie, Mr. Ron Kinnel, Mr. Ron Marshall and Dr. Konstan Konstantinov for their help in many regards. Special thanks go to Prof. John Norrish and Prof. Geoff Spinks, for their timely and generous help to my work. Thank you also to my fellow work colleagues, Nam N. Huynh, Qiang Zhu and Yuan Gao, for their genuine help and encouragement in my 
work. I would like to thank Matthew Franklin and Philip Whitten, in particular, whose knowledge and experience helped me go through difficulties in this research.

To my great parents, I am forever indebted to their non-stop financial and spiritual support---I could never have asked for better parents. My dear Mum and Dad, I love you forever.

Most importantly, I wish to express my gratitude to my husband, Zhenguo Huang. His unfailing love, patience, perseverance, and encouragement enabled me to really concentrate on my study. Zhenguo, I am extremely grateful for your love. Thank you. 


\section{Publication}

L.M. Yang, A.K. Tieu, D.P. Dunne, S.W. Huang, H.J. Li, D. Wexler, Z.Y. Jiang, Cavitation erosion resistance of NiTi thin films produced by Filtered Arc Deposition, Wear 267 (2009) p. 233-243 


\section{List of Tables}

Table 5.1: Chemical compositions (in wt \%) of 316 austenitic stainless steel and mild

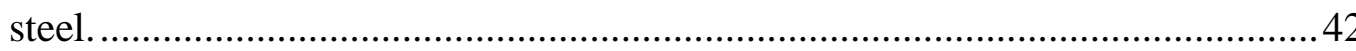

Table 5.2: Chemical composition of NiTi bulk alloy .................................................4 44

Table 5.3: Chemical composition of electroless Ni plating bath...............................51

Table 6.1: Chemical compositions (atomic \% Ti) of NiTi films deposited at different

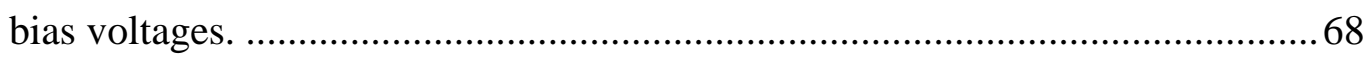

Table 7.1: Transformation temperatures of bulk and thin films with similar Ti contents. 84

Table 7.2: Transformation temperatures of NiTi thin films deposited at $430^{\circ} \mathrm{C}$ and $600^{\circ} \mathrm{C}$ 89

Table 7.3: Transformation temperatures of bulk NiTi alloy and thin films deposited at different substrate bias voltages.

Table 7.4: Transformation temperatures of bulk NiTi alloy and amorphous thin films after being crystallized 96

Table 8.1: Hardness and elastic modulus of the amorphous and crystalline NiTi thin film deposited on austenitic stainless steel and mild steel. 


\section{List of Figures}

Figure 2.1: Schematic representation of the cavitation erosion mechanism [1] .6

Figure 2.2: Schematic representation of typical variation of liquid-erosion rate with exposure time [1].

Figure 3.1: Phase equilibrium diagram for Ni-Ti binary alloy [9], [36].... 13

Figure 3.2: Crystal structures of NiTi alloys; (a) cubic parent B2 structure, (b) monoclinic B19' martensite structure, (c) R-phase structure [40]

Figure 3.3: Schematic illustration of parent and martensite with invariant plane as a habit plane [9].

Figure 3.4: Schematic diagram of martensitic deformations: (a) undeformed lattice, (b) lattice distortion, (c) lattice distortion and lattice invariant slip, (d) lattice distortion and lattice invariant twinning [45].

Figure 3.5: Lattice change from B2 parent (a) to B19' martensite (b). i, j, and k refer to parent lattice, and i', j' and k' refer to the martensite lattice [9].

Figure 3.6: $\mathrm{M}_{\mathrm{S}}$ temperature versus $\mathrm{Ni}$ content in NiTi alloys [50], [51]. ...................2 24

Figure 3.7: Schematic diagram of one way shape memory effect [4], [52]. ..............25

Figure 3.8: Schematic diagram of two way shape memory effect [4], [52]..............22

Figure 3.9: Schematic diagram of the superelastic effect [4], [52] ............................29

Figure 4.1: Schematic of a parallel-plate diode sputtering system [65] ..................... 35

Figure 4.2: Schematic of an ion plating system using a DC diode discharge and a thermal vaporization source [65]. 36

Figure 4.3: Basic components of an evaporation system with resistance heating source [68].

Figure 4.4: Macroparticle filtering system using a magnetic plasma duct system [80],

[88]-[90]

Figure 4.5: Effect of deposition current on the composition of films deposited using

FADS [14]

Figure 6.1: Effect of arc current on the atomic percentage of $\mathrm{Ti}($ Bias voltage $=80 \mathrm{~V})$. 
Figure 6.2: Effect of substrate bias voltage on the atomic percentage of Ti (Arc current=115 A).

Figure 6.3: X-ray diffraction patterns for Ni-42.00at\% Ti for 2 Theta from (a) $30^{\circ}$ to $100^{\circ}$; (b) $40^{\circ}$ to $50^{\circ}$ .57

Figure 6.4: TEM image of the Ni-42.00at\% Ti thin film. ......................................57

Figure 6.5: X-ray diffraction pattern for Ni-54.05at\% Ti........................................58

Figure 6.6: TEM image of the Ni-54.05at\% Ti film. 59

Figure 6.7: X-ray diffraction pattern for the near-equiatomic NiTi thin film for 2-Theta from (a) $35^{\circ}$ to $50^{\circ}$; (b) $55^{\circ}$ to $100^{\circ}$. 60

Figure 6.8: TEM image of the near-equiatomic NiTi at (a) low magnification and (b) high magnification 61

Figure 6.9: $\mathrm{XRD}$ patterns of the thin films deposited at $130^{\circ} \mathrm{C}$ and $300^{\circ} \mathrm{C}$. The pattern for the mild steel substrate is also shown.

Figure 6.10: XRD pattern of the thin film deposited at $430^{\circ} \mathrm{C}$. The pattern for the mild steel substrate is also shown.

Figure 6.11: TEM image of a cross-section of the thin film deposited at $430^{\circ} \mathrm{C}$ (inset is the electron diffraction pattern taken from the selected region). 65

Figure 6.12: XRD pattern of the thin film deposited at $600^{\circ} \mathrm{C}$. 66

Figure 6.13: TEM image of a cross section of the thin film deposited at $600{ }^{\circ} \mathrm{C}$ (inset is the electron diffraction pattern taken from the selected region). ([101] B2 zone axis pattern).

Figure 6.14: XRD patterns of thin films deposited at $150^{\circ} \mathrm{C}$

Figure 6.15: Effect of bias voltage on the phases of thin films deposited at $600^{\circ} \mathrm{C}$ in the (a) whole range of counts and the (b) smaller range of counts.

Figure 6.16: TEM image of the thin film deposited at $80 \mathrm{~V}$ with a starting temperature of $600^{\circ} \mathrm{C}$.

Figure 6.17: XRD patterns of the thin film deposited on austenitic stainless steel substrate (a) without preheating; (b) with a pre-heat substrate temperature of $430^{\circ} \mathrm{C}$; (c) a smaller angular range of (b). 
Figure 6.18: TEM image of a cross section of the thin film deposited on austenitic 316 stainless steel with the substrate preheated to $430^{\circ} \mathrm{C}$. 77

Figure 6.19: XRD patterns of the crystallized thin film deposited at $130^{\circ} \mathrm{C}$.............. 78

Figure 6.20: XRD patterns of the crystallized thin film deposited at $300^{\circ} \mathrm{C}$. ..............78

Figure 7.1: DSC traces of the NiTi target (heating and cooling rates of $10^{\circ} \mathrm{C} / \mathrm{min}$ )...79

Figure 7.2: DSC curves of the thin film with Ni-42.00at\% Ti (heating and cooling rates of $\left.10^{\circ} \mathrm{C} / \mathrm{min}\right)$.

Figure 7.3: DSC traces of the thin film with Ni-54.05at\% Ti (heating and cooling rates of $\left.10^{\circ} \mathrm{C} / \mathrm{min}\right)$

Figure 7.4: DSC traces of the thin film with Ni-49.98at\% Ti (heating and cooling rates of $\left.10^{\circ} \mathrm{C} / \mathrm{min}\right)$

Figure 7.5: DSC traces of the thin film obtained at $130^{\circ} \mathrm{C}$ (heating and cooling rates of $\left.10^{\circ} \mathrm{C} / \mathrm{min}\right)$

Figure 7.6: DSC traces of the thin film obtained at $300^{\circ} \mathrm{C}$ (heating and cooling rates of $\left.10^{\circ} \mathrm{C} / \mathrm{min}\right)$. 86

Figure 7.7: DSC traces of the thin film obtained at $430^{\circ} \mathrm{C}$ (heating and cooling rates of $\left.10^{\circ} \mathrm{C} / \mathrm{min}\right)$.

Figure 7.8: DSC of the thin film obtained at $600^{\circ} \mathrm{C}$ (heating and cooling rates of $\left.10^{\circ} \mathrm{C} / \mathrm{min}\right)$ 88

Figure 7.9: DSC traces of the thin film deposited at $50 \mathrm{~V}$.

Figure 7.10: DSC traces of the thin film deposited at $80 \mathrm{~V}$. 91

Figure 7.11: DSC traces of the thin film deposited at $150 \mathrm{~V}$. 92

Figure 7.12: Crystallization of the amorphous thin film deposited at $130^{\circ} \mathrm{C}$ and $300^{\circ} \mathrm{C}$

Figure 7.13: DSC traces of the thin film deposited at $130^{\circ} \mathrm{C}$ after being crystallized.95

Figure 7.14: DSC traces of the thin film deposited at $300^{\circ} \mathrm{C}$ after being crystallized.95

Figure 8.1: AFM image of the surface of a near-equiatomic crystalline NiTi thin film.

Figure 8.2: Plot of the load versus displacement resulting from indents on a near-equiatomic NiTi thin film constrained on mild steel substrate. 
Figure 8.3: Plot of normal load versus distance during scratch tests on a near-equiatomic crystalline NiTi thin film. 100

Figure 8.4: SEM image of scratch tracks on a near-equiatomic NiTi thin film at (a) lower critical load; (b) upper critical load. 101

Figure 8.5: AFM images of thin films deposited at different substrate temperatures.

(a) $130^{\circ} \mathrm{C}$; (b) $300^{\circ} \mathrm{C}$; (c) $430^{\circ} \mathrm{C}$; (d) $600^{\circ} \mathrm{C}$ 104

Figure 8.6: Roughness of thin films deposited at different substrate temperatures... 104

Figure 8.7: Plots of the load versus displacement from the indents on the constrained NiTi thin films deposited at different substrate temperatures. 106

Figure 8.8: Hardness and elastic modulus of thin films deposited at different substrate temperatures. 106

Figure 8.9: Plots of normal load versus distance from scratch tests on thin films deposited at different substrate temperatures. (a) $130^{\circ} \mathrm{C}$; (b) $300^{\circ} \mathrm{C}$; (c) $430^{\circ} \mathrm{C}$; (d) $600^{\circ} \mathrm{C}$. 109

Figure 8.10: AFM images of thin films deposited at $600^{\circ} \mathrm{C}$ at different substrate bias voltages. (a) $50 \mathrm{~V}$; (b) $80 \mathrm{~V}$; (c) $120 \mathrm{~V}$; (d) $150 \mathrm{~V}$.

Figure 8.11: Roughness of thin films deposited at different substrate bias voltages. 113

Figure 8.12: Plots of the load versus displacement from the indents on samples deposited at different substrate bias voltages.

Figure 8.13: Hardness and elastic modulus of thin films deposited at different substrate bias voltages.

Figure 8.14: Plots of normal load versus distance from scratch tests on thin films deposited at different bias voltages. (a) $50 \mathrm{~V}$; (b) $80 \mathrm{~V}$; (c) $120 \mathrm{~V}$; (d) $150 \mathrm{~V} . .117$

Figure 8.15: Plots of the load versus displacement curves from the indents made on constrained NiTi thin films on stainless steel (SS) and mild steel (MS). 119

Figure 8.16: Optical images of scratch tests with $500 \mathrm{mN}$ ramping force on constrained NiTi thin films on different substrate materials $\left(776 \times 578 \mu \mathrm{m}^{2}\right) . .121$

Figure 8.17: Plots of normal force, normal displacement, lateral force, and lateral displacement versus time from a representative $500 \mathrm{mN}$ ramping force scratch test on crystalline NiTi film on stainless steel. 
Figure 8.18: Plots of normal force, normal displacement, lateral force, and lateral displacement versus time from a representative $500 \mathrm{mN}$ ramping force scratch test on crystalline NiTi film on mild steel.

Figure 8.19: Plots of nomal force, normal displacement, lateral force, and lateral displacement versus time from a representative $500 \mathrm{mN}$ ramping force scratch test on amorphous NiTi film on stainless steel.

Figure 8.20: Plots of normal force, normal displacement, lateral force, and lateral displacement versus time from a representative $500 \mathrm{mN}$ ramping force scratch test on amorphous NiTi film on mild steel.

Figure 8.21: A TriboAnalysis ${ }^{\mathrm{TM}}$ plot of normal displacement versus lateral displacement from the $500 \mathrm{mN}$ ramping force scratch tests performed on constrained NiTi films on different substrate materials.

Figure 9.1: Low and high magnification SEM images before cavitation erosion testing. Stainless steel 316 (a) and (b); NiTi bulk alloy (c) and (d); Near-equiatomic NiTi thin film (e) and (f).

Figure 9.2: Low and high magnification SEM images after 4 hours cavitation erosion testing. Stainless steel 316 (a) and (b); NiTi bulk alloy (c) and (d); Near-equiatomic NiTi thin film (e) and (f)

Figure 9.3: Low and high magnification SEM images after 10 hours cavitation erosion testing. Stainless steel 316 (a) and (b); NiTi bulk alloy (c) and (d); Near-equiatomic NiTi thin film (e) and (f); (g) cross-sectional view of a pit in the NiTi thin film that extended into the substrate.

Figure 9.4: Low and high magnification SEM images after 13 hours cavitation erosion testing. Stainless steel 316 (a) and (b); NiTi bulk alloy (c) and (d); Near-equiatomic NiTi thin film on mild steel (e) and (f). 130

Figure 9.5: Low and high magnification SEM images after 20 hours cavitation erosion testing. Stainless steel 316 (a) and (b); NiTi bulk alloy (c) and (d); Near-equiatomic NiTi thin film (e) and (f). 132

Figure 9.6: Mass loss of NiTi thin film, 316 austenitic stainless steel and NiTi bulk as a function of cavitation exposure time. 
Figure 9.7: Low and high magnification SEM images after 4 hour cavitation erosion testing. NiTi thin film deposited at $130^{\circ} \mathrm{C}$ (a) and (b); $300^{\circ} \mathrm{C}(\mathrm{c})$ and (d); $430^{\circ} \mathrm{C}$ (e) and (f); and $600^{\circ} \mathrm{C}(\mathrm{g})$ and $(\mathrm{h})$. 135

Figure 9.8: Low and high magnification SEM images after 10 hours cavitation erosion testing. NiTi thin film deposited at $130^{\circ} \mathrm{C}(\mathrm{a})$ and $(\mathrm{b}) ; 300^{\circ} \mathrm{C}(\mathrm{c})$ and (d); $430^{\circ} \mathrm{C}(\mathrm{e})$ and (f); and $600^{\circ} \mathrm{C}(\mathrm{g})$ and (h).

Figure 9.9: Low and high magnification SEM images after 13 hours cavitation erosion testing. NiTi thin film deposited at $130^{\circ} \mathrm{C}$ (a) and (b); $300^{\circ} \mathrm{C}(\mathrm{c})$ and (d); $430^{\circ} \mathrm{C}(\mathrm{e})$ and (f); and $600^{\circ} \mathrm{C}(\mathrm{g})$ and $(\mathrm{h})$. 138

Figure 9.10: Low and high magnification SEM images after 20 hours cavitation erosion testing. NiTi thin film deposited at $130^{\circ} \mathrm{C} \mathrm{(a)} \mathrm{and} \mathrm{(b);} 300^{\circ} \mathrm{C}(\mathrm{c})$ and (d); $430^{\circ} \mathrm{C}(\mathrm{e})$ and (f); and $600^{\circ} \mathrm{C} \mathrm{(g)} \mathrm{and} \mathrm{(h).}$ 140

Figure 9.11: Mass loss of NiTi thin films deposited at different substrate temperatures as a function of cavitation exposure time.

Figure 9.12: Low and high magnification SEM images before cavitation erosion testing. NiTi thin film deposited at $600^{\circ} \mathrm{C}$ with $50 \mathrm{~V}$ (a) and (b); $80 \mathrm{~V}$ (c) and (d); $120 \mathrm{~V}(\mathrm{e})$ and $(\mathrm{f})$; and $150 \mathrm{~V}(\mathrm{~g})$ and $(\mathrm{h})$ 143

Figure 9.13: SEM images after 4 hours of cavitation erosion testing. NiTi thin film deposited at $600^{\circ} \mathrm{C}$ at $50 \mathrm{~V}(\mathrm{a}) ; 80 \mathrm{~V}(\mathrm{~b}) ; 120 \mathrm{~V}$ (c); and $150 \mathrm{~V}(\mathrm{~d})$. 144

Figure 9.14: SEM images after 10 hours of cavitation erosion testing. NiTi thin film deposited at $600^{\circ} \mathrm{C}$ at $50 \mathrm{~V}$ (a); $80 \mathrm{~V}$ (b); $120 \mathrm{~V}$ (c); and $150 \mathrm{~V}$ (d). 145

Figure 9.15: SEM images after 13 hours of cavitation erosion testing. NiTi thin film deposited at $600^{\circ} \mathrm{C}$ at $50 \mathrm{~V}(\mathrm{a}) ; 80 \mathrm{~V}(\mathrm{~b}) ; 120 \mathrm{~V}(\mathrm{c}) ;$ and $150 \mathrm{~V}(\mathrm{~d})$. 146

Figure 9.16: SEM images after 20 hours of cavitation erosion testing. NiTi thin film deposited at $600^{\circ} \mathrm{C}$ at $50 \mathrm{~V}(\mathrm{a}) ; 80 \mathrm{~V}(\mathrm{~b}) ; 120 \mathrm{~V}$ (c); and $150 \mathrm{~V}(\mathrm{~d})$.

Figure 9.17: Mass loss of NiTi thin films deposited at different substrate biases as a function of cavitation exposure time. 148

Figure 9.18: Low and high magnification SEM images of the NiTi thin film deposited on austenitic stainless steel after cavitation erosion testing for 4 hours (a) and (b); 10 hours (c) and (d); 13 hours (e) and (f); and 20 hours (g) and (h).150 
Figure 9.19: Mass loss of the NiTi thin film deposited on austenitic stainless steel as a

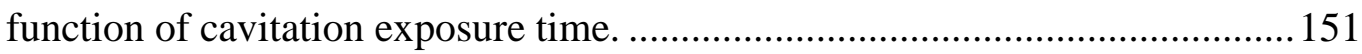




\section{Table of Contents}

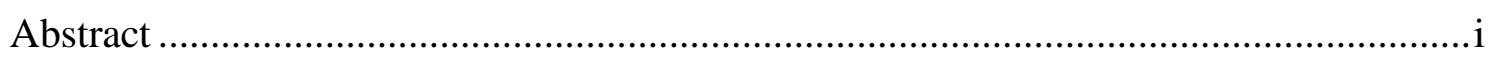

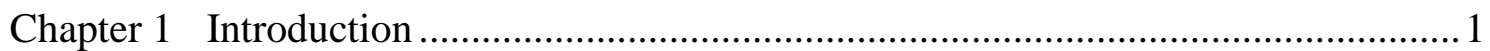

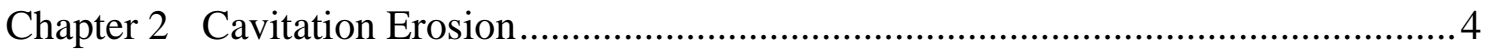

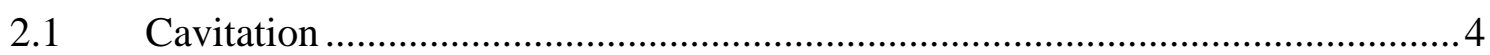

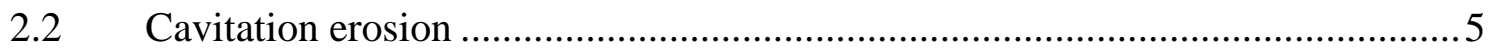

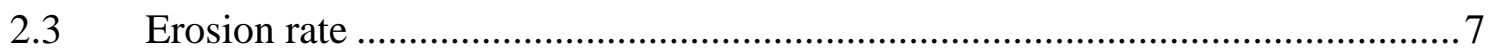

2.4 Evaluation methods of cavitation resistance (ASTM G32) ............................ 8

2.5 Prevention of cavitation erosion damage ....................................................

Chapter 3 NiTi Shape Memory Alloy ......................................................................... 11

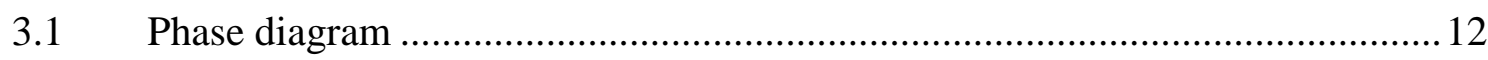

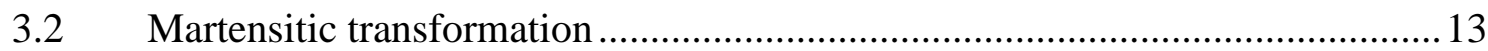

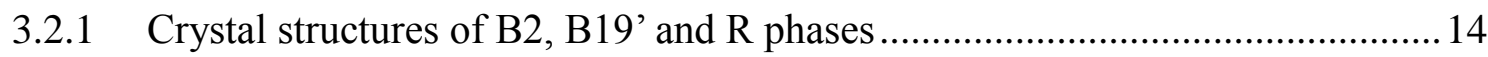

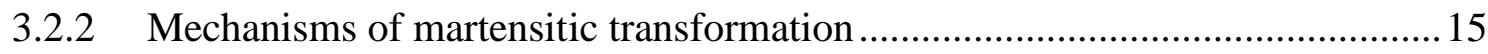

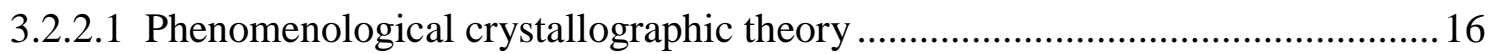

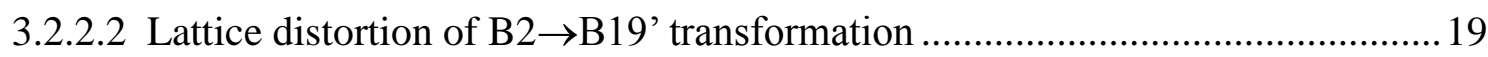

3.2.2.3 Accommodation of lattice distortion of martensite ..........................................2 20

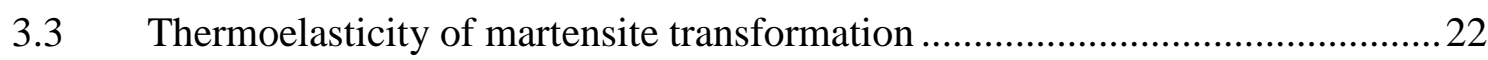

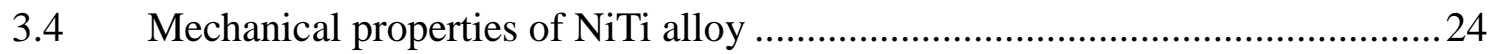

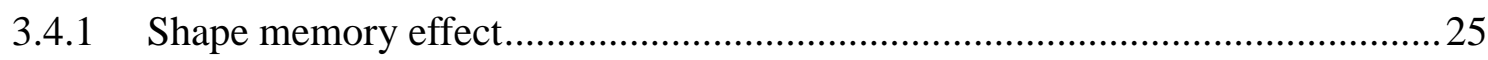

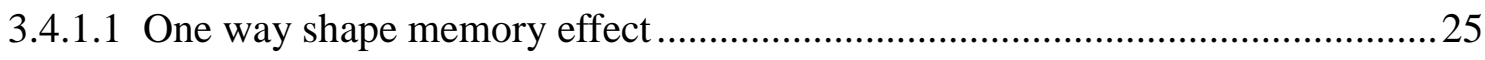

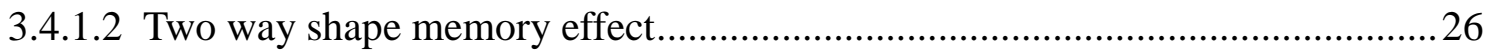

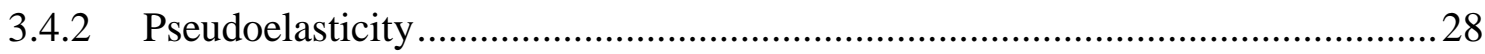

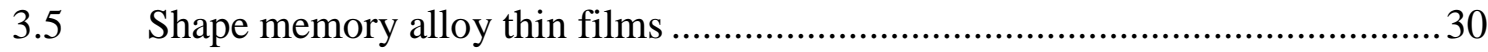

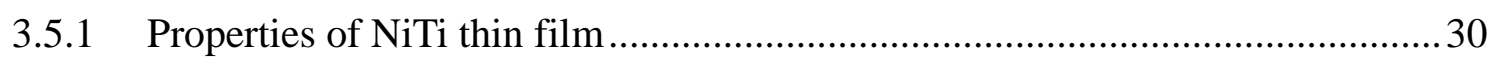

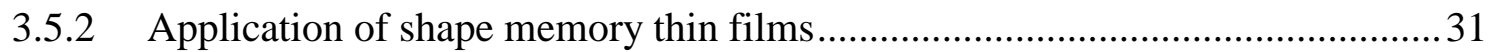

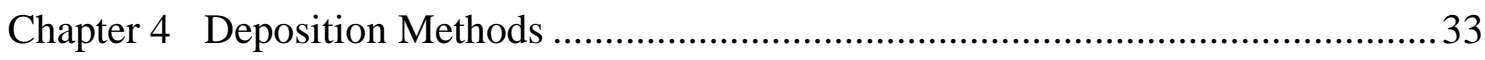

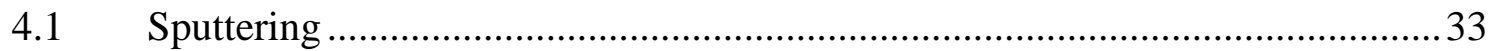




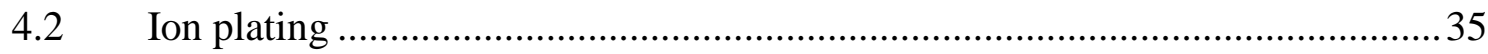

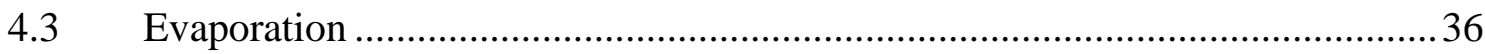

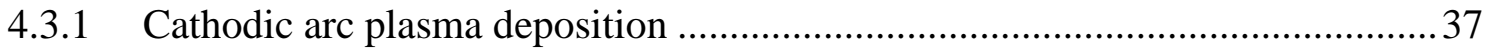

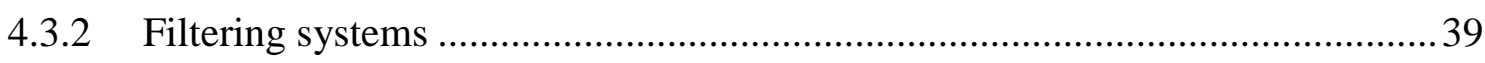

4.4 Film deposition method used in the current research....................................... 40

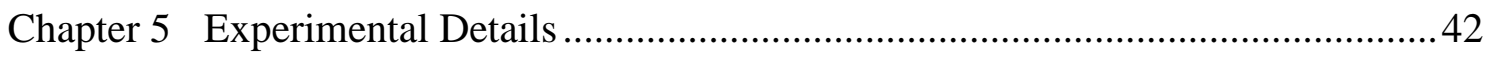

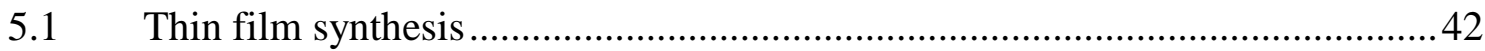

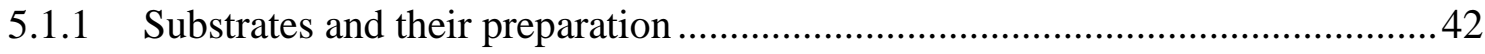

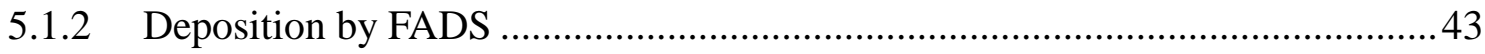

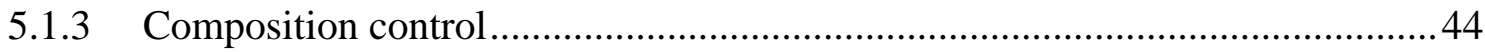

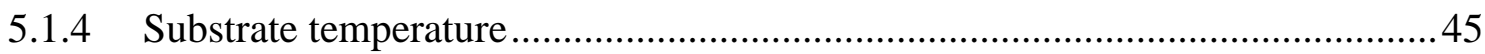

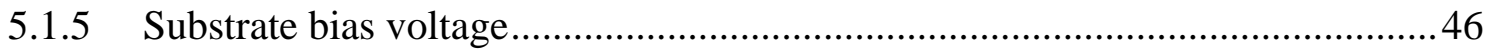

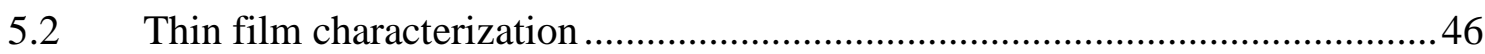

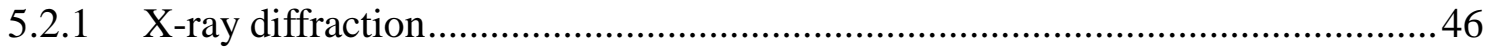

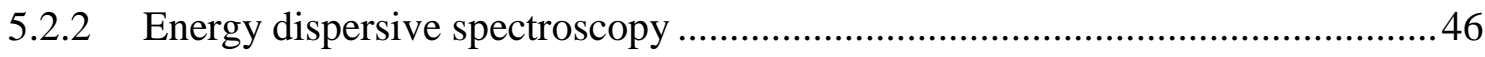

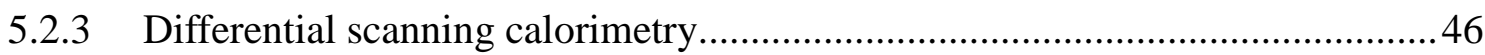

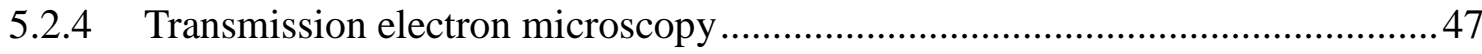

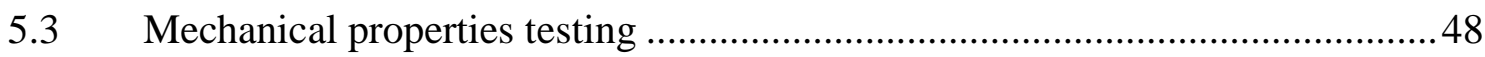

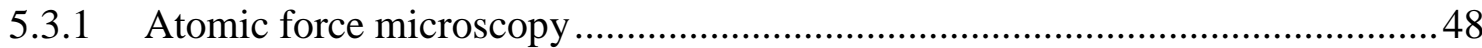

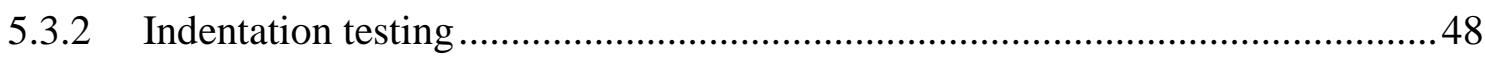

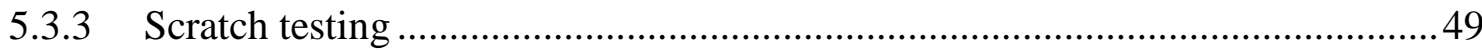

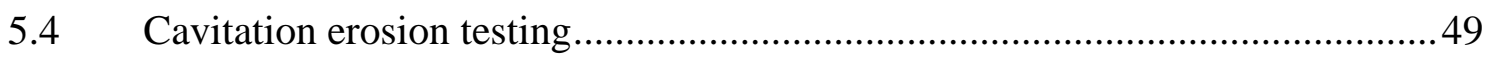

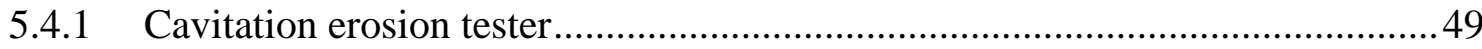

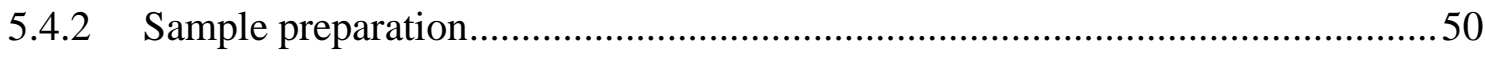

5.4.3 Measurement of cavitation erosion resistance ................................................. 51

Chapter 6 XRD and TEM Characterization of NiTi Thin Films ...............................53

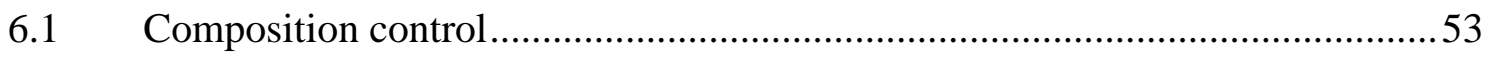

6.1.1 Effects of arc current and substrate bias voltage on thin film composition .......53

6.1.2 Microstructures of thin films with different compositions..................................55

6.1.2.1 XRD and TEM analysis of the Ni-42.00at\% Ti film ....................................55 
6.1.2.2 XRD and TEM analysis of the Ni-54.05at\% Ti film .....................................58

6.1.2.3 XRD and TEM analysis of the near-equiatomic Ni-49.98at\% Ti film...............59

6.2 Effect of substrate temperatures on microstructure .......................................62

6.2.1 Microstructure of thin films deposited at low temperatures ............................. 62

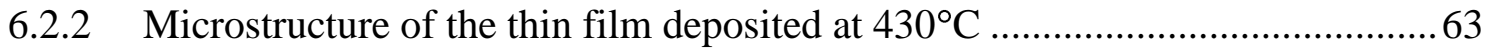

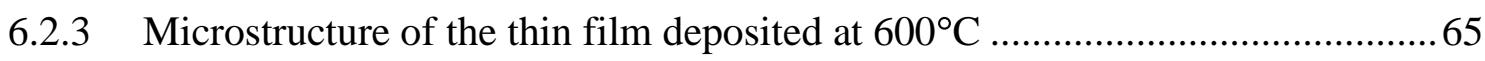

6.3 Effect of substrate bias voltages on microstructure .......................................6 68

6.3.1 Effect of bias voltage on the phases of thin films deposited at $150^{\circ} \mathrm{C} \ldots \ldots \ldots \ldots . . . .68$

6.3.2 Effect of substrate bias voltage on the phases of thin films deposited at $600^{\circ} \mathrm{C} 70$

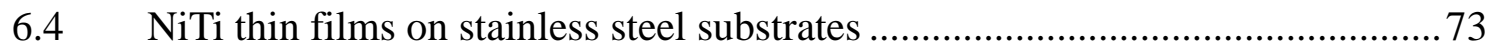

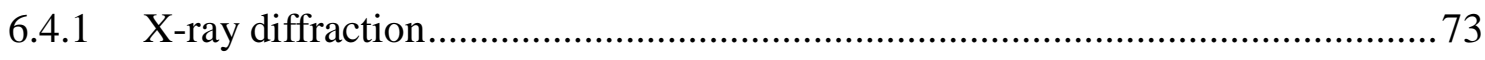

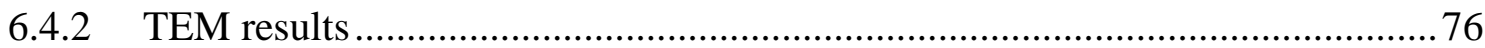

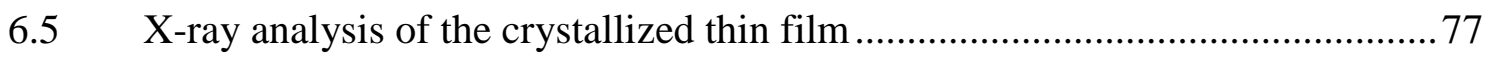

Chapter 7 Thermal Properties of NiTi Thin Films ................................................... 79

7.1 Thermal transformation behaviour of the target alloy .................................... 79

7.2 Thermal behaviour of NiTi thin films with different chemical compositions ... 80

7.3 Thermal behaviour of NiTi thin films deposited at different substrate temperatures

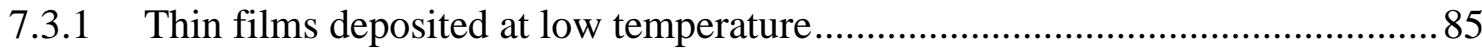

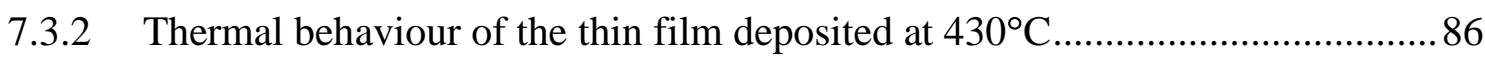

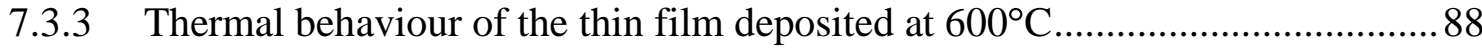

7.4 Thermal behaviour of NiTi thin films deposited at different bias voltages with a

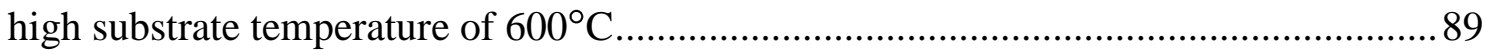

7.5 Comparison of amorphous and crystalline thin films ....................................93

Chapter 8 Mechanical Properties of NiTi Thin Films................................................ 97

8.1 Mechanical properties of equiatomic NiTi thin films ....................................97

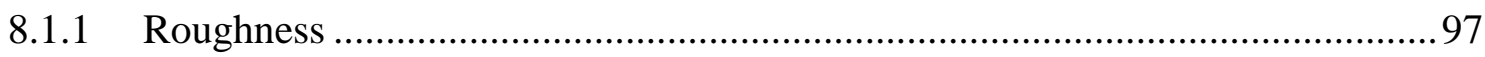

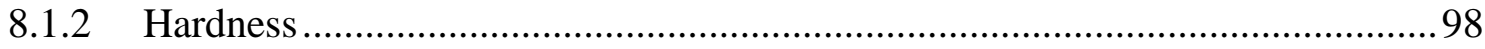

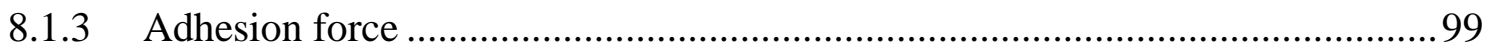


8.2 Mechanical properties of NiTi thin films deposited at different substrate

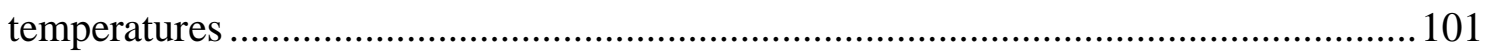

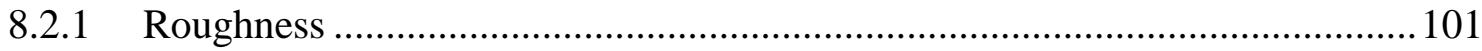

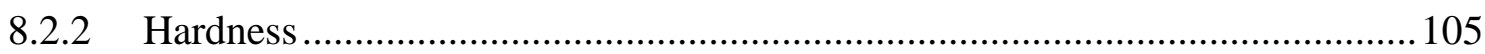

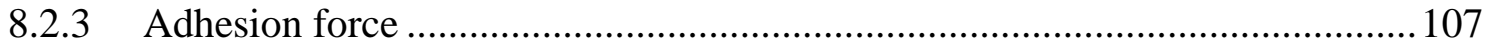

8.3 Mechanical properties of thin films deposited at different substrate bias voltages

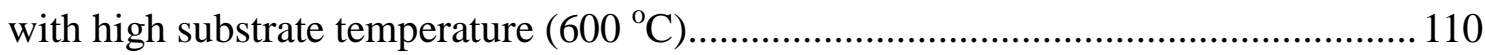

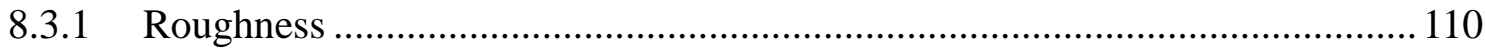

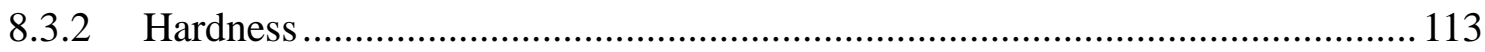

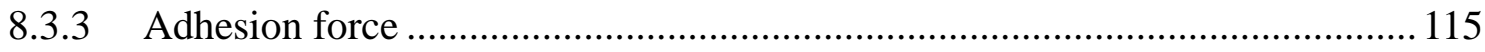

8.4 Mechanical properties of thin films deposited on austenitic stainless steel..... 117

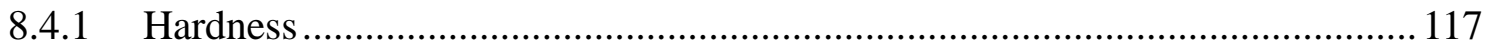

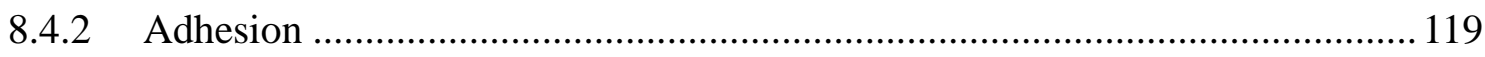

Chapter 9 Cavitation Erosion Resistance of NiTi Thin Films ................................. 125

9.1 Cavitation erosion resistance of NiTi bulk alloy, austenitic stainless steel and

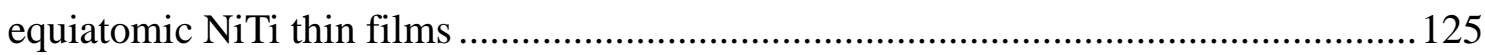

9.2 Cavitation erosion resistance of NiTi thin films deposited at different substrate

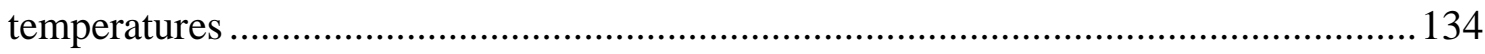

9.3 Cavitation erosion resistance of NiTi thin films deposited at different substrate

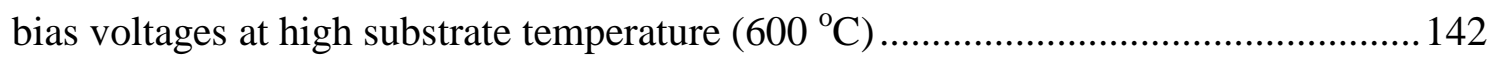

9.4 Cavitation erosion resistance of thin films on austenitic stainless steel ..........149

Chapter 10 Conclusions and Future Research ..................................................... 152

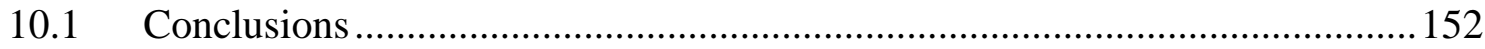

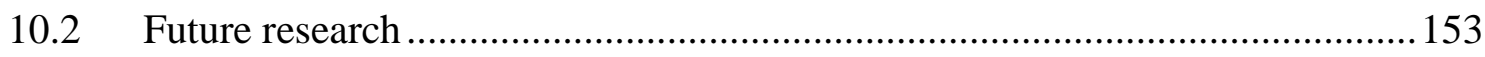

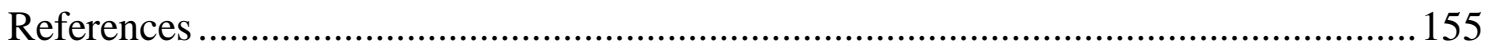

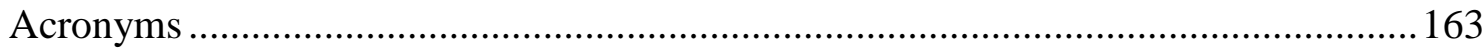




\begin{abstract}
The objective of this work was to produce near-equiatomic NiTi thin films by filtered arc deposition system (FADS) to improve the cavitation erosion resistance of a steel base working in liquid. First, deposition conditions were optimized in order to obtain near-equiatomic NiTi films. Energy dispersive spectroscopy (EDS) was used to measure the composition of films. It was found that both the substrate bias voltage and arc current affect the compositions of as-deposited NiTi films. X-ray diffractometry (XRD) and transmission electron microscopy (TEM) were used to investigate the microstructures of Ni-rich, Ti-rich and near-equiatomic films. Their thermal behaviours were tested using differential scanning calorimetry (DSC). Atomic force microscopy (AFM), ultra micro-indentation system (UMIS) and Romulus scratch testing were used to measure the roughness, hardness and adhesive force of a near-equiatomic thin film. The cavitation erosion resistance of the near-equiatomic NiTi film was assessed using ASTM Test Method G32. It was found that NiTi thin films showed significantly higher cavitation erosion resistance than 316 austenitic stainless steel. The improved cavitation erosion resistance was attributed to the recoverable deformation associated with pseudoelasticity of the NiTi thin film.
\end{abstract}

The effect of substrate temperature on the properties of NiTi thin films was investigated by preheating substrates to different temperatures $\left(130^{\circ} \mathrm{C}, 300^{\circ} \mathrm{C}, 430^{\circ} \mathrm{C}\right.$ and $\left.600^{\circ} \mathrm{C}\right)$. 
The films deposited at low temperatures $\left(130^{\circ} \mathrm{C}\right.$ and $\left.300^{\circ} \mathrm{C}\right)$ were amorphous and at high temperatures $\left(430^{\circ} \mathrm{C}\right.$ and $\left.600^{\circ} \mathrm{C}\right)$ were crystalline with a preferred orientation. The crystalline films were sectioned using the focused ion beam (FIB) milling technique and the cross-sections were viewed by TEM. The crystalline NiTi film deposited at the highest temperature $\left(600^{\circ} \mathrm{C}\right)$ is dominated by $\mathrm{B} 2$ parent phase. The retention of $\mathrm{B} 2$ phase probably arises from increased solution of $\mathrm{O}$ and $\mathrm{N}$ from the chamber atomosphere at the higher deposition temperature. The crystalline films deposited at $430^{\circ} \mathrm{C}$ contained a mixture of $\mathrm{B} 2$ parent phase, $\mathrm{B} 19^{\prime}$ product phase and $\mathrm{R}$ intermediate phase. The crystalline films were significantly more resistant to cavitation erosion than the amorphous films because of their capacity to accommodate stress by pseudoelastic strain. The film deposited at $600^{\circ} \mathrm{C}$ showed less cavitation erosion resistance than thin films deposited at $430^{\circ} \mathrm{C}$ because of its larger grain size and precipitates formed at high temperature. The mechanical properties of the deposited NiTi films were also dependent on the substrate temperature. The surface roughness increased with increasing substrate temperature due to an increase in grain size. The adhesive force between the film and substrate was strengthened by atomic interdiffusion at higher temperatures.

The effect of deposition bias voltage on the properties of NiTi thin films was investigated under different bias voltages $(50 \mathrm{~V}, 80 \mathrm{~V}, 120 \mathrm{~V}$ and $150 \mathrm{~V})$. A higher bias voltage led to a high deposition temperature likely due to the higher kinetic energy of atoms and ions. The thin film deposited at the highest bias voltage $(150 \mathrm{~V})$ was dominated by B2 parent phase. The bonding force of the films increased with increasing 
bias voltage because of the enhanced interdiffusion occurring at high temperature. Due to improved pseudoelastic behaviour, the thin film obtained at $80 \mathrm{~V}$ with a substrate temperature of $600^{\circ} \mathrm{C}$ was more resistant to cavitation erosion than films deposited at other bias voltages with a similar substrate temperature.

The effect of substrate material on the properties of NiTi thin films was investigated by comparing films on mild steel and on austenitic stainless steel. For similar deposition conditions, the NiTi film deposited on mild steel consisted of B2, B19' and R phases, while the NiTi film on stainless steel was dominated by B2 parent phase. This is probably because the lower thermal conductivity of austenitic stainless steel resulted in a higher deposition temperature.

The dominance of the B2 phase for deposition with a high substrate temperature, a high bias voltage and the use of stainless steel substrate was not found to be due to $\mathrm{Ni}$-enrichment of the films, but is consistent with stabilization of the parent phase by possible pick-up oxygen and nitrogen from the chamber atmosphere when the deposition temperature is high.

The research program successfully produced homogeneous near-equiatomic NiTi thin films by using an advanced deposition technique, FADS. Although only two micron thick, NiTi films exhibited markedly superior cavitation erosion resistance, compared with an austenitic stainless steel reference material, and this is ascribed to their 
pseudoelastic behaviour under cavitation stress. 


\section{Chapter 1}

\section{Introduction}

Wear damage to engineering components as a result of corrosion and erosion in liquid environments results in significant economic loss to industry through materials loss, production downtime and costs associated with repair and refurbishment. Cavitation erosion is an example of a serious material wear problem in systems subject to hydrodynamic turbulence. Examples of metal parts susceptible to cavitation damage include components of hydraulic machinery, ship propellers and water turbines. The mechanism of cavitation erosion involves the action of bubbles in a liquid which form and then collapse at the surface of the material as a result of rapid changes in pressure [1].

Research work on the cavitation damage of certain types of shape memory alloys (SMA) indicates unusually high resistance to erosion [2], [3]. It appears that their capacity to accommodate stress or pressure arises from pseudoelastic behavior, rather than plastic deformation, thus retarding the initiation of wear damage. Following the definition by Ostuka and Wayman [4], pseudoelasticity considered in this thesis includes both superelasticity and rubber-like behaviour. The term "ferroelasticity" is also used as an alternative to "rubber-like behaviour" [5], [6]. 
Nitinol, an approximately equiatomic NiTi alloy, exhibits recoverable "elastic" strains of up to $8 \%$, more than an order of magnitude higher than for a normal metal. The pseudoelastic (PE) behaviour of Nitinol contributes to its enhanced cavitation erosion resistance [7]

The expense of Nitinol would normally preclude its use for larger components subject to cavitation erosion, and coatings of Nitinol on a steel base appear to be the most cost-effective alternative. Ishida et al. successfully produced the first NiTi thin film by sputtering in 1993 [8]. A series of investigations have proved that the NiTi thin films have the same shape memory behaviour and pseudoelasticity as bulk alloys [8]-[10].

Several deposition methods have been used for fabricating NiTi-based thin films, such as sputtering [8], laser ablation [11] and flash evaporation [12]. In this work, the filtered arc deposition system (FADS) was used to produce NiTi coatings on steel substrates (both ferritic mild steel and austenitic stainless steel). FADS and sputtering are both physical vapour deposition techniques, but FADS can produce NiTi thin films with better chemical homogeneity [13]. The typical deposition rate for FADS is between 0.06-0.6 $\mu \mathrm{m} / \mathrm{min}$, which is about an order of magnitude higher than the range reported for sputtering [8].

The main objective of this work was to develop NiTi thin film on a steel base using FADS, to test its cavitation resistance, and to enhance understanding of the mechanism 
of cavitation erosion resistance of NiTi thin films. FADS has been used by Stanford et al. [14] to produce NiTi thin films on glass and silicon wafers, for potential application in micro-electro-mechanical systems (MEMS) rather than for improving cavitation erosion resistance. He et al. [15] produced cavitation-resistant NiTi film on a steel base, but the deposited film was Ni-40at\% Ti, being Ni-rich. The SME and PE characteristics of this alloy film are inferior to those of near-equiatomic NiTi [16]. A different deposition system, cathodic arc plasma (CAP) ion plating was also used. The application of near-equiatomic NiTi thin films produced by FADS for the improvement of cavitation erosion resistance has not been previously reported. In the current work, the effects of deposition conditions (substrate temperature, bias voltage and substrate material) on microstructure, thermal bahaviour and mechanical properties have been determined and discussed in detail. Finally, the cavitation erosion resistance is compared between the reference bulk materials and NiTi thin films deposited under different conditions. 


\section{Chapter 2}

\section{Cavitation Erosion}

In all aspects of engineering, wear damage causes many problems in safety and efficiency, as well as adding significantly to costs. There are many types of wear based on different mechanisms, such as adhesive wear, abrasive wear, surface fatigue, fretting wear and erosive wear. When erosive wear takes place in a liquid medium without the presence of abrasive particles, it is termed liquid erosion. One mechanism of liquid erosion known as cavitation involves the formation and subsequent collapse of bubbles within the liquid. The high pressures from the bubble collapse near the surface remove material from the surface resulting in cavitation wear. Another form of liquid erosion is impingement in which high velocity liquid droplets impact the surface and cause its damage. Both cavitation erosion and liquid impingement exert similar hydrodynamic forces on solid surface and progressively remove material from a surface by repeated impulse loading on microscopically small areas. Therefore, the damaged surface topography and the relative material resistance to erosion are similar for both liquid impingement and cavitation erosion [1].

\subsection{Cavitation}

Cavitation is the spontaneous vaporization of a liquid due to localized regions of absolute pressure at or below a liquid's vapour pressure [17]. From the Bernoulli 
equation, the local pressures in some regions are reduced because of the acceleration of flow. Eventually the absolute pressure falls to a level where cavities nucleate and grow within the body of liquid in two forms, vapour-filled bubbles or gas-filled bubbles. Ideally, the gas in the bubbles is the vapour of the liquid. If cavities formed in a low-pressure region pass subsequently into a region of higher pressure, their growth will be reversed as the vapour condenses and eventually collapses. However, in most real cases, the gas in the bubbles would be molecules of a substance that formerly was dissolved in the liquid. Growth of gas-filled bubbles will occur more slowly compared to vapour-filled bubbles as the gas is re-dissolved in the liquid [18].

\subsection{Cavitation erosion}

The mechanisms of cavitation erosion involve shock waves that are produced by collapse and rebound (Figure 2.1 (a)), and impingement of a micro-jet of liquid through the collapse of a non-symmetrical cavity (Figure 2.1(b)) [1]. 

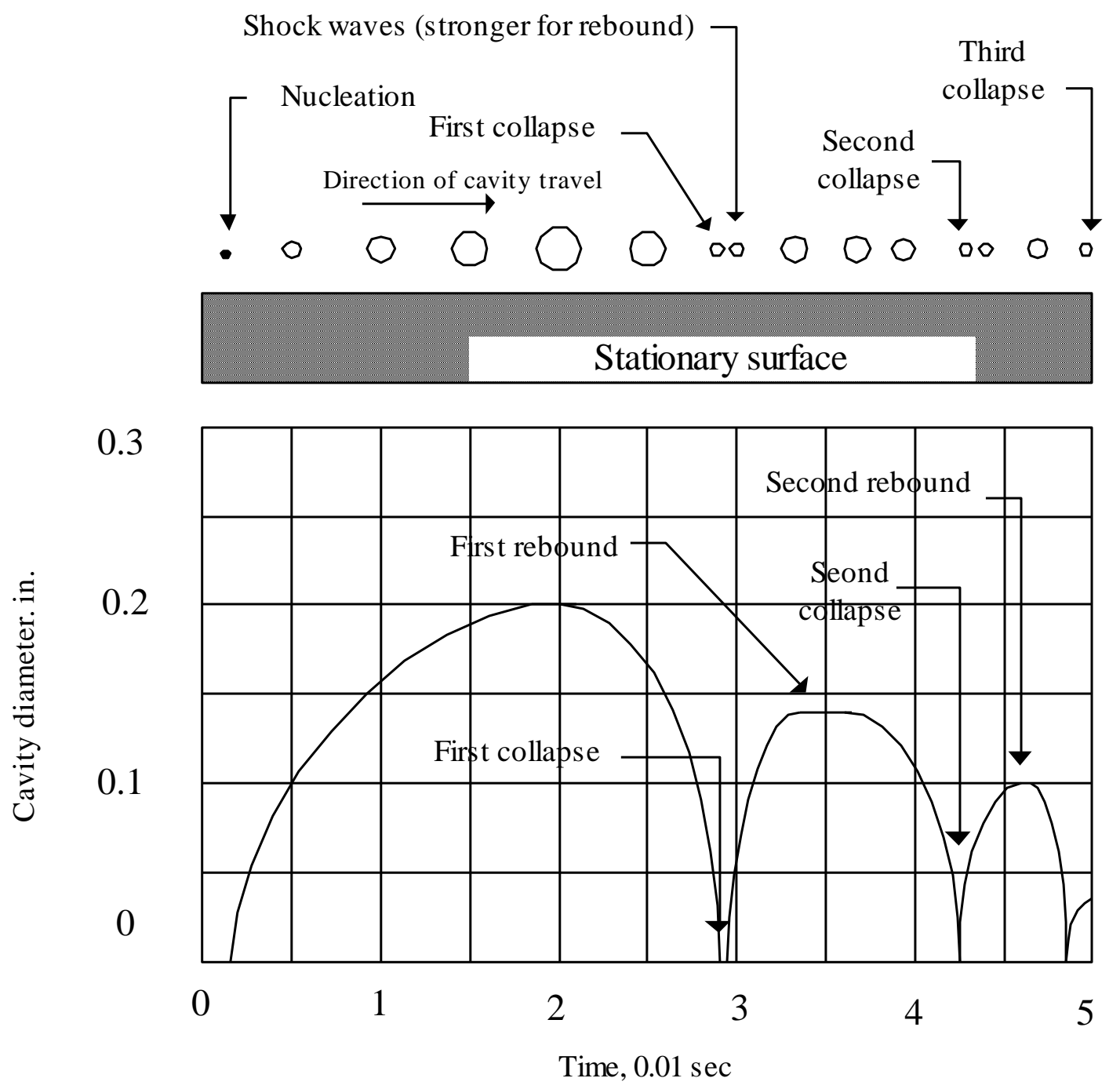

(a) Shock waves produced by collapse and rebound of a cavity

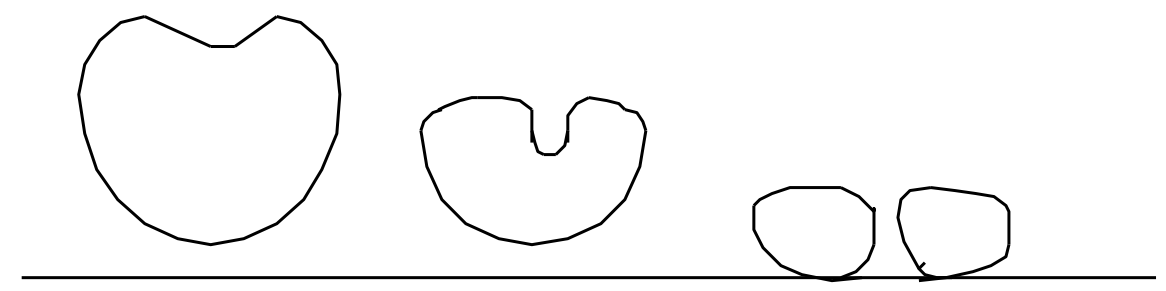

(b) Impingement of a liquid microjet through the nonsymmetrical cavity collapse

Figure 2.1: Schematic representation of the cavitation erosion mechanism [1]. 
These cavities can dissipate energy at each separate collapse [19]. When the cavities collapse in liquid, the transfer of their momentum can result in highly directed dynamic pressures around the collapsing area [20]. Therefore, cavities collapsing at critical distances from the material surface can cause damage to a rigid surface. After the collapsing, the non-condensable gas in the bubble undergoes compression, which is responsible for the rebound and oscillatory nature of some cavities [21].

\subsection{Erosion rate}

The cavitation erosion rate is defined as weight or volume loss per unit of time and Figure 2.2 shows the typical patterns of erosion rate for most materials. In the first phase, the weight loss of most materials is not detectable and the erosion rate is close to zero. This phase is termed the incubation period. During the incubation period, there is only random pitting of the material surface in widely separated locations. After the incubation period, weight loss starts to be detectable and the erosion rate increases rapidly to a maximum with fracture and pitting becoming more evident, and then usually drops to a lower value. The following reduction of the weight loss rate occurs because the surface becomes so rough that liquid can be trapped between ridges, reducing the effects of individual impacts. In some cases, the maximum value may persist for some time, as shown in the dashed curve in Figure 2.2. The erosion rate patterns, i.e. length of the incubation period, the maximum damage rate and the curve shape after maximum erosion rate, are influenced by many factors, such as the intensity of cavitation, the properties of the material, and the original surface condition [1]. 


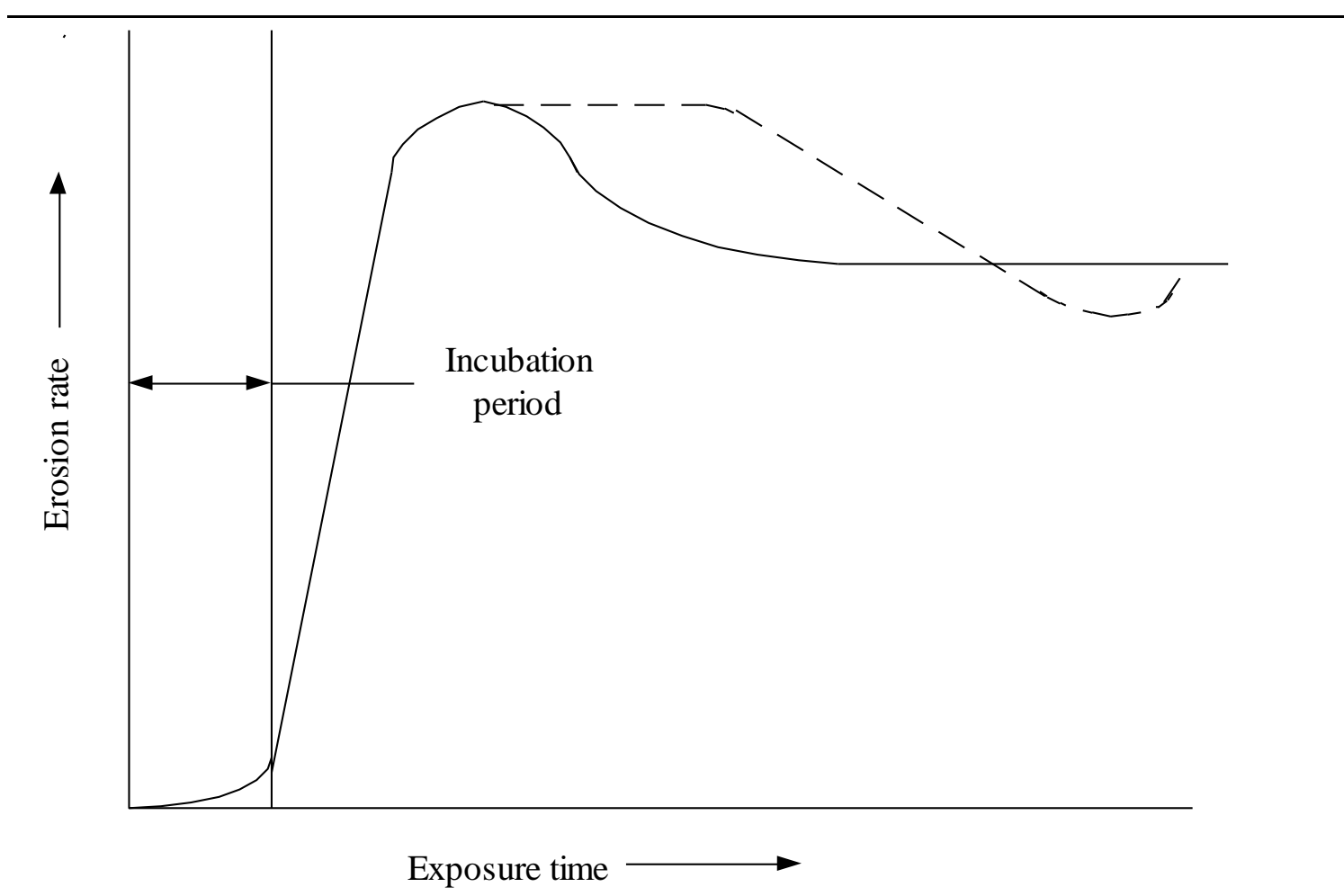

Figure 2.2: Schematic representation of typical variation of liquid-erosion rate with exposure time [1].

In order to decrease the extremely long time of cavitation erosion experiments, erosion is only evaluated in the incubation period by the number and size of the pits [22] or by the sum of the damaged area [23]. The final mass loss rate can be qualitatively predicted based on measurements in the incubation period [24].

\subsection{Evaluation methods of cavitation resistance (ASTM G32)}

The resistance of materials to cavitation erosion is commonly evaluated by ASTM G32 (Standard Method for Vibratory Cavitation Erosion Test) [25], which is a small-scale, 
relatively simple and controllable test. The curve of mass loss versus time can be obtained by weighing the sample before testing and during periodic interruptions of the test. The standard test conditions specify the amplitude and frequency of vibratory, the amount of test liquid and the immersion depth of specimen in the liquid. Distilled water is normally used as test liquid.

\subsection{Prevention of cavitation erosion damage}

Cavitation erosion damage can be prevented or minimized by either decreasing the erosion intensity or increasing the cavitation erosion resistance of materials. The erosion intensity is reduced with a decrease of the hydrodynamic intensity and the cavitation intensity by simply increasing the radius of curvature of the flow path or removing surface discontinuities. The reduction of erosion intensity can also be achieved by entraining gas in the liquid due to a decrease in collapse pressures by a cushioning effect [1]

Another practical way to solve cavitation erosion damage problem is to increase the cavitation erosion resistance of the component by using erosion-resistant metals or elastomeric coatings. Since cavitation erosion only damages the material surface, many erosion-resistant metals can be applied as welded overlays. Stellite alloys and stainless steels are the most widely used overlays [1]. Highly elastic materials are also resistant to erosion at low hydrodynamic intensities. Instead of being attracted toward inflexible metallic surfaces, microjets formed during cavitation collapse tend to be repelled from 
highly flexible surface. Therefore, the internal energy is dissipated into the fluid rather than against the surface [1].

Research work on cavitation damage indicates that nickel-aluminium bronze containing $\mathrm{Mn}, \mathrm{Ni}$ and $\mathrm{Fe}$ is one of the most important materials to prevent cavitation damage [26], [27]. Reddy attributed the good erosion resistance of nickel-aluminium bronze alloys to their high work hardening rate and the low stacking fault energy under high stress and high strain rate deformation conditions induced by bubble collapse [28]. However, Suh and Saka found that there is no simple relationship between stacking fault energy and wear rate [29]. Nitinol alloys also show excellent performance in investigations on cavitation damage due to their capacity to accommodate stress or pressure from bubble collapse [2], [3]. However, the alloy composition and processing treatment determine the phases and crystal structures, which, in turn, affect the cavitation erosion characteristics [30]. 


\section{Chapter 3}

\section{NiTi Shape Memory Alloy}

In some alloys, a given "plastic" strain recovers completely when the concerned alloy is heated above a certain temperature. This type of "shape memory" was observed in Au-Cd and In-Tl alloys in the first half of 1950s [31], [32]. However, this effect was not a major focus of research until it was found in a Ti-Ni alloy in 1963 [33], when the phenomenon was first termed the shape memory effect (SME). In following years, many different alloy systems were discovered that exhibit similar phenomena. Since then, shape memory alloys (SMAs) have been extensively applied in the medical and dental fields, for orthodontic devices, surgical probes and guidewires, stents and grafts, clamps and screws, and other fixing devices. Non-medical application include joints and connectors, in the form of heat-shrink mechanical couplings, electrically manipulated actuators, thermal actuators for micro-electro-mechanical systems, super-elastic wires or strips in fashion and accessory goods, damping systems in civil construction for protection against earthquake, activation, springs in robotics and remote control devices, and materials for smart structures [34]. As it provides appropriate material and mechanical properties, near-equiatomic NiTi is widely used in many engineering and technological applications. Therefore, the research undertaken was mainly focused on equiatomic NiTi alloy film, particularly in relation to its reversible martensitic 
transformation and the material properties and performance relevant to cavitation erosion resistance.

\subsection{Phase diagram}

The phase diagram for the $\mathrm{Ni}-\mathrm{Ti}$ alloy system in Figure 3.1 is important for heat-treatment of the alloys and improvement of the shape memory characteristics [9]. Much research work has been done to establish the phase diagram, especially the central area bounded by the $\mathrm{Ti}_{2} \mathrm{Ni}$ and $\mathrm{TiNi}_{3}$ intermetallic phases. The body centred cubic intermetallic compound TiNi has a relatively large solubility range at elevated temperatures, but the solvus boundary on the Ni-rich side slopes from right to left with decreasing temperature reducing the solubility range of TiNi to almost zero at $500^{\circ} \mathrm{C}$ [9]. On the Ti-rich side of the TiNi field, the solvus boundary is nearly vertical. $\mathrm{The}^{\mathrm{Ti}}{ }_{2} \mathrm{Ni}$ phase is cubic with the space group $\mathrm{Fd} 3 \mathrm{~m}$ and has a lattice constant of $1.132 \mathrm{~nm}$ [9]. The $\mathrm{TiNi}_{3}$ phase has a hexagonal $\mathrm{DO}_{24}$ type ordered structure. The lattice constant $a$ is $0.51010 \mathrm{~nm}$ and $c$ is $0.83067 \mathrm{~nm}$ [35]. Some investigations have shown $\mathrm{Ti}_{3} \mathrm{Ni}_{4}$ and $\mathrm{Ti}_{2} \mathrm{Ni}_{3}$ in diffusion-controlled transformations at high temperatures for a Ni-rich $\mathrm{TiNi}$ alloy [35]. It has been confirmed that both $\mathrm{Ti}_{3} \mathrm{Ni}_{4}$ and $\mathrm{Ti}_{2} \mathrm{Ni}_{3}$ are intermediate phases [9]. 


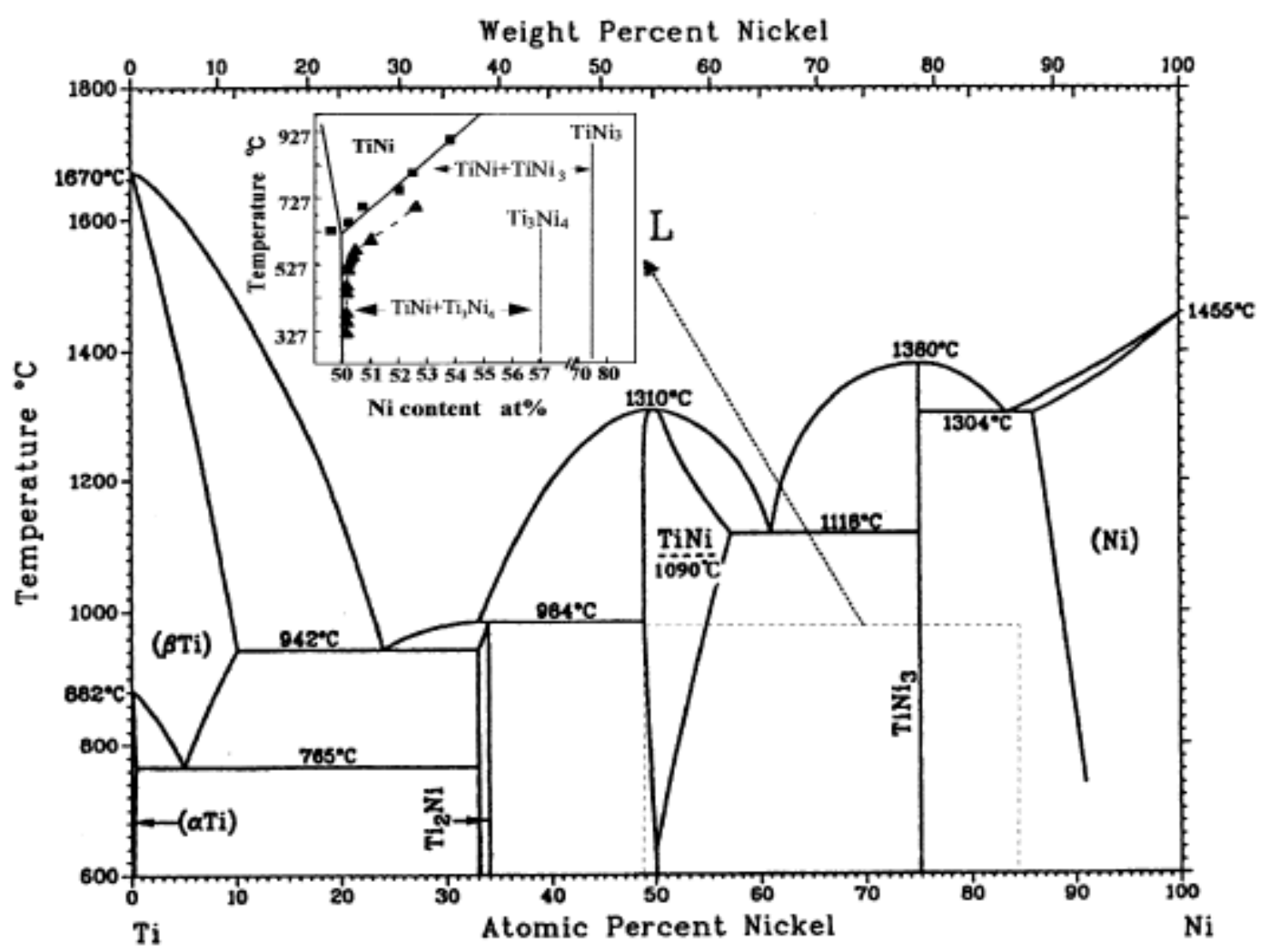

Figure 3.1: Phase equilibrium diagram for Ni-Ti binary alloy [9], [36].

\subsection{Martensitic transformation}

In 1970, Otsuka and Shimizu concluded that SME is characteristic of alloys exhibiting thermoelastic martensitic transformation [37]. For the NiTi alloy, the martensitic transformation is from an ordered body-centered cubic phase to an ordered monoclinic phase. The parent and product phase are conventionally called austenite and martensite, respectively. It has also been reported that a so-called $\mathrm{R}$ phase can occur before the formation of the monoclinic martensite [9]. The transformation from austenite to $\mathrm{R}$ phase is also a martensitic transformation, with successive transformation from $\mathrm{R}$ phase to martensitic phase, which competes the transformation from austenite to martensite 
phase [9].

\subsubsection{Crystal structures of B2, B19' and R phases}

It has been established that near-equiatomic NiTi alloys exhibit three main phases: parent phase of austenite (A) at high temperatures, product phase of martensite (M) at low temperatures, with $\mathrm{R}$ phase being present as an intermediate transformation product. The crystal structures of the three phases are shown in

Figure 3.2. The lattice parameters of these phases are determined by means of X-ray diffraction (XRD) measurements and transmission electron microscopy (TEM). Similar results were also obtained by other techniques, such as single crystal X-ray diffraction measurements, single crystal neutron diffraction measurements and high-resolution electron microscopy [38], [39].

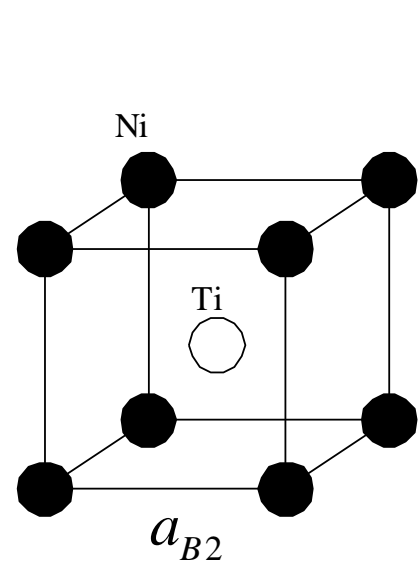

(a)

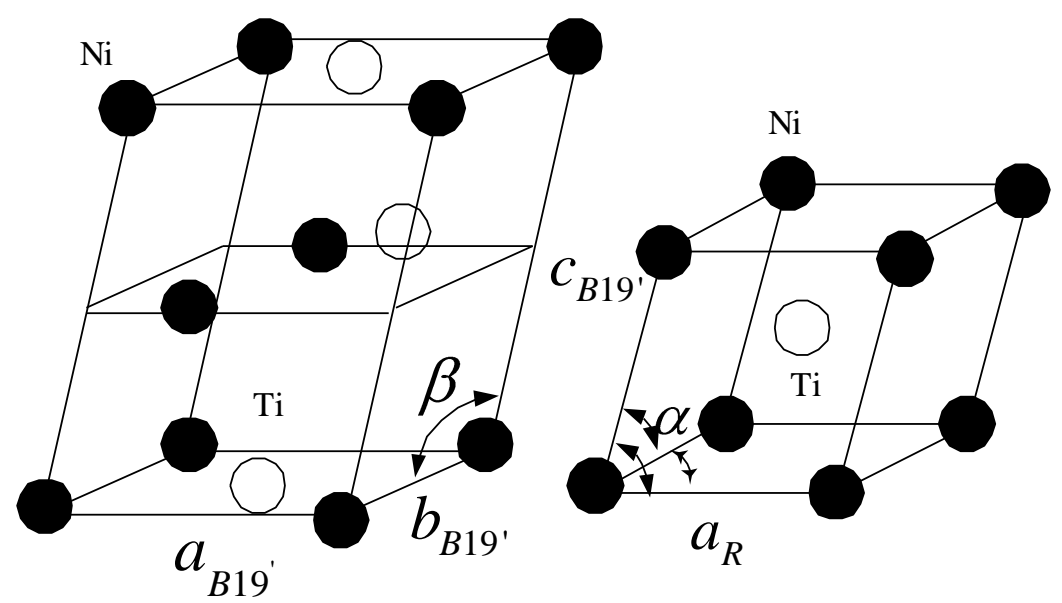

(b)

(c)

Figure 3.2: Crystal structures of NiTi alloys; (a) cubic parent B2 structure, (b) 
monoclinic B19' martensite structure, (c) R-phase structure [40].

\section{A) Parent phase}

The parent phase, "TiNi" has a B2 $(\mathrm{CsCl})$ type ordered super lattice structure, which is fundamentally body-centered cubic (BCC) lattice with a lattice parameter of $0.3015 \mathrm{~nm}$ [40].

\section{B) Martensite phase}

Martensite is obtained when binary Ti-Ni alloys are cooled from high temperatures. The crystal structure of the martensite formed in Ti-49.75at\% $\mathrm{Ni}$ has a $\mathrm{B} 19^{\prime}$ monoclinic

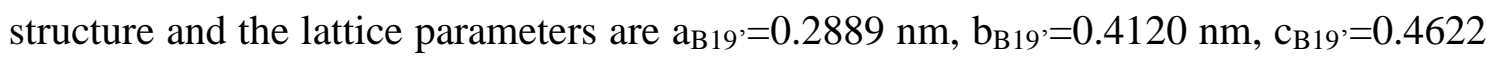
$\mathrm{nm}$ and $\beta_{\mathrm{B} 19^{\prime}}=96.80^{\circ}[40]$.

\section{C) $\mathbf{R}$ phase}

The crystal structure of the " $R$ phase" was initially identified as rhombohedral with the lattice constant reported as $0.3015 \mathrm{~nm}$ and the interaxial angle $\alpha$ as $89.46^{\circ}$, measured at $35^{\circ} \mathrm{C}$ - the transformation temperature from the austenite to the $\mathrm{R}$ phase [41]. However, the crystal structure was later reported to be triclinic [9].

\subsubsection{Mechanisms of martensitic transformation}

From a crystallographic point of view, the mechanism of martensitic transformation is 
well understood by the "phenomenological crystallographic theory of martensitic transformations" that was developed by Wechsler, Lieberman and Read (WLR theory) [42], [43], and Bowles and Mackenzie (BM theory) [44], independently. The phenomenological crystallographic theory is able to predict the shape strain, habit plane, and orientation relationship between parent and product phases.

\subsubsection{Phenomenological crystallographic theory}

According to WLR theory, the martensitic transformation is characterised by an invariant plain strain (IPS). The IPS is the product of the following three operators:

a) The lattice deformation (LD) from the parent lattice to the martensite lattice;

b) The lattice invariant shear (LIS), which is an inhomogeneous shear, such as twinning, stacking fault formation or slipping, that occurs without changing the martensite structure; and

c) The lattice rotation (LR).

In order to minimize the strain energy associated with transformation, the transformation occurs along an invariant plane that gives the lowest strain energy. The invariant plane is an undistorted and unrotated habit plane, and is created by the above three operators as shown schematically in Figure 3.3, where the lattice invariant shear is twinning. The left-hand side represents the parent phase, while the right-hand side is a martensite plate. This martensite plate, which consists of its matrix and its twin, is called the habit plane variant (HPV). On the other hand, the martensite matrix and the 
twin, which are the smallest scale martensite variants, also have specific lattice correspondence with the parent phase. These are called lattice correspondence variants (LCV) [9].

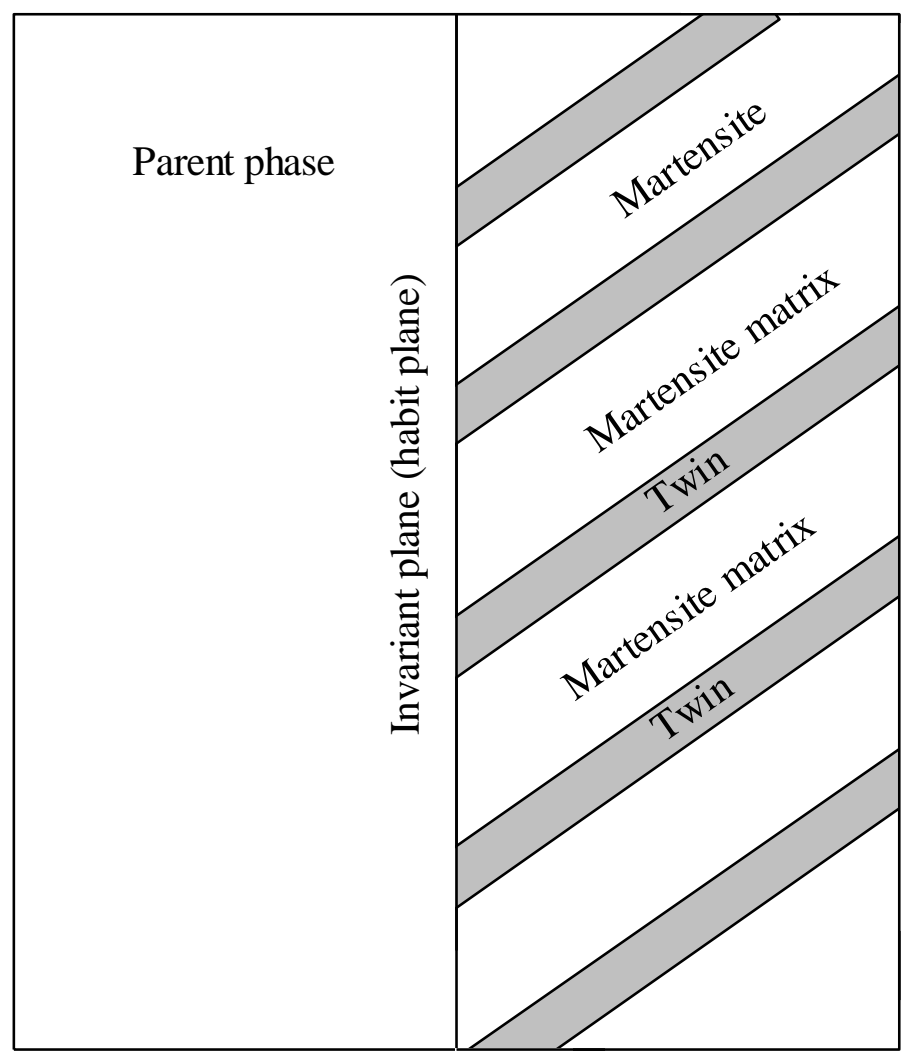

Figure 3.3: Schematic illustration of parent and martensite with invariant plane as a habit plane [9].

Minimization of the strain energy during transformation can occur without atomic diffusion by the formation of internal twins. The WLR theory is geometrically illustrated in Figure 3.4 [45]. The initial lattice (Figure 3.4 (a)) transforms into the martensite (Figure 3.4 (b)) by lattice distortion with a shape change. However, due to the constraint imposed by the surrounding matrix within the grain in which the martensite is forming, the interface between the martensite and austenite must be 
macroscopically undistorted and unrotated. A lattice invariant shear by slip (Figure 3.4 (c)) or twinning (Figure 3.4 (d)) can ensure that the interface plane remains invariant. Nevertheless, transformation is, in general, accompanied by a volumetric strain and a shear strain and groups of martensite plate variants frequently occur to mutually accommodate the shear strains. This is known as self-accommodating martensitic transformation.

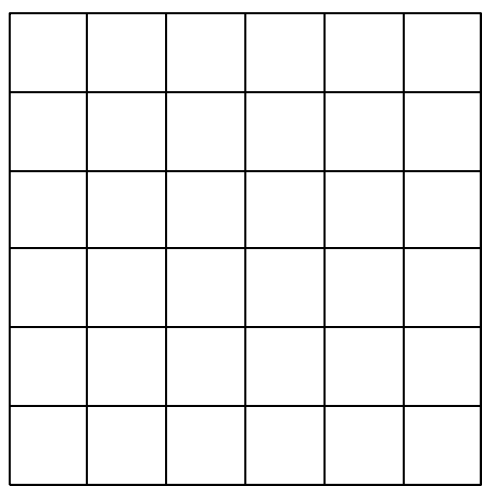

(a)

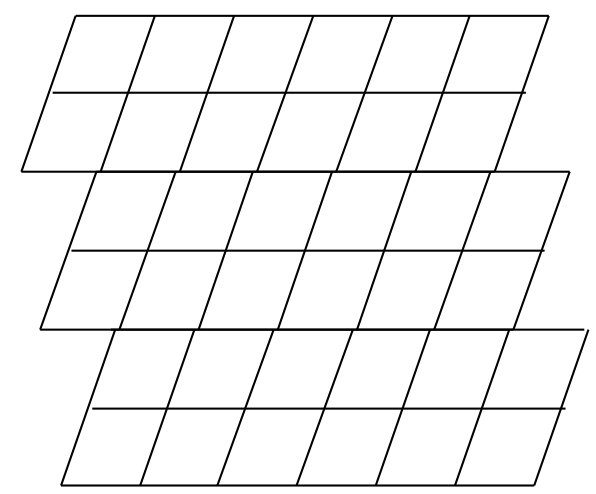

(c)

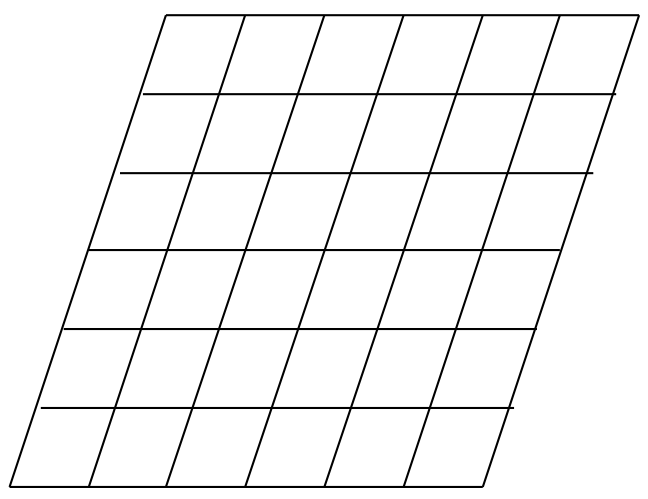

(b)

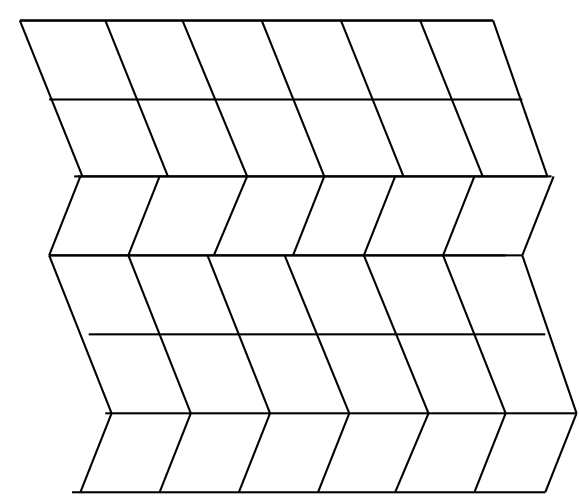

(d)

Figure 3.4: Schematic diagram of martensitic deformations: (a) undeformed lattice, (b) lattice distortion, (c) lattice distortion and lattice invariant slip, (d) lattice distortion and lattice invariant twinning [45].

Lattice invariant shear by the slip mechanism is, in effect, mechanically irreversible, 
whereas the twinning and faulting mechanism are potentially reversible. Obviously, twinning or stacking fault formation applys to the case of reversible martensitic transformation in shape memory alloys.

\subsubsection{Lattice distortion of $\mathrm{B} 2 \rightarrow \mathrm{B} 19$ ' transformation}

For a given austenite crystal, there are total 12 equivalent mono-crystalline lattice correspondence variants (LCVs) conforming to the same lattice correspondence. The internal twinning allows for 24 possible martensite variants. Each variant is identical in structure, but oriented differently with respect to the parent crystal. Figure 3.5 shows schematically one of the lattice transformations from B2 to B19'. 


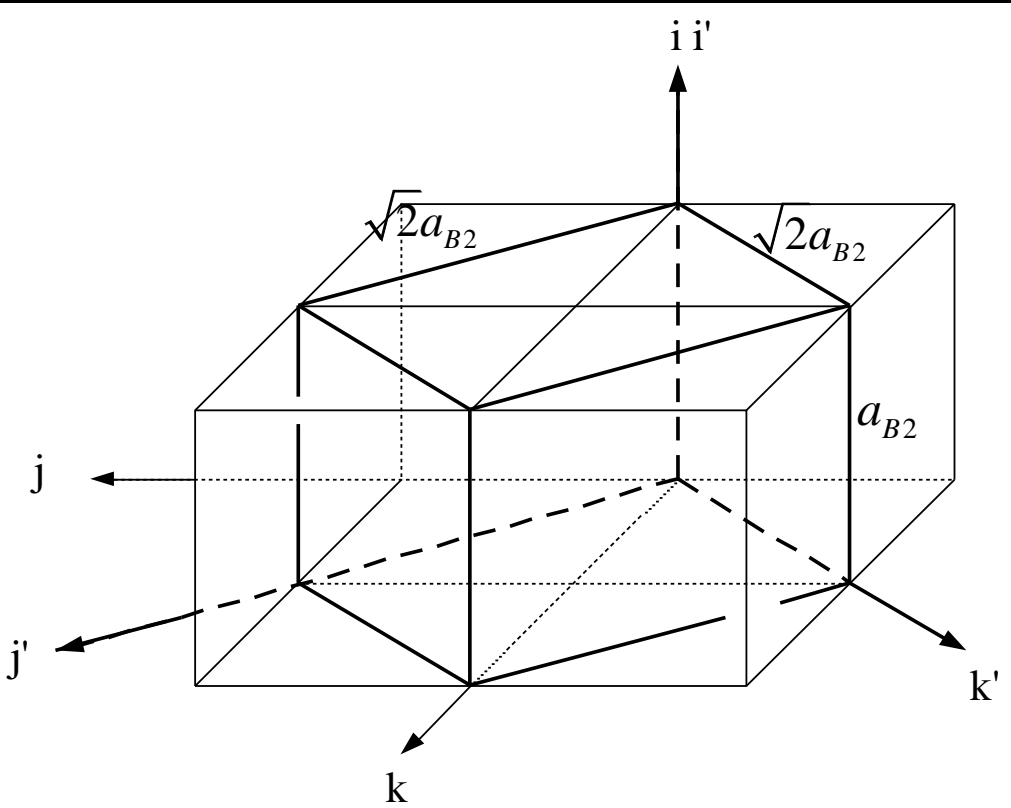

(a)

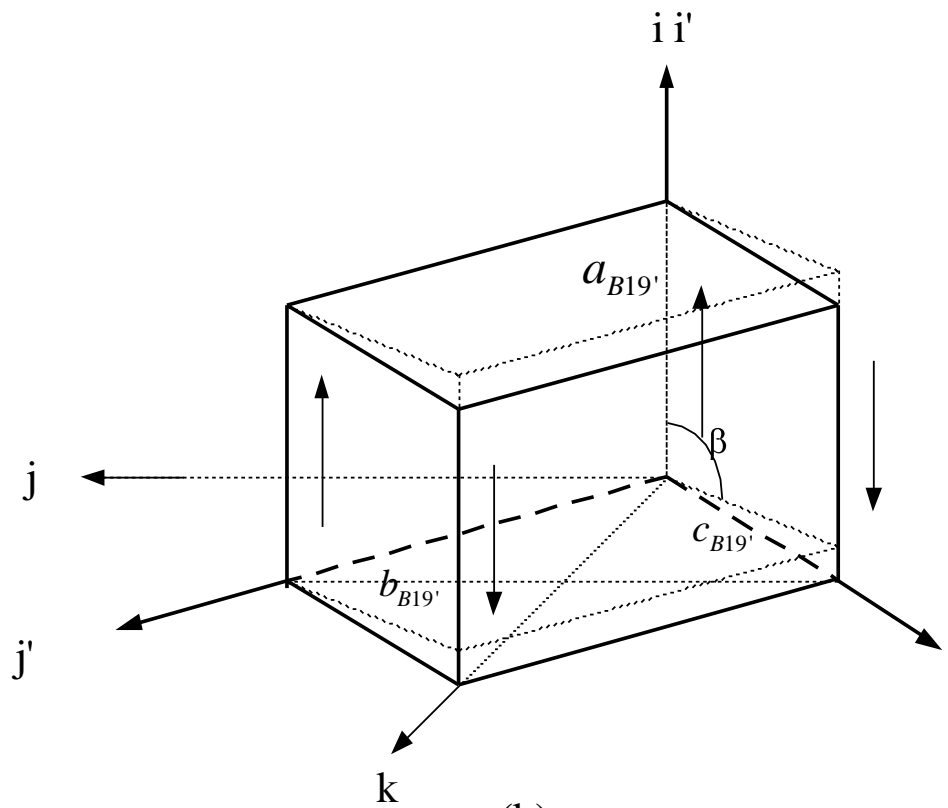

(b)

Figure 3.5: Lattice change from B2 parent (a) to B19' martensite (b). i, j, and k refer to parent lattice, and i', j' and k' refer to the martensite lattice [9].

\subsubsection{Accommodation of lattice distortion of martensite}

Although the formation of each martensite variant is accompanied by a definite shape strain, the macroscopic shape of the material does not change as a whole before or after 
the transformation when transformation occurs thermally without external stress. This is the result of self-accommodation of the martensite, which has been discussed earlier.

The 24 possible habit plane variants consist of six groups, and four habit planes in each group are normally symmetrically clustered around one of the six $\{110\}$ poles of parent phase. The four habit plane variants are actually formed side by side in a characteristic diamond-shaped morphology upon cooling [46]. Such grouping causes the average shape strain in each group to be essentially zero. Therefore, for the thermally induced transformation on cooling, there is virtually no macroscopic shape change because of the internal twinning and HPV self-accommodation.

The martensitic transformation of austenite can also be induced mechanically by external stress. However, a net shape change is introduced because of the stress-induced formation of particular HPVs. In this case, the selected variants in the resultant martensite collectively produce the maximum crystal shape change to accommodate the external load.

A shape change can also be produced when the external stress is applied to a thermally produced twinned martensitic structure. Within the thermally formed, self-accommodating martensites groups, the variants are twin related and their twin boundaries are highly mobile. Therefore, the twin and interface boundaries can move in response to the external load and produce a net shape change. This process is referred to 
as martensite reorientation and the resultant martensite is termed detwinned martensite, which can transform back to austenite by heating, with shape recovery.

\subsection{Thermoelasticity of martensite transformation}

In many martensitic transformations, martensite forms and grows continuously when the temperature is lowered, and shrinks and vanishes as the temperature is raised [47]. The reversible movement of martensite plates is also achievable upon loading and unloading. The forward or reverse motion of the austenite/martensite interface with small changes in temperature or stress is referred to as thermoelasticity.

The driving force for martensitic transformation arises from the free energy change between the parent and martensite phases. For thermoelastic transformation, the increase in chemical driving force with decreasing temperature is opposed by resistive force due to the elastic energy stored in the product phase, which is related to the size of the martensite plate. This local thermodynamic balance of the transformation results in the continuous growth or shrinkage of martensite plates with small changes in temperature. The high mobility of the transformation interface in a thermoelastic transformation indicates that the required driving force is low.

Thermoelasticity is also characterized by crystallographic reversibility because the reverse transformation takes place by the simple backwards movement of the interface. Therefore thermoelastic transformations have highly coherent interfaces, which are 
capable of the reverse movements whilst maintaining the crystallographic continuity between the two lattices. The recovered parent phase has exactly the same orientation as before the forward transformation [48], [49].

The thermoelastic martensitic transformation is charaterised by four temperatures: the martensite start temperature $\left(\mathrm{M}_{\mathrm{S}}\right)$, at which martensite plates spontaneously appears; the martensite finish temperature $\left(\mathrm{M}_{\mathrm{F}}\right)$, at which the entire specimen is transformed into martensite; the austenite start temperature $\left(\mathrm{A}_{S}\right)$, at which the austenite spontaneously appears in the martensitic structure on heating; and the austenite finish temperature $\left(A_{F}\right)$, at which the specimen is transformed completely to austenite. The $\mathrm{M}_{\mathrm{S}}$ temperature is affected by the composition, and is particularly sensitive to Ni/Ti atomic ratio in NiTi alloys, as shown in Figure 3.6. The temperature difference between $M_{S}$ and $A_{S}$ is referred to as the hysteresis. Generally, thermoelastic martensitic transformations is characterized by a small hysteresis, which indicates a small driving force for transformation [9]. 


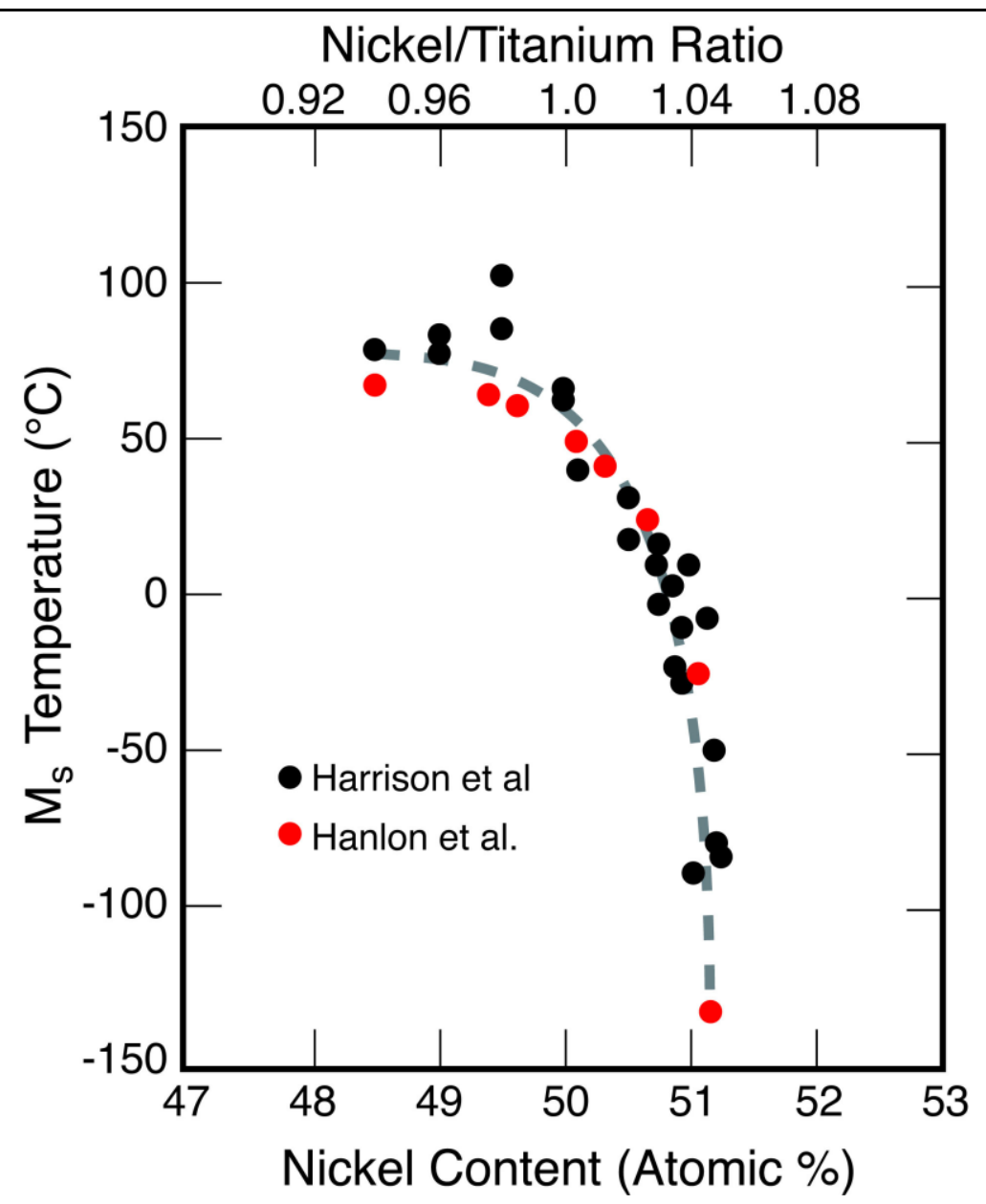

Figure 3.6: $\mathrm{M}_{\mathrm{S}}$ temperature versus Ni content in NiTi alloys [50], [51].

\subsection{Mechanical properties of NiTi alloy}

Thermoelastic nature is a required condition for both the shape memory effect and the pseudoelasticity of SMAs [9]. These properties depend on the essential mechanism of interface motion under the stimulus, resulting in pseudo-strain, which can be recovered immediately by reverse interface motion on stress removal (pseudoelasticity, PE) or progressively on moderate heating (shape memory effect, SME). The required stimulus for the transformation is the force $(F)$ or the temperature $(T)$. 


\subsubsection{Shape memory effect}

\subsubsection{One way shape memory effect}

The one way shape memory effect allows a deformed material to return to its original shape by simply increasing the temperature. The thermodynamic cycle shown in Figure 3.7 is required to obtain the shape memory effect.

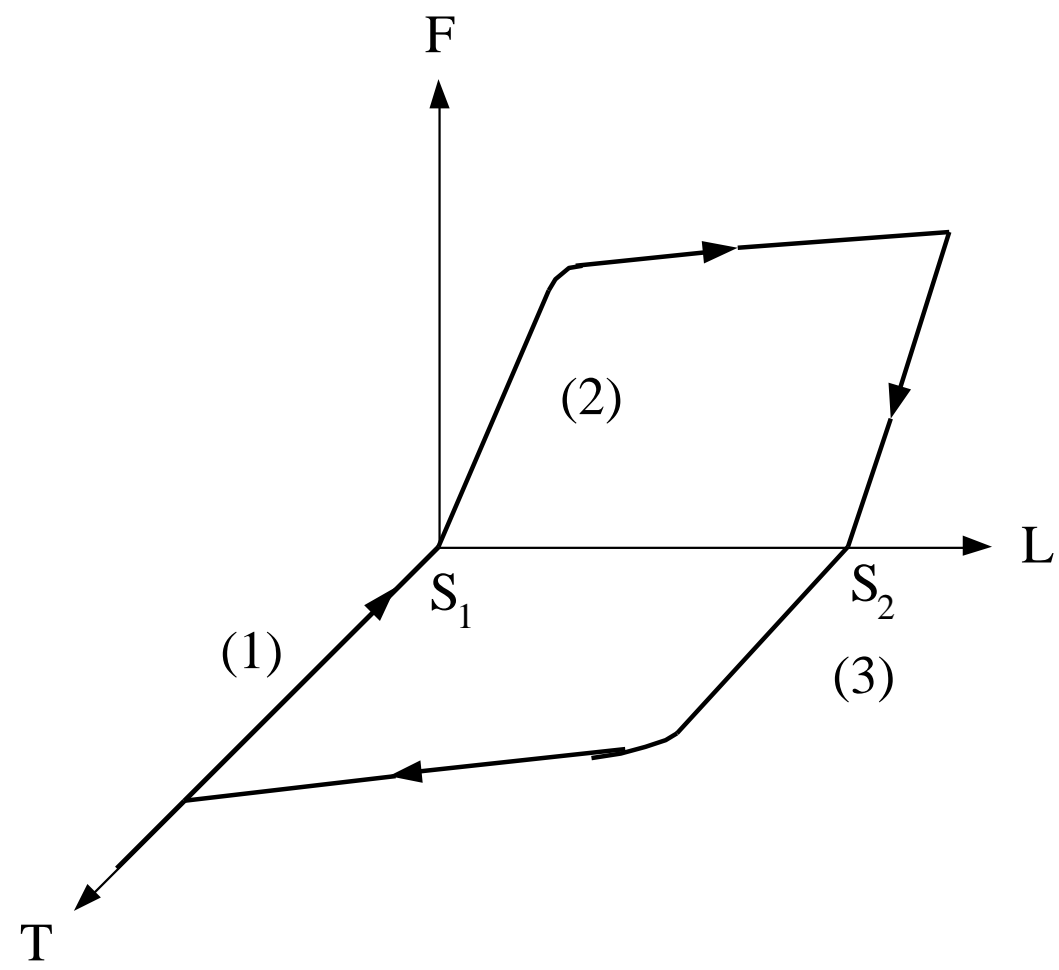

Figure 3.7: Schematic diagram of one way shape memory effect [4], [52].

In step (1), the austenitic phase is transformed to the twinned martensitic phase by decreasing the temperature $(\mathrm{T} \downarrow)$ without an external force $(\mathrm{F}=0)$. The resultant martensite retains the initial shape ( $\mathrm{S} 1$ ), so there is no visible macroscopic shape change $(\Delta \mathrm{L}=0)$. 
At a constant temperature $(\mathrm{T}=\mathrm{k})$ in step (2), the twinned martensite is transformed to the deformed martensite with an increase in the external force $(\mathrm{F} \uparrow)$, which is termed martensite reorientation. The result is a change to a new shape (S2) producing a net shape change $(\Delta \mathrm{L}=\mathrm{S} 2-\mathrm{S} 1 \neq 0)$.

Without applying an external force $(\mathrm{F}=0)$ in step $(3)$, the deformed martensitic phase transforms back to the austenite phase and returns to its initial shape (S1) with an increase in temperature $(\mathrm{T} \uparrow)$. This phenomenon is referred to as the one way shape memory effect.

\subsubsection{Two way shape memory effect}

Apart from allowing the material to return to its original shape by increasing the temperature, the two way shape memory effect also permits the return of a second shape by simply cooling. However, this behaviour is not a natural property of a shape memory alloy and needs to be developed through a learning process, which is termed two way memory training. There are two training routines: thermal processing and mechanical processing. In the thermal process, the material is educated by a thermal cycling between $A_{F}$ and $M_{F}$ with a constant force. In the mechanical process, the training is performed by loading and unloading the material at a constant temperature higher than $\mathrm{A}_{\mathrm{F}}$. The microstructural process in the two types of cycling is different, but the results are comparable because the role of the force and temperature are equivalent from a 
thermodynamic point of view. Therefore, there are other various routines, combined by thermal and mechanical process, used for two way memory training. The essential process in the two way memory training is to free the energy stored thermally or mechanically through cooling, in which the last effect can be memorized by the material. The required thermodynamic cycle to obtain the two way shape memory effect is as follows (Figure 3.8):

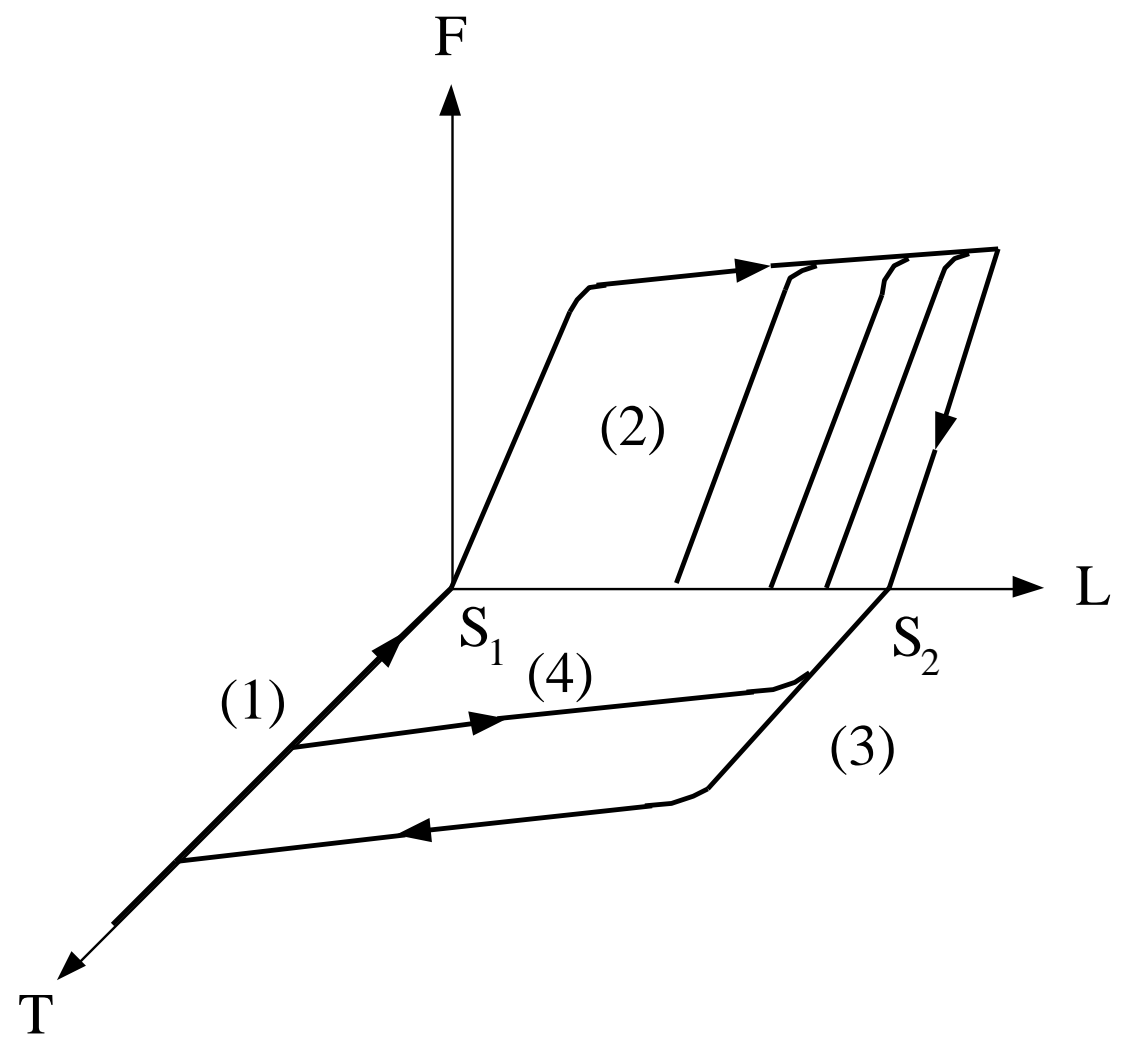

Figure 3.8: Schematic diagram of two way shape memory effect [4], [52].

The first step is same as the first one in the thermodynamic cycle for one way memory effect. The austenitic phase change to the twinned martensitic phase by decreasing the temperature $(T \downarrow)$ without an external force $(F=0)$ and any shape change $(\Delta L=0)$ 
At a constant temperature ( $\mathrm{T}=\mathrm{k}$ ) in step (2), the material transforms at least a dozen times between twinned martensite with the initial shape (S1) and the deformed

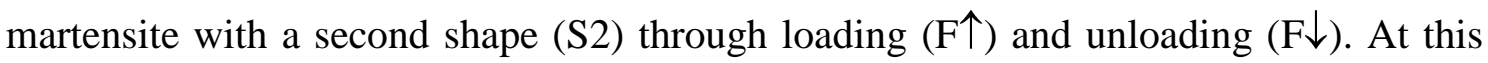
stage, the specimen has memorized its second shape (S2) in the martensitic state.

Similar to the one way shape memory effect, in step (3) the deformed martensitic phase in its new shape (S2) transforms back to the austenite phase and returns to its initial shape (S1) due to an increase in temperature $(\mathrm{T} \uparrow)$, where there is no external force $(\mathrm{F}=$ $0)$.

Without applying an external force $(\mathrm{F}=0)$ and with a decrease in temperature $(\mathrm{T} \downarrow)$ in step (4), the austenite phase transforms from its initial shape (S1) to the deformed martensite with its second shape (S2) memorized in the training process.

In the last two steps for the above cycle, the material changes from the initial shape to the memorized shape repeatedly with a simple modification of the temperature and without external force. This phenomenon is referred as to two way shape memory effect.

\subsubsection{Pseudoelasticity}

Pseudoelasticity is enhanced "elastic" behaviour, which allows a material to recover 
completely from apparently permanent "plastic" deformation due to an applied force. In the superelastic effect, the transformation occurs between the austenitic phase and the stress-induced martensitic phase due to the loading and unloading cycle. The recoverable strain for a mono-crystalline sample of SMA can reach 10\% [52]. The superelastic effect is illustrated by the mechanical cycle shown in Figure 3.9. The temperature is constant throughout this process.

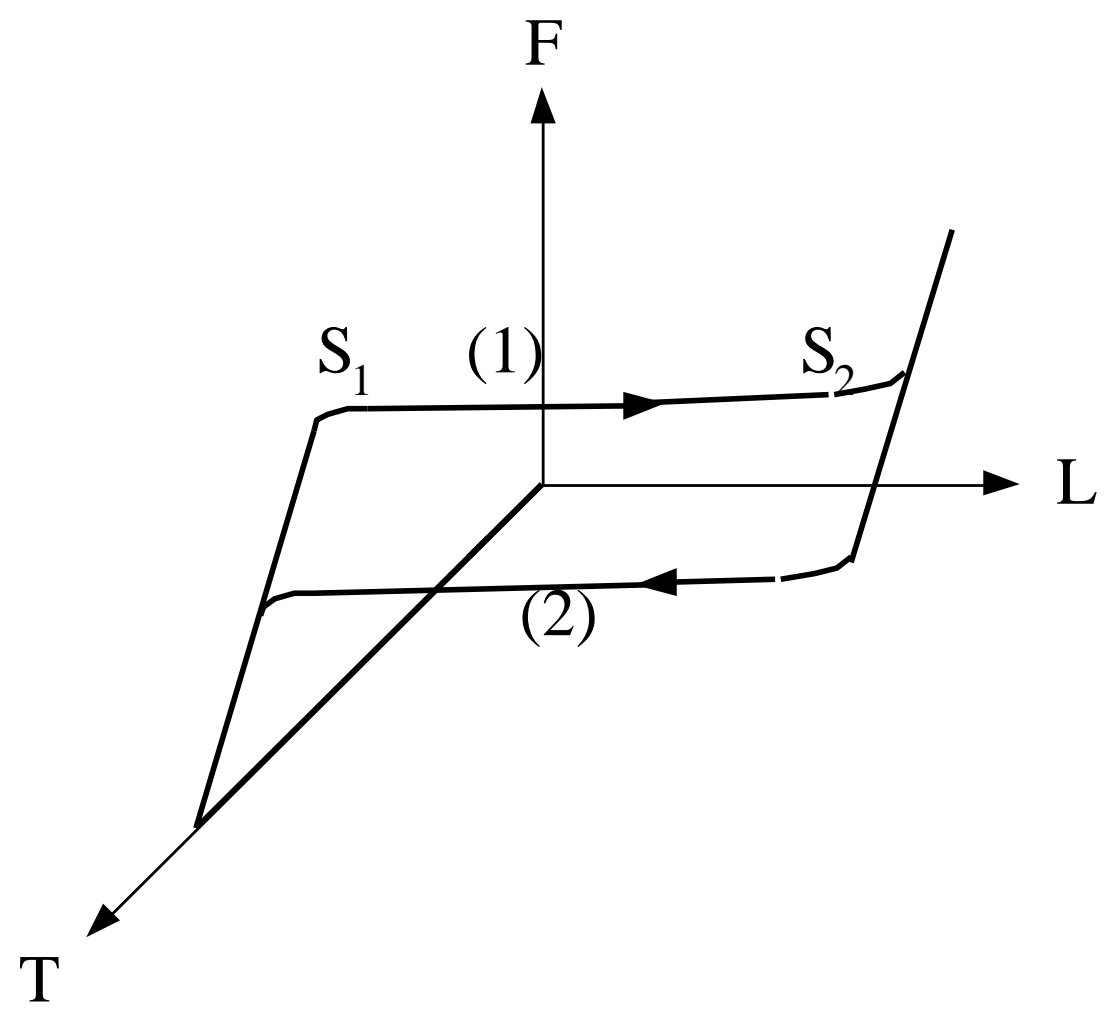

Figure 3.9: Schematic diagram of the superelastic effect [4], [52].

With a loading $(\mathrm{F} \uparrow)$ in step in step (1), the austenitic phase transforms to the deformed martensitic phase, producing a shape change from $S 1$ to $S 2$. 
With the unloading ( $\mathrm{\downarrow} \downarrow$ ) in step (2), the martensite transforms back to the austenite phase in its original shape (S1). A similar F-L curve can also be obtained for isothermal deformation in the martensitic condition and in this case the pseudoelastic behaviour is referred to as rubber-like effect [4], [53] or ferroelasticity [5], [6].

$\mathrm{NiTi}$ alloys have been found to exhibit excellent wear resistance to sliding wear, impact abrasion and sand-blasting erosion, which is attributed to their pseudoelastic behaviour and high rate of work-hardening [54]. Suzuki [55] and Shida [56] also reported good erosion resistance of NiTi alloys under slurry and water jet conditions. Excellent cavitation erosion resistance of NiTi was reported by Richman [57].

\subsection{Shape memory alloy thin films}

Because of their excellent and unusual properties, shape memory alloys are in demand for various innovative applications, particularly in actuation mechanisms. TiNi-based alloys can provide a high work output of up to $10 \mathrm{~J} / \mathrm{cm}^{3}$ [58]. Ishida et al. successfully produced the first NiTi thin film in 1993 [8]. Since then, many deposition methods have been used to obtain shape memory thin films.

\subsubsection{Properties of NiTi thin film}

The crystal structures of NiTi thin films are essentially the same as those measured in bulk specimens, although the lattice parameters differ slightly depending on the alloy 
content [59]. In an equiatomic TiNi thin film, the maximum elongation is more than $40 \%$ [59]. The yield and fracture stresses of the martensite phase are higher than 600 and $800 \mathrm{MPa}$, respectively [59]. These mechanical properties prove that the TiNi thin films are not brittle and possess sufficient ductility for practical applications. The stability of shape memory behaviour associated with martensitic transformation against cyclic deformation was investigated in TiNi thin films [60]. Under $100 \mathrm{MPa}$, the martensitic transformation showed perfect stability of shape memory effect because no slip deformation occurred during cyclic deformation. In addition, perfect reproducibility of the shape memory effect was also observed in the direct martensitic transformation [59].

A series of investigations have proved that the stable shape memory effect and pseudoelasticity, which are similar to those of bulk alloys, can be achieved in sputter-deposited TiNi thin films. Narrow transformation temperature hysteresis and high transformation temperatures were also achieved in shape memory thin films [8], [10]. When shape memory alloy is used in the form of thin film, the intrinsic disadvantage of a low response rate due to the limitation of the cooling rate can be greatly improved, since thin film is easily cooled due to the large surface area to volume ratio.

\subsubsection{Application of shape memory thin films}

SMA thin films have been applied to actuator fabrication in MEMS in cases where there 
is insufficient space for large comb structures or large piezo stacks [54]. SMA thin film actuators are dedicated to multiactuator systems like arrays for particle transport or cooperating microgrippers [61].

Other applications of thin films that have been realized are functional miniature devices for microfluidics like microvalves fabricated by Johnson and Shahoian [62] as well as Kohl et al. [62], [63] and micropumps developed by Bernard et al. [64]. Active surfaces for tactile devices in medical technology also have a great market potential. These technologies need smart material systems with different material composites and complex thin film actuator design. Future research work in the field of SMA thin film actuators will therefore combine material research as well as design studies for multifunctional systems and developments for lithographic manufacturing steps. Due to the extensive application of shape memory thin films, the technique to synthesize the thin films with required characteristics assumes central importance. 


\section{Chapter 4}

\section{Deposition Methods}

Coating of a base material can confer improved performance under service conditions. It can be a low cost alternative to the use of a bulk material in cases that require surface properties such as high temperature strength, impact strength, specific optical properties, electrical or magnetic properties, wear resistance, fabrication into complex shapes or biocompatibility [65]. There are generally two categories of deposition processes, chemical vapour deposition (CVD) and physical vapour deposition (PVD). In PVD process, atoms or molecules are generated and transferred physically onto a substrate. The thickness of films and coatings can vary from nanometers to millimeters. According to the physical mechanism of the generation of the depositing atoms, PVD processes are mainly divided to three categories: sputtering, ion plating and evaporation [66].

\subsection{Sputtering}

Sputtering is widely used for thin film deposition because of its specific advantages. The thin films produced by sputtering possess a uniform thickness and are free of droplets. Sputtering is also capable of depositing refractory materials [67].

A schematic of a sputtering system is shown in Figure 4.1. Sputter deposition is a vacuum coating process and the evacuated chamber is refilled with argon to establish a 
glow discharge. The power supply shown in Figure 4.1 is a parallel plate planar-diode source. Another widely used source is a magnetron which is a diode modified by moderate-strength magnetic fields. The magnetron source usually has higher deposition rates and lower substrate heating in comparison with the planar-diode source. The target and the substrate are located opposite to each other. A negative potential is applied to the target and the substrate is grounded. The ejection of the target atoms is achieved by the collision of the inert gas ion/neutral atoms close to the surface of the target. In the striking process, the momentum of the energetic ion/neutral is transferred to the target atoms within a few atomic distances [68]. After acquiring sufficient momentum to overcome the local bonding forces, the solid target material becomes vapour phase with the target atoms being released [65]. 


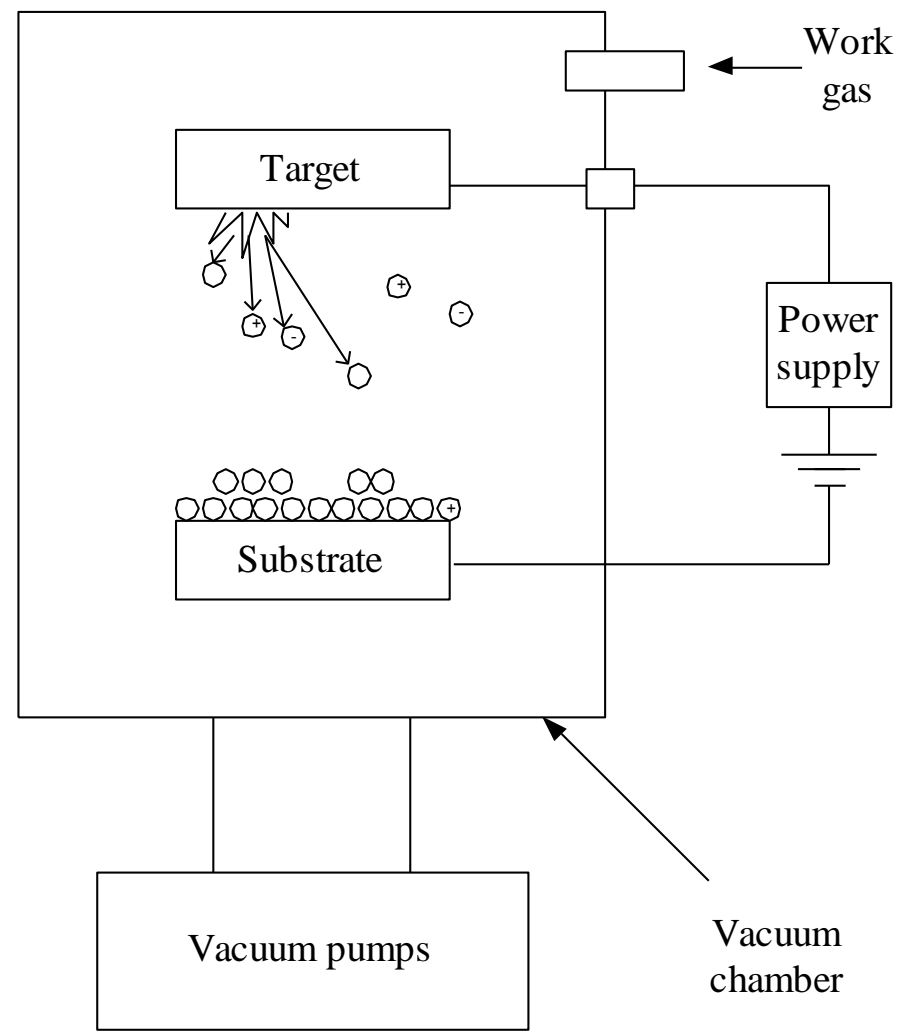

Figure 4.1: Schematic of a parallel-plate diode sputtering system [65].

\subsection{Ion plating}

A simple ion plating system is shown in Figure 4.2. Ion plating is a vacuum deposition process and the evacuated chamber is backfilled with an inert gas, such as argon, or reactive gas, such as nitrogen or oxygen. In ion plating, the substrate is cathodic, which is different from sputtering using a cathodic target. Prior to deposition, the substrate surface can be cleaned by the energetic ions. Bombardment during deposition can improve adhesion between coating and substrate, and promote the growth of dense and equiaxed-grained coatings [65], [68]. 


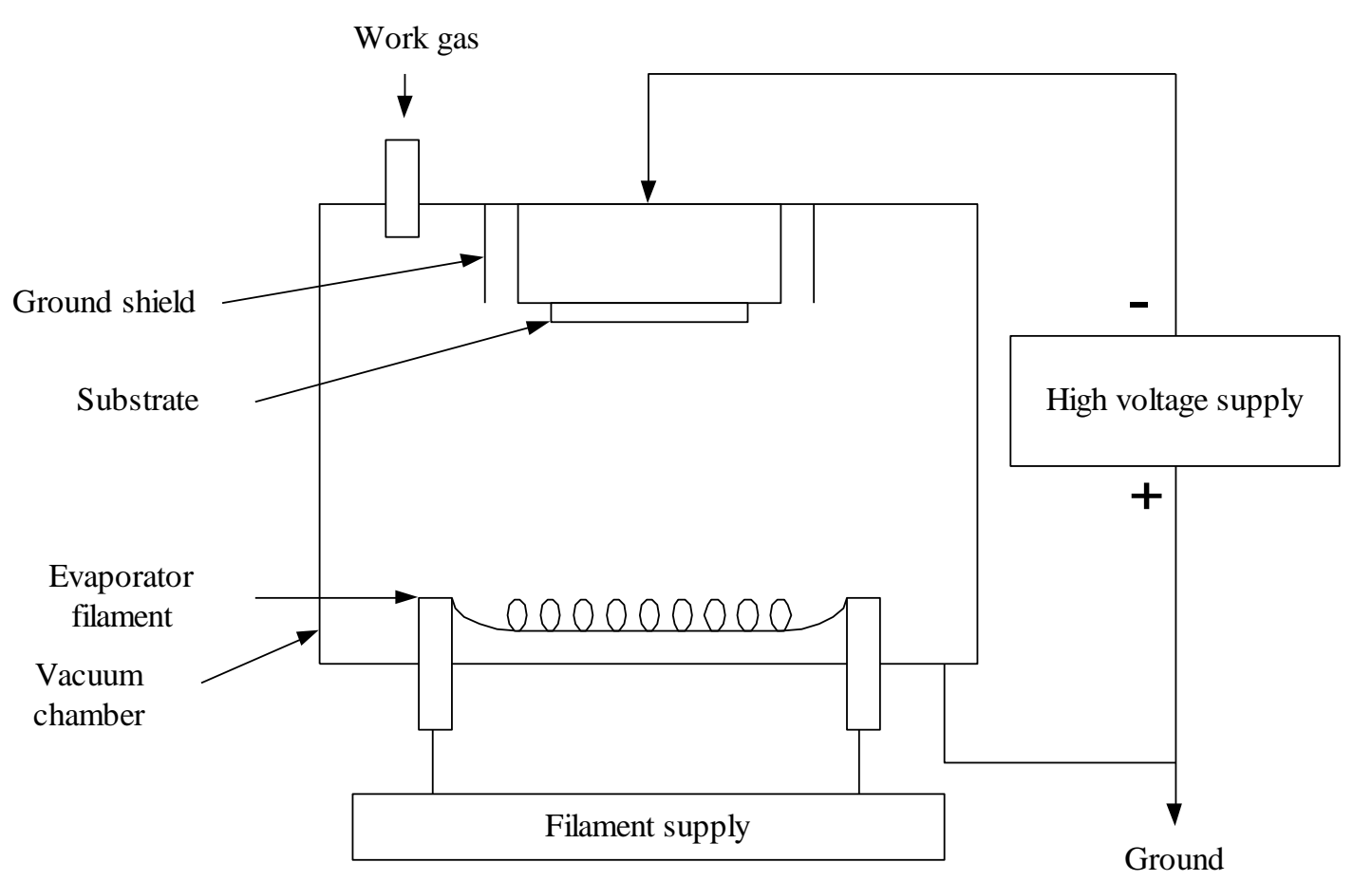

Figure 4.2: Schematic of an ion plating system using a DC diode discharge and a thermal vaporization source [65].

\subsection{Evaporation}

Evaporation is a thermal process that involves changing the target material from a solid to a vapour phase by heating the source material, rather than the mechanical process of transferring the momentum of energetic ions or neutral atoms to the atoms involved in sputter deposition.

A basic evaporation system is shown in Figure 4.3. The evaporation takes place under high vacuum conditions. An evaporation source is opposite to a specimen in the substrate holder [68]. The target material is vapourized by heating. The different heating 
modes classify the evapouration systems, such as resistance heating, induction heating, electron beam heating, exploding wire sources and vacuum cathodic arc heating. In resistance heating system, the vaporized atoms or molecules travel throughout the vacuum chamber with low kinetic energies. The evaporation process is employed in this research and a cathodic arc is used to produce vapour.

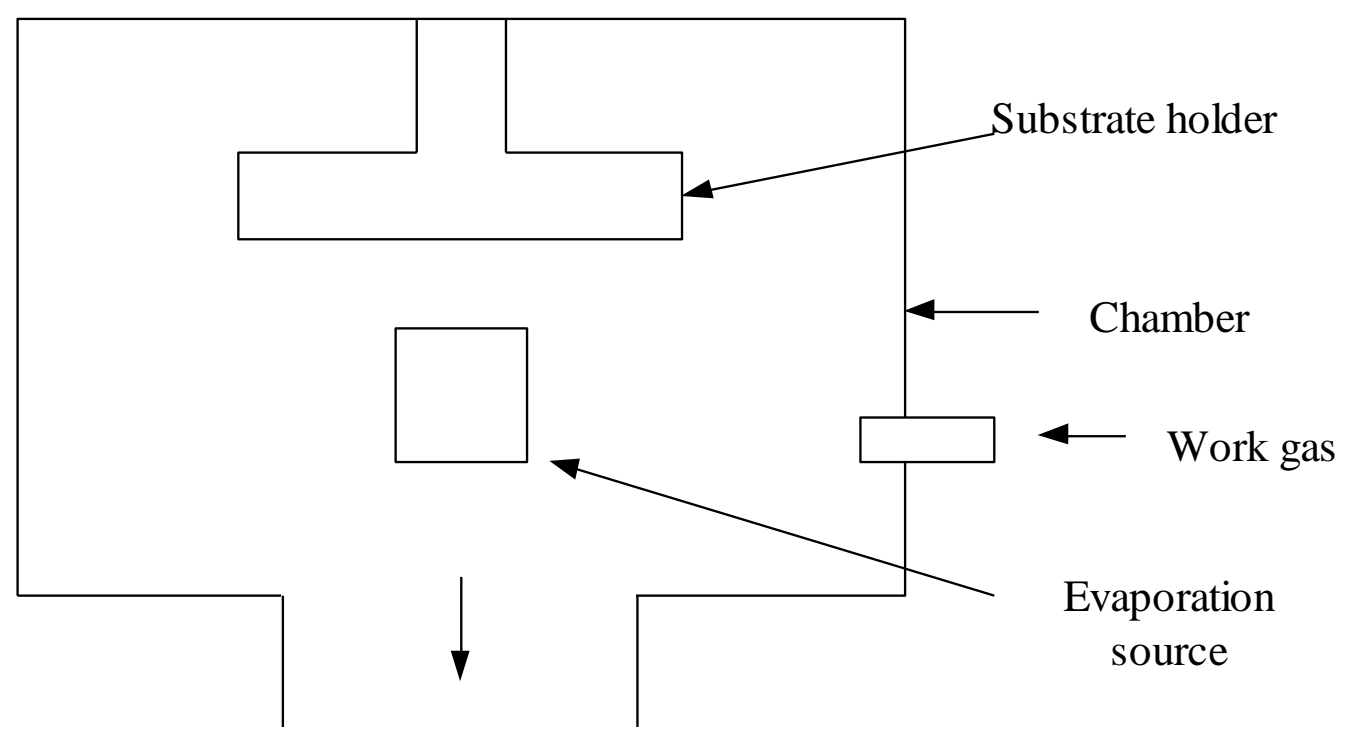

Vacuum pumping

Figure 4.3: Basic components of an evaporation system with resistance heating source [68].

\subsubsection{Cathodic arc plasma deposition}

The use of a vacuum arc for generating coatings was first suggested by Thomas Edison in 1892 [69]. A vacuum cathodic arc source can be defined as "a self-sustained discharge capable of supporting large currents by providing its own mechanism of 
electron emission from the negative electrode" [70]. Arc-produced vapour has a high degree of ionization that results in certain coating property advantages. Specifically, the ions can be steered by magnetic and electric fields. This technique enhances the film adhesion, film density and composition control [71].

The mechanism of the arc discharge differs significantly from that of glow discharges used for conventional sputtering and ionized sputtering. The arc discharge occurs most likely at asperities on the surface of the cathode [72], [73]. The electrons concentrate at asperities and the electric field of the cathode is amplified. The field attracts ions existing in the plasma, which bombard and heat the asperity [74], [75]. Due to the combination of high field with heat, some electrons are liberated from the cathodic surface, which results in electron-atom collisions producing positive ions. The luminous area, where the arc discharge current is concentrated, is termed the cathode spot area [76], [77], in which the cathode material transforms from the solid phase to fully ionized plasma.

Cathodic arcs have two operation modes: pulsed or continuous. The current research work employed a continuous cathodic arc. In the continuous mode, a series of arc discharges occur at high frequency and form moving arcs [78]. The cathode needs to be cooled by water at its back side because of the successive discharges. Since the cathodes are cooled, the continuous arcs can be operated in any orientation [69], [78]. Another advantage is that the entire target, except the very edge part, can be utilized [65]. In 
addition, the continuous cathodic arc is capable of very high deposition rates.

\subsubsection{Filtering systems}

During the cathodic arc evaporation, there are not only ionized plasma from the cathodic spot, but also droplets and debris particles, commonly referred to as macroparticles. The undesirable macroparticles can cause local shadowing and the formation of voids in their immediate vicinity as well as large-scale defects in the film [79]. Several filtering systems, such as shielding and magnetic sheering, can be equipped to prevent or remove macroparticles.

The electro-magnetic filtering system is used in current research. The elimination of macroparticles is achieved by a non-line-of-sight design between the cathode and substrate. Due to their trajectory, the macroparticles are blocked out very effectively by the non-direct path [80]-[85]. At the same time, the emitted electrons and ions need to be guided efficiently to the substrate, which is achieved by a combination of an axial magnetic field and an electric field around the travel path of the plasma. The electrons are steered by the magnetic field spiraling along the axial field lines. The ions are controlled by the electric filed by following the guided electrons in order to maintain a quasi-neutral state of the plasma. Martin et al. [86] conclude that the filtering system with a magnetic plasma duct is the most effective method of producing macroparticle-free coatings. The Aksenov toroidal-type filter in Figure 4.4 is one of the most practical and popular designs [87]. 


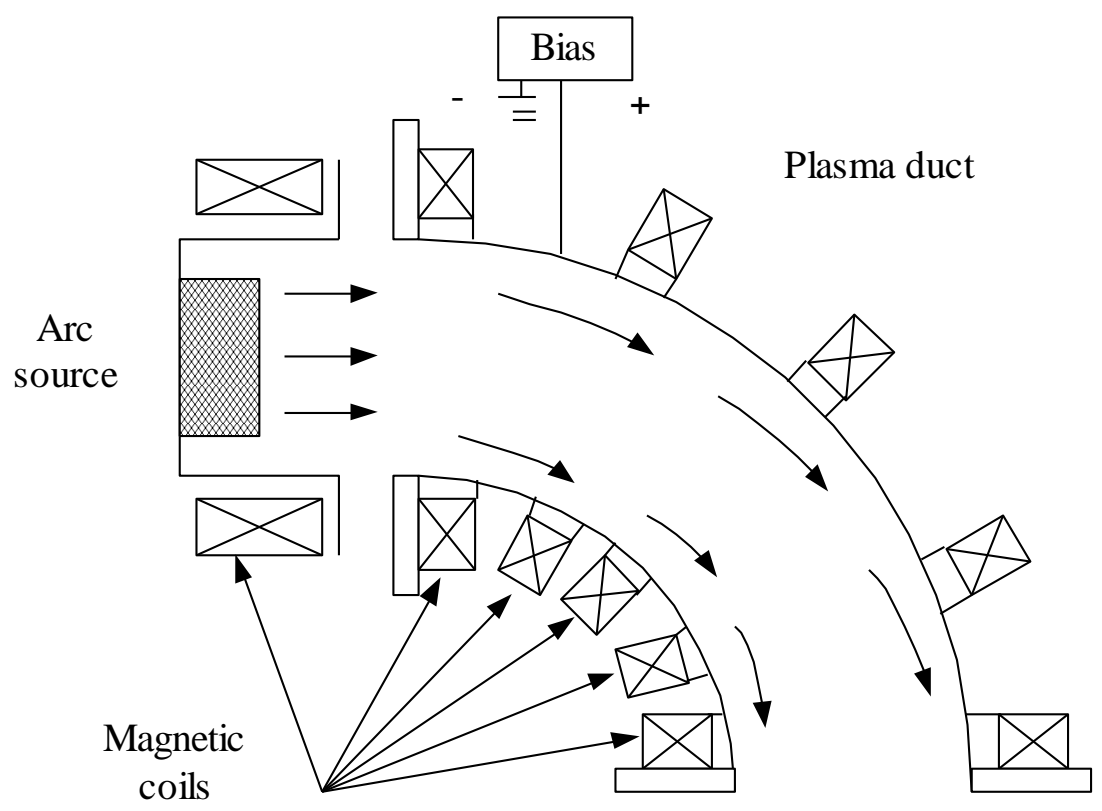

Figure 4.4: Macroparticle filtering system using a magnetic plasma duct system [80], [88]-[90].

\subsection{Film deposition method used in the current research}

The FADS used in the current research employed the electro-magnetic filtering method, shown schematically in Figure 4.4, to eliminate macroparticles.

The use of this system for deposition of NiTi thin films was investigated and reported by Stanford et al. [14]. They found that the value of arc current influenced the composition of the as-deposited NiTi thin film. Figure 4.5 shows the atomic percentage of $\mathrm{Ni}$ as a function of arc current. The Ni content decreased with increasing arc current. An equiatomic NiTi film was produced on a silicon substrate at a deposition current of 
110 A with a bias voltage of $100 \mathrm{~V}$.

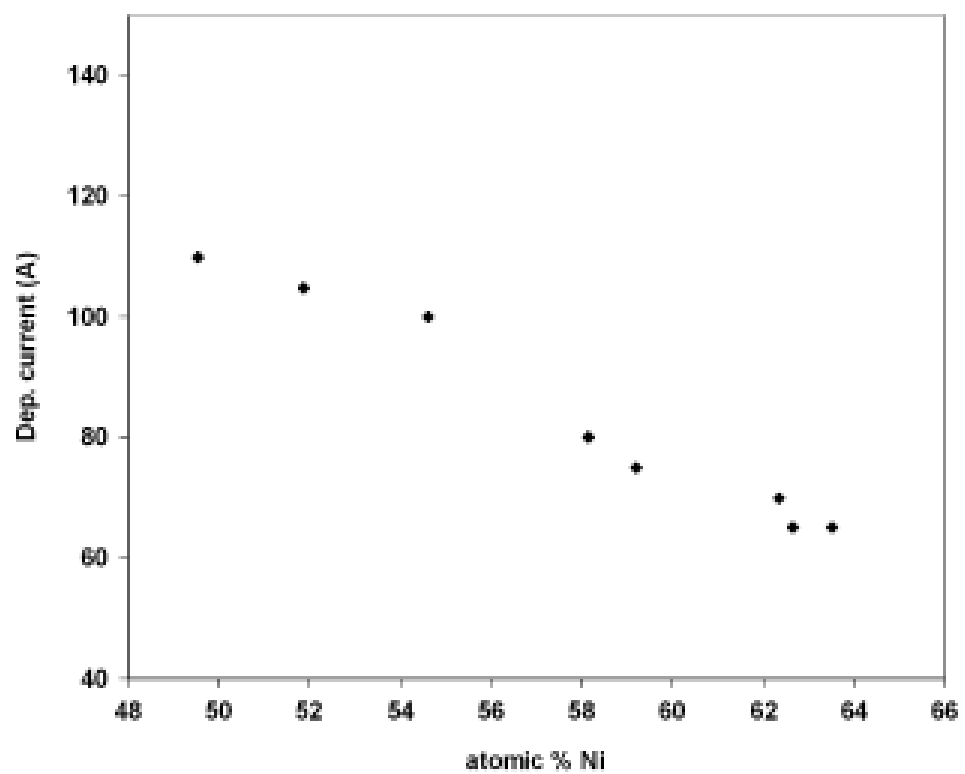

Figure 4.5: Effect of deposition current on the composition of films deposited using FADS [14].

Due to different deposition conditions associated with arc current, substrate bias voltage, temperature and substrate material, the deposited thin films showed different compositions, microstructures and mechanical properties, which in turn resulted in different cavitation erosion behaviours. Therefore, it was a major objective of this research work to investigate the effects of deposition conditions on structure and cavitation erosion resistance of the deposited NiTi thin films. 


\section{Chapter 5}

\section{Experimental Details}

\subsection{Thin film synthesis}

\subsubsection{Substrates and their preparation}

Mild steel and 316 austenitic stainless steel were used as substrates for deposition and their chemical compositions are listed in Table 5.1. Initial deposition trials were conducted using a stainless steel substrate, but because stainless steel is difficult to etch by chemical reagents to free the film, a mild steel substrate was also used. Both materials are potential substrates for coated materials for use in practical applications.

Table 5.1: Chemical compositions (in wt \%) of 316 austenitic stainless steel and mild steel.

\begin{tabular}{lcccccccccc}
\hline Element (wt. \%) & $\mathrm{Cr}$ & $\mathrm{Ni}$ & $\mathrm{C}$ & $\mathrm{Mn}$ & $\mathrm{Si}$ & $\mathrm{P}$ & $\mathrm{S}$ & $\mathrm{N}$ & Mo & $\mathrm{Fe}$ \\
\hline Stainless steel & $16-18$ & $10-14$ & 0.03 & 2 & 0.75 & 0.045 & 0.03 & 0.10 & $2.0-3.0$ & Bal. \\
Mild steel & ------- & ------- & 0.08 & 0.35 & 0.17 & 0.014 & 0.018 & ------ & ------ & Bal. \\
\hline
\end{tabular}

The substrate material was machined to a disc shape with a diameter of $40 \mathrm{~mm}$ and thickness of $4 \mathrm{~mm}$. A Struer's Abramin polishing machine was used to polish the substrate disc to a $1 \mu \mathrm{m}$ diamond finish. Before transferring the substrates into the 
FADS chamber for deposition, they were cleaned using detergent, distilled water and acetone.

\subsubsection{Deposition by FADS}

FADS was used to produce NiTi coatings on the substrates. Figure 5.1 is a schematic diagram of FADS. The target material for the FADS was purchased from Special Metals Corporations and was annealed before shipping. The composition of the target is given in Table 5.2.

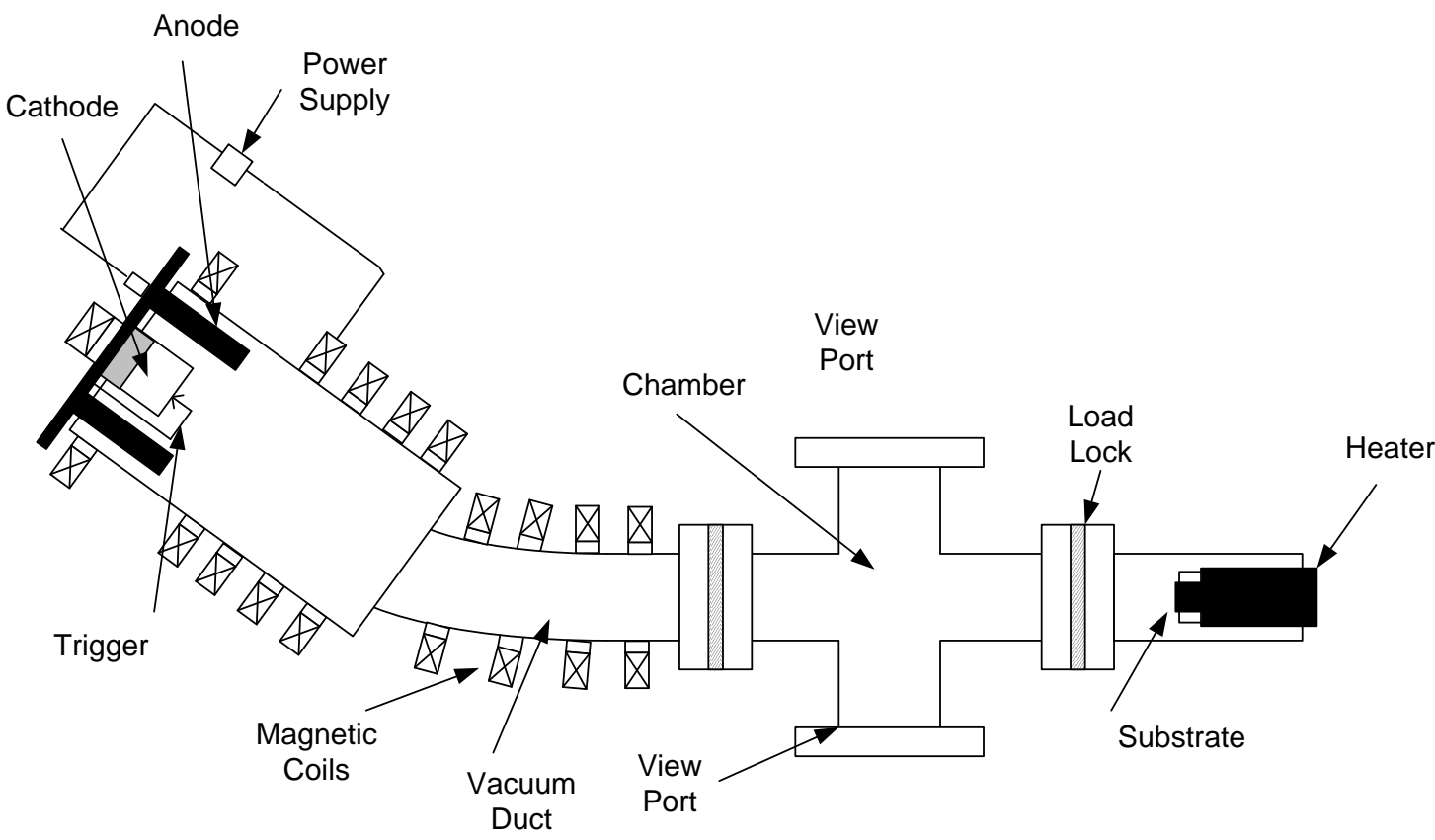

Figure 5.1: Schematic diagram of FADS [86]. 
Table 5.2: Chemical composition of NiTi bulk alloy

\begin{tabular}{ccc}
\hline Element & Wt.\% & At.\% \\
\hline $\mathrm{Ni}$ & $55.09 \%$ & $50.02 \%$ \\
$\mathrm{Ti}$ & $44.89 \%$ & $49.98 \%$ \\
$\mathrm{C}$ & $260 \quad \mathrm{ppm}$ & \\
$\mathrm{O}$ & $198 \quad \mathrm{ppm}$ & \\
$\mathrm{Fe}$ & 110 & $\mathrm{ppm}$ \\
\hline
\end{tabular}

The deposition chamber was evacuated to $5 \times 10^{-5}$ Torr before deposition. The substrate was pre-heated and the temperature was recorded by using a Type $\mathrm{K}$ (chromel-alumel) thermocouple inserted into a hole drilled into the side of the substrate. Before deposition, the bias voltage was set to $800 \mathrm{~V}$ for sputter cleaning for 30 seconds to eliminate surface impurities and oxides. During this process, the substrate temperature rose dramatically because of bombardment by the plasma. The deposition time was 12 minutes in all cases and the deposited films were around $2 \mu \mathrm{m}$ thick.

\subsubsection{Composition control}

In order to optimize the deposition condition to obtain near-equiatomic NiTi thin film, two groups of samples were deposited on the mild steel substrate at different arc currents and substrate bias voltages, with the starting substrate temperatures of around $420^{\circ} \mathrm{C}$. The first group of samples were produced at a substrate bias voltage of $80 \mathrm{~V}$ with arc current varying from $60 \mathrm{~A}$ to $135 \mathrm{~A}$. Ni-rich, Ti-rich and near-equiatomic NiTi 
were obtained during the optimization process. Three film samples, Ni-42.00at\% Ti, $\mathrm{Ni}-54.05 \mathrm{at} \% \mathrm{Ti}$ and $\mathrm{Ni}-49.98 \mathrm{at} \% \mathrm{Ti}$, were compared for their different material and mechanical properties. The second group were deposited at constant current of $115 \mathrm{~A}$, but with bias voltages ranging from $20 \mathrm{~V}$ to $150 \mathrm{~V}$.

\subsubsection{Substrate temperature}

One group of thin films were deposited on the mild steel substrates with different starting substrate temperatures of $130^{\circ} \mathrm{C}, 300^{\circ} \mathrm{C}, 430^{\circ} \mathrm{C}$, and $600^{\circ} \mathrm{C}$. All the other deposition parameters remained the same. The substrate bias voltage was $80 \mathrm{~V}$ and the arc current was $115 \mathrm{~A}$. As to the starting temperature of $130^{\circ} \mathrm{C}$, the actual substrate temperature rose by about $200^{\circ} \mathrm{C}$ during deposition because of the bombardment. For samples with starting temperatures of $300^{\circ} \mathrm{C}$ and $430^{\circ} \mathrm{C}$, the temperature remained almost constant during deposition. However, the substrate temperature fell by about $100^{\circ} \mathrm{C}$ for an initial temperature of $600^{\circ} \mathrm{C}$, as a result of the balance between deposition energy and heat loss.

Using similar bias voltage and arc current, 316 austenitic stainless steel was also used as a substrate for NiTi thin film deposition, and the low and high starting substrate temperatures were $23^{\circ} \mathrm{C}$ and $430^{\circ} \mathrm{C}$ respectively. 


\subsubsection{Substrate bias voltage}

Two groups of thin films, with four films in each group, were deposited on mild steel substrate at $50 \mathrm{~V}, 80 \mathrm{~V}, 120 \mathrm{~V}$ and $150 \mathrm{~V}$. The arc current was adjusted from 110 A to $135 \mathrm{~A}$ to adjust the atomic ratio of $\mathrm{Ti}$ to $\mathrm{Ni}$ to be as close as possible to 1:1. The substrate for the first group of films was preheated to $150^{\circ} \mathrm{C}$, and for the second group the substrate was preheated to $600^{\circ} \mathrm{C}$.

\subsection{Thin film characterization}

\subsubsection{X-ray diffraction}

XRD (GBC MMA) with $\mathrm{Cu} \mathrm{K} \alpha$ radiation $(\lambda=0.15418 \mathrm{~nm})$ was used to study the phases of the NiTi thin films. The scanning speed was $2^{\circ} \mathrm{min}^{-1}$ with a step size of $0.02^{\circ}$.

\subsubsection{Energy dispersive spectroscopy}

An energy dispersive spectroscope (EDS) system fitted to a scanning electron microscope (SEM JEOL JSM-6460A) was used to measure the composition of the as-deposited thin films with an accuracy of $0.1 \mathrm{at} \%$. A bulk sample Ti-49.98at $\% \mathrm{Ni}$ from the target material was used as the reference sample.

\subsubsection{Differential scanning calorimetry}

DSC (TAQ 100) was employed to determine the phase transformation characteristics of 
the as-supplied bulk alloy and the thin films. The ramping rate was set as $10^{\circ} \mathrm{C} \mathrm{min}^{-1}$.

First, the thermal behaviour of NiTi target was tested. One small piece of NiTi bulk alloy with dimensions of $3 \times 3 \times 1\left(\mathrm{~mm}^{3}\right)$ and a mass of $38.3 \mathrm{mg}$ was cut from the target using a precision cut-off machine (Struers Accutum-50). Thin film samples were released from the mild steel substrate by surface layer dissolution of the substrate in $8 \%$ Nital.

\subsubsection{Transmission electron microscopy}

The microstructure of the thin films was examined by TEM (JEOL FX 2011). TEM was first used to examine cross-sections of the constrained thin films on the substrate. The thickness of coatings can be measured. The electron transparent cross-sections of the deposited films were produced by focused ion beam (FIB) milling using a Nova Nanolab 200 Dual beam FIB instrument.

For thin film samples, $3 \mathrm{~mm}$ diameter discs were cut out from the free standing films with a Disc Punch. Then, twin-jet electro-polishing was used to thin the disc foils by penetrating a central hole at $20 \mathrm{~V}$ and $10^{\circ} \mathrm{C}$ in an electrolyte of $95 \%$ acetic acid and $5 \%$ perchloric acid. 


\subsection{Mechanical properties testing}

\subsubsection{Atomic force microscopy}

The roughness of thin films was measured by means of atomic force microscopy (AFM, Dimension 3100 scanning probe microscope) with a scan size of $50 \mu \mathrm{m}$ and a scan rate of $1 \mathrm{~Hz}$ in the contact mode.

\subsubsection{Indentation testing}

Indentation testing was used to measure the hardness and elastic modulus of NiTi thin films. Two indentation testing instruments were employed in this work, an Ultra micro-indentation system (UMIS 2000 Ultra Micro-Indenter) and a Hysitron TI-900 TriboIndenter.

The UMIS was equipped with a triangular-shaped pyramidal Berkovich indenter and the maximum load applied was either $8 \mathrm{mN}$ or $10 \mathrm{mN}$. Each indent was accomplished by a series of 20 incremental loading steps and the penetration depth was up to $10 \%$ of the film thickness.

The Hysitron TI-900 TriboIndenter employs a 3D OmniProbe ${ }^{\mathrm{TM}}$ equipped with a diamond Berkovich probe. The load function used for the indentation tests consists of a five-second linear loading segment, a two-second hold segment, and a five-second linear unloading segment. The hold segment was included to reduce the effects of 
sample creep during unloading. The peak force of indentation was $11.5 \mathrm{mN}$.

\subsubsection{Scratch testing}

The adhesion force between thin films and substrate was evaluated by scratching testing. A Romulus Materials Tester III (Quad group, USA) was employed for the scratch testing with a $300 \mu \mathrm{m}$ radius tip. Each sample was loaded at a rate of $0.5 \mathrm{mN} / \mathrm{s}$ until failure, with a maximum normal load of $30 \mathrm{mN}$.

Later on, scratch testing performed using a TI-900 TriboIndenter (Hysitron) with a 3D

OmniProbe $^{\mathrm{TM}}$ equipped with a $60^{\circ}$ conical probe with a $5 \mu \mathrm{m}$ tip radius. Each test consisted of a linearly ramping normal force to a peak load of $500 \mathrm{mN}$ over a scratch length of $250 \mu \mathrm{m}$ and a duration of 60 seconds. The scratch data was then analysed to determine whether a critical point of interfacial adhesion failure was observed.

\subsection{Cavitation erosion testing}

\subsubsection{Cavitation erosion tester}

ASTM Test Method G32 was used to evaluate the cavitation erosion resistance of the NiTi thin films, the austenitic 316L stainless steel, and a NiTi bulk sample from the target alloy [25]. A schematic diagram of the cavitation erosion tester is shown in Figure 5.2. The transducer was vibrated at a frequency of $20 \mathrm{kHz}$ with displacement amplitude of $50 \mu \mathrm{m}$. Samples were set $1.5 \mathrm{~mm}$ beneath the titanium alloy tip and were immersed 
in fresh water in a beaker. The water temperature was maintained at about $23^{\circ} \mathrm{C}$ by a cooling bath surrounding the beaker.

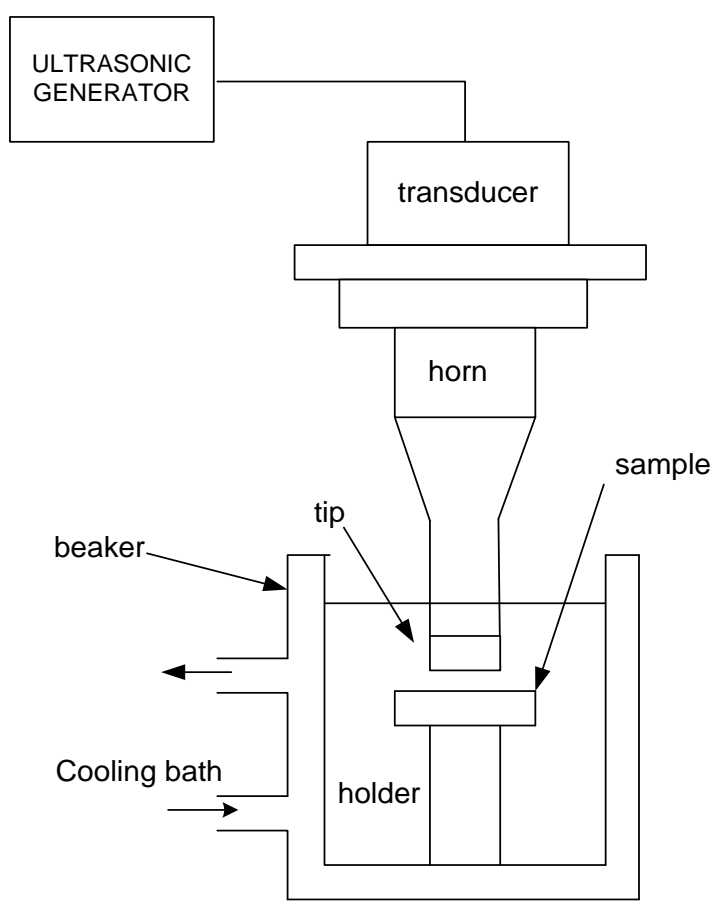

Figure 5.2: Schematic diagram of the cavitation erosion tester.

\subsubsection{Sample preparation}

The reference materials, stainless steel and NiTi alloy, were polished to $1 \mu \mathrm{m}$ diamond finish before cavitation erosion testing.

Before the NiTi thin film samples on the mild steel substrate were placed in the cavitation erosion tester, the exposed surface of the mild steel was coated with $\mathrm{Ni}$ by electroless plating, because of the susceptibility of the mild steel to corrosive attack in the aqueous solution. The layer of Ni coating prevented any corrosion-induced weight 
change during the test.

Before the samples were immersed in the electroless Ni plating bath, the surface of the thin films was covered by silicone grease (Molykote 111) to prevent contamination from the Ni coating. A standard sodium hypophosphite bath was used for the electroless nickel plating and its chemical composition is given in Table 5.3. The electroless plating was performed on a hot plate with a magnetic stirrer for the metallising reaction. The solution temperature was maintained at $88 \pm 2^{\circ} \mathrm{C}$ and the coating process lasted for more than one hour. The coating rate was $0.015 \mu \mathrm{m} / \mathrm{min}$.

Table 5.3: Chemical composition of electroless Ni plating bath.

\begin{tabular}{llc}
\hline \multicolumn{1}{c}{ Chemical } & \multicolumn{1}{c}{ Formula } & Quantity $(\mathrm{g} / \mathrm{l})$ \\
\hline Nickel sulphate & $\mathrm{NiSO}_{4} \bullet 6 \mathrm{H}_{2} \mathrm{O}$ & 10 \\
Sodium citrate & $\mathrm{Na}_{3} \mathrm{C}_{6} \mathrm{H}_{5} \mathrm{O}_{7} \bullet \mathrm{H}_{2} \mathrm{O}$ & 15 \\
Ammonium sulphate & $\mathrm{NH}_{4} \mathrm{SO}_{4}$ & 15 \\
Sodium hypophosphite & $\mathrm{NaH}_{2} \mathrm{PO}_{2} \bullet \mathrm{H}_{2} \mathrm{O}$ & 16 \\
\hline
\end{tabular}

\subsubsection{Measurement of cavitation erosion resistance}

A SEM (JEOL JSM-6460A) was used to observe the surface morphology change as a result of cavitation erosion testing. The mass loss was measured by an electronic balance with an accuracy of $0.1 \mathrm{mg}$. The eroded samples on the mild steel substrate 
were cross sectioned for the observations of pits. 


\section{Chapter 6}

\section{XRD and TEM Characterization of NiTi Thin Films}

\subsection{Composition control}

\subsubsection{Effects of arc current and substrate bias voltage on thin film composition}

The results of a calibration experiment investigating the effects of deposition current and bias voltage on the composition of the as-deposited thin films are shown in Figure 6.1 and Figure 6.2. It can be seen from Figure 6.1 that the atomic concentration of $\mathrm{Ti}$ increased with an increase in the arc current. This may be due to differential rates of ejection of the $\mathrm{Ni}$ and $\mathrm{Ti}$ atoms from the target as a function of arc intensity. However, the atomic percentage of Ti decreased with an increase of substrate bias voltage, as shown in Figure 6.2. Increasing the bias voltage increases the kinetic energy of the metallic ions as they are accelerated towards the substrate. The heavier Ni ions will acquire higher kinetic energies than the $\mathrm{Ti}$ ions and will therefore show a different susceptibility to filtering by the magnetic field. Balancing the fluxes of incident $\mathrm{Ni}$ and Ti ions on the substrate was achieved by control of both the arc current and the bias voltage.

Based on the results presented in Figure 6.1 and Figure 6.2, the composition of the as-deposited thin film can be controlled by an appropriate combination of substrate bias voltage and arc current. For a substrate bias voltage of $80 \mathrm{~V}$, a near-equiatomic NiTi thin 
film was obtained at $115 \mathrm{~A}$.

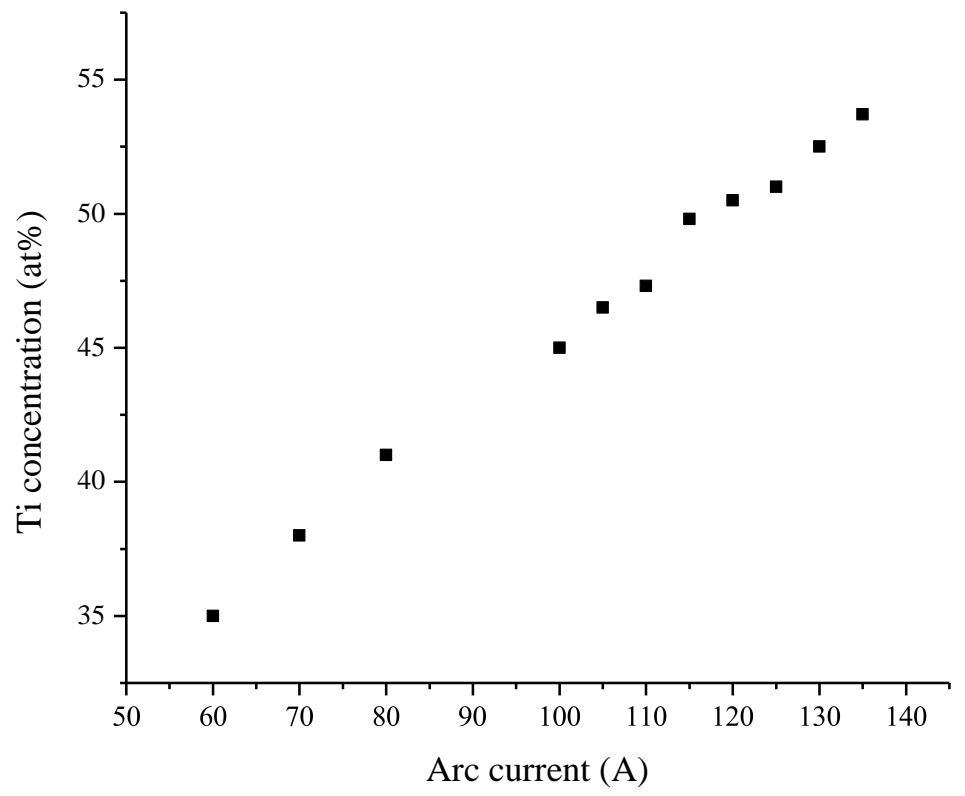

Figure 6.1: Effect of arc current on the atomic percentage of Ti (Bias voltage $=80 \mathrm{~V})$.

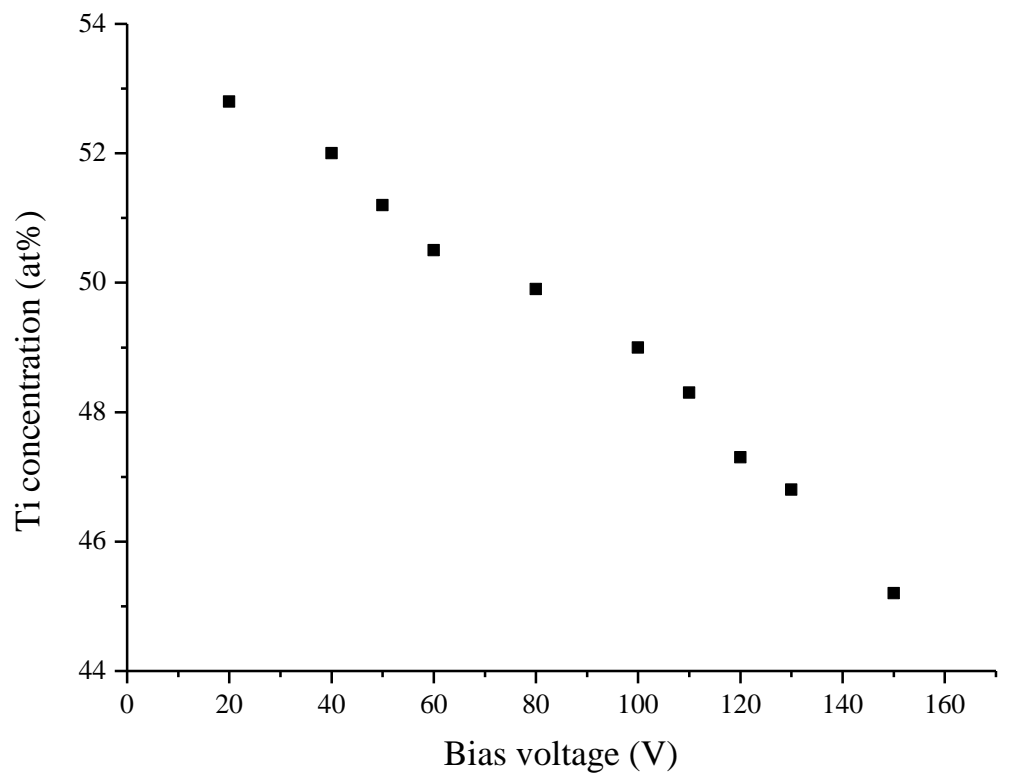

Figure 6.2: Effect of substrate bias voltage on the atomic percentage of $\mathrm{Ti}$ (Arc current=115 A). 
Films were prepared from different combination of bias voltage and arc current to produce the three basic types of thin fims: Ti-rich, Ni-rich and near-equiatomic.

\subsubsection{Microstructures of thin films with different compositions}

Three thin film samples with different $\mathrm{Ti}$ contents were obtained by varying the deposition conditions. The substrate starting temperatures were about $420^{\circ} \mathrm{C}$ for these samples. The EDS analysis showed that the Ti content in the three as-deposited films were $42.00 \mathrm{at} \%, 54.05 \mathrm{at} \%$ and $49.98 \mathrm{at} \%$.

\subsubsection{XRD and TEM analysis of the Ni-42.00at\% Ti film}

Figure 6.3 (a) shows the X-ray diffraction pattern of the Ni-42.00at\%Ti film. Since the film is thin, the X-ray diffraction pattern also includes diffraction peaks from the substrate. As shown in Figure 6.3, the peaks at $44.5^{\circ}, 65^{\circ}$ and $82^{\circ}$ correspond to Fe (110), Fe (200) and Fe (211), respectively. The strongest peak at $42.5^{\circ}$ is associated with the (110) planes of the NiTi B2 phase. B2 is expected to be dominant as increasing the Ni content strongly depresses $\mathrm{M}_{\mathrm{S}}$ (Figure 3.6). Although the B2 (220) peak was present at about $93.0^{\circ}, \mathrm{B} 2(211)$ at $78.0^{\circ}$ and $\mathrm{B} 2(200)$ at $61.0^{\circ}$ were absent. This result indicates that the as-deposited film has a strong preferred orientation. Grains of the B2 phase are evident in the TEM image of the Ni-rich NiTi film (Figure 6.4). 
Figure $6.3(\mathrm{~b})$ is an enlarged X-ray diffraction pattern ranging from $40^{\circ}$ to $50^{\circ}$. The small peak at about $48^{\circ}$ is consistent with the presence of $\mathrm{Ni}_{3} \mathrm{Ti}$, as predicted by the phase diagram (Figure 3.1). The presence of other $\mathrm{Ni}_{3} \mathrm{Ti}$ peaks, (110) at $41.5^{\circ}$ and (004) at $43.5^{\circ}$, was not confirmed because of the intense B2 (110) peak at $42.5^{\circ}$.

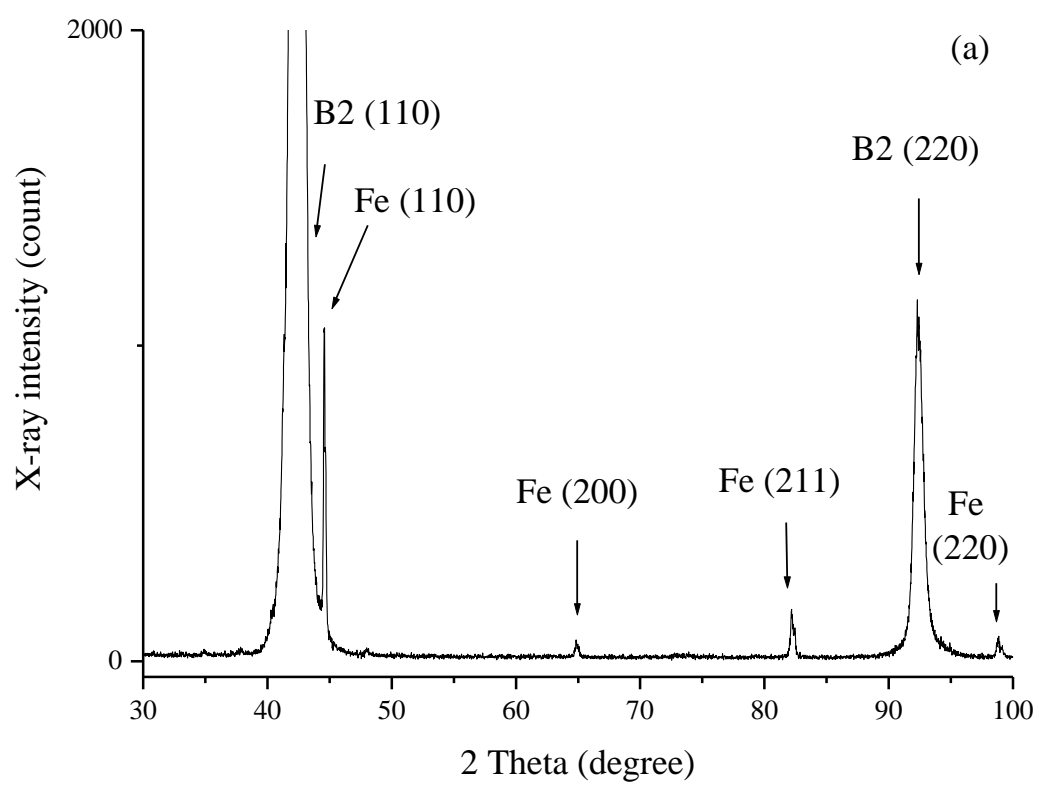




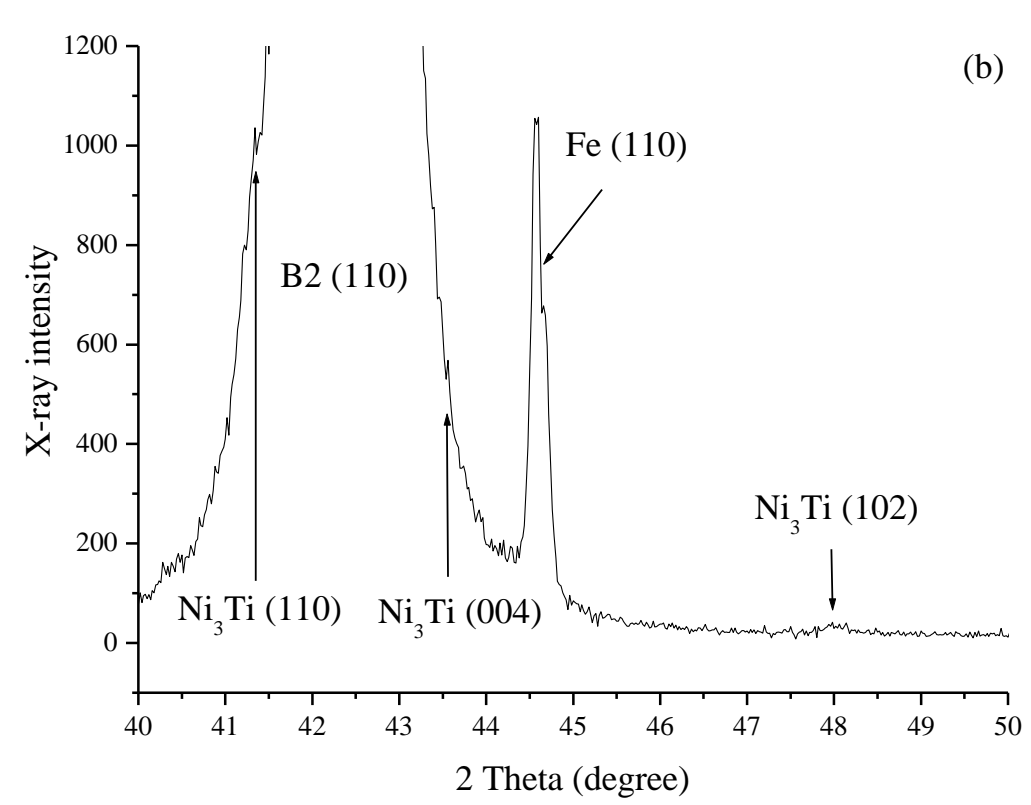

Figure 6.3: X-ray diffraction patterns for $\mathrm{Ni}-42.00 \mathrm{at} \% \mathrm{Ti}$ for 2 Theta from (a) $30^{\circ}$ to $100^{\circ}$; (b) $40^{\circ}$ to $50^{\circ}$.

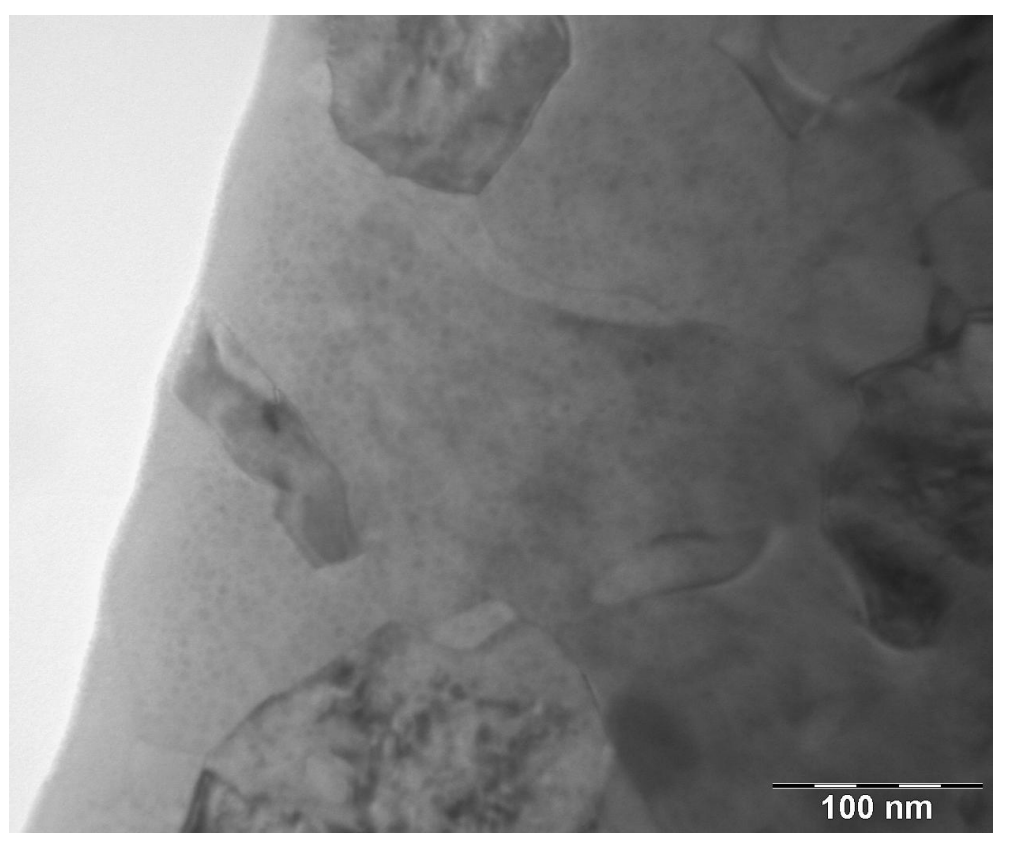

Figure 6.4: TEM image of the Ni-42.00at\%Ti thin film. 


\subsubsection{XRD and TEM analysis of the Ni-54.05at\% Ti film}

Figure 6.5 shows the X-ray diffraction pattern of the Ni-54.05at\% Ti film. Since this film is Ni-depleted the room temperature structure is expected to be pre-dominantly martensitic. The strong peak at about $42.0^{\circ}$ is consistent with $\mathrm{R}$ (112) with overlap from B2(110). The peaks at 39.0, 41.0 and $45.0^{\circ}$ correspond to B19' (002), B19' (-111) and B19' (012). The presence of martensite is consistent with Figure 3.6 which shows that the $\mathrm{M}_{\mathrm{S}}$ temperature stabilizes at about $80-100^{\circ} \mathrm{C}$ in bulk NiTi binary alloys for $\mathrm{Ni}$ contents of about 47-49 at\%. Due to the extra Ti content, trace amounts of $\mathrm{NiTi}_{2}$ is present in the Ti-rich film, as indicated by the small peaks of $\mathrm{NiTi}_{2}(511), \mathrm{NiTi}_{2}(440)$ and $\mathrm{NiTi}_{2}$ (442). The TEM image in Figure 6.6 shows the substantial presence of both martensite and untransformed parent phase.

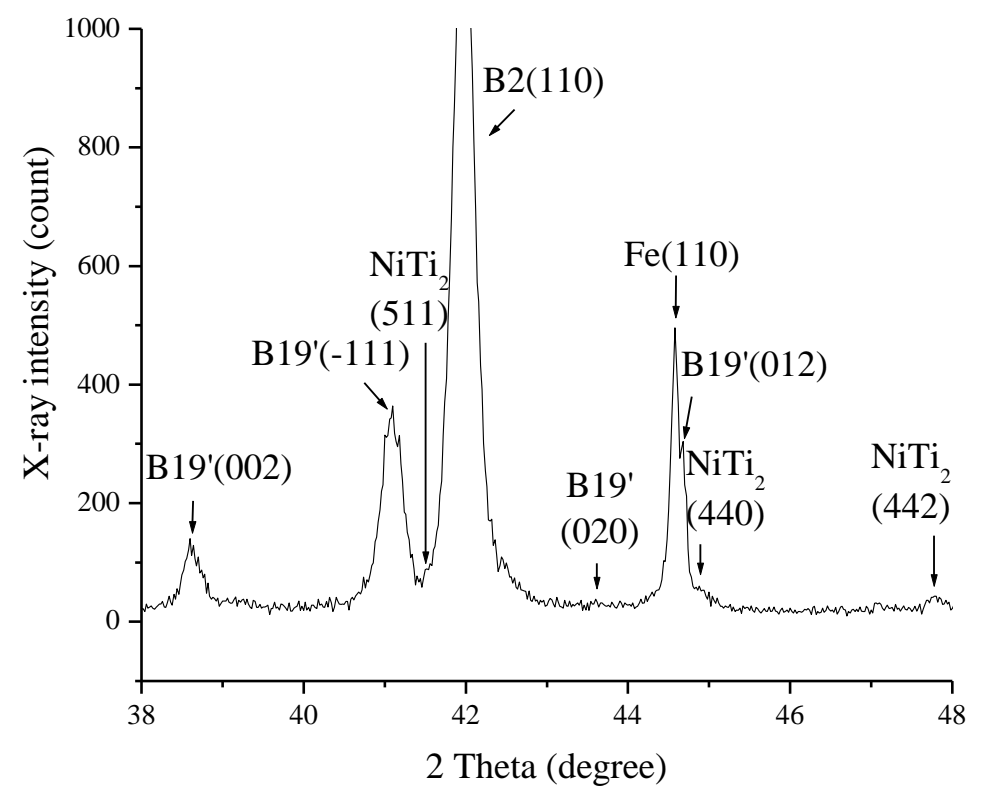

Figure 6.5: X-ray diffraction pattern for Ni-54.05at\% Ti. 


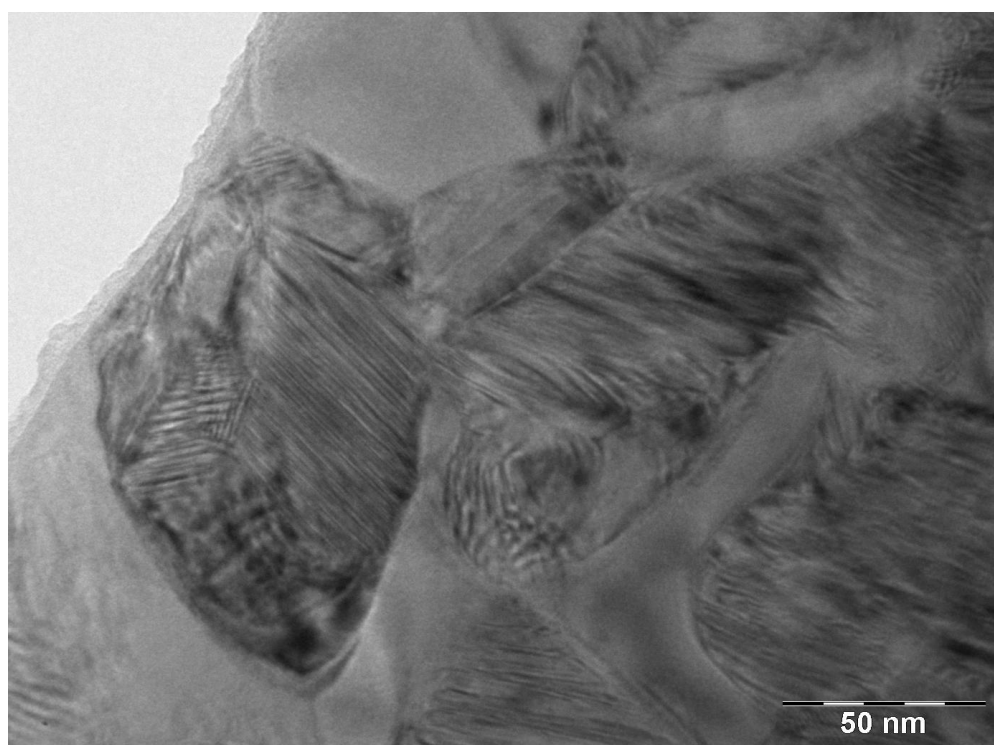

Figure 6.6: TEM image of the Ni-54.05at\% Ti film.

\subsubsection{XRD and TEM analysis of the near-equiatomic Ni-49.98at\% Ti film}

The X-ray diffraction pattern of the near-equiatomic NiTi is shown in Figure 6.7. The strong double peak over the range from $41.5^{\circ}$ to $43^{\circ}$ (Figure 6.7 (a)) is consistent with $\mathrm{R}$ (112) at $42^{\circ}$ and B2 (110) at $42.5^{\circ}$. The second order peaks, R (224) and B2 (220), are shown in Figure 6.7 (b). The martensitic phase was also observed in the near-equiatomic NiTi thin film. The diffraction patterns show B19' (002), B19' (-111), B19' (020), B19' (012) and B19' $(003)$ at $39.0^{\circ}, 41.4^{\circ}, 44.0^{\circ}, 45.0^{\circ}$ and $60.0^{\circ}$ (Figure 6.7 (a) and (b)). These X-ray results are similar to those reported by Wang for near-equiatomic NiTi films [91]. Therefore, the XRD patterns indicate that the near-equiatomic NiTi thin film was composed of austenite, martensite and the R phase. 

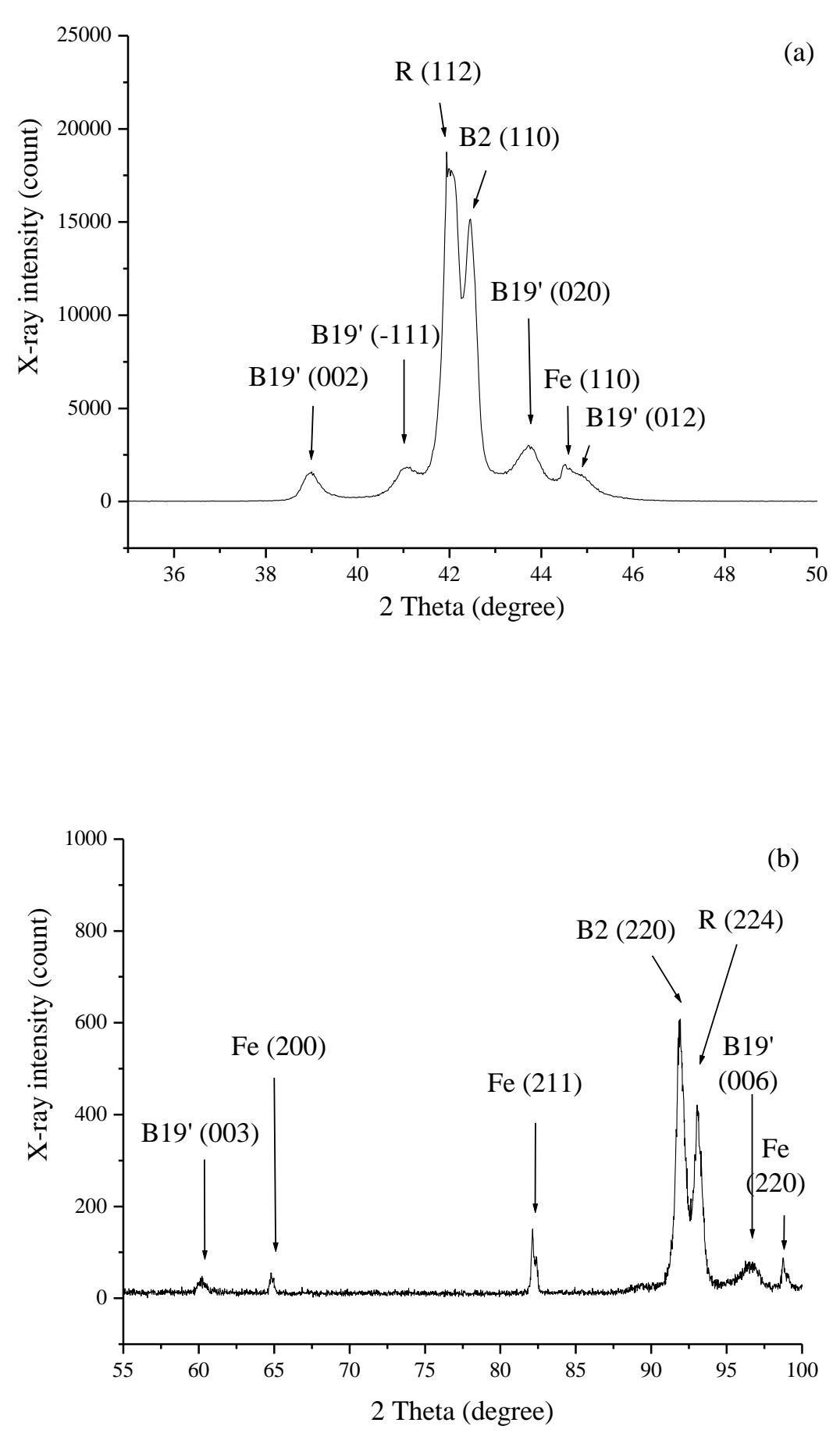

Figure 6.7: X-ray diffraction pattern for the near-equiatomic NiTi thin film for 2-Theta from (a) $35^{\circ}$ to $50^{\circ}$; (b) $55^{\circ}$ to $100^{\circ}$.

Figure 6.8 shows TEM bright field images of the near-equiatomic NiTi. The deposited film consists of parent phase grains (Figure 6.8 (a)) with significant transformation to 
martensite (Figure 6.8 (b)).
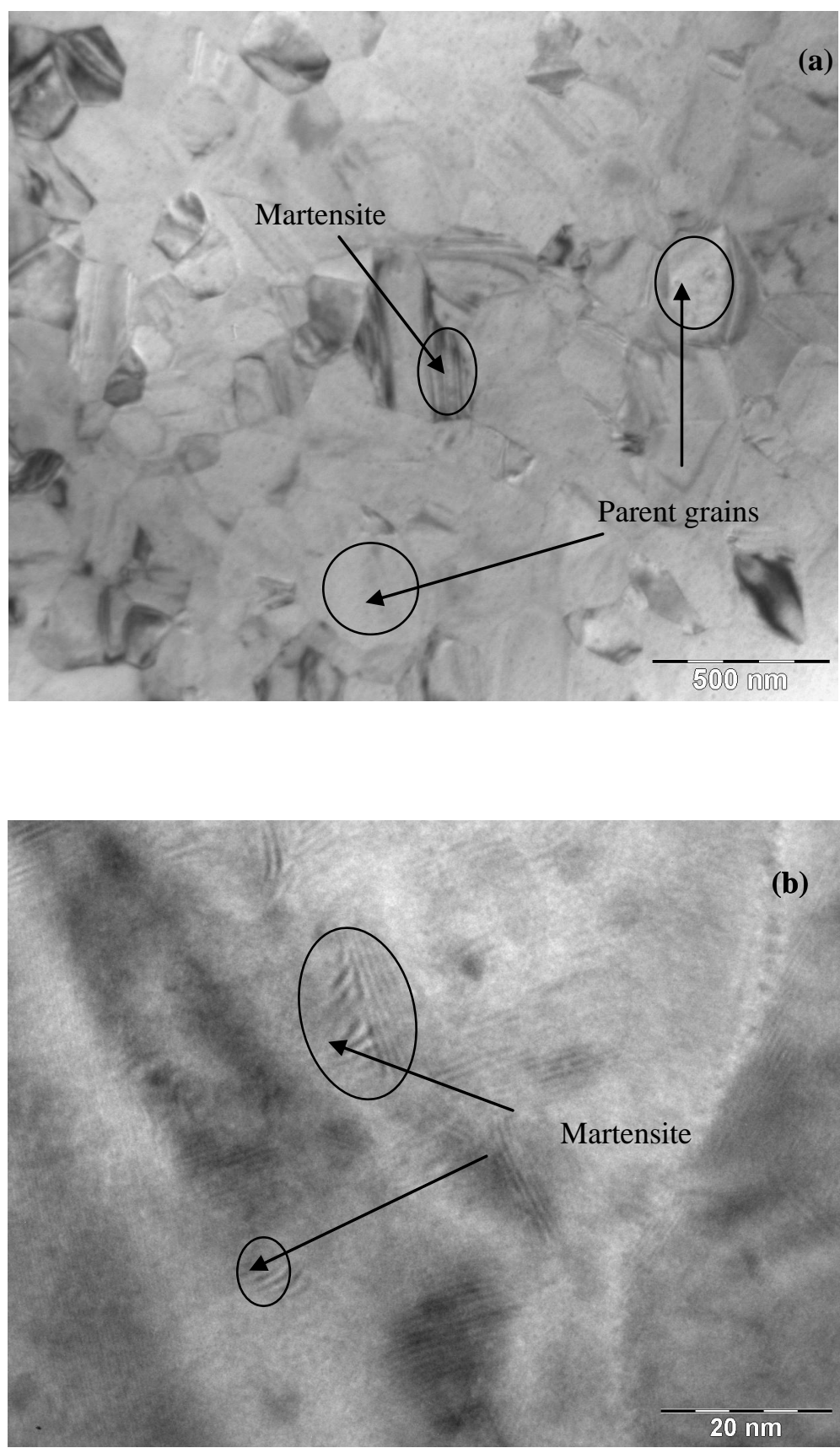

Figure 6.8: TEM image of the near-equiatomic NiTi at (a) low magnification and (b) high magnification. 


\subsection{Effect of substrate temperatures on microstructure}

A bias voltage of $80 \mathrm{~V}$ and an arc current of $115 \mathrm{~A}$ were selected to obtain NiTi thin films with different substrate temperatures. Before deposition, the substrates were preheated to different temperatures, $130^{\circ} \mathrm{C}, 300^{\circ} \mathrm{C}, 430^{\circ} \mathrm{C}$ and $600^{\circ} \mathrm{C}$. The $\mathrm{EDS}$ analysis of the deposited films showed that the respective atomic ratios of $\mathrm{Ni}$ to $\mathrm{Ti}$ in the samples were 51.0:49.0; 50.5:49.5; 49.5:50.5; and 50.0:50.0. Since these ratios are all close to $1: 1$, the substrate temperature did not significantly affect the film composition.

\subsubsection{Microstructure of thin films deposited at low temperatures}

The X-ray diffraction patterns of the films deposited at low temperatures are shown in Figure 6.9. It is clear that the films deposited at $130^{\circ} \mathrm{C}$ and $300^{\circ} \mathrm{C}$ showed low crystallinity with a very broad peak centered at about $42.0^{\circ}$. These films are considered to be amorphous. The peaks, which are located at $44.5^{\circ}, 64.8^{\circ}$ and $82.1^{\circ}$, correspond respectively to $\mathrm{Fe}(110), \mathrm{Fe}(200)$ and $\mathrm{Fe}(211)$ from the steel substrate. 


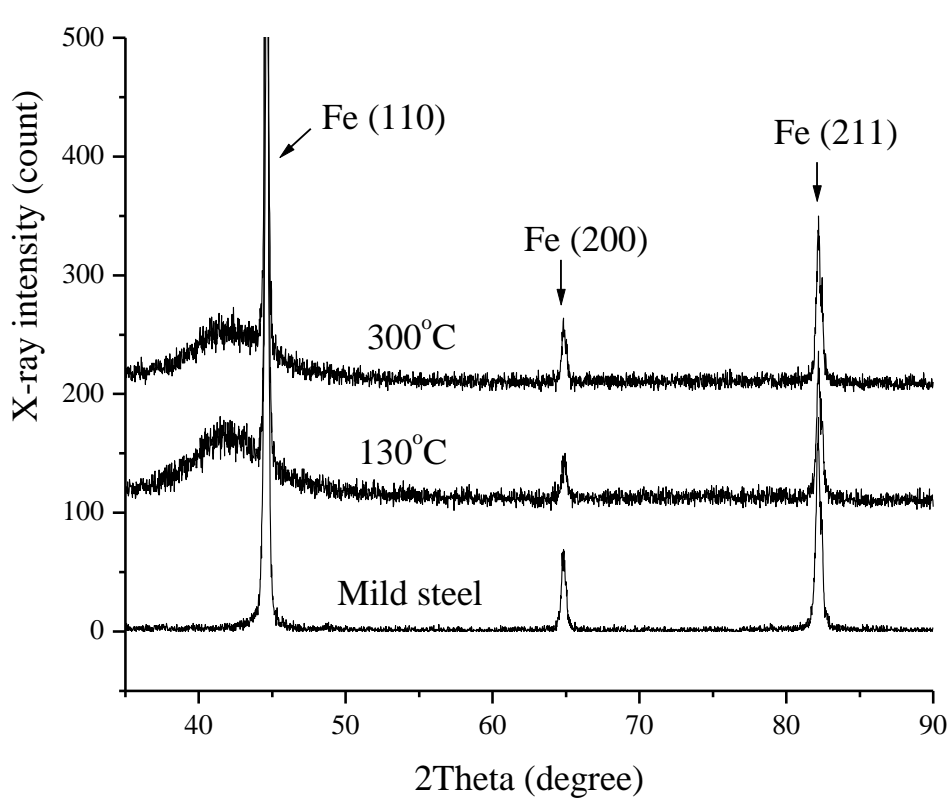

Figure 6.9: XRD patterns of the thin films deposited at $130^{\circ} \mathrm{C}$ and $300^{\circ} \mathrm{C}$. The pattern for the mild steel substrate is also shown.

\subsubsection{Microstructure of the thin film deposited at $430^{\circ} \mathrm{C}$}

The XRD pattern (Figure 6.10) of the NiTi film deposited at $430^{\circ} \mathrm{C}$ shows that the film is crystalline. Peaks for both the ordered BCC parent phase (B2) and the monoclinic martensitic phase (B19') were present. The strongest peak at $42.4^{\circ}$ is due to the principal reflection of B2 (110). The satellite peak to B2 (110) at about $42^{\circ}$ is due to $\mathrm{R}$ (112) [91]. Since peaks of B2 (211) at $78^{\circ}$ and B2 (200) at $61^{\circ}$ are absent, the parent phase B2 has a preferred orientation. 


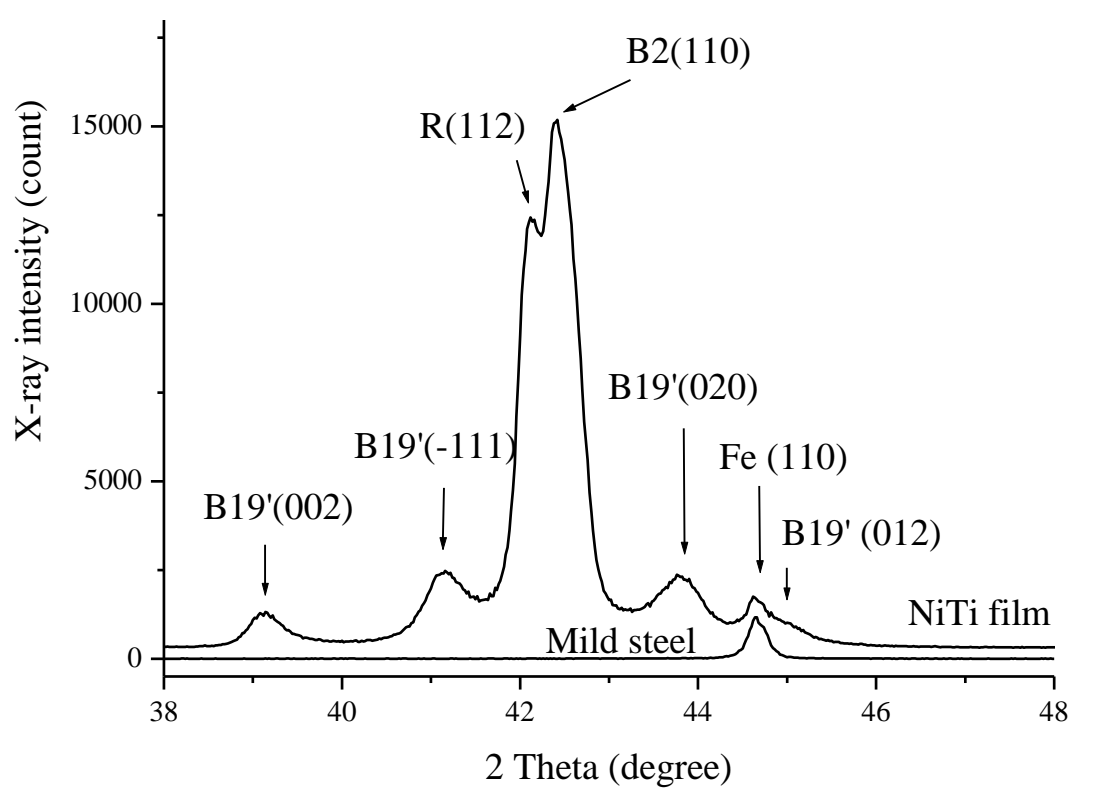

Figure 6.10: XRD pattern of the thin film deposited at $430^{\circ} \mathrm{C}$. The pattern for the mild steel substrate is also shown.

The cross section of the thin film deposited at $430^{\circ} \mathrm{C}$ was observed using TEM (Figure 6.11). The thin film was covered with a protective platinum layer. The narrow band present at the interface with the substrate reflects the formation of fine grains of parent phase for a transient period before the establishment of coarse columnar grains by growth selection under steady state conditions. An electron diffraction pattern (inset in Figure 6.11) was obtained from the selected area indicated by the circle in the bright field image. This area corresponds to a transition zone in the middle of the film, which is inferred to be due to an interruption in deposition that resulted in a layer of very fine randomly oriented B2 grains. The diffuse $\{110\}$ ring pattern arises from these grains, whereas the spot pattern is due to an adjacent coarse B2 grain. The XRD diffraction pattern shown in Figure 6.10 represents a much larger volume of the film and shows 
partial transformation to martensite. The martensite formed in coarser parent grains of the film, whereas the fine grained transition layer is likely to be substantially untransformed because fine grains have been shown by Stanford et al. [14] to stabilize the B2 phase.

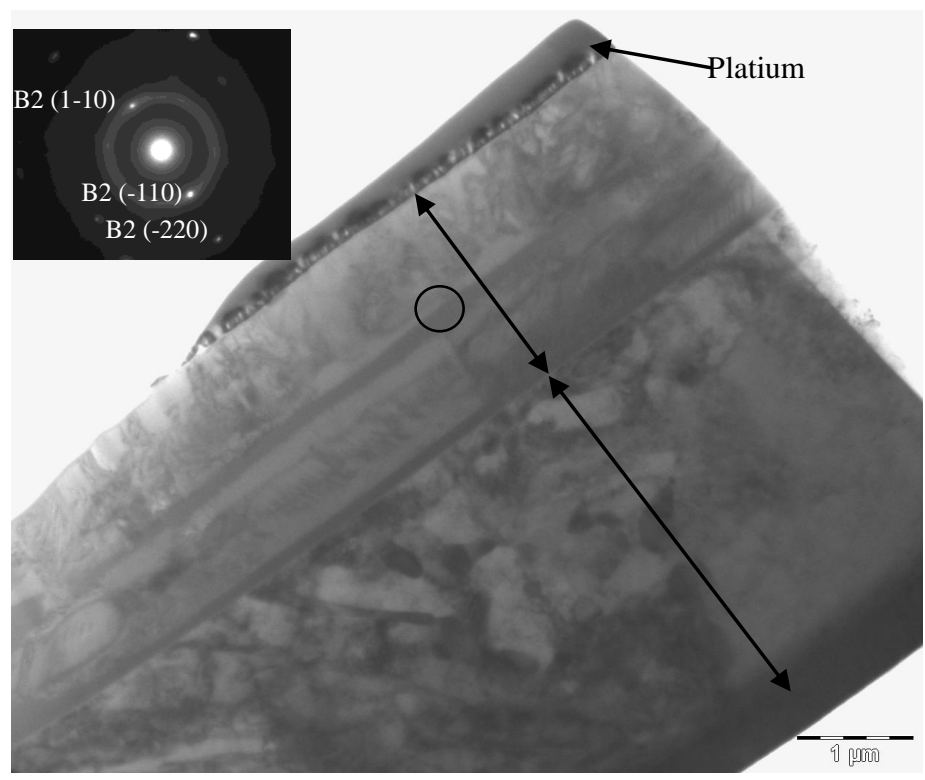

Figure 6.11: TEM image of a cross-section of the thin film deposited at $430^{\circ} \mathrm{C}$ (inset is the electron diffraction pattern taken from the selected region).

\subsubsection{Microstructure of the thin film deposited at $600^{\circ} \mathrm{C}$}

The XRD pattern (Figure 6.12) for the thin film deposited at $600^{\circ} \mathrm{C}$ shows a strong B2 (110) peak at $42.4^{\circ}$ and a weak B19' peak situated at $39^{\circ}$. B2 parent phase is therefore the dominant phase in the NiTi film deposited at $600^{\circ} \mathrm{C}$. 


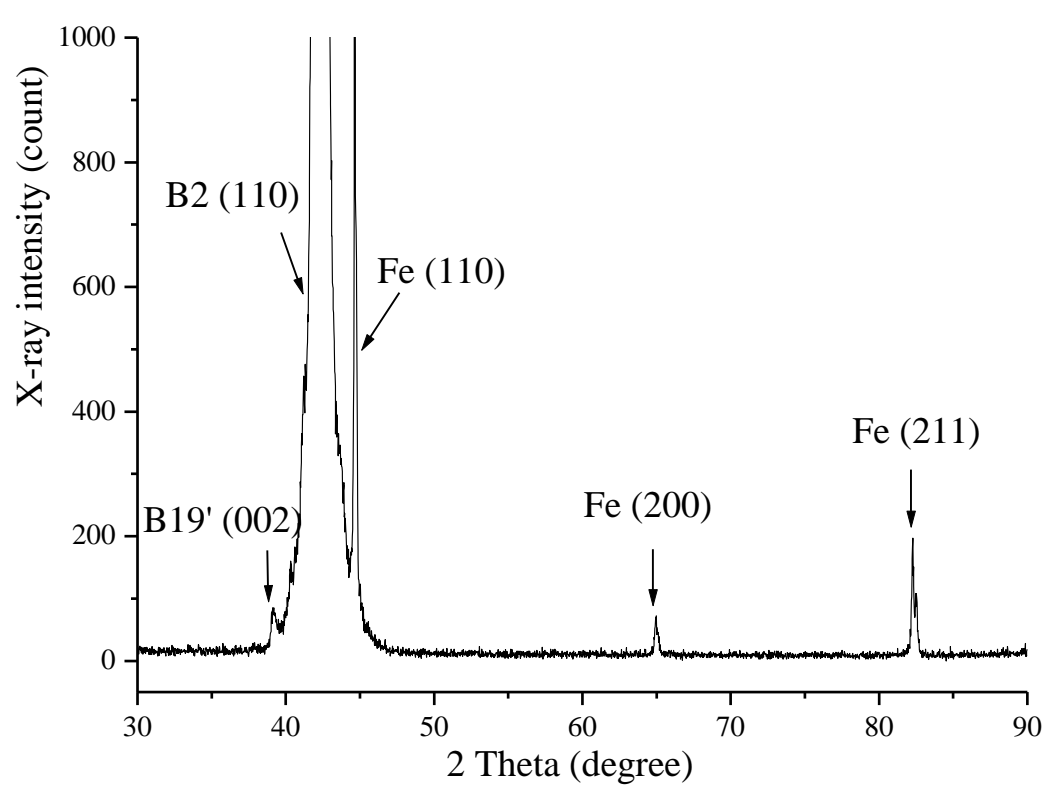

Figure 6.12: XRD pattern of the thin film deposited at $600^{\circ} \mathrm{C}$.

The TEM image (Figure 6.13) shows the typical structure of NiTi B2 parent phase, present as a columnar grain structure. The electron diffraction pattern (Inset Figure 6.13) shows that B2 parent phase is the dominant phase in the film. The $\left(\begin{array}{lll}1 & 0 & -1\end{array}\right)$ plane normal is perpendicular to the film surface, consistent with the strong $\{110\}$ texture revealed by the XRD pattern shown in Figure 6.12. 


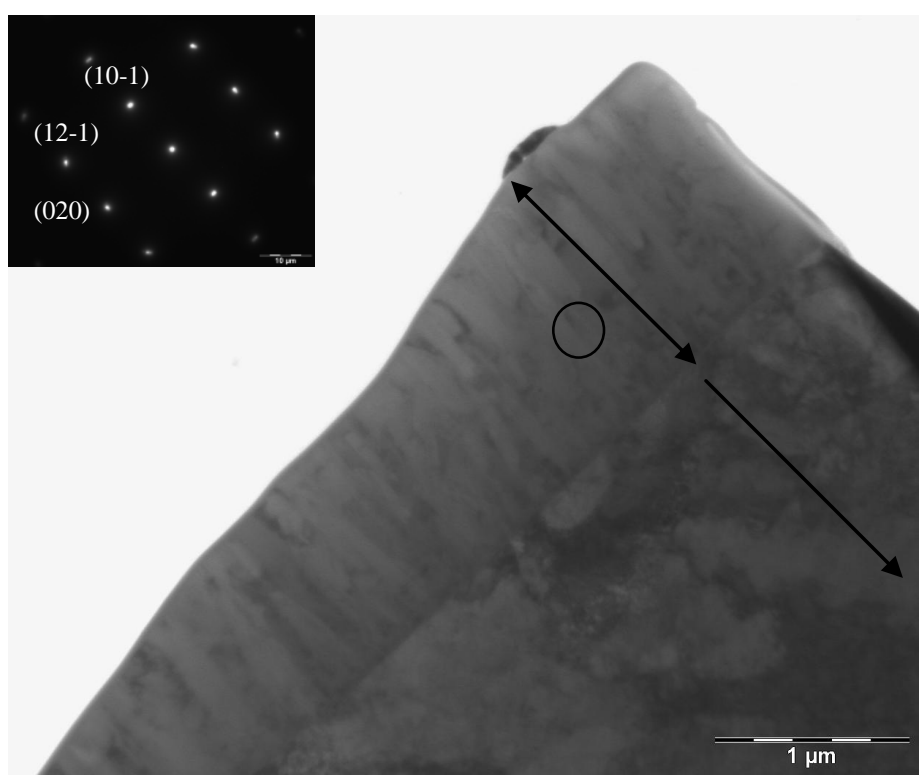

Figure 6.13: TEM image of a cross section of the thin film deposited at $600{ }^{\circ} \mathrm{C}$ (inset is the electron diffraction pattern taken from the selected region). ([101] B2 zone axis pattern).

It is obvious that the structure of the thin film is highly dependent on the substrate temperature. The as-deposited thin films were amorphous when the substrate temperature was below $300^{\circ} \mathrm{C}$, whereas both films deposited at $430^{\circ} \mathrm{C}$ and $600^{\circ} \mathrm{C}$ showed crystalline structure. With increasing substrate temperature, parent phase (B2) became the dominant phase in the as-deposited thin film. A likely explanation, which was not tested in the experimental program because of equipment limitations, is that $\mathrm{O}$ and $\mathrm{N}$ dissolve more readily in coatings at higher deposition temperature and stabilize the parent phase [92]. 


\subsection{Effect of substrate bias voltages on microstructure}

Two groups of samples were obtained to investigate the effect of substrate bias voltages on the microstructure of thin films. Four samples in each group were obtained at different bias voltages, $50 \mathrm{~V}, 80 \mathrm{~V}, 120 \mathrm{~V}$ and $150 \mathrm{~V}$. The arc current was adjusted from $110 \mathrm{~A}$ to $135 \mathrm{~A}$ in order to produce the near-equiatomic NiTi thin films. For the first group, the substrates were pre-heated to $150^{\circ} \mathrm{C}$ and the second group were pre-heated to $600^{\circ} \mathrm{C}$. EDS analysis showed that the composition varied from $52.50 \mathrm{at} \% \mathrm{Ni}$ to 50.00at\% Ni across the film being slightly $\mathrm{Ni}$ rich. Although measurements for a particular sample were relatively consistent, films deposited at different bias voltages and different substrate temperatures showed different compositions (Table 6.1). Variations in the chemical composition could be due to variable arc current and slight segregation in the target after multiple depositions.

Table 6.1: Chemical compositions (atomic \% Ti) of NiTi films deposited at different bias voltages.

\begin{tabular}{lllll}
\hline & $50 \mathrm{~V}$ & $80 \mathrm{~V}$ & $120 \mathrm{~V}$ & $150 \mathrm{~V}$ \\
\hline $150^{\circ} \mathrm{C}$ & 49.90 & 50.00 & 48.10 & 47.40 \\
$600^{\circ} \mathrm{C}$ & 49.10 & 48.00 & 47.50 & 49.95 \\
\hline
\end{tabular}

\subsubsection{Effect of bias voltage on the phases of thin films deposited at $150^{\circ} \mathrm{C}$}

Figure 6.14 compares the XRD patterns of thin films deposited at different bias voltages for a starting deposition temperature of $150{ }^{\circ} \mathrm{C}$. There are no visible peaks associated 
with the NiTi thin film deposited at $50 \mathrm{~V}$ indicating that the as-deposited film is amorphous. With an increase in bias voltage to $80 \mathrm{~V}$, the XRD pattern still indicates a low crystallinity, with a small broad peak centered at about $42^{\circ}$. When the bias voltage was increased to $120 \mathrm{~V}$, multiple peaks appear in the XRD pattern, indicating that the as-deposited thin film is dominantly crystalline. The strongest peak at $42.5^{\circ}$ is associated with the principal reflection of the ordered BCC parent phase, B2 (110), and the other peaks at $39.1^{\circ}, 41.2^{\circ}$ and $43.7^{\circ}$ correspond to the monoclinic martensitic phase, B19' (002), B19' (-111) and B19' (020). For the highest bias, $150 \mathrm{~V}$, the as-deposited film was dominated by parent phase with a distinct B2 (110) peak at $42.5^{\circ}$.

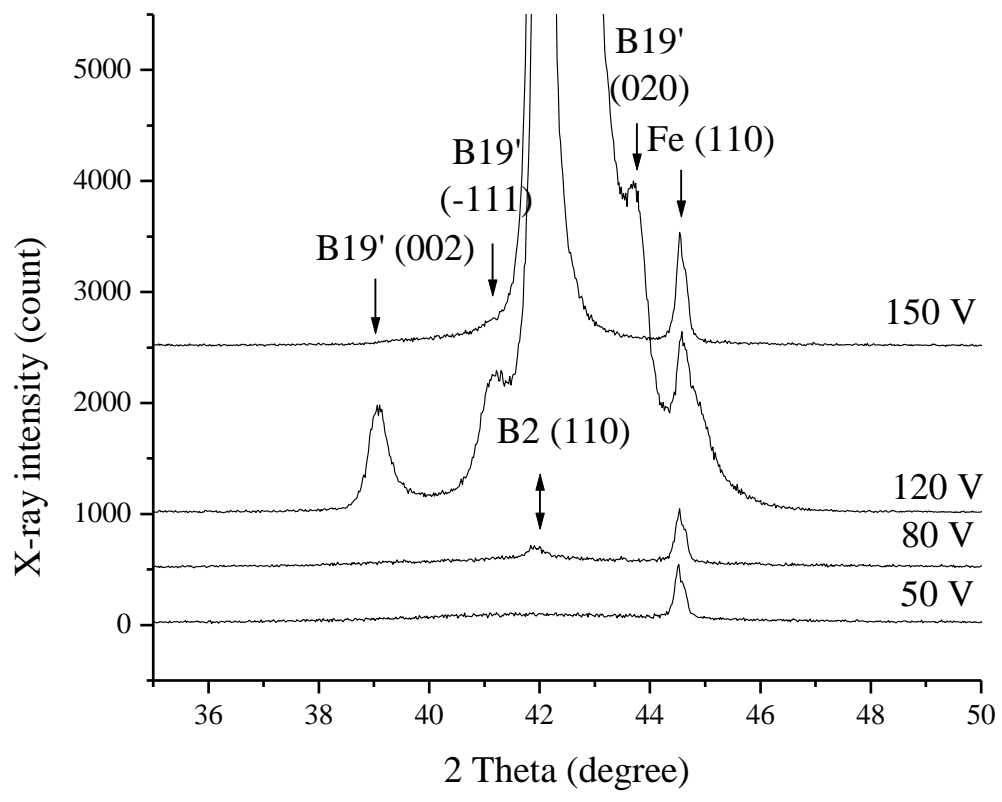

Figure 6.14: XRD patterns of thin films deposited at $150^{\circ} \mathrm{C}$. 


\subsubsection{Effect of substrate bias voltage on the phases of thin films deposited at $600^{\circ} \mathrm{C}$}

Figure 6.15 compares the XRD diffraction patterns from thin films deposited at high substrate temperature $\left(600^{\circ} \mathrm{C}\right)$ with bias voltages of $50 \mathrm{~V}, 80 \mathrm{~V}, 120 \mathrm{~V}$ and $150 \mathrm{~V}$. As can be seen in Figure 6.15 (a), the four XRD diffraction patterns show clear peaks, indicating that all thin films formed at this temperature were crystalline. Figure 6.15 (b) reveals the peaks from the product phase (B19'). For the thin film deposited at $50 \mathrm{~V}$, the B19' (002) peak is visible at $39.1^{\circ}$. For a bias voltage of $80 \mathrm{~V}$, the pattern showed two more martensite peaks at $41.2^{\circ}$ and $43.7^{\circ}$, corresponding to $\mathrm{B} 19^{\prime}(-111)$ and $\mathrm{B} 19^{\prime}(020)$. However, when the bias voltage was increased to $120 \mathrm{~V}$, there was only one significant peak associated with the reflection of the product phase, B19' (-111). For the highest bias voltage of $150 \mathrm{~V}$, only traces of the B19' (002) and B19' (-111) peaks appear in the pattern, indicating that the as-deposited thin film is dominated by the parent phase.

The films deposited at 80 and $120 \mathrm{~V}$ were 2 and 2.5 at $\% \mathrm{Ni}$ above the equiatomic composition (Table 6.1) and it is possible that the satellite peak appearing at about $43^{\circ}$ in the XRD patterns corresponds to $\mathrm{Ni}_{4} \mathrm{Ti}_{3}$. Yang et al. [93] identified this precipitate species in crystallised sputter-deposited $\mathrm{Ni}_{51.6} \mathrm{Ti}$ films after 1 hour at $500^{\circ} \mathrm{C}$. It is therefore likely that deposition of Ni-rich films at $600^{\circ} \mathrm{C}$ for 12 minutes would produce precipitates of $\mathrm{Ni}_{4} \mathrm{Ti}_{3}$ as a transition phase in advance of formation of the equilibrium product, $\mathrm{Ni}_{3} \mathrm{Ti}$ (Figure 3.1 ). 

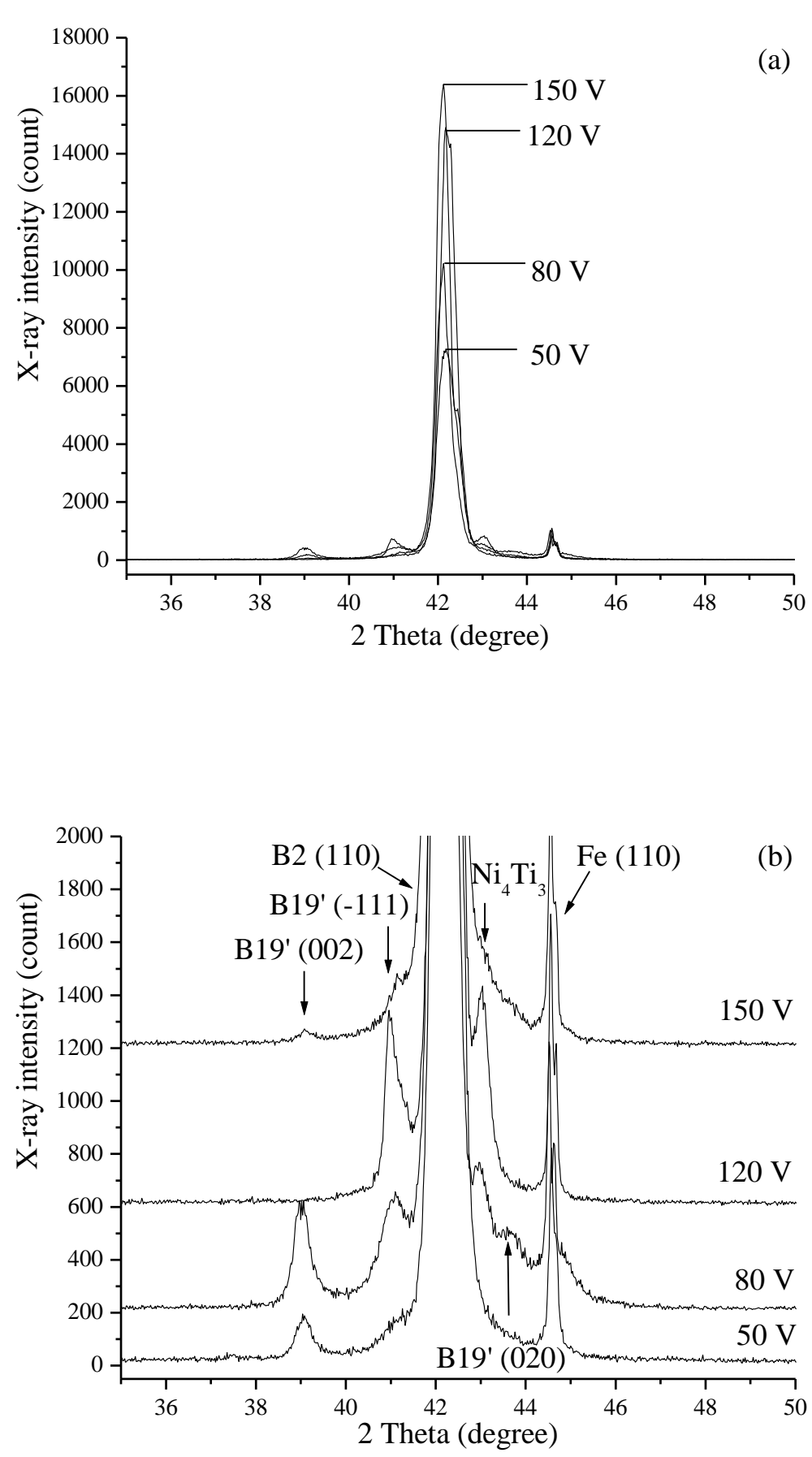

Figure 6.15: Effect of bias voltage on the phases of thin films deposited at $600^{\circ} \mathrm{C}$ in the (a) whole range of counts and the (b) smaller range of counts.

It is obvious that the structure of the thin film is highly dependent on the substrate bias. When the substrate was preheated to $150{ }^{\circ} \mathrm{C}$, the as-deposited thin films were 
amorphous for substrate bias voltage below $80 \mathrm{~V}$, whereas crystalline thin films were obtained for voltages of $120 \mathrm{~V}$ and $150 \mathrm{~V}$. Parent phase became the dominant phase in the as-deposited thin films when $150 \mathrm{~V}$ was aplied. For a starting substrate temperature of $600^{\circ} \mathrm{C}$, all four thin films were crystalline. This result is consistent with the previous conclusion in Section 6.2 that the high substrate temperature promotes formation of crystalline thin films. Similar to the effect of a higher substrate temperature, a higher bias voltage contributes to formation of crystalline films because a higher bias voltage results in a hotter substrate due to the increased energy of the deposited atoms and ions. As discussed previously, a high deposition temperature could result in increased $\mathrm{O}$ and $\mathrm{N}$ pickup from the chamber atmosphere with a depression of the $\mathrm{M}_{\mathrm{S}}$ temperature [92] and result in a predominantly parent phase structure, as observed for thin films deposited at the highest substrate bias voltage of $150 \mathrm{~V}$.

Figure 6.16 shows TEM images of the thin film deposited at $80 \mathrm{~V}$ with a substrate pre-heat temperature of $600^{\circ} \mathrm{C}$. The grains are relatively coarse and martensite plates are large and easily identified. The TEM result is consistent with the XRD pattern in Figure 6.15. 


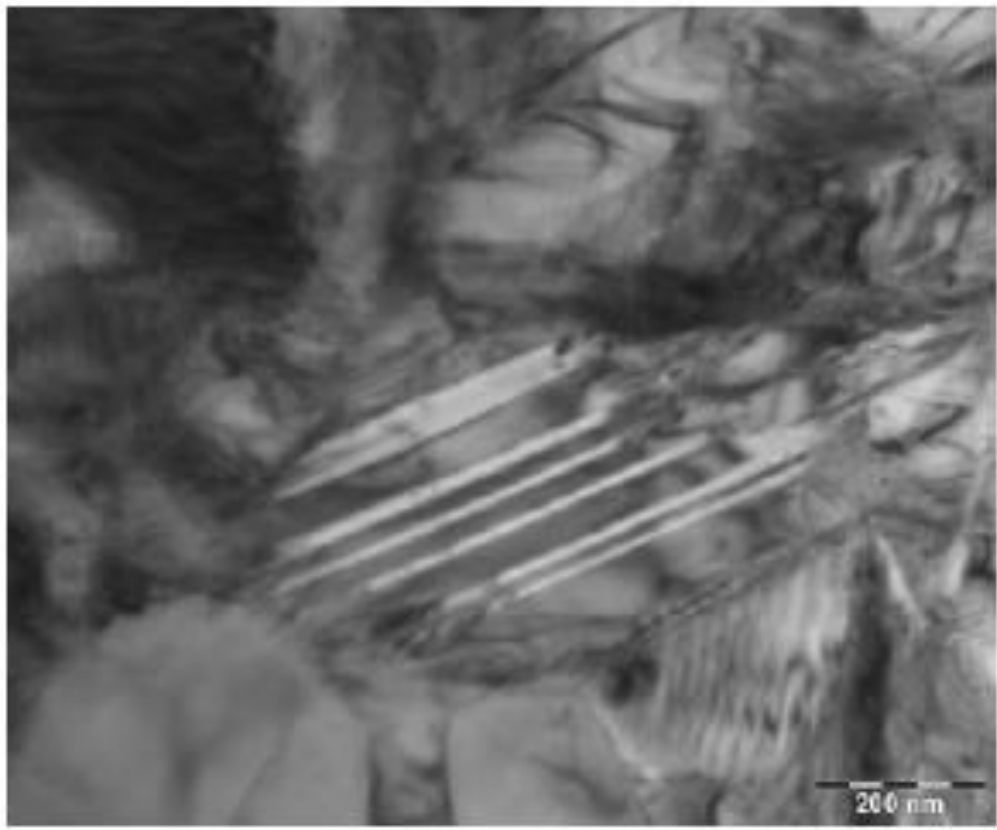

Figure 6.16: TEM image of the thin film deposited at $80 \mathrm{~V}$ with a starting temperature of $600^{\circ} \mathrm{C}$.

\subsection{NiTi thin films on stainless steel substrates}

The effect of substrate material on the microstructure of thin films was investigated by comparing the film on stainless steel with that on mild steel. The EDS results show that the atomic ratios of $\mathrm{Ni}$ to $\mathrm{Ti}$ were 50.80:49.20 and 50.50:49.50, which are both close to 1:1. Therefore, the substrate material has no significant effect on the composition of the as-deposited thin films.

\subsubsection{X-ray diffraction}

Figure 6.17 shows the XRD pattern of the thin films deposited on the austenitic stainless steel. With no substrate preheating $\left(23^{\circ} \mathrm{C}\right)$, the XRD pattern (Figure 6.17 (a)) is 
dominated by the FCC crystal structure (austenite) of the substrate, indicating the NiTi film deposited at this low temperature was amorphous. The thin film obtained at $430^{\circ} \mathrm{C}$ (Figure 6.17 (b)) showed XRD peaks from B2 (110) and B2 (220), indicating the presence of a preferred orientation. Focus on a narrower angular range in Figure 6.17 (c) reveals traces of B19' (002), B19' (-111) and B19' (020).

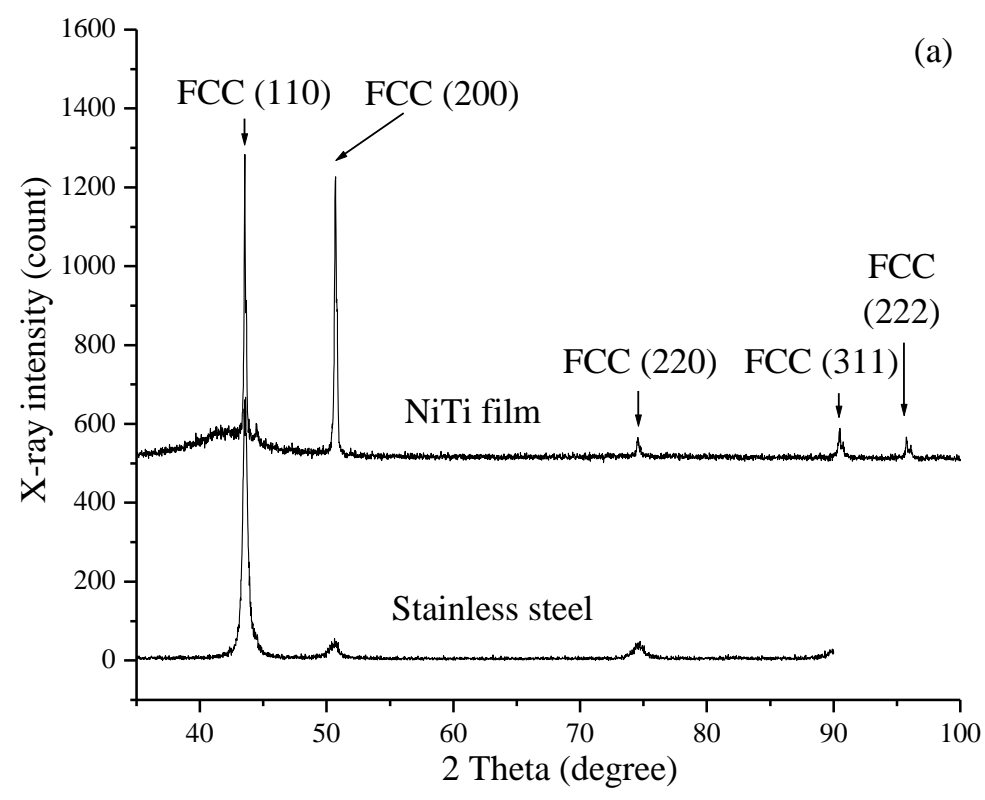



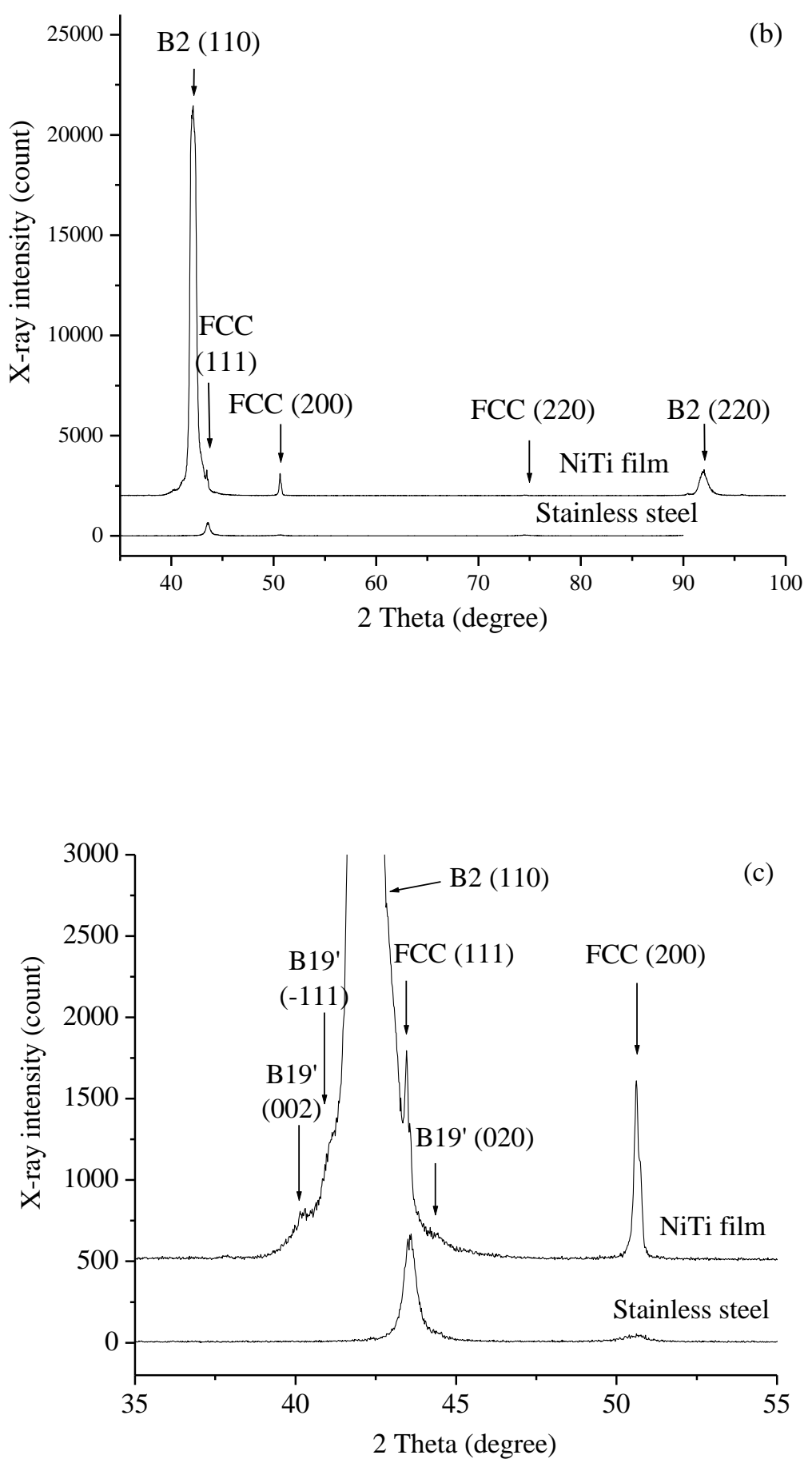

Figure 6.17: XRD patterns of the thin film deposited on austenitic stainless steel substrate (a) without preheating; (b) with a pre-heat substrate temperature of $430^{\circ} \mathrm{C}$; (c) a smaller angular range of (b).

The thin films obtained on austenitic stainless steel were dominated by the ordered B2 
parent phase. In contrast, the as-deposited thin film (Figure 6.10) on mild steel substrate under similar deposition conditions, consisted of the ordered parent phase (B2), product phase (B19') and the R phase. It is possible that pickup of $\mathrm{Ni}$ for the stainless steel substrate stabilizes the austenite phase in the as-deposited thin films, but other processing differences are also likely to contribute to the observed structural difference. For example, differential pickup in $\mathrm{O}$ and $\mathrm{N}$ due to variations in substrate temperature could be influential. Austenitic steels have a lower thermal conductivity than ferritic steels (less than half) and so the increase in substrate temperature during deposition could have been higher for the SS substrate, resulting in more effective gettering of $O$ and $\mathrm{N}$ from the chamber atmosphere. Oxygen and nitrogen in small concentrations are known to stabilize the parent phase [92].

\subsubsection{TEM results}

The TEM image shown in Figure 6.18 is from the constrained NiTi film on the stainless steel substrate. The columnar B2 grains are unusually coarse and this effect could also arise from the stainless steel substrate reaching a higher temperature than the mild steel substrate due to its lower thermal conductivity, despite both substrates being heated to the same starting temperature. 


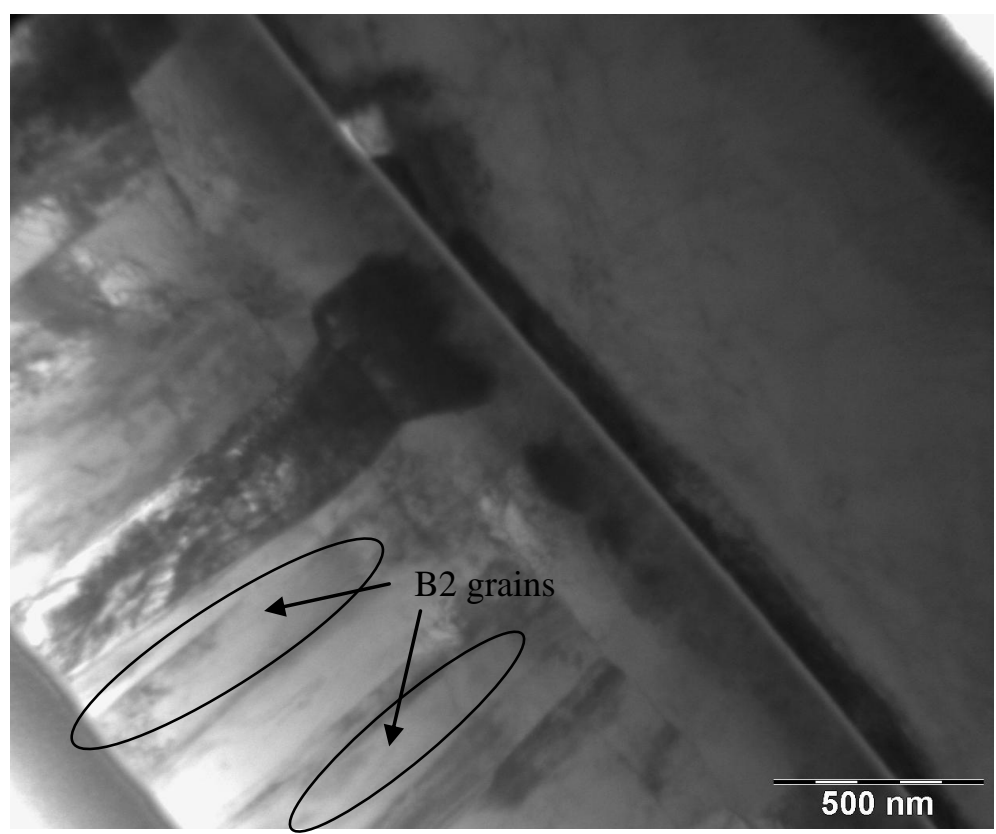

Figure 6.18: TEM image of a cross section of the thin film deposited on austenitic 316 stainless steel with the substrate preheated to $430^{\circ} \mathrm{C}$.

\subsection{X-ray analysis of the crystallized thin film}

As discussed previously, the as-deposited thin films are amorphous when they are obtained at low substrate temperatures (Figure 6.9), whereas the thin films are crystalline at high temperatures (Figure 6.10 and Figure 6.12). The amorphous thin films can be crystallized by heating up to $500^{\circ} \mathrm{C}$ [94]. Figure 6.19 and Figure 6.20 show XRD patterns of the films after crystallization. They are composed of martensite and austenite phases, but are distinctive insofar as the residual parent phase shows a random grain orientation, as opposed to the strongly textured grains in the crystalline as-deposited films. 


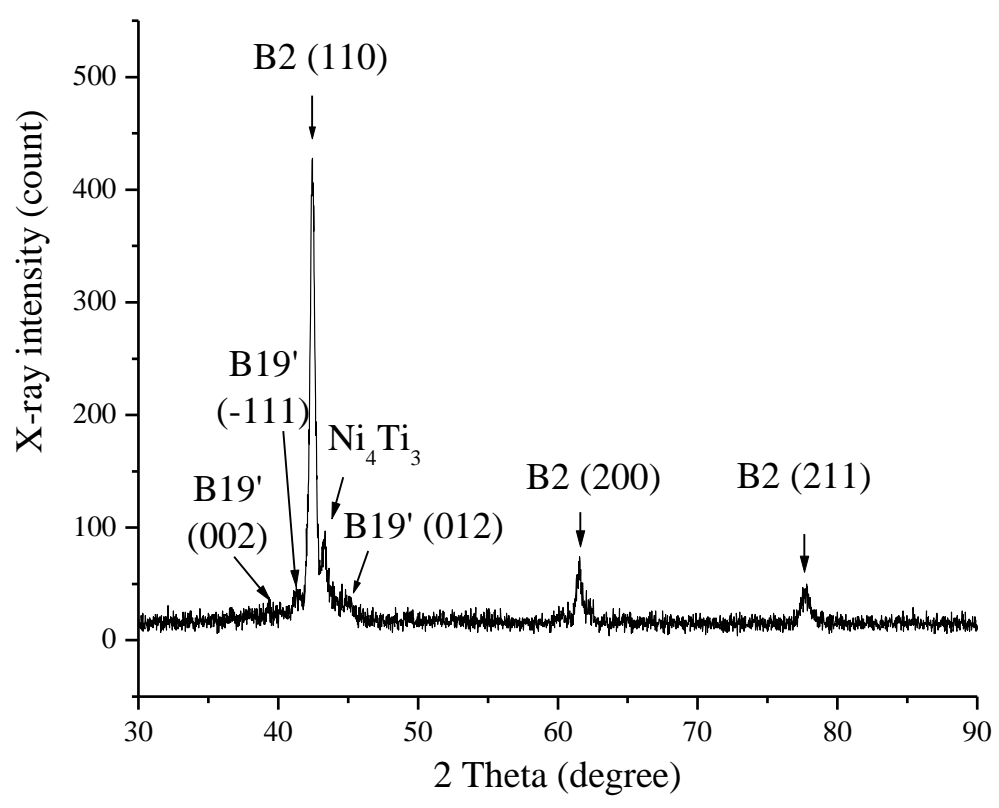

Figure 6.19: XRD patterns of the crystallized thin film deposited at $130^{\circ} \mathrm{C}$.

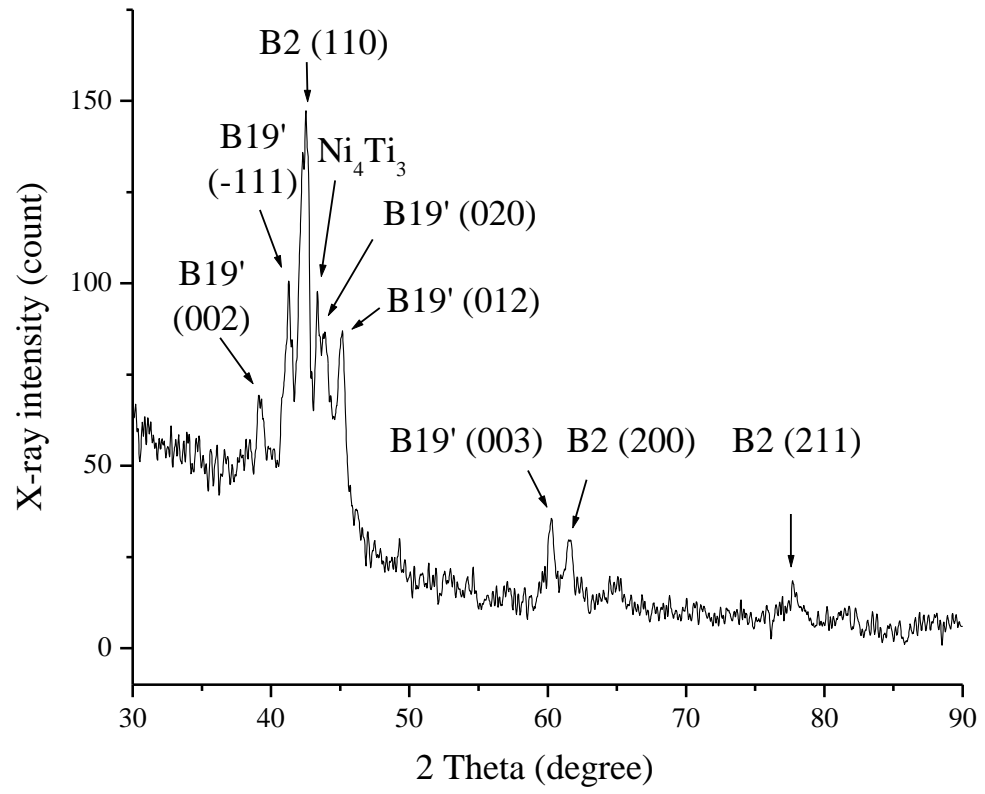

Figure 6.20: XRD patterns of the crystallized thin film deposited at $300^{\circ} \mathrm{C}$. 


\section{Chapter 7}

\section{Thermal Properties of NiTi Thin Films}

\subsection{Thermal transformation behaviour of the target alloy}

The transformation behaviour of the target alloy is shown in Figure 7.1. The forward and reverse transformations are characterized by their start and the finish temperatures: $\mathrm{M}_{\mathrm{S}}, \mathrm{M}_{\mathrm{F}}, \mathrm{A}_{\mathrm{S}}$ and $\mathrm{A}_{\mathrm{F}}$. In the cooling cycle, the forward transformation to martensite occurred at between $81{ }^{\circ} \mathrm{C}\left(\mathrm{M}_{\mathrm{S}}\right)$ and $8^{\circ} \mathrm{C}\left(\mathrm{M}_{\mathrm{F}}\right)$. In the reversed transformation on heating, martensite transformed to austenite at between $34^{\circ} \mathrm{C}\left(\mathrm{A}_{\mathrm{S}}\right)$ and $126^{\circ} \mathrm{C}\left(\mathrm{A}_{\mathrm{F}}\right)$.

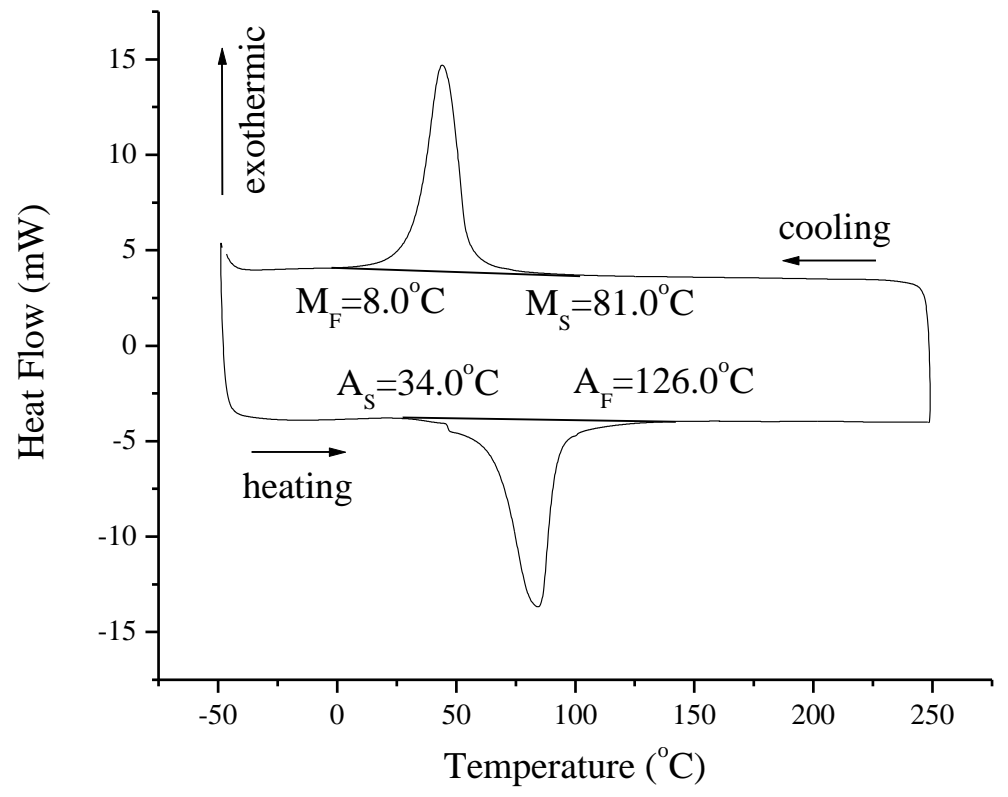

Figure 7.1: DSC traces of the NiTi target (heating and cooling rates of $10^{\circ} \mathrm{C} / \mathrm{min}$ ). 


\subsection{Thermal behaviour of NiTi thin films with different chemical compositions}

Figure 7.2 shows the DSC traces from the Ni-rich thin film with only 42.00 at\% Ti.

There was no transformation occurring between $-50^{\circ} \mathrm{C}$ and $250^{\circ} \mathrm{C}$. It was found that the phase transition temperatures shift with the change in $\mathrm{Ni}$ content [92] and the start temperature of martensitic transformation $\left(\mathrm{M}_{\mathrm{S}}\right)$ decreases rapidly with an increase in the Ni content [94]. Therefore, the transformation temperature falls out of the scanning range.

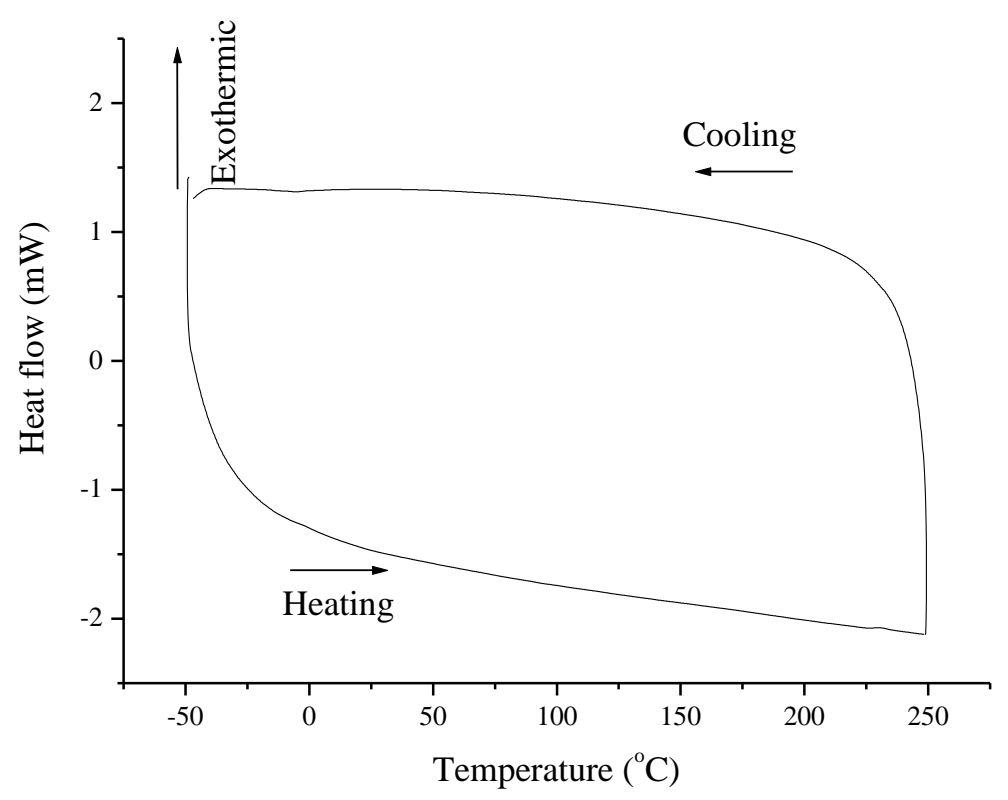

Figure 7.2: DSC curves of the thin film with Ni-42.00at\% Ti (heating and cooling rates of $\left.10^{\circ} \mathrm{C} / \mathrm{min}\right)$. 
The DSC curve of a Ti-rich (54.05at\% Ti) NiTi film is presented in Figure 7.3. During heating, the austenitic transformation started at $39.0^{\circ} \mathrm{C}$ and ended at $73.5^{\circ} \mathrm{C}$. In the cooling cycle, the martenstic transformation began at $65.0^{\circ} \mathrm{C}$. The $\mathrm{M}_{\mathrm{S}}$ temperature is normally high for Ti-rich NiTi alloys, but it is less sensitive to Ni content [50], [51]. Two distinct peaks are evident in the DSC trace during cooling. This two-step transformation sequence is unlikely to be associated with compositional variations in the film because the heating curve shows only a single peak. The results are similar to those reported by Nam et al. [97] for bulk near-equiatomic NiTi following thermal cycling or thermomechanical treatmen. A two-step transformation occurs on cooling: B2 $\rightarrow$ R-phase and R-phase $\rightarrow$ B19'. These steps are evident as distinct DSC peaks, whereas only a single peak is observed on heating. The DSC results for bulk alloy are similar to those obtained for the thin film of Ni-54.05 at\% Ti alloy (Figure 7.3), except that the peak-to-peak separation is about $50^{\circ} \mathrm{C}$ for the thin film and about $30^{\circ} \mathrm{C}$ for bulk alloy [97]. This difference could arise from differences in composition of the B2 phase. Although no thermal cycling or thermo-mechanical processing was involved, the presence of $\mathrm{R}$ phase in the as-deposited thin film could be a consequence of residual thermal stresses or coherency strain fields around precipitated $\mathrm{NiTi}_{2}$ particles, as indicated by the XRD pattern shown in Figure 6.5. These precipitates would also be expected to locally reduce the solute Ti content of the B2 phase towards the equiatomic ratio that is typical of $\mathrm{R}$-phase formation in bulk alloys. 
DSC traces of other thin films also showed multiple forward and reverse transformation peaks and in some cases the results appear to be consistent with B2 to R-phase to B19' transformations. Therefore, two sets of transformation start and finish temperatures would be relevant. However, to simplify labeling, the $\mathrm{M}_{\mathrm{S}}$ (and $\mathrm{A}_{\mathrm{S}}$ ) and $\mathrm{M}_{\mathrm{F}}\left(\right.$ and $\mathrm{A}_{\mathrm{F}}$ ) are used to indicate the temperatures of the first appearance of martensite (austenite) and the completion of transformation.

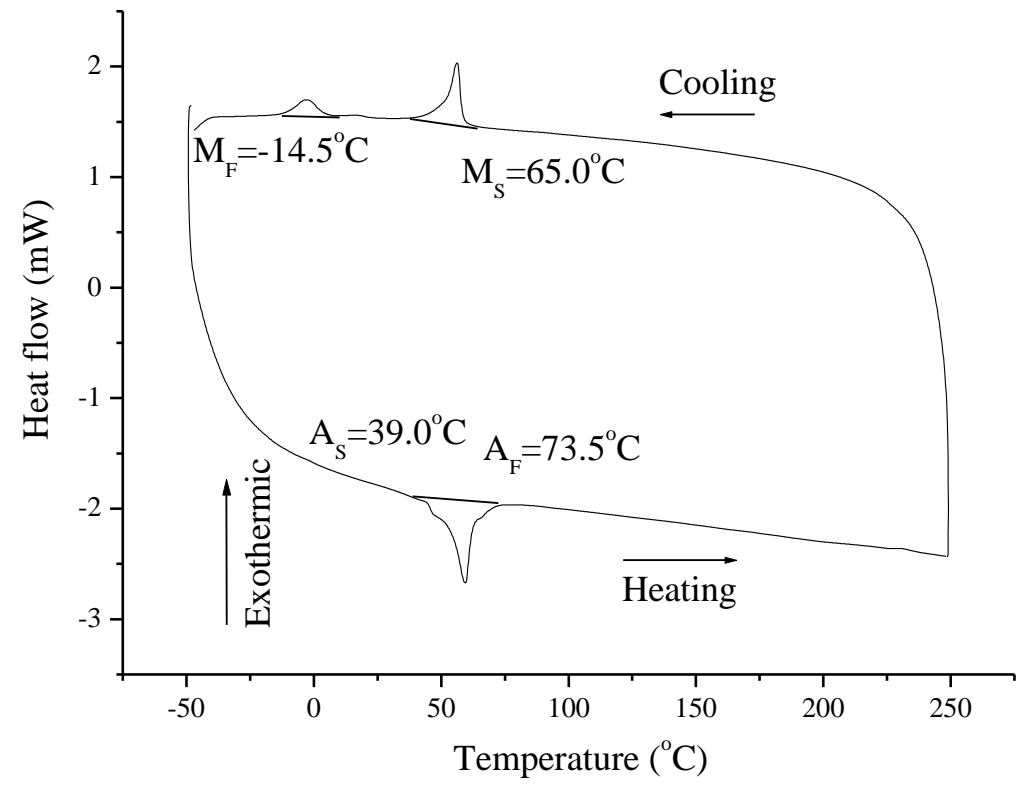

Figure 7.3: DSC traces of the thin film with Ni-54.05at\% Ti (heating and cooling rates of $\left.10^{\circ} \mathrm{C} / \mathrm{min}\right)$.

Figure 7.4 shows the DSC curves from the Ni-49.98at\% Ti thin film. The endothermic peak during heating occurred from $18.0^{\circ} \mathrm{C}$ to $93.5^{\circ} \mathrm{C}$, corresponding to austenite transformation. The exothermic peak during cooling is between $60.0^{\circ} \mathrm{C}$ to $-1.0^{\circ} \mathrm{C}$, indicating the martensite transformation from B2 to B19'. The broad transformation 
peak around ambient could include transformation to R-phase which is in agreement with the room temperature XRD results in Figure 6.7, where the presence of B2, B19' and R-phase are observed. Table 7.1 compares the transformation temperatures of the Ni-49.98at\% Ti thin film with those of bulk alloy. Both austenitic and martensitic transformation temperatures of the thin film are lower, particularly for the $A_{S}$ and $A_{F}$ temperatures of the reverse transformation.

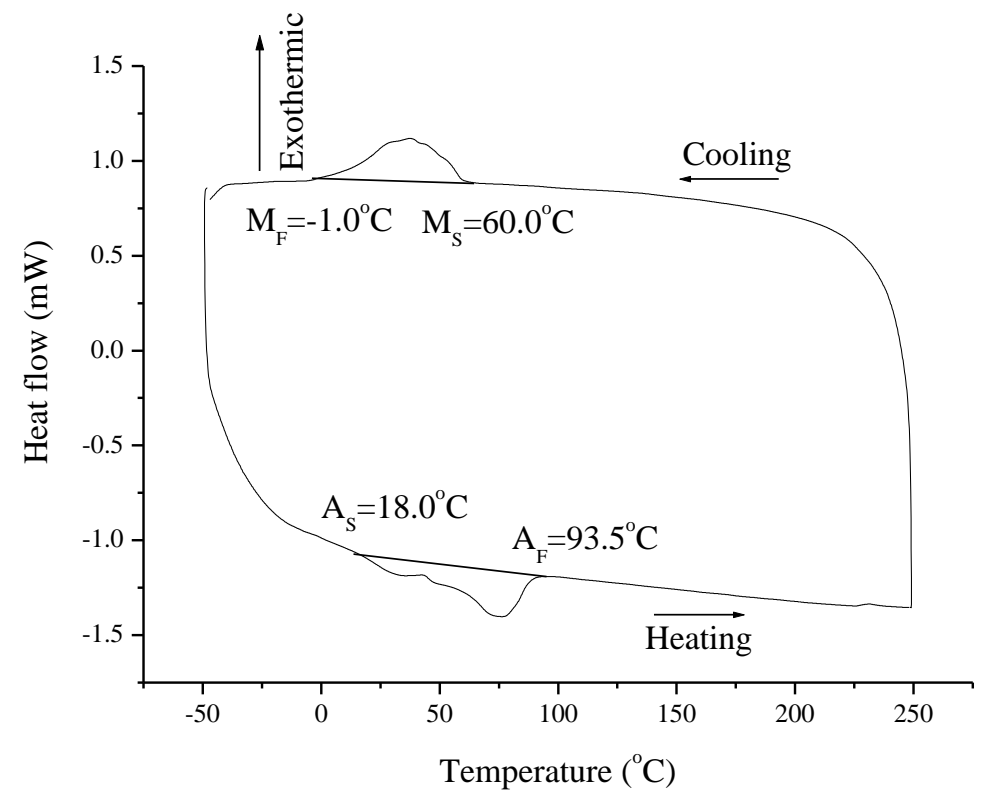

Figure 7.4: DSC traces of the thin film with Ni-49.98at\% $\mathrm{Ti}$ (heating and cooling rates of $\left.10^{\circ} \mathrm{C} / \mathrm{min}\right)$.

The transformation hysteresis is reflected by the temperature difference between the mid-points of the austenitic and martensitic transformations, which is associated with $\mathrm{A}_{\mathrm{F}}-\mathrm{M}_{\mathrm{S}}$ and $\mathrm{A}_{\mathrm{S}}-\mathrm{M}_{\mathrm{F}}$ in Table 7.1. The temperature hysteresis of the film is much smaller than that of the bulk. The reduced hysteresis could arise because the restraints to 
reversion of martensite are greatly reduced in the thin film, which has a 2-dimensional rather than a 3-dimensional (bulk) form. It is known that narrow transformation hysteresis at $50 \%$ transformation corresponds to a faster thermoelastic transformation response to both change in temperature and change in stress at constant temperature. Therefore, the deposited thin film possesses higher thermoelastic reversibility than the bulk alloy.

Table 7.1: Transformation temperatures of bulk and thin films with similar Ti contents.

\begin{tabular}{lllllll}
\hline & $\mathrm{A}_{\mathrm{S}}\left({ }^{\circ} \mathrm{C}\right)$ & $\mathrm{A}_{\mathrm{F}}\left({ }^{\circ} \mathrm{C}\right)$ & $\mathrm{M}_{\mathrm{S}}\left({ }^{\circ} \mathrm{C}\right)$ & $\mathrm{M}_{\mathrm{F}}\left({ }^{\circ} \mathrm{C}\right)$ & $\mathrm{A}_{\mathrm{S}}-\mathrm{M}_{\mathrm{F}}\left({ }^{\circ} \mathrm{C}\right)$ & $\mathrm{A}_{\mathrm{F}}-\mathrm{M}_{\mathrm{S}}\left({ }^{\circ} \mathrm{C}\right)$ \\
\hline Bulk & 34.0 & 126.0 & 81.0 & 8.0 & 26.0 & 45.0 \\
Thin film & 18.0 & 93.5 & 60.0 & -1.0 & 19.0 & 33.5 \\
\hline
\end{tabular}

By comparing the thermal properties of the as-deposited thin films with different compositions, it is concluded that the near-equiatomic thin film displays the most favourable transformation behaviour. When the atomic ratio of $\mathrm{Ni}$ to $\mathrm{Ti}$ is close to $1: 1$, the thin film exists as a mixture of parent phase B2, product phase B19' and R phase at room temperature. This structure is capable of rapidly accommodating externally applied stress by reversible transformation between the phases, mainly involving forward and reverse movement of martensite/parent phase interfaces and motion of interplate and twin interfaces within regions of martensite. In these ways, the reversible martensitic transformation can absorb the stress or pressure from the cavitation process. Therefore, enhanced cavitation erosion resistance is exhibited by equiatomic thin film at room temperature. The high thermoelastic reversibility makes equiatomic NiTi thin film 
suitable for actuation control in MEMS [94].

\subsection{Thermal behaviour of NiTi thin films deposited at different substrate temperatures}

\subsubsection{Thin films deposited at low temperature}

Figure 7.5 and Figure 7.6 show DSC traces of the thin films deposited at relatively low temperatures of $130^{\circ} \mathrm{C}$ and $300^{\circ} \mathrm{C}$. It can be seen that no thermal events occurred in the temperature range from $-50^{\circ} \mathrm{C}$ to $250^{\circ} \mathrm{C}$ because the films were amorphous.

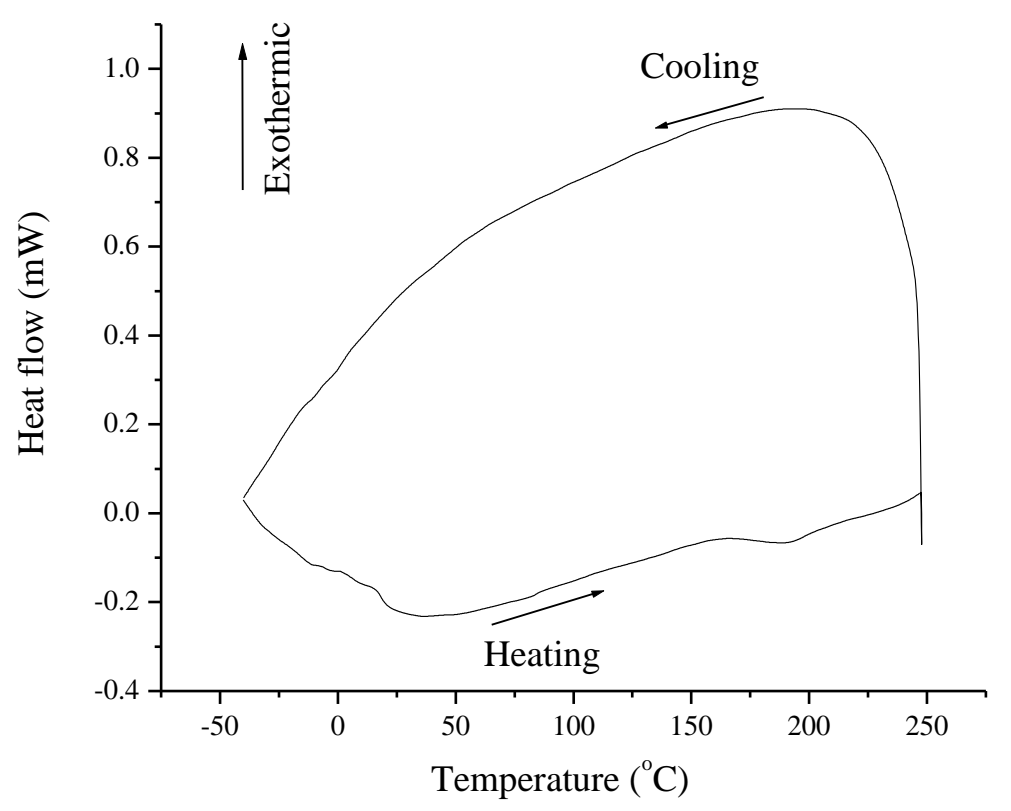

Figure 7.5: DSC traces of the thin film obtained at $130^{\circ} \mathrm{C}$ (heating and cooling rates of $\left.10^{\circ} \mathrm{C} / \mathrm{min}\right)$. 


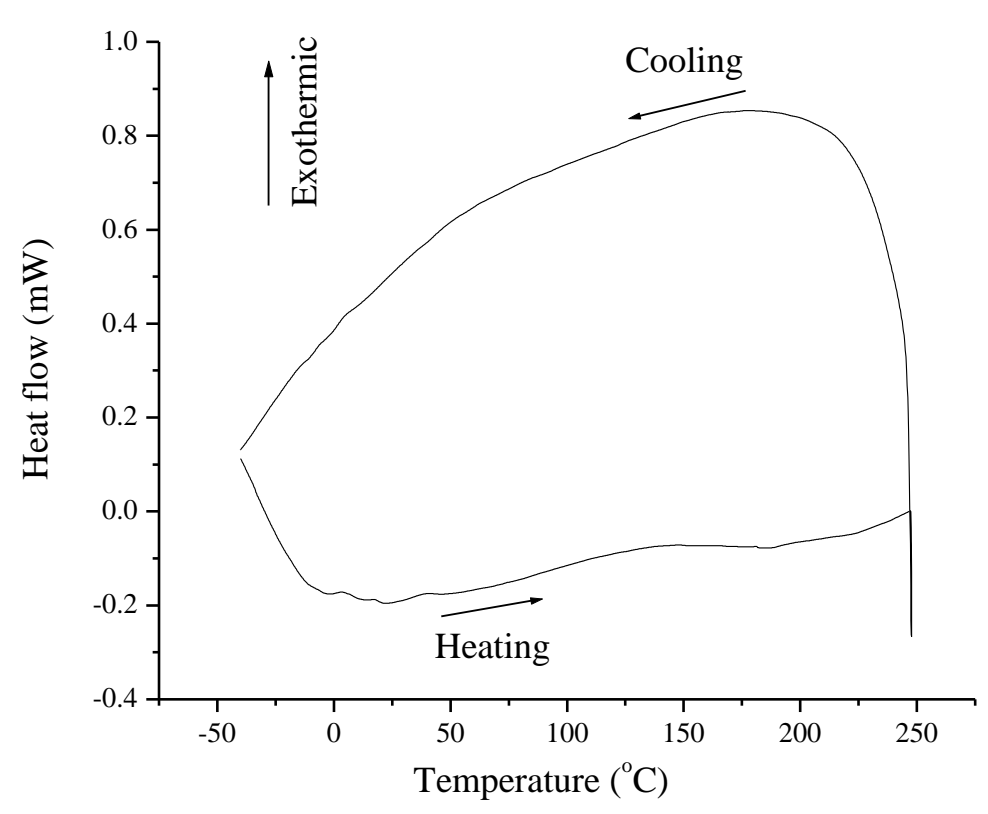

Figure 7.6: DSC traces of the thin film obtained at $300^{\circ} \mathrm{C}$ (heating and cooling rates of $\left.10^{\circ} \mathrm{C} / \mathrm{min}\right)$.

\subsubsection{Thermal behaviour of the thin film deposited at $430^{\circ} \mathrm{C}$}

The transformation behaviour of a near-equiatomic thin film deposited at $430^{\circ} \mathrm{C}$ is shown in Figure 7.7. The DSC traces exhibited multiple peaks during both martensitic transformation and austenitic transformation. The overlapping exothermic peaks on cooling could be associated with the formation of R-phase and the martensite phase [95]. Multiple-step martensitic transformations in Ni-rich and near-equiatomic bulk alloys have been reported by Bataillard et al. [98] and Carroll et al. [96]. Carroll et al. attributed the first peak on cooling to the phase transition from B2 to R-phase [96]. Then, the martensitic phase B19' starts to grow from the R-phase along matrix interfaces producing the second peak. On further cooling, the remaining R-phase transforms to B19', which corresponds to a third peak at a lower temperature. Carroll et 
al. proposed that the R-phase can not transform to B19' completely in the second step because of the presence of dislocations or strain fileds introduced by thermal or thermo-mechanical processing [96]. With a decrease in temperature, a higher driving force will be accumulated and the martensitic phase will nucleate in the remaining $\mathrm{R}$ phase. Bataillard et al. identified local stress fields due to $\mathrm{Ni}_{4} \mathrm{Ti}_{3}$ precipitation as the cause of multiple stage transformation [98].

The extended, multiple peaked DSC trace on cooling of the near-equiatomic film (Figure 7.7) could originate in a similar way, by the presence of residual thermal stresses in the as-deposited thin film or coherency strain fields around $\mathrm{Ni}_{4} \mathrm{Ti}_{3}$ precipitates, which spread transformation over a range of temperatures.

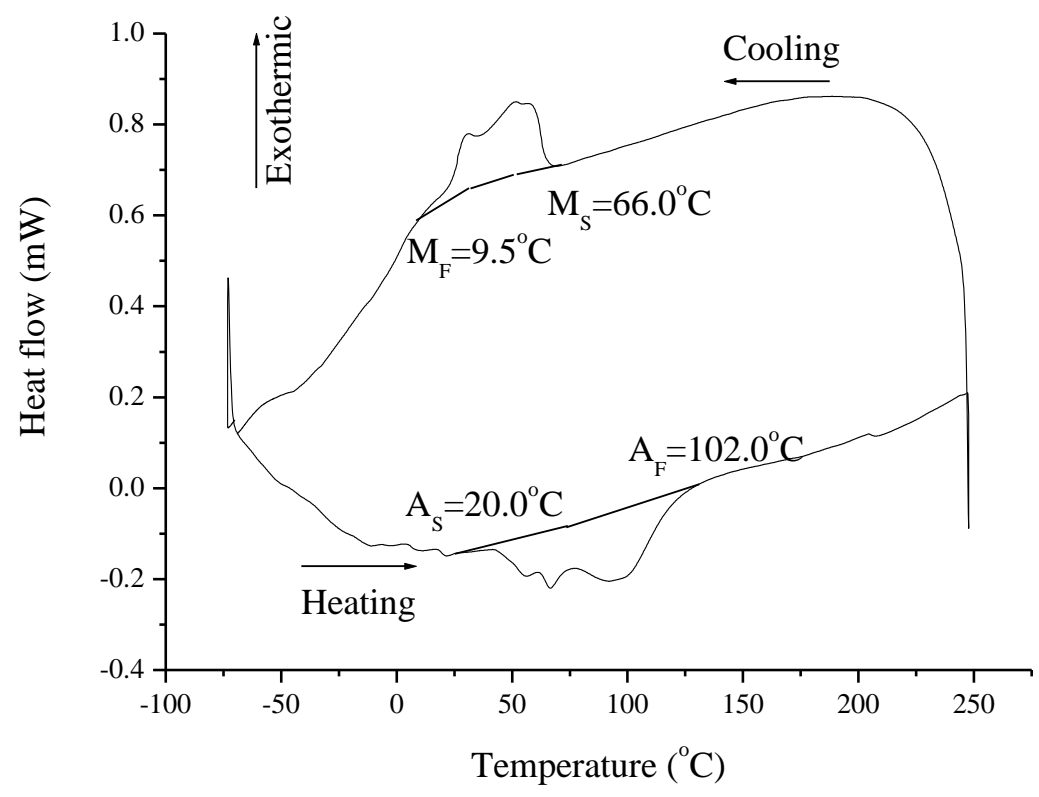

Figure 7.7: DSC traces of the thin film obtained at $430^{\circ} \mathrm{C}$ (heating and cooling rates of $\left.10^{\circ} \mathrm{C} / \mathrm{min}\right)$. 


\subsubsection{Thermal behaviour of the thin film deposited at $600^{\circ} \mathrm{C}$}

Figure 7.8 shows the DSC trace of the thin film deposited at $600^{\circ} \mathrm{C}$. There are two peaks in both the austenite transformation during heating and the martensite transformation during cooling. As discussed in Section 7.2, the presence of two peaks on cooling is consistent with bulk alloy DSC results which show the successive transformations B2 $\rightarrow \mathrm{R}$ and R-phase $\rightarrow \mathrm{B} 19^{\prime}[97]$

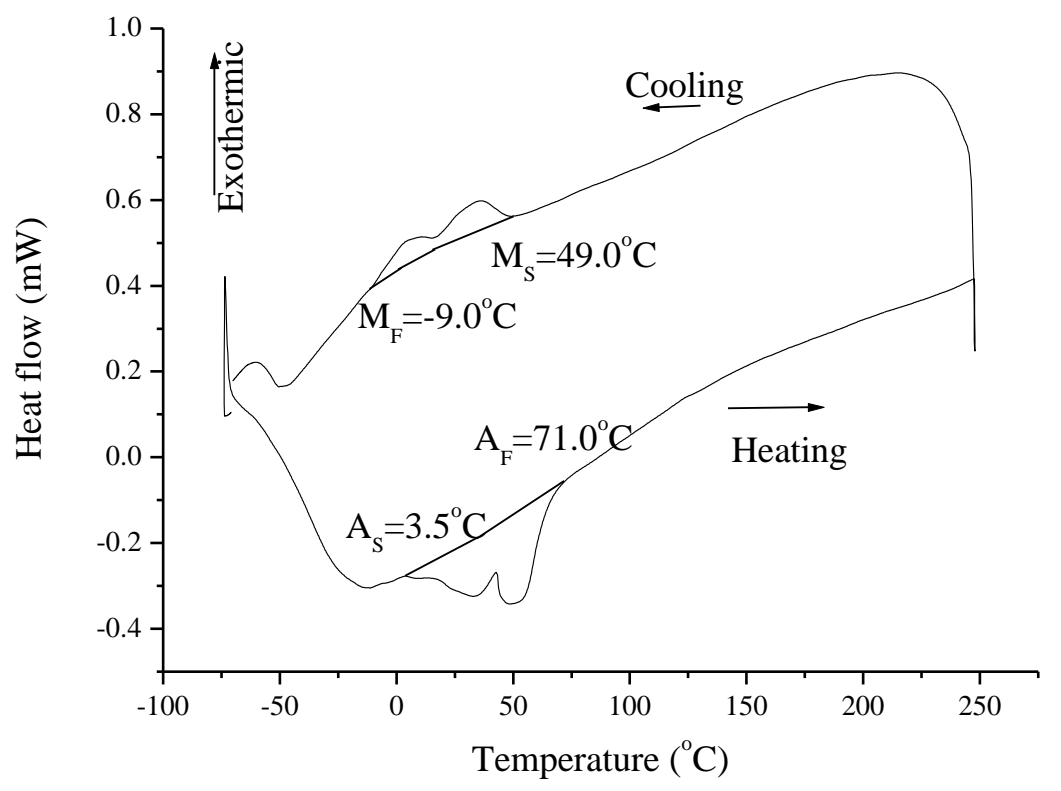

Figure 7.8: DSC of the thin film obtained at $600^{\circ} \mathrm{C}$ (heating and cooling rates of $\left.10^{\circ} \mathrm{C} / \mathrm{min}\right)$.

Table 7.2 summarizes the transformation temperatures of the thin films deposited at $430^{\circ} \mathrm{C}$ and $600^{\circ} \mathrm{C}$, as well as $\mathrm{A}_{\mathrm{S}}-\mathrm{M}_{\mathrm{F}}$ and $\mathrm{A}_{\mathrm{F}}-\mathrm{M}_{\mathrm{S}}$, which measure transformation hysteresis. Compared with bulk alloy, thin films exhibit a narrow transformation 
hysteresis, indicating a faster thermoelastic transformation response than bulk TiNi alloy.

Table 7.2: Transformation temperatures of NiTi thin films deposited at $430^{\circ} \mathrm{C}$ and $600^{\circ} \mathrm{C}$

\begin{tabular}{ccccccc}
\hline & $\mathrm{M}_{\mathrm{S}}\left({ }^{\circ} \mathrm{C}\right)$ & $\mathrm{M}_{\mathrm{F}}\left({ }^{\circ} \mathrm{C}\right)$ & $\mathrm{A}_{\mathrm{S}}\left({ }^{\circ} \mathrm{C}\right)$ & $\mathrm{A}_{\mathrm{F}}\left({ }^{\circ} \mathrm{C}\right)$ & $\mathrm{A}_{\mathrm{S}}-\mathrm{M}_{\mathrm{F}}\left({ }^{\circ} \mathrm{C}\right)$ & $\mathrm{A}_{\mathrm{F}}-\mathrm{M}_{\mathrm{S}}\left({ }^{\circ} \mathrm{C}\right)$ \\
\hline Bulk & 81.0 & 8.0 & 34.0 & 126.0 & 26.0 & 45.0 \\
$430^{\circ} \mathrm{C}$ & 66.0 & 9.5 & 20.0 & 102.0 & 10.5 & 36.0 \\
$600^{\circ} \mathrm{C}$ & 49.0 & -9.0 & 3.5 & 71.0 & 12.5 & 22.0 \\
\hline
\end{tabular}

\subsection{Thermal behaviour of NiTi thin films deposited at different bias voltages with a high substrate temperature of $600^{\circ} \mathrm{C}$}

Figure 7.9 and Figure 7.10 show the DSC curves of the films deposited at $50 \mathrm{~V}$ and 80 $\mathrm{V}$ with substrate preheated to $600^{\circ} \mathrm{C}$. The austenitic transformation occurred between $43.0^{\circ} \mathrm{C}$ and $100.0^{\circ} \mathrm{C}$ and the martensitic transformation took place in a lower temperature range, from $73.0^{\circ} \mathrm{C}$ to $-10.0^{\circ} \mathrm{C}$. Therefore, the thin films possess both parent and product phases at room temperature. For both $50 \mathrm{~V}$ (Figure 7.9) and $80 \mathrm{~V}$ (Figure 7. 10) bias voltages, two peaks were observed during cooling and these are likely to correspond to the transformation from martensite to R-phase followed by the transition from R-phase to austenite. The DSC results are consistent with the X-ray data in Figure 6.15, which indicate the presence at room temperature of parent phase (B2), 
intermediate phase (R) and product phase (B19'). Figure 6.15 also indicates the presence of $\mathrm{Ni}_{4} \mathrm{Ti}_{3}$, especially for $80 \mathrm{~V}$ bias voltage. According to Bataillard et al. [98], the presence of stress fields around these particles can induce multiple-step transformation and the extended transformation range on cooling shown in Figure 7.9 and Figure 7.10 may reflect this effect.

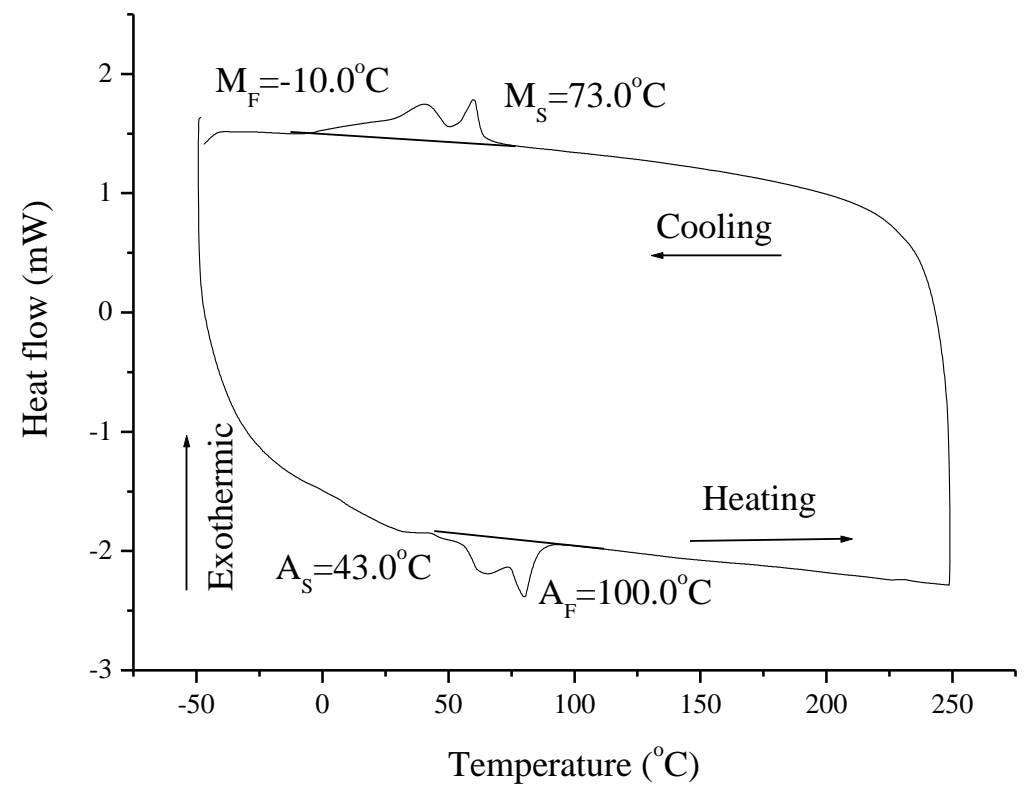

Figure 7.9: DSC traces of the thin film deposited at $50 \mathrm{~V}$. 


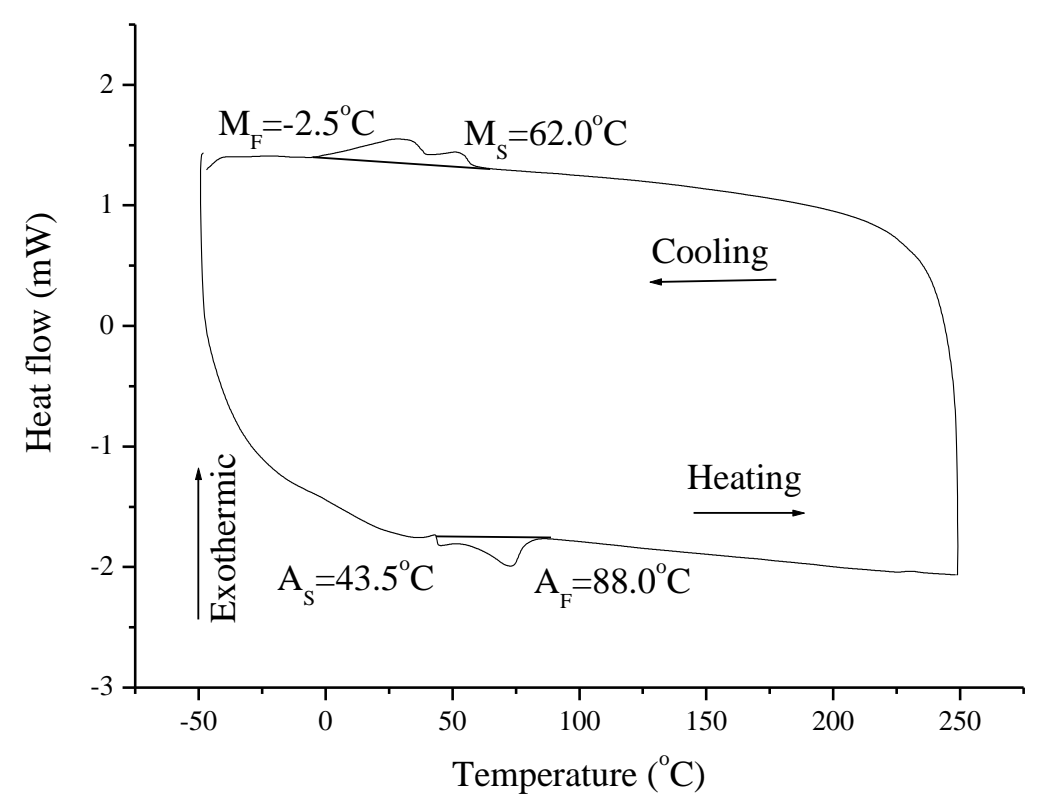

Figure 7.10: DSC traces of the thin film deposited at $80 \mathrm{~V}$.

The DSC curve for the thin film deposited at $120 \mathrm{~V}$ showed no transformation between $-50^{\circ} \mathrm{C}$ and $250^{\circ} \mathrm{C}$, which is due to the high $\mathrm{Ni}$ content of 52.50 at $\%$ determined by means of EDS. The DSC result is consistent with the correlation between the phase transition temperature range and $\mathrm{Ni}$ content [92].

Figure 7.11 shows the transformation bahaviour of thin film deposited at $150 \mathrm{~V}$. The transformation temperature ranges are similar to those of the thin films deposited at 50 $\mathrm{V}$ and $80 \mathrm{~V}$. The extended peak during cooling could indicate that formation of the intermediate $\mathrm{R}$ phase is occurring during martensitic transformation. It is clear that the heat flow in Figure 7.11 is very low $(2.9 \mathrm{~J} / \mathrm{g}$ on heating and $1.5 \mathrm{~J} / \mathrm{g}$ on cooling). It is likely therefore that only a small part of the sample was transforming to martensite. Material in the outer surface could be stabilised by $\mathrm{N}$ and $\mathrm{O}$ pickup. Although the 
substrates were preheated to the same temperature of $600^{\circ} \mathrm{C}$, the sample obtained at 150 $\mathrm{V}$ remained at a higher temperature during deposition due to the high substrate bias voltage. Consequently, the high deposition temperature could contribute to significant $\mathrm{O}$ and $\mathrm{N}$ pickup from the chamber atmosphere.

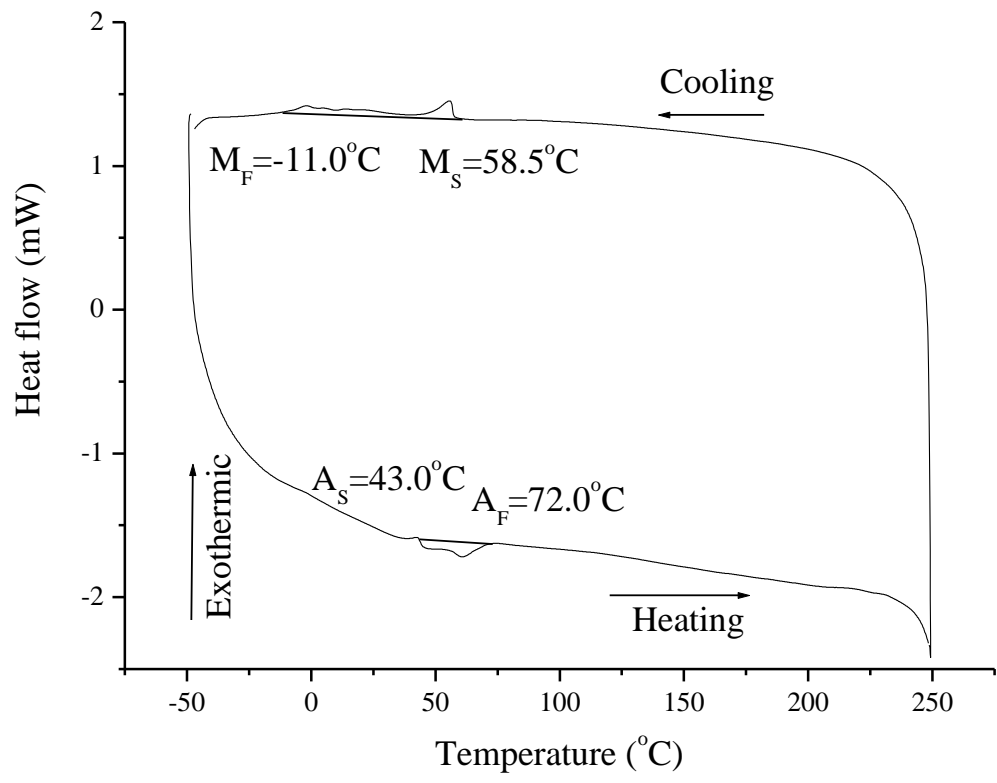

Figure 7.11: DSC traces of the thin film deposited at $150 \mathrm{~V}$.

Table 7.3 summarizes the transformation temperatures of the thin films deposited at different bias voltages from $50 \mathrm{~V}$ to $150 \mathrm{~V}$. Except for the Ni-rich thin film obtained at $120 \mathrm{~V}$, the near-equiatomic thin films deposited at other bias voltages consisted of a mixture of parent phase (B2), intermediate phase (R) and product phase (B19') at room temperature. This conclusion is in agreement with the XRD results in Figure 6.15. Therefore, the thin films are capable of reversible transformation under stress and are expected to show enhanced cavitation erosion resistance at room temperature. The low 
transformation hysteresis of the NiTi thin films should provide a faster transformation response than NiTi bulk target.

Table 7.3: Transformation temperatures of bulk NiTi alloy and thin films deposited at different substrate bias voltages.

\begin{tabular}{ccccccc}
\hline & $\mathrm{A}_{\mathrm{S}}$ & $\mathrm{A}_{\mathrm{F}}$ & $\mathrm{M}_{\mathrm{S}}$ & $\mathrm{M}_{\mathrm{F}}$ & $\mathrm{A}_{\mathrm{S}}-\mathrm{M}_{\mathrm{F}}\left({ }^{\circ} \mathrm{C}\right)$ & $\mathrm{A}_{\mathrm{F}}-\mathrm{M}_{\mathrm{S}}\left({ }^{\circ} \mathrm{C}\right)$ \\
\hline Bulk & 34.0 & 126.0 & 81.0 & 8.0 & 26.0 & 45.0 \\
$50 \mathrm{~V}$ & 43.0 & 100.0 & 73.0 & -10.0 & 10.5 & 36.0 \\
$80 \mathrm{~V}$ & 43.5 & 88.0 & 62.0 & -2.5 & 12.5 & 22.0 \\
$120 \mathrm{~V}$ & - & - & - & - & & \\
$150 \mathrm{~V}$ & 43.0 & 72.0 & 58.5 & -11.0 & 54.0 & 13.5 \\
\hline
\end{tabular}

\subsection{Comparison of amorphous and crystalline thin films}

Due to the low crystallinity of the thin films deposited at $130^{\circ} \mathrm{C}$ and $300^{\circ} \mathrm{C}$ (Figure 7.5 and Figure 7.6$)$, the initial $\mathrm{DSC}$ scans $\left(-50^{\circ} \mathrm{C}\right.$ to $\left.250^{\circ} \mathrm{C}\right)$ showed no obvious transformation peaks. When the thin films were heated to $500^{\circ} \mathrm{C}$, Figure 7.12 , a sharp exothermic peak occurred at $475^{\circ} \mathrm{C}\left(130^{\circ} \mathrm{C}\right.$ film $)$ and $460^{\circ} \mathrm{C}\left(300^{\circ} \mathrm{C}\right.$ film), indicating crystallization of the amorphous structure. These crystallization temperatures are very close to those reported for NiTi thin film with a similar composition [8]. 


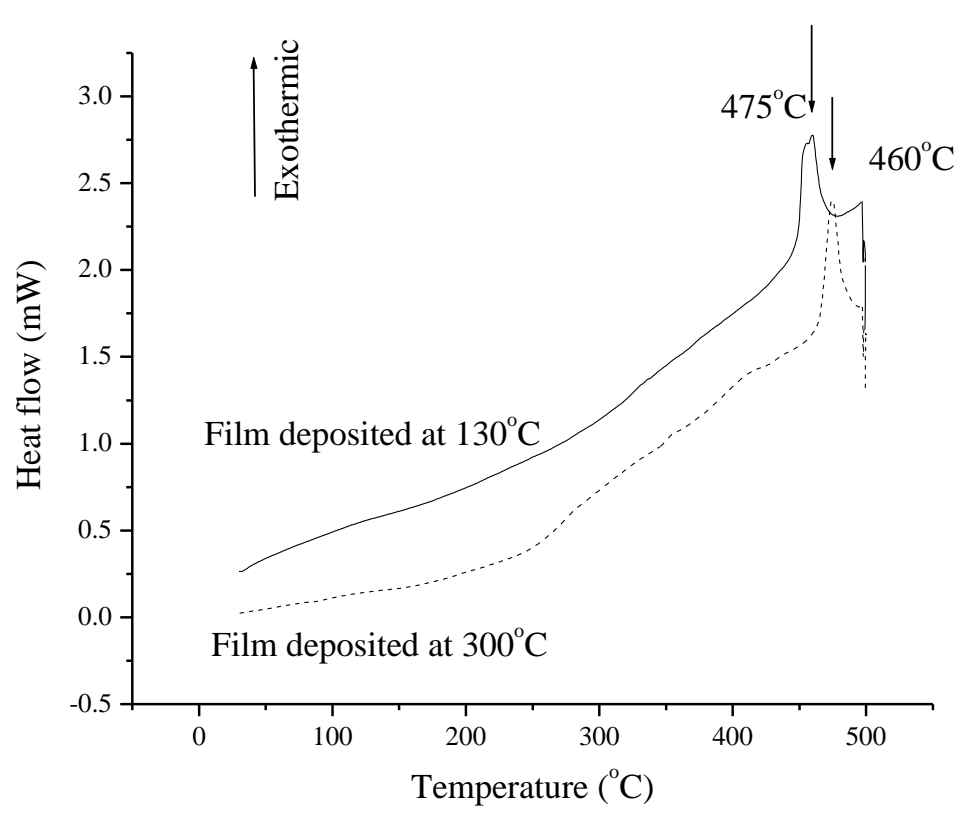

Figure 7.12: Crystallization of the amorphous thin film deposited at $130^{\circ} \mathrm{C}$ and $300^{\circ} \mathrm{C}$.

Figure 7.13 and Figure 7.14 show the thermal behaviour of the crystallized thin films deposited at low temperatures which were originally amorphous. The DSC curves showed multiple-step phase transition peaks during both cooling and heating, which were similar to the crystalline as-deposited thin films obtained at higher temperatures (Figure 7.7 and Figure 7.8). The transformation temperatures are summarized in Table 7.4. Similar to the crystalline thin films, the crystallized NiTi films could also be expected to respond faster to both temperature change and stress change than the NiTi bulk target alloy due to their small transformation hysteresis. 


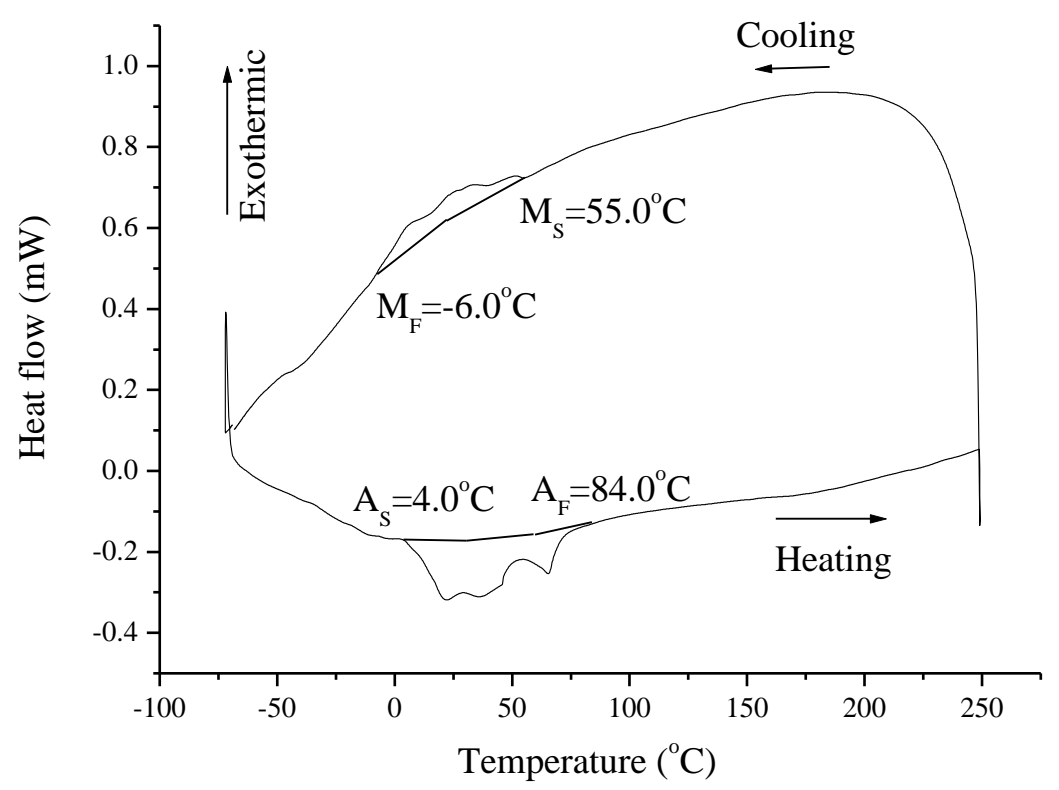

Figure 7.13: DSC traces of the thin film deposited at $130^{\circ} \mathrm{C}$ after being crystallized.

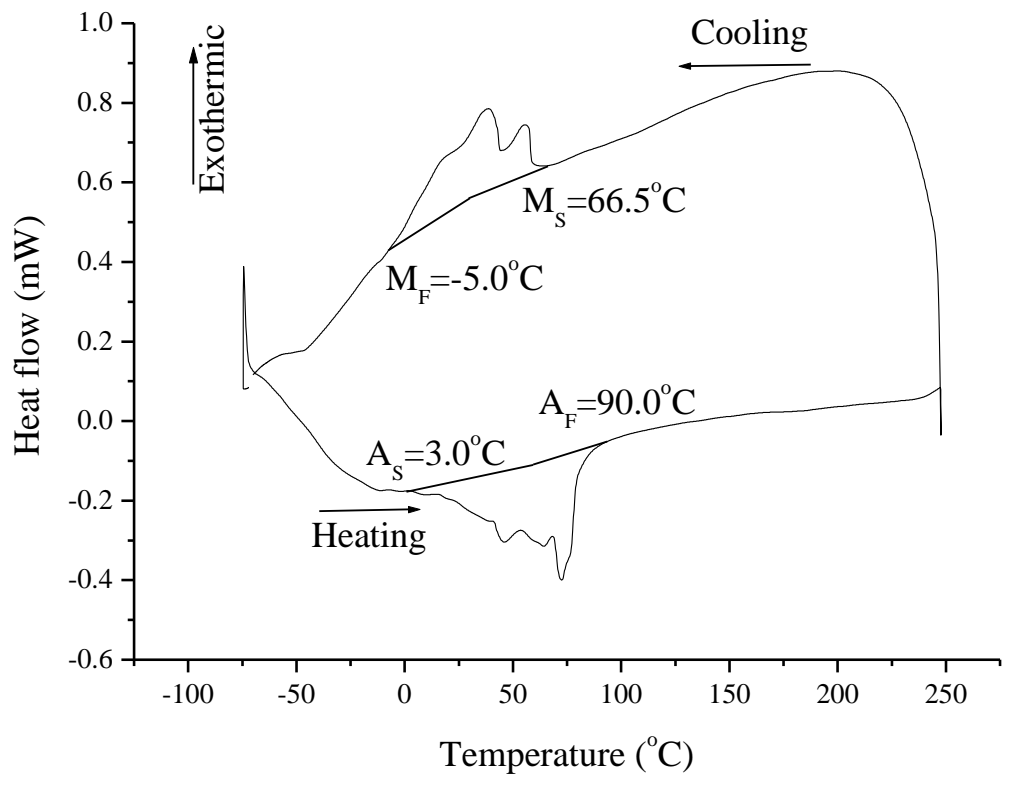

Figure 7.14: DSC traces of the thin film deposited at $300^{\circ} \mathrm{C}$ after being crystallized. 
Table 7.4: Transformation temperatures of bulk NiTi alloy and amorphous thin films after being crystallized.

\begin{tabular}{ccccccc}
\hline & $\mathrm{M}_{\mathrm{S}}\left({ }^{\circ} \mathrm{C}\right)$ & $\mathrm{M}_{\mathrm{F}}\left({ }^{\circ} \mathrm{C}\right)$ & $\mathrm{A}_{\mathrm{S}}\left({ }^{\circ} \mathrm{C}\right)$ & $\mathrm{A}_{\mathrm{F}}\left({ }^{\circ} \mathrm{C}\right)$ & $\mathrm{A}_{\mathrm{S}}-\mathrm{M}_{\mathrm{F}}\left({ }^{\circ} \mathrm{C}\right)$ & $\mathrm{A}_{\mathrm{F}}-\mathrm{M}_{\mathrm{S}}\left({ }^{\circ} \mathrm{C}\right)$ \\
\hline Bulk & 81.0 & 8.0 & 34.0 & 126.0 & 26.0 & 45.0 \\
$130^{\circ} \mathrm{C}$ & 55.0 & -6.0 & 4.0 & 84.0 & 10.0 & 29.0 \\
$300^{\circ} \mathrm{C}$ & 66.5 & -5.0 & 3.0 & 90.0 & 8.0 & 23.5 \\
\hline
\end{tabular}

The DSC curves for the crystalline thin films were generally more complex than similar data for bulk alloys. The presence of two or more transformation peaks on cooling and heating of the thin films is consistent with, although less well-defined than, multiple-step transformations observed in bulk alloys. The thermal characteristics of the foil samples are likely to be influenced by specific characteristics of the thin film, such as residual thermal stresses, compositional variations and reduced volumetric constraints. In addition, the deposition conditions can provide an in-situ heat treatment that promotes precipitation of intermetallic phases. These factors are likely to account for the prevalence of the R-phase transformation in thin films, despite the requirement of specific thermal or thermo-mechanical treatments for R-phase formation in bulk alloys. These treatments are considered to generate favourable precipitate distributions or dislocation substructures [96].

The interpretation of the DSC data from crystalline films in terms of the sequential transformations of B2 to R-phase and R-phase to B19' is generally consistent with the X-ray data and the microstructures observed by TEM. 


\section{Chapter 8}

\section{Mechanical Properties of NiTi Thin Films}

\subsection{Mechanical properties of equiatomic NiTi thin films}

\subsubsection{Roughness}

Figure 8.1 shows the AFM surface topographical image of a near-equiatomic NiTi thin film over an area in $50 \times 50 \mu \mathrm{m}^{2}$. It can be seen that the surface of the as-deposited NiTi thin film is reasonably smooth except for some dents resulting from the bombardment by the relatively large plasma particles. The average value of the root mean square roughness $(\mathrm{Rq})$ was $40 \mathrm{~nm}$.

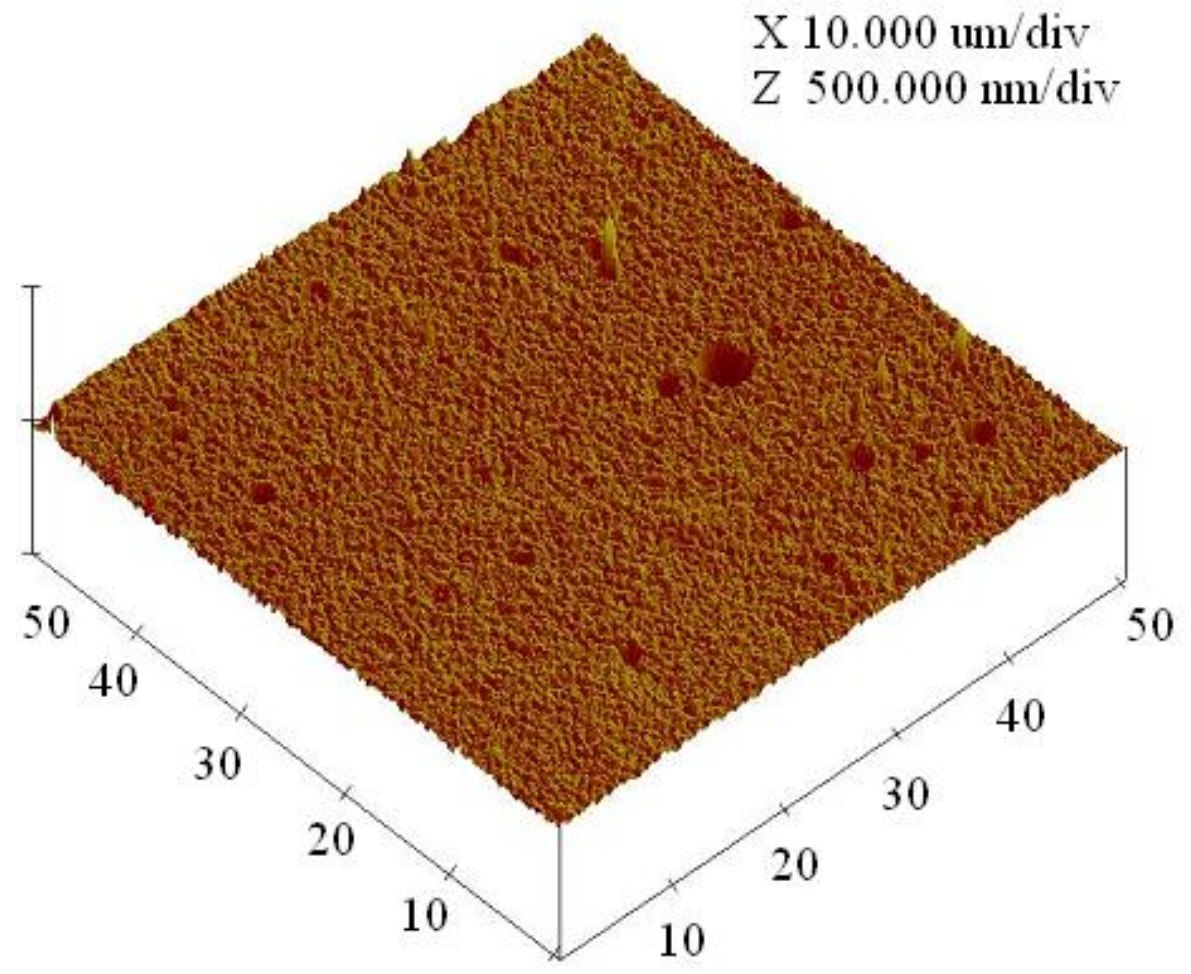

Figure 8.1: AFM image of the surface of a near-equiatomic crystalline NiTi thin film. 


\subsubsection{Hardness}

The indentation testing was performed using an UMIS indenter on the constrained thin film. The load versus depth curve during the tests is displayed in Figure 8.2. The maximum normal load was $8 \mathrm{mN}$ while the plastic depth $(\mathrm{Hp})$ of indentation was 0.2 $\mu \mathrm{m}$, about one tenth of the film thickness. It is known that the influence of substrate on the tested hardness value is minimal when the plastic depth is less than one tenth of the coating thickness [99]. The derived hardness and nominal elastic modulus were 4.5 and $137 \mathrm{GPa}$, respectively.

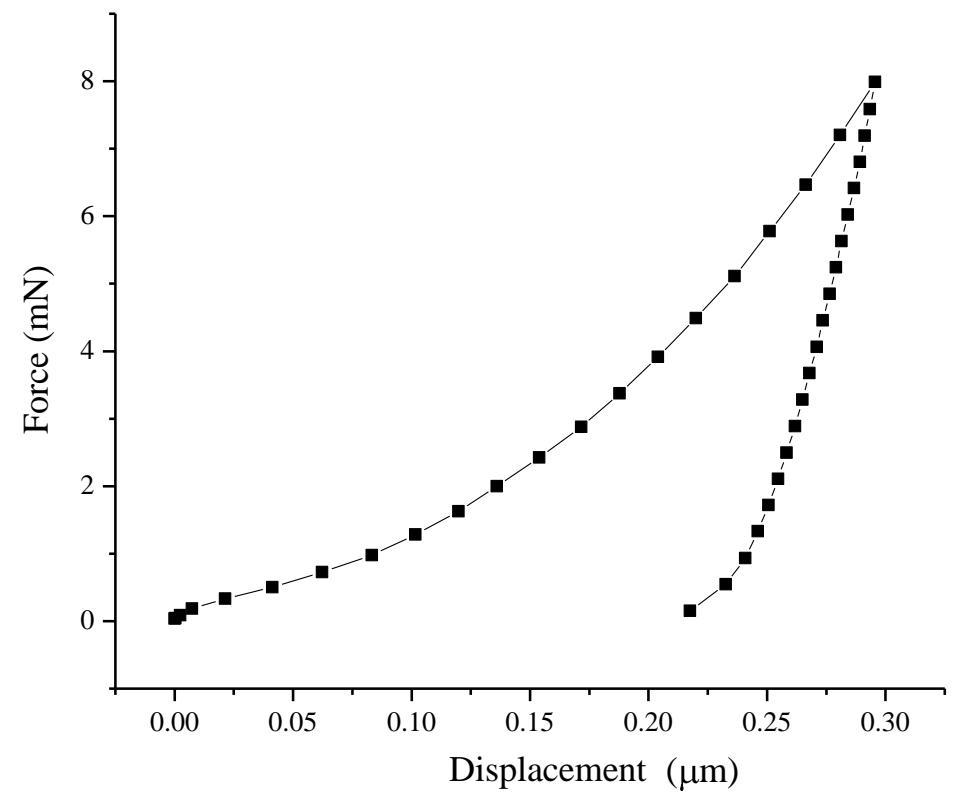

Figure 8.2: Plot of the load versus displacement resulting from indents on a near-equiatomic NiTi thin film constrained on mild steel substrate. 


\subsubsection{Adhesion force}

Scratch testing was performed on the near-equiatomic NiTi thin film to determine the adhesion force by using a diamond stylus. Figure 8.3 presents the curve of normal load versus the scratch distance. For normal load up to $30 \mathrm{~N}$, the lateral force and acoustic emission were monitored and the results are also shown in Figure 8.3. The lower critical load (LCL) and upper critical load (UCL) reflect the adhesion strength between the coating and substrate. The LCL is defined as the normal load at which the first micro-cracking of the coating is created, as shown in Figure 8.4 (a). When the coating damage starts to occur, there is an abrupt increase in the acoustic emission because of the detected elastic waves released by micro-fracture of the coating. As shown in Figure 8.3, the acoustic emission signal sharply increases when the scratch distance is $0.1 \mathrm{~cm}$, at which the corresponding normal load is $5.2 \mathrm{~N}$, which is defined as the LCL. Another increase in acoustic emission occurs at $0.18 \mathrm{~cm}$, which could be due to noise from the environment since the scratch tester was not covered by a sound insulation lid. The UCL is defined as the normal load at which the coating is removed from the substrate, as shown in Figure 8.4 (b). When the coating is penetrated by the probe and the substrate starts to be crushed, a significant change takes place in the lateral frictional force curve corresponding to the interface change from the coating to the substrate. The UCL for the near-equiatomic NiTi film is $22.6 \mathrm{~N}$. 


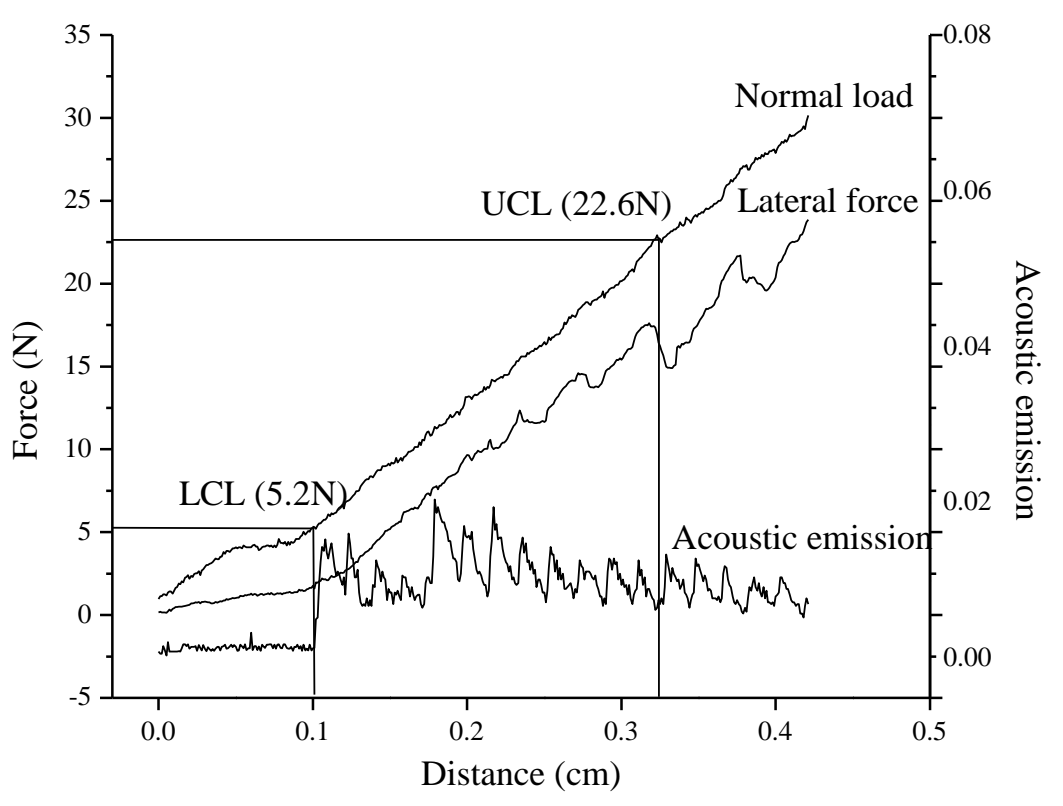

Figure 8.3: Plot of normal load versus distance during scratch tests on a near-equiatomic crystalline NiTi thin film.

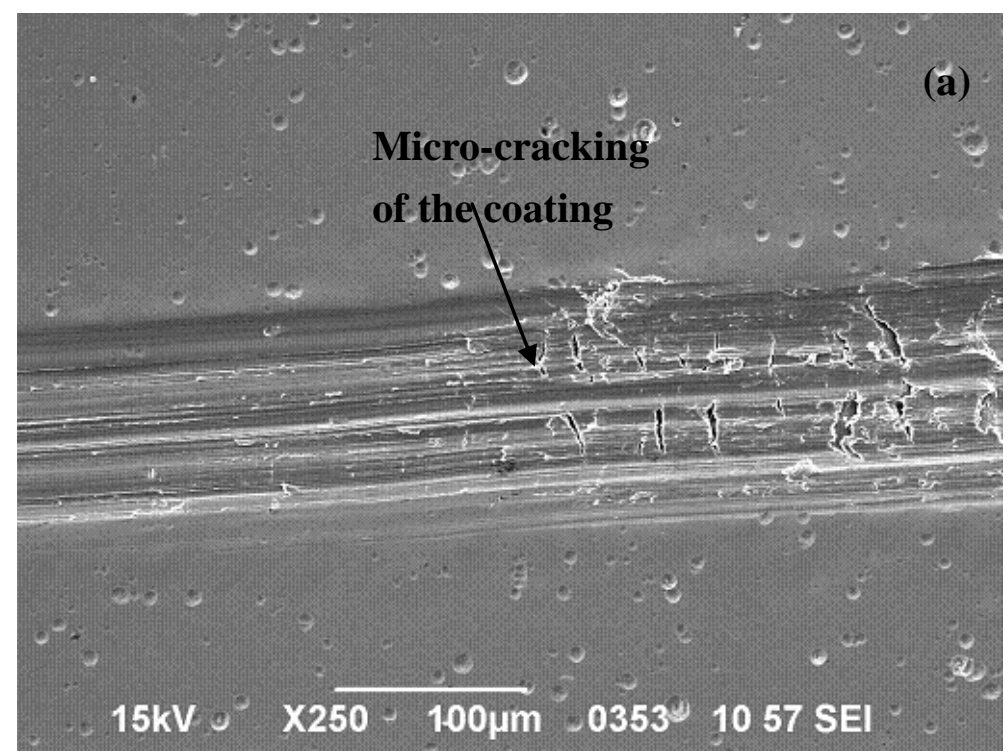




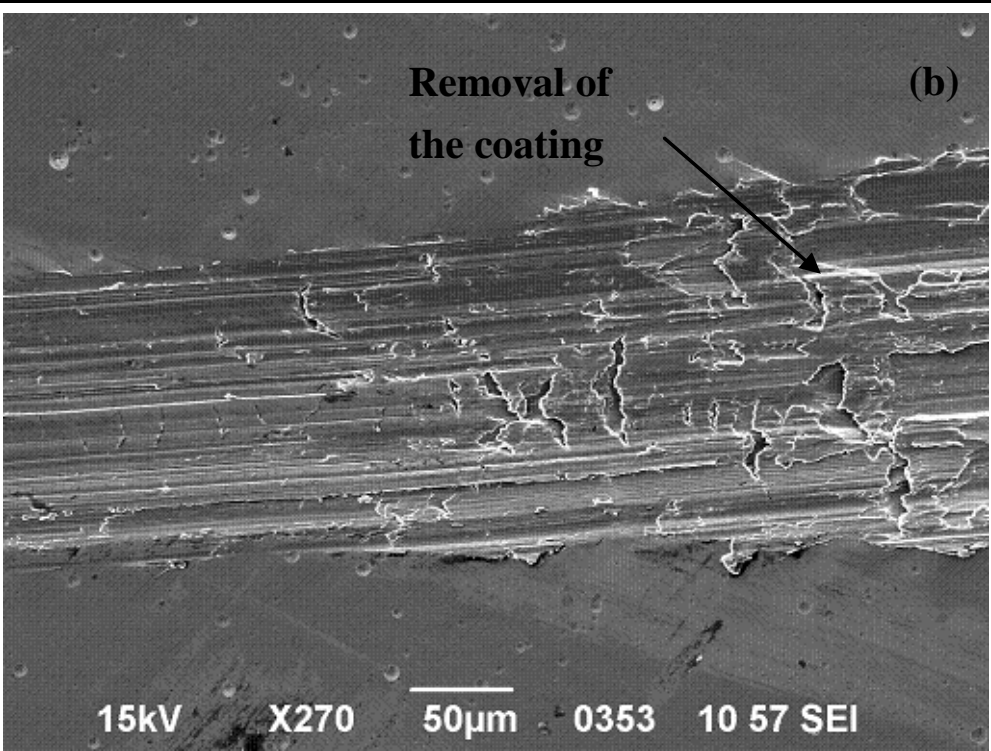

Figure 8.4: SEM image of scratch tracks on a near-equiatomic NiTi thin film at (a) lower critical load; (b) upper critical load.

\subsection{Mechanical properties of NiTi thin films deposited at different substrate temperatures}

\subsubsection{Roughness}

Figure 8.5 shows the AFM images of the surface topography of thin films deposited at different substrate temperatures. The surfaces are quite smooth for all the four thin films, especially for the films produced at low temperatures $\left(130^{\circ} \mathrm{C}\right.$ and $\left.300^{\circ} \mathrm{C}\right)$. The scratches in the underlying substrate surface have been replicated in the film, as shown in Figure 8.5 (a) to (c). The Root Mean Square roughness ( $\mathrm{Rq})$ of the four thin films is compared in Figure 8.6. It can be seen that the roughness of all the thin films produced by FADS is very low, less than $50 \mathrm{~nm}$. With the increase of the substrate temperature, the roughness of the deposited thin films increases from about $10 \mathrm{~nm}$ to more than $30 \mathrm{~nm}$. The increase of roughness correlates with the significant growth of the grains caused by 
increasing the substrate temperatures (Figure 6.13) [100]. Despite a strong preferred orientation, the grains have different spatial orientations and the rate of build-up of deposited atoms will be a function of the grain surface orientation. Therefore, the surface is expected to undulate, as shown in Figure 6.13, because of differential growth rates of the grains. The effect on roughness will be amplified as the cross-sectional area of the grains increases.

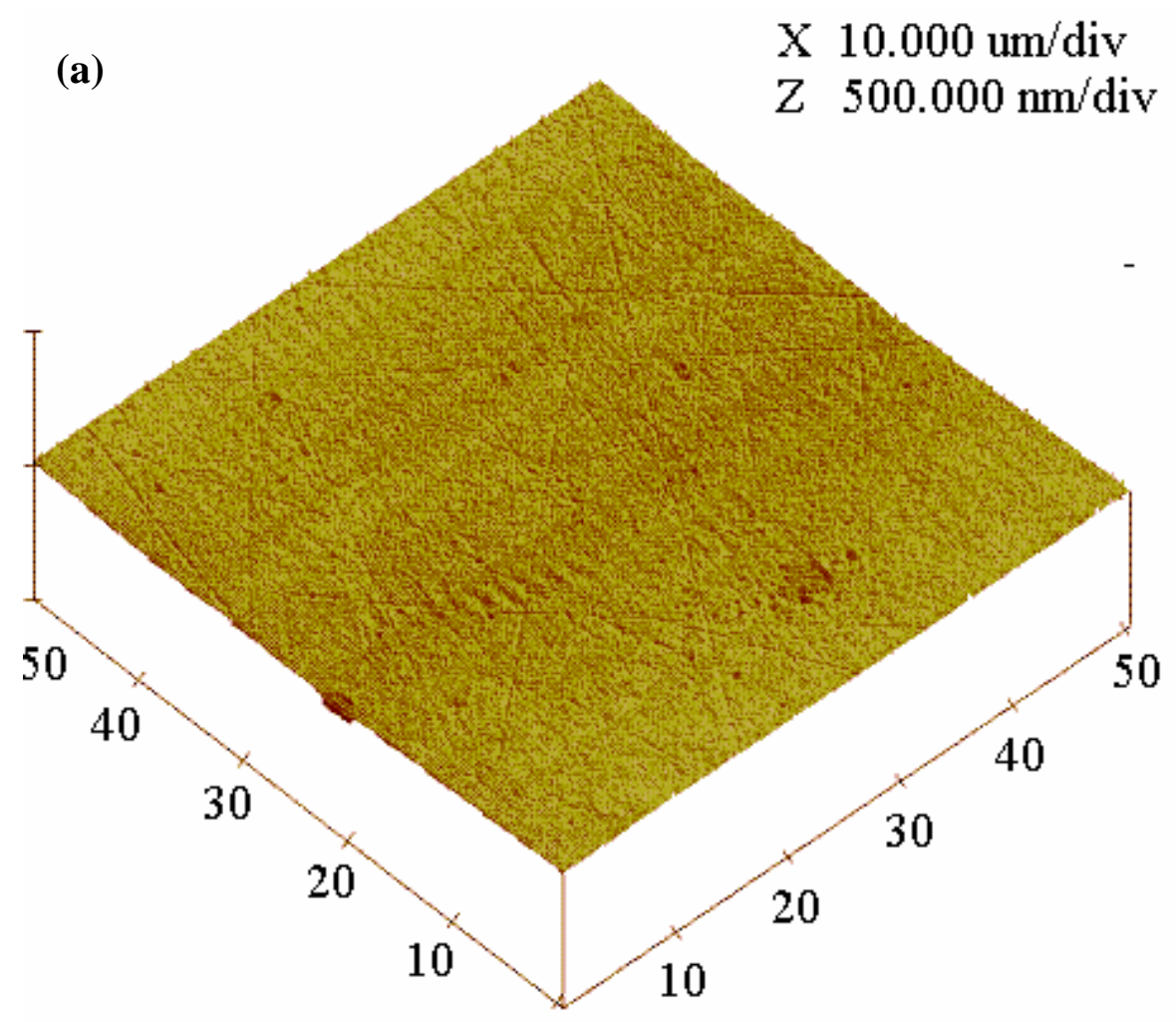



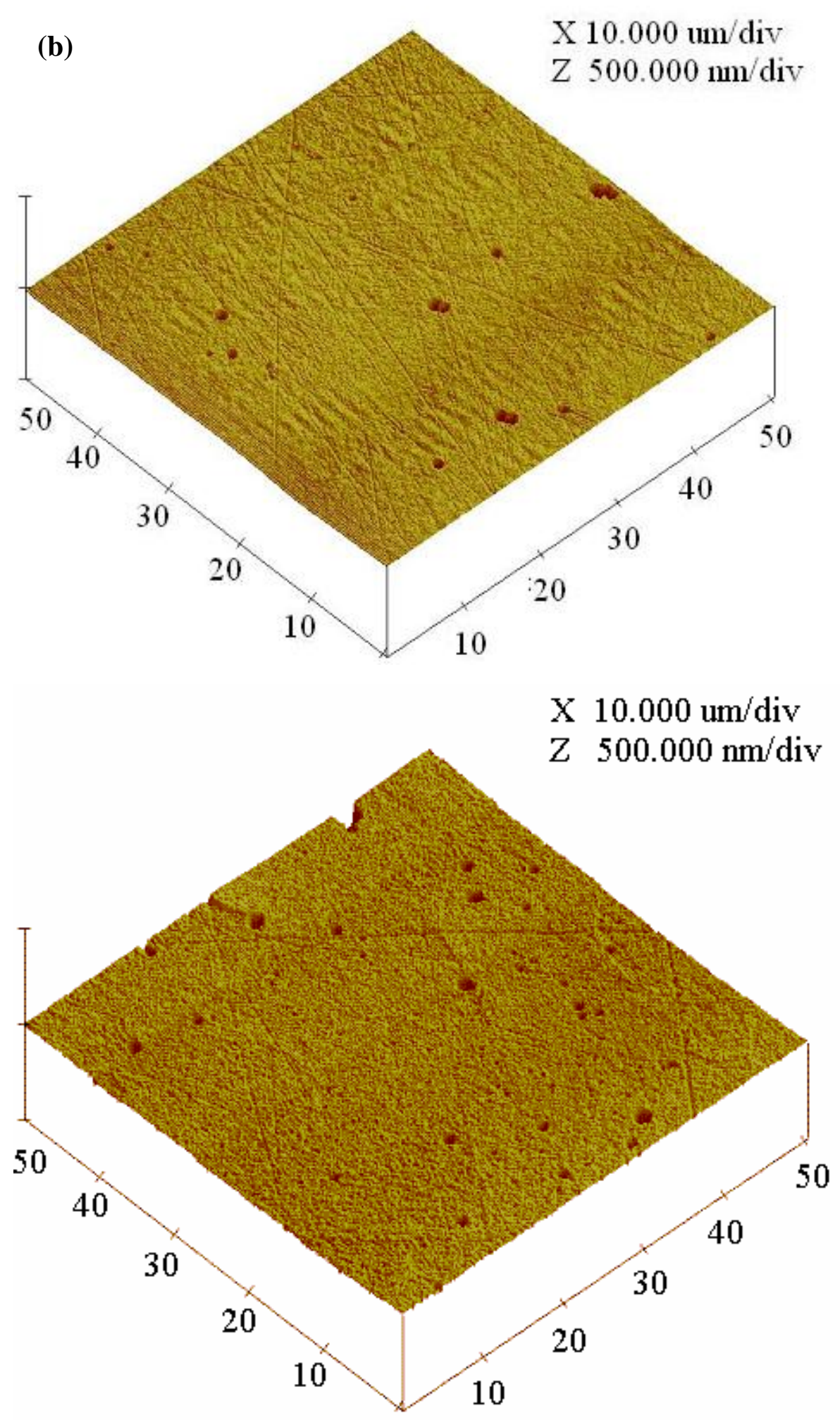


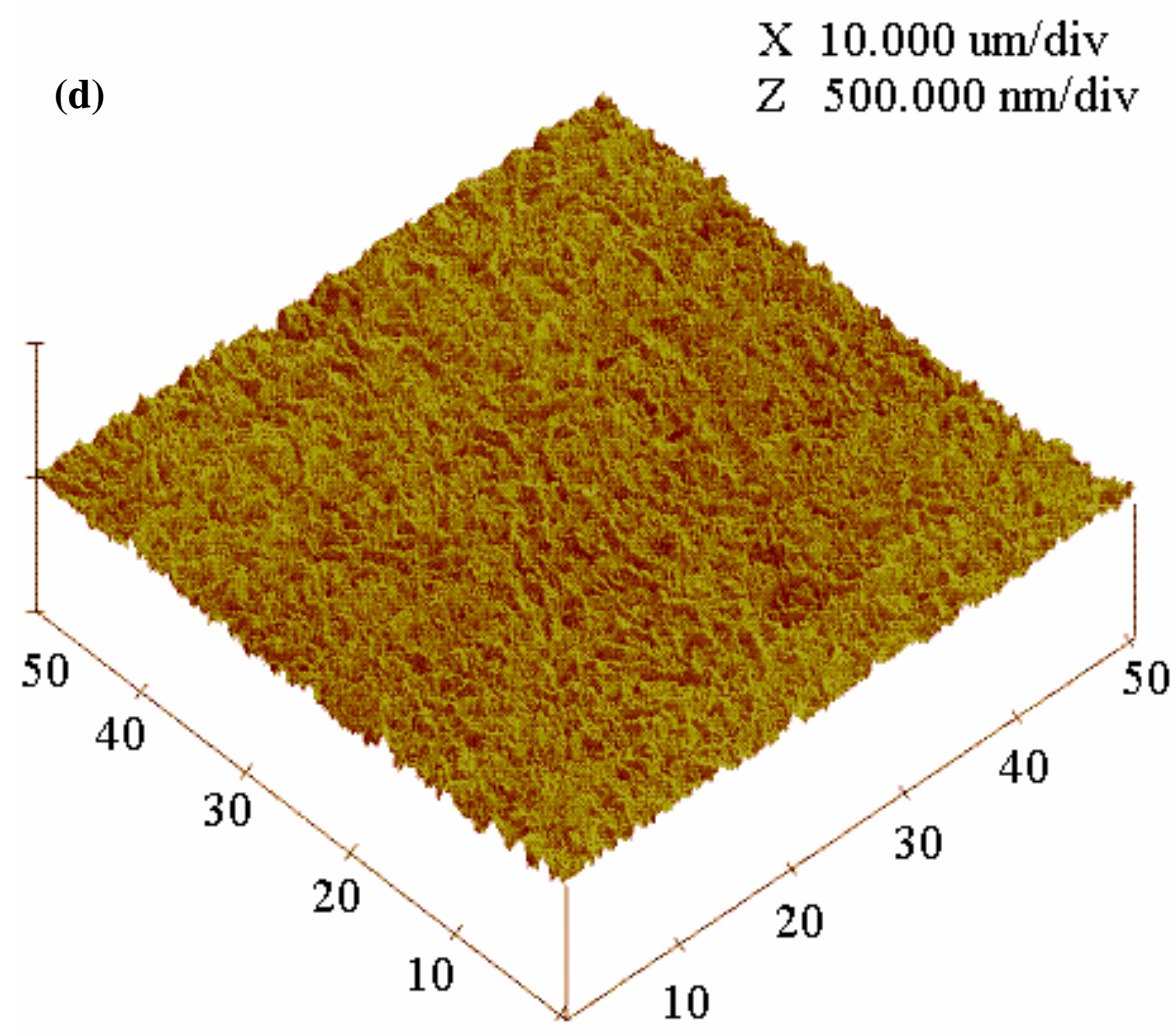

Figure 8.5: AFM images of thin films deposited at different substrate temperatures. (a) $130^{\circ} \mathrm{C}$; (b) $300^{\circ} \mathrm{C}$; (c) $430^{\circ} \mathrm{C}$; (d) $600^{\circ} \mathrm{C}$.

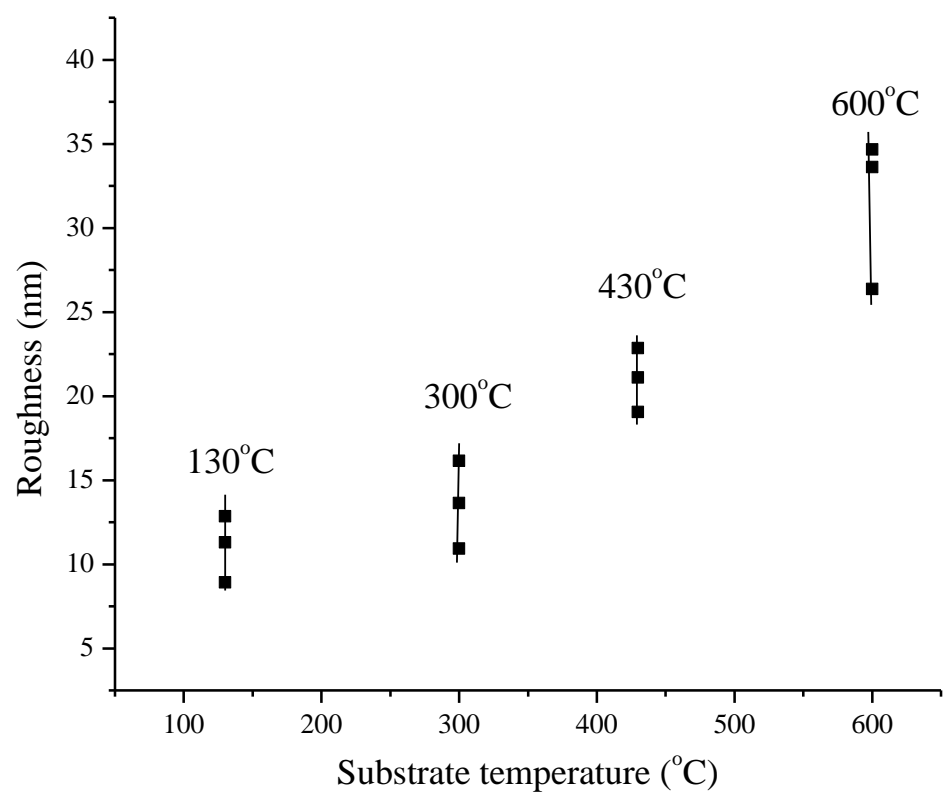

Figure 8.6: Roughness of thin films deposited at different substrate temperatures. 


\subsubsection{Hardness}

Figure 8.7 presents the curves of the load versus depth from indentation tests on constrained NiTi films deposited at different substrate temperatures. While the applied maximum load was $10 \mathrm{mN}$, the plastic depth (Hp) of indents was from 0.19 to $0.23 \mu \mathrm{m}$ which is about one tenth of the film thickness. The hardness and elastic modulus of the four thin films are compared in Figure 8.8. It can be seen that both the hardness and elastic modulus of the thin films deposited at low temperatures $\left(130^{\circ} \mathrm{C}\right.$ and $\left.300^{\circ} \mathrm{C}\right)$ were higher than those of the films obtained at high temperatures $\left(430^{\circ} \mathrm{C}\right.$ and $\left.600^{\circ} \mathrm{C}\right)$. Therefore, the amorphous thin films obtained at $130^{\circ} \mathrm{C}$ and $300^{\circ} \mathrm{C}$ (Figure 6.9) possess higher hardness and elastic modulus than the crystalline thin films obtained at $430^{\circ} \mathrm{C}$ and $600^{\circ} \mathrm{C}$ (Figure 6.10 and Figure 6.12 ). The pseudoelasticity of crystalline films deposited at high temperatures lowers the hardness, whereas the amorphous films formed at low temperatures do not exhibit this behaviour. The thin film deposited at $600^{\circ} \mathrm{C}$ shows higher hardness and elastic modulus than the film obtained at $430^{\circ} \mathrm{C}$. This trend correlates with the different crystalline phases in the films because it is known that the material hardness and elastic modulus vary with the phase structure [100], [101]. As discussed in Figure 6.12 , the thin film obtained at $600^{\circ} \mathrm{C}$ was dominated by $\mathrm{B} 2$ parent phase whereas the film deposited at $430^{\circ} \mathrm{C}$ was a mixture of the $\mathrm{B} 2$, B19' and R phases (Figure 6.10). Another contributing factor could be "gettering" of residual $\mathrm{O}$ and $\mathrm{N}$ in the chamber, which was more pronounced at higher temperature, thus hardening the film. The strength and hardness of titanium rise steeply with increasing concentrations 
interstitial $\mathrm{O}$ and $\mathrm{N}$ [102] and a similar trend has been reported for NiTi [103].

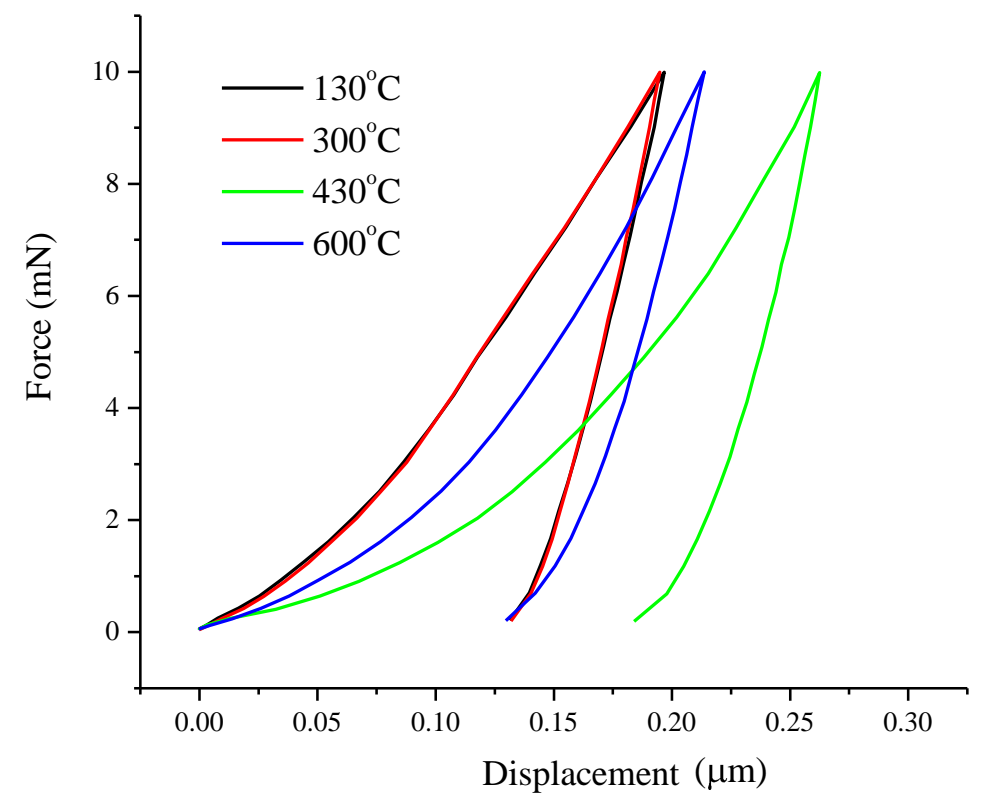

Figure 8.7: Plots of the load versus displacement from the indents on the constrained NiTi thin films deposited at different substrate temperatures.

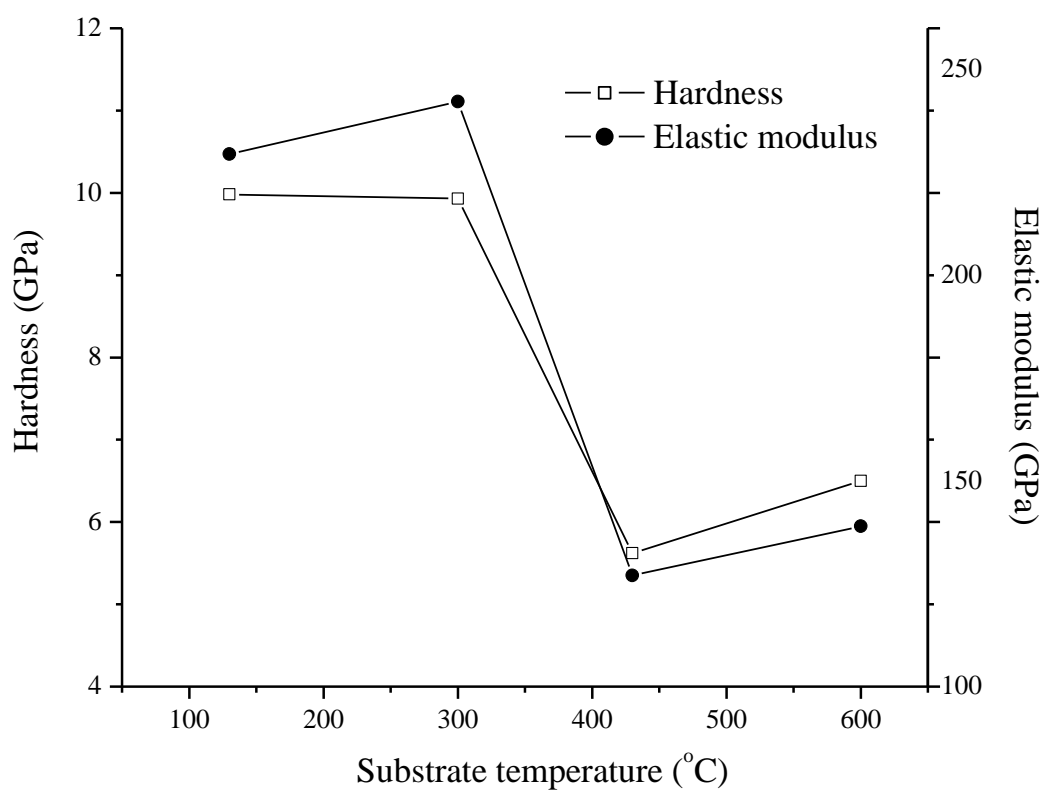

Figure 8.8: Hardness and elastic modulus of thin films deposited at different substrate temperatures. 


\subsubsection{Adhesion force}

Scratch tests were performed on the constrained thin films deposited at different substrate temperatures. Figure 8.9 shows the normal load, lateral force and acoustic emission as a function of distance during scratching and the lower and upper critical loads determined from the curves. It is clear that both the lower and upper critical loads for the thin films deposited at low temperatures $\left(130^{\circ} \mathrm{C}\right.$ and $\left.300^{\circ} \mathrm{C}\right)$ were lower than those for the films obtained at high temperatures $\left(430^{\circ} \mathrm{C}\right.$ and $\left.600^{\circ} \mathrm{C}\right)$, especially the upper critical loads, which were less than $10 \mathrm{~N}$ compared to more than $20 \mathrm{~N}$ for thin films produced at high temperatures. Normally, a higher critical load indicates a higher interfacial adhesion. Therefore, it can be concluded that the crystalline NiTi thin films, obtained at high temperatures, possess higher adhesion force than the amorphous films obtained at low temperatures. This is probably attributed to greater inter-diffusion between atoms in the film and substrate at high temperatures which strengthens the interfacial region. 

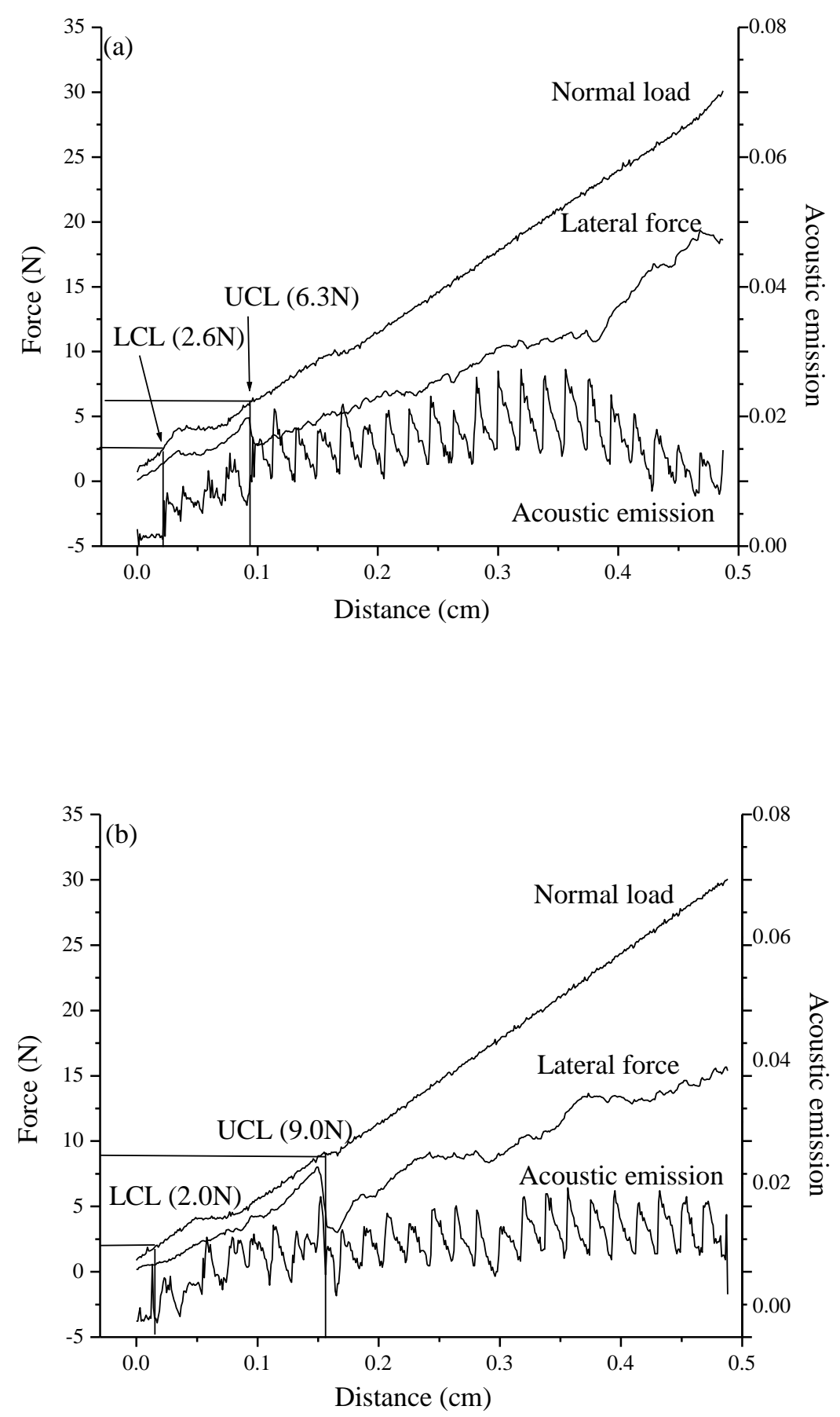

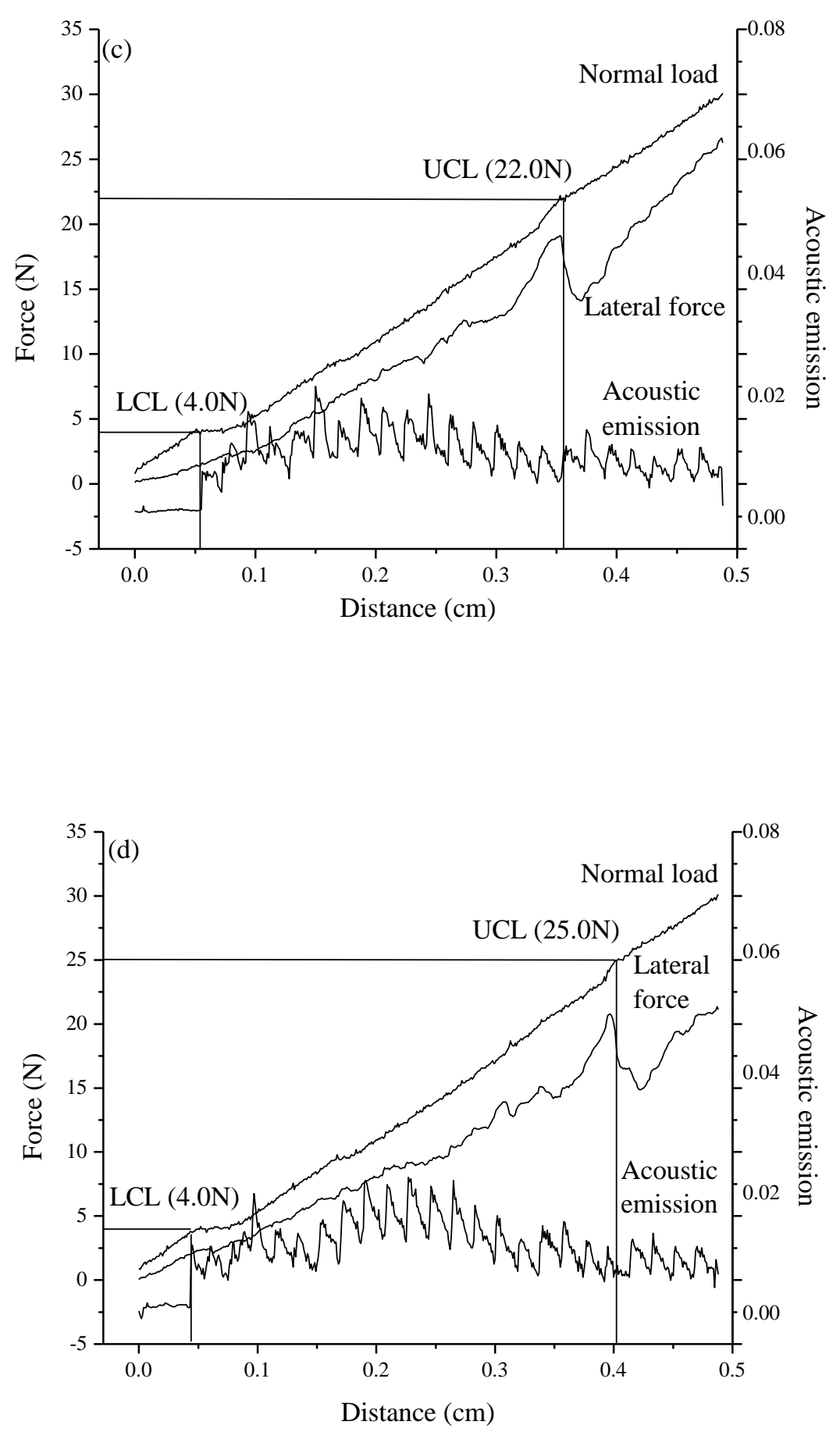

Figure 8.9: Plots of normal load versus distance from scratch tests on thin films deposited at different substrate temperatures. (a) $130^{\circ} \mathrm{C}$; (b) $300^{\circ} \mathrm{C}$; (c) $430^{\circ} \mathrm{C}$; (d) $600^{\circ} \mathrm{C}$. 


\subsection{Mechanical properties of thin films deposited at different substrate bias voltages with high substrate temperature $\left(600{ }^{\circ} \mathrm{C}\right)$}

\subsubsection{Roughness}

The surface topography of thin films deposited at different substrate bias voltages were examined by AFM (Figure 8.10 (a)-(d)). As can be seen from Figure 8.11, the surface of thin films produced by FADS is reasonably smooth, with the roughness being less than $100 \mathrm{~nm}$. The NiTi thin film deposited at the lowest bias voltage of $50 \mathrm{~V}$ exhibits a relatively rough surface with the Root Mean Square Roughness (Rq) being about $80 \mathrm{~nm}$. This is presumably due to the low energy of the ions and atoms associated with low substrate bias, which leads to the formation of large clusters [104]. This creates shadowing effect and leads to the growth of a columnar microstructure [105]. Therefore, coarse grains with voids are formed, leading to a high roughness. With the bias voltage of $80 \mathrm{~V}$, the RMS roughness of the as-deposited thin film decreased to about $35 \mathrm{~nm}$. Due to the improved atomic mobility at higher bias, the plasma can spread their energies over a larger depth, which restricts the growth of large cluster and decreases the shadowing effect [104]. As a result, the grains grow finer and the surface becomes smoother with minimum voids, referred to as the densification of the film. However, when the bias voltage increased to $120 \mathrm{~V}$ and $150 \mathrm{~V}$, the RMS roughness increased to about 50 and $65 \mathrm{~nm}$, respectively. Figure 8.10 (c) and (d) show hole-like defects in the films, especially the film deposited at the highest bias voltage of $150 \mathrm{~V}$. This arises because the ions and atoms bombard substrate deeply with high energy and velocity due to the high substrate bias. It is inferred that, instead of the densification effect, the ion 
bombardment effect becomes the dominant factor in the case of high bias.
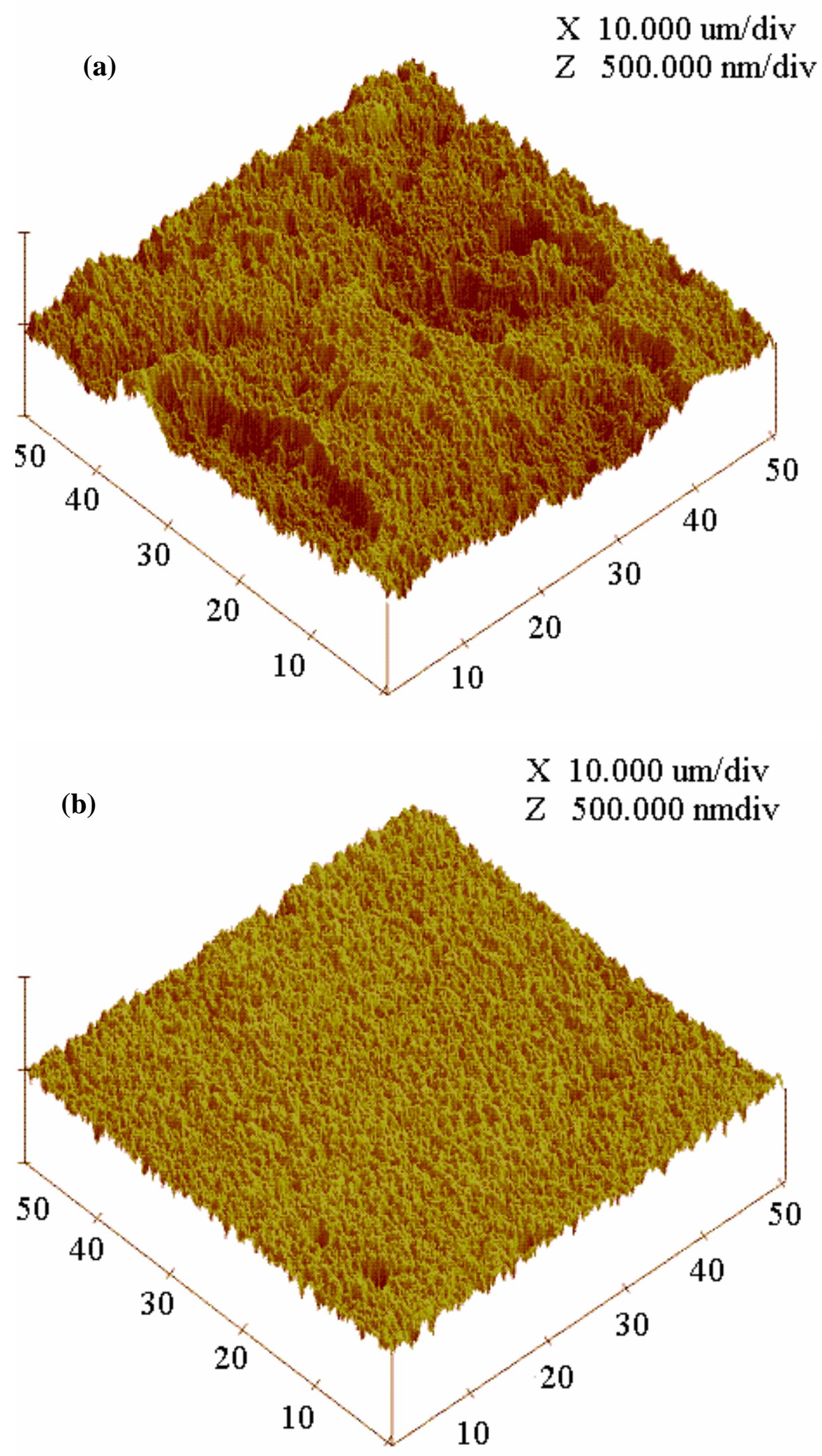

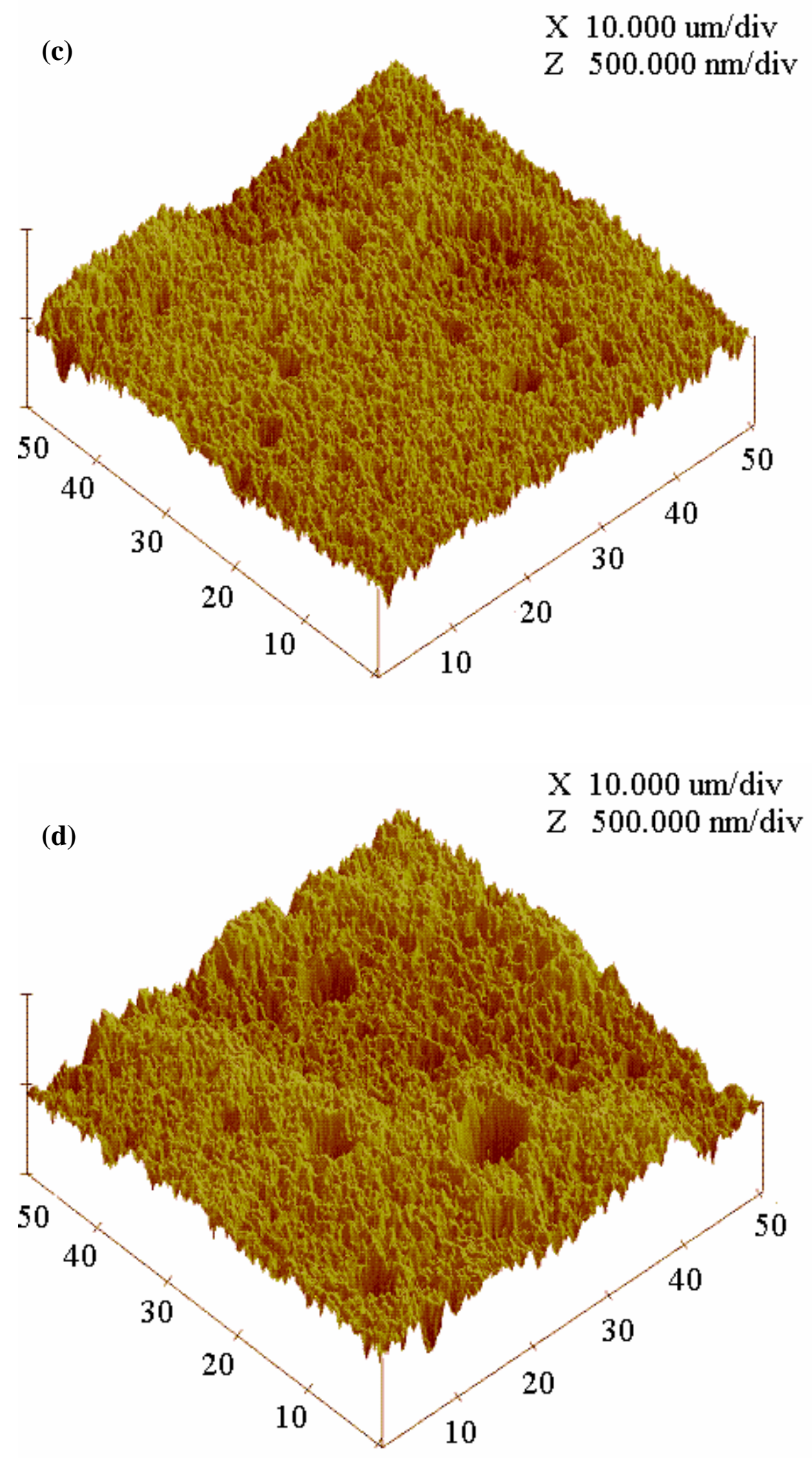

Figure 8.10: AFM images of thin films deposited at $600{ }^{\circ} \mathrm{C}$ at different substrate bias voltages. (a) $50 \mathrm{~V}$; (b) $80 \mathrm{~V}$; (c) $120 \mathrm{~V}$; (d) $150 \mathrm{~V}$. 


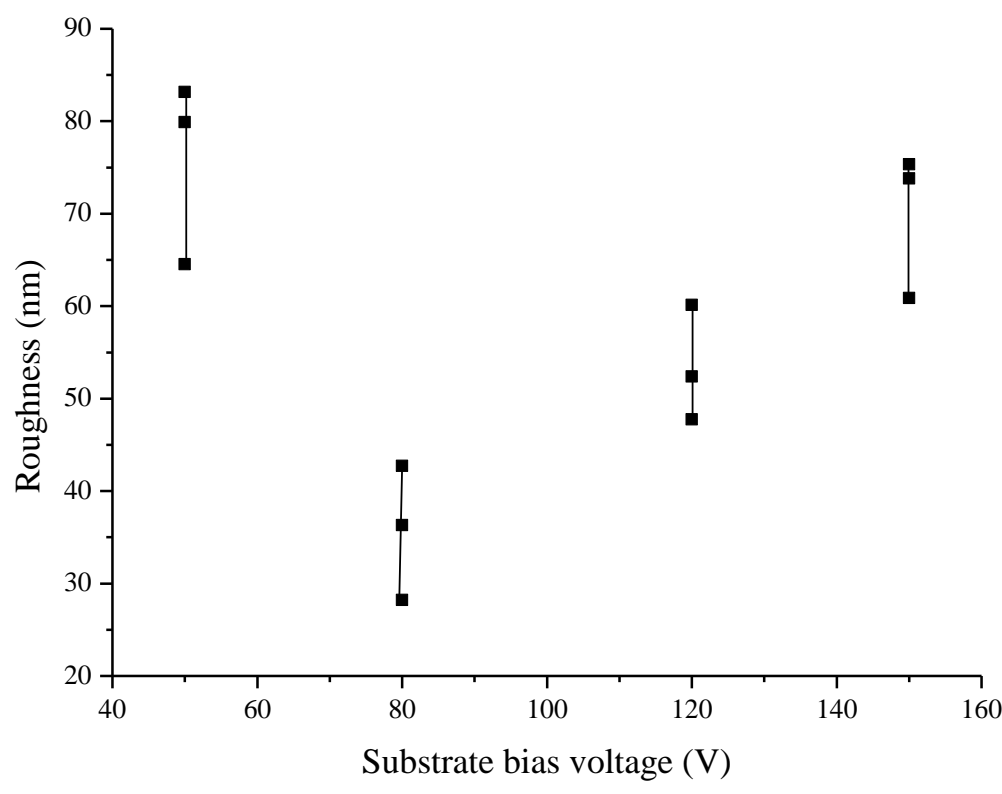

Figure 8.11: Roughness of thin films deposited at different substrate bias voltages.

\subsubsection{Hardness}

Indentation testing was used for measuring the hardness and elastic modulus of the thin films deposited at different bias voltages. Figure 8.12 shows the curves of the indentation force as a function of the contact depth during the tests. The maximum normal load was $8 \mathrm{mN}$ and the corresponding plastic depth (Hp) was from 0.14 to 0.23 $\mu \mathrm{m}$. Figure 8.13 shows the effect of deposition bias voltage on the hardness and elastic modulus of the thin films. As the bias voltage increases from $50 \mathrm{~V}$ to $150 \mathrm{~V}$, the hardness rises from $4 \mathrm{GPa}$ to $13 \mathrm{GPa}$ and the elastic modulus increases from $90 \mathrm{GPa}$ to $255 \mathrm{GPa}$. At a higher bias voltage, the depositing atoms and ions with higher impact energy increase the surface temperature of the film. Therefore, there could be more 
pronounced gettering of residual $\mathrm{O}$ and $\mathrm{N}$ atoms in the chamber atmosphere that results in an increase in the hardness of the films.

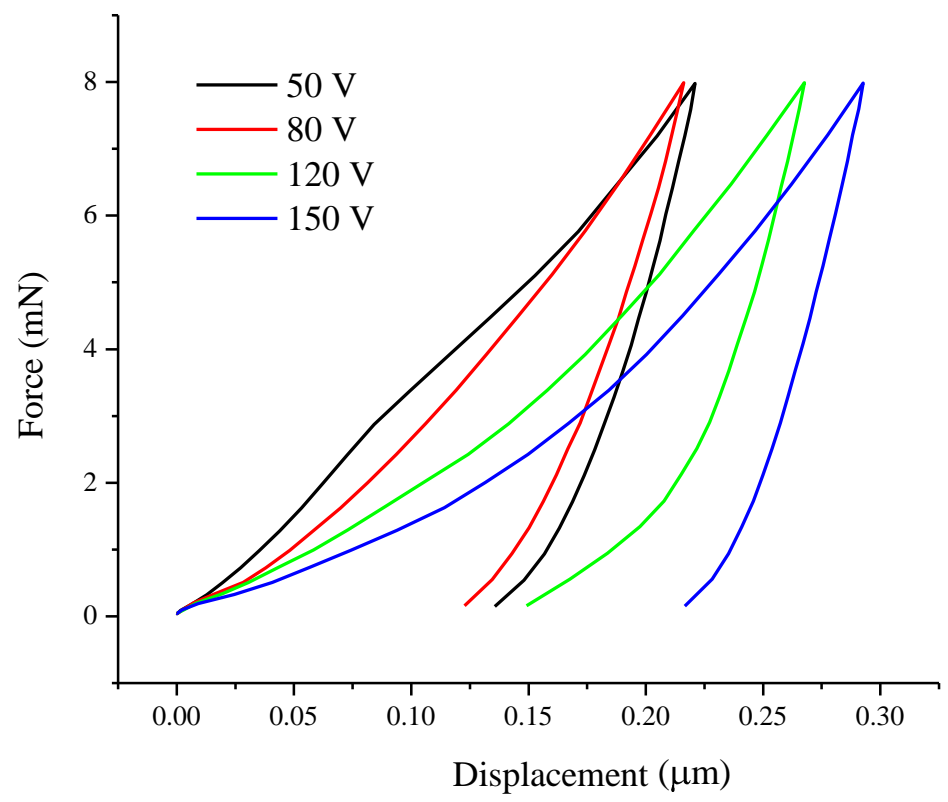

Figure 8.12: Plots of the load versus displacement from the indents on samples deposited at different substrate bias voltages.

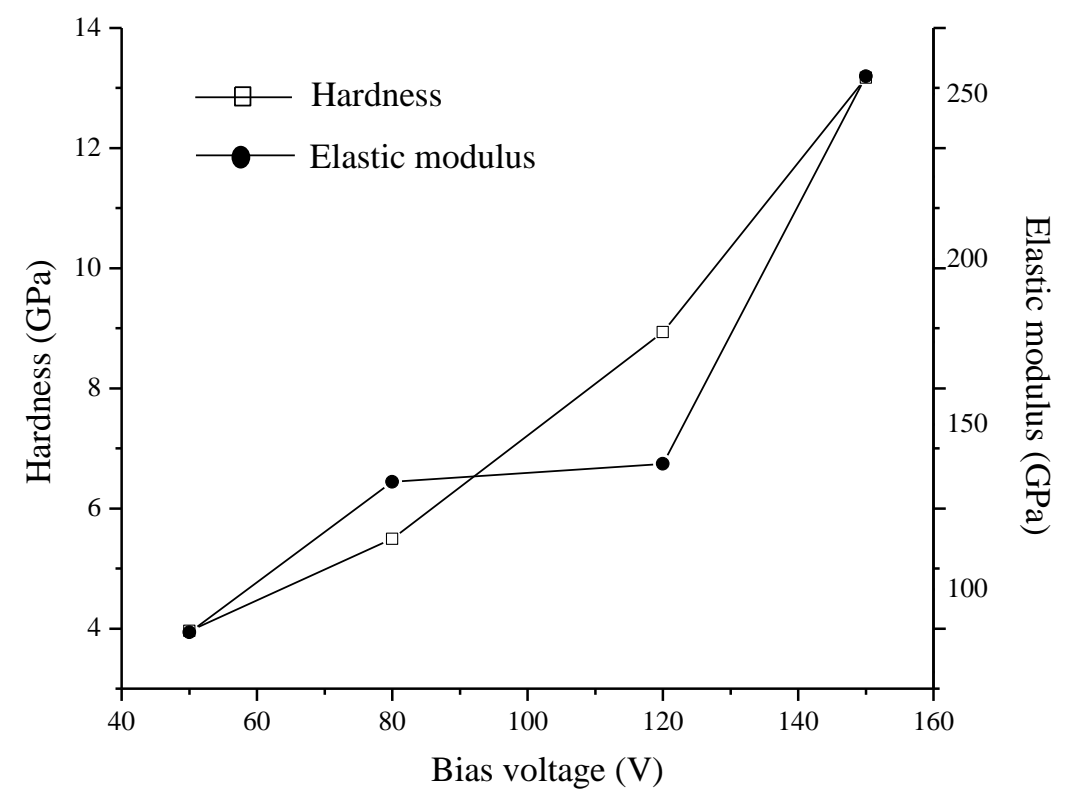

Figure 8.13: Hardness and elastic modulus of thin films deposited at different substrate bias voltages. 


\subsubsection{Adhesion force}

Scratch tests were performed on thin films obtained at different substrate bias voltages.

Figure 8.14 compares the lower and upper loads for the four different samples. Both the lower and upper critical loads generally rise with the increase in substrate bias voltage. Therefore, for high deposition bias voltage the bonding force between the film and substrate increased due to the high bombardment and greater interfacial inter-diffusion.

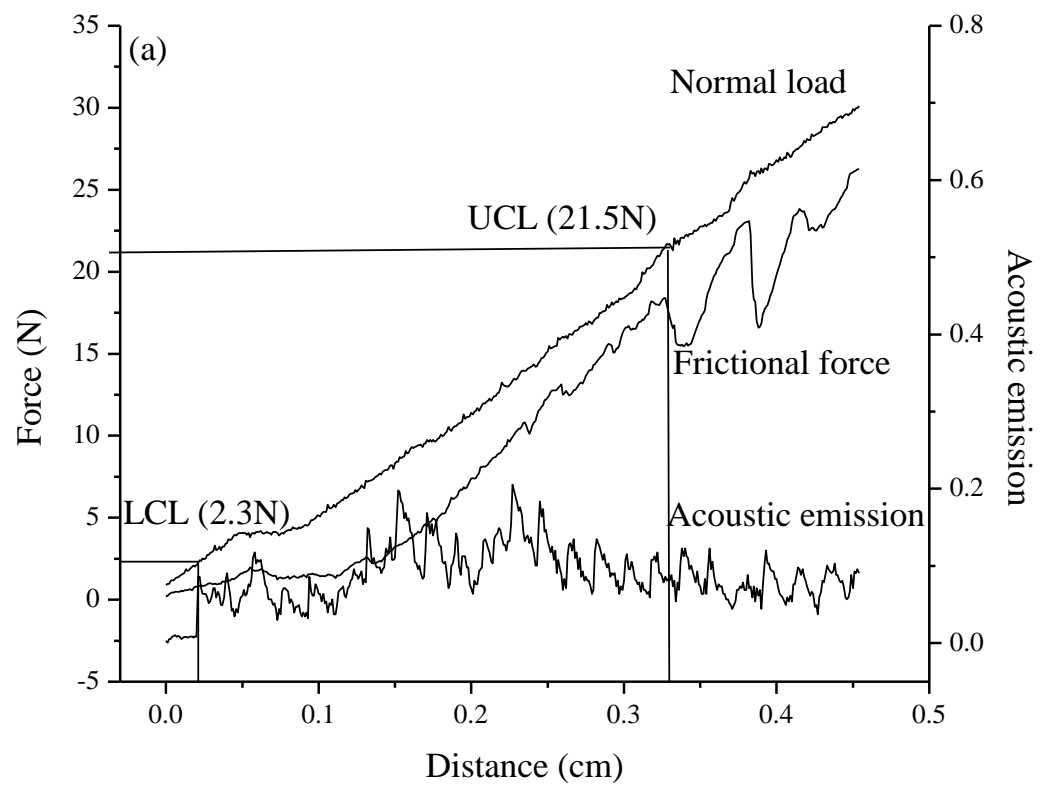



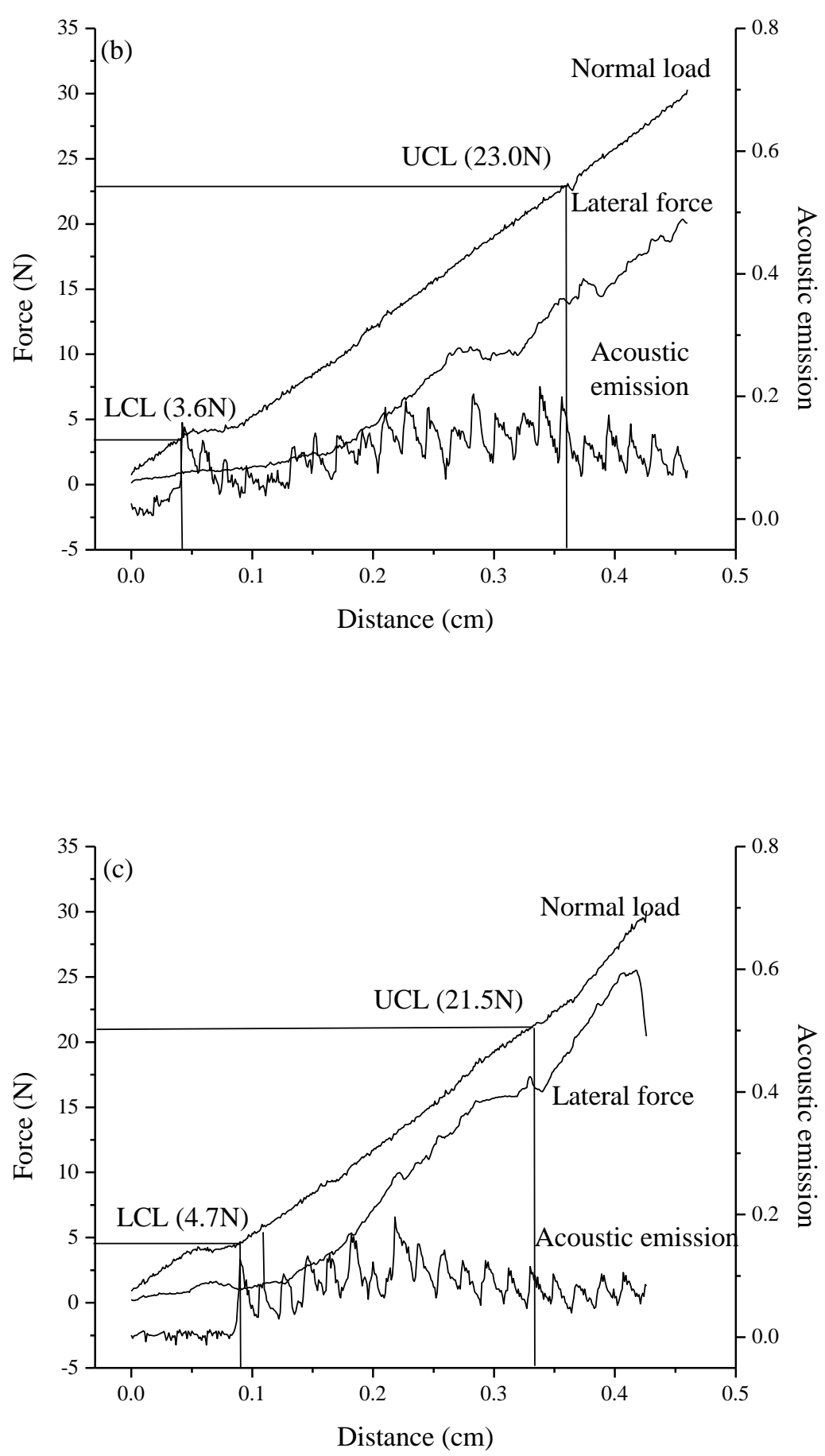


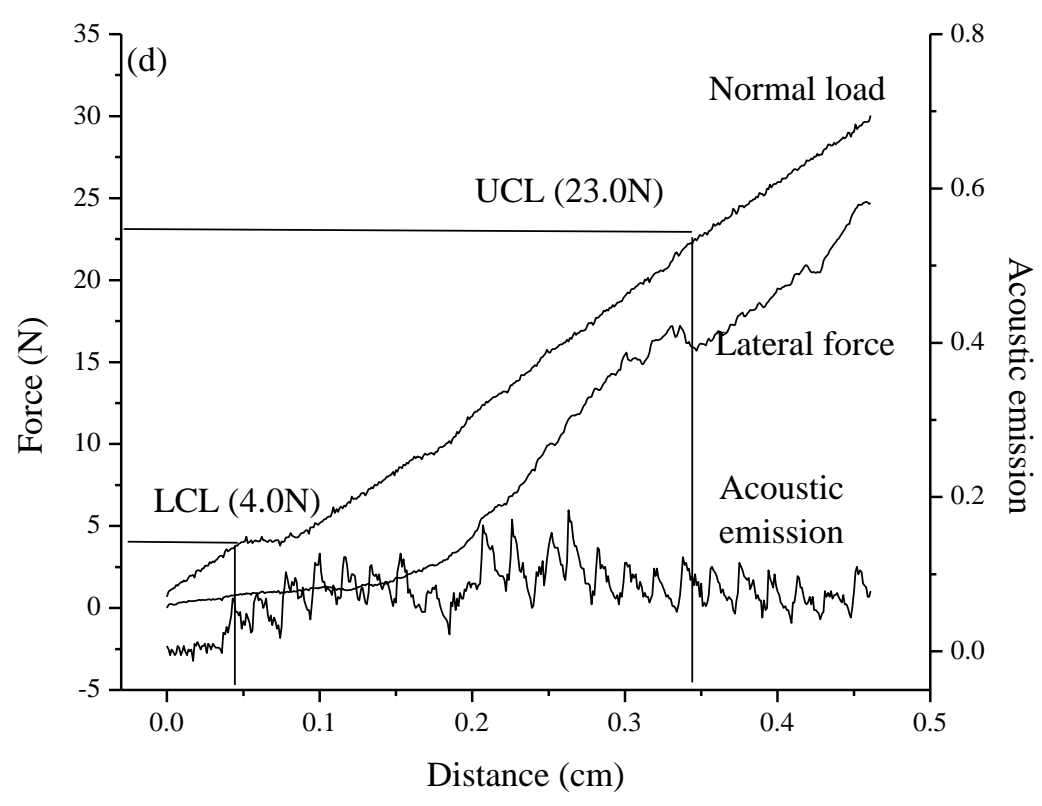

Figure 8.14: Plots of normal load versus distance from scratch tests on thin films deposited at different bias voltages. (a) $50 \mathrm{~V}$; (b) $80 \mathrm{~V}$; (c) $120 \mathrm{~V}$; (d) $150 \mathrm{~V}$.

\subsection{Mechanical properties of thin films deposited on austenitic stainless steel}

\subsubsection{Hardness}

The indentation tests for the NiTi films deposited on different substrates were performed using the Hysitron TI-900 TriboIndenter. When the obtained plastic depth was around one tenth of the film thickness, the corresponding maximum load was 11.5 $\mathrm{mN}$. It can be seen that the maximum load, either $8 \mathrm{mN}$ or $10 \mathrm{mN}$, used during previous UMIS indentation tests was close to the peak load obtained by using Hysitron TI-900 TriboIndenter because both indentation tests were performed using a Berkovich probe. Figure 8.15 shows the curves of the indentation load as a function of the contact depth 
and Table 8.1 compares the hardness and elastic modulus of films on stainless steel and mild steel. It shows that the amorphous NiTi films were harder than the crystalline NiTi films on the same substrate materials. The result is in agreement with the previous conclusion for the thin films deposited on mild steel at different substrate temperatures (Figure 8.7 and Figure 8.8). For amorphous thin films on stainless steel and mild steel, there was no significant difference in their hardness and elastic modulus values. However, the crystalline NiTi film on stainless steel possessed higher hardness than that deposited on mild steels. This difference could be due to the different crystalline phases in the films. It is known from Figure 6.17 that the thin film deposited on stainless steel was dominated by B2 parent phase and the film on mild steel was a mixture of B2, B19' and R phases. This similar result is observed from the NiTi films deposited at different substrate temperatures (Figure 8.8). Another possible reason could be associated with the lower thermal conductivity of stainless steel than mild steel. Although stainless steel and mild steel were both preheated to the same temperature before deposition, stainless steel sustained higher temperatures during depsotion due to its lower thermal conductivity, which would promote more effective $\mathrm{O}$ and $\mathrm{N}$ pickup, thereby increasing the hardness of the films. 


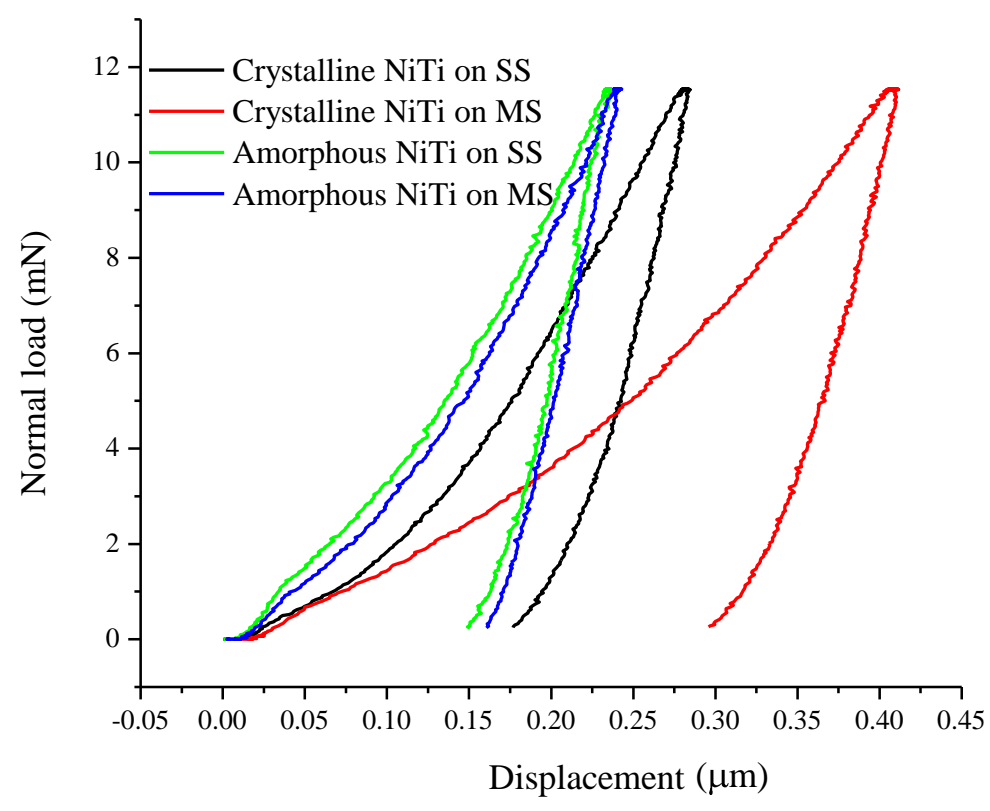

Figure 8.15: Plots of the load versus displacement curves from the indents made on constrained NiTi thin films on stainless steel (SS) and mild steel (MS).

Table 8.1: Hardness and elastic modulus of the amorphous and crystalline NiTi thin film deposited on austenitic stainless steel and mild steel.

\begin{tabular}{lccc}
\hline \multicolumn{1}{c}{ Substrate } & Film & Hardness (GPa) & Elastic modulus (GPa) \\
\hline Stainless steel & Crystalline & 7.5 & 132.3 \\
Mild steel & Crystalline & 3.5 & 81.7 \\
Stainless steel & Amorphous & 12.1 & 185.3 \\
Mild steel & Amorphous & 11.7 & 162.2 \\
\hline
\end{tabular}

\subsubsection{Adhesion}

Figure 8.16 shows optical images of $500 \mathrm{mN}$ ramping force scratch tests on four samples. Figure 8.17-Figure 8.20 present plots of normal force, normal displacement, lateral force, and lateral displacement versus time during scratch tests on the four 
samples, respectively. For crystalline thin film deposited on stainless steel substrate (Figure 8.17), there was a sharp drop in normal displacement at around 60 seconds, when the lateral force increased significantly. A similar change also occurred on the amorphous thin film deposited on stainless steel at around 55 seconds in Figure 8.19. The sudden change in normal displacement and lateral force indicates the failure of the film and substrate interface. The crystalline film showed stronger bonding force than amorphous film since the failure of the crystalline film took place later. This conclusion is consistent with the results of the films deposited at different substrate temperatures (Figure 8.9). However, for the NiTi film deposited on mild steel substrate, as shown in Figure 8.18 and Figure 8.20, there was no abrupt change in the normal displacement or lateral force during scratch testing. This difference can be seen clearly from Figure 8.21, which shows the plot of normal displacement versus lateral displacement during scratch tests. The NiTi film samples on stainless steel substrates exhibit sharp drops in normal displacement near the end of the test, whereas there was no sudden change in the normal displacement for NiTi films on mild steel substrates. Therefore, no film delamination occurred within this applied force range. It can be concluded that the NiTi films deposited on mild steel possess stronger bonding force than those on stainless steel substrate. 

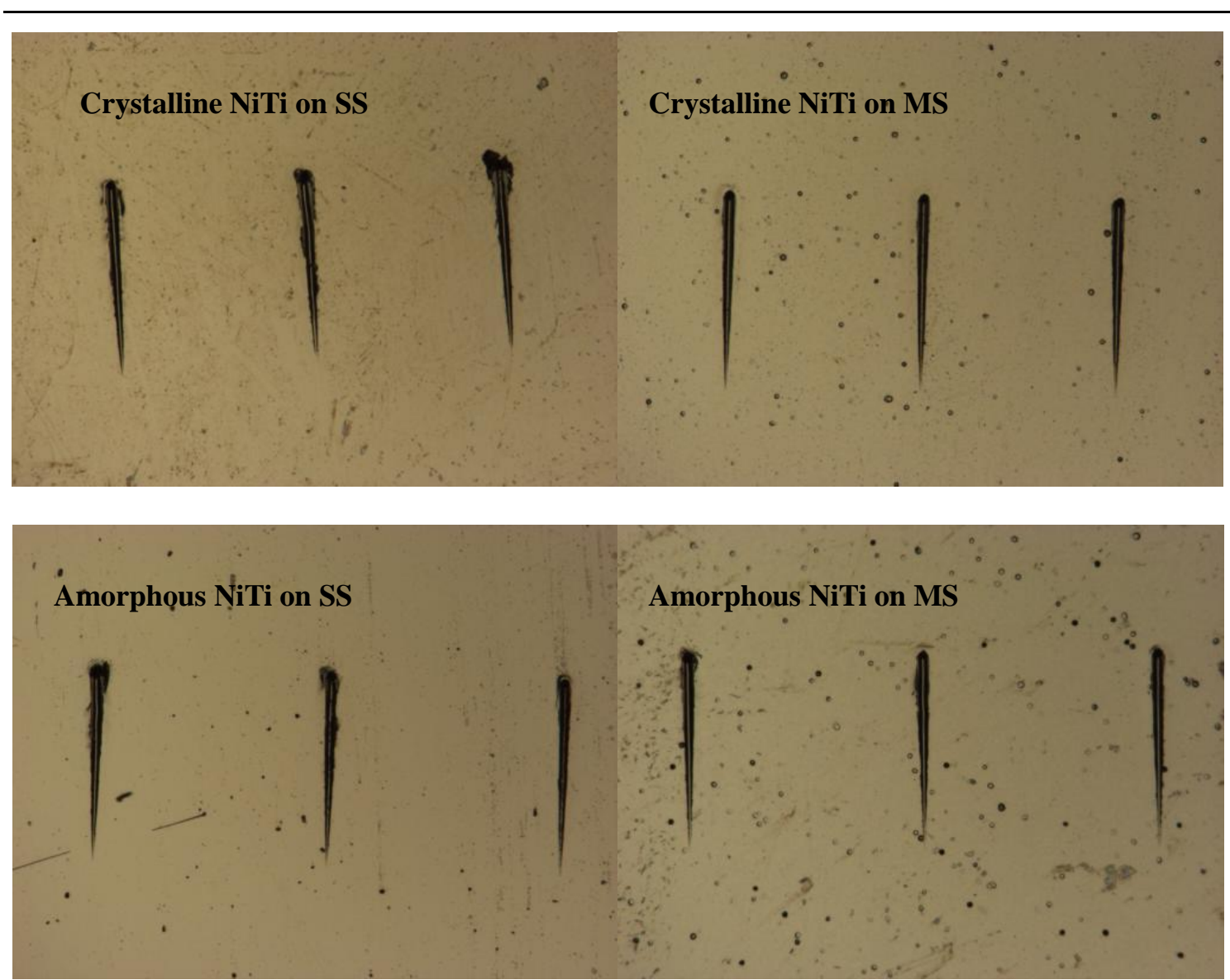

Figure 8.16: Optical images of scratch tests with $500 \mathrm{mN}$ ramping force on constrained NiTi thin films on different substrate materials $\left(776 \times 578 \mu \mathrm{m}^{2}\right)$. 


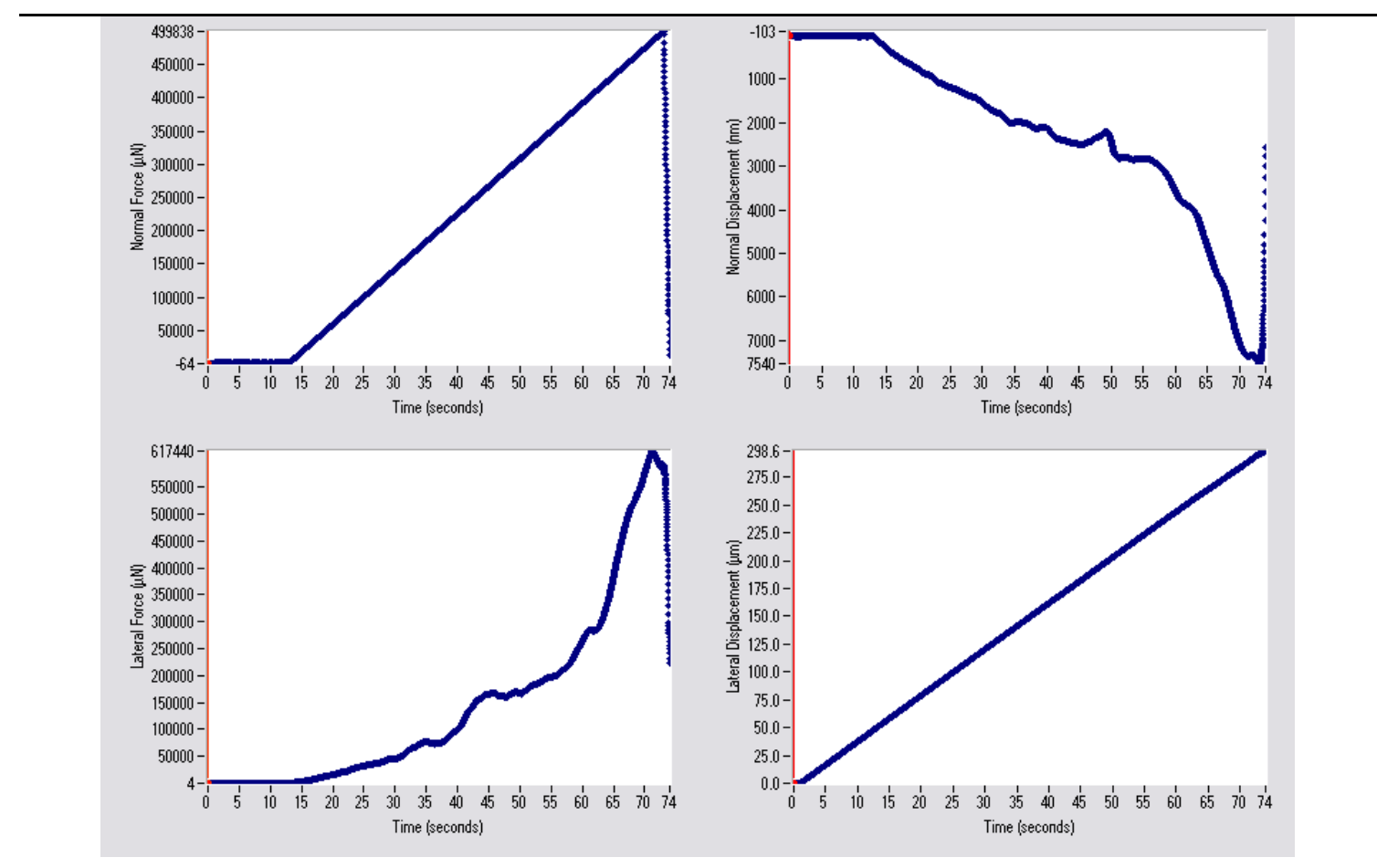

Figure 8.17: Plots of normal force, normal displacement, lateral force, and lateral displacement versus time from a representative $500 \mathrm{mN}$ ramping force scratch test on crystalline NiTi film on stainless steel.
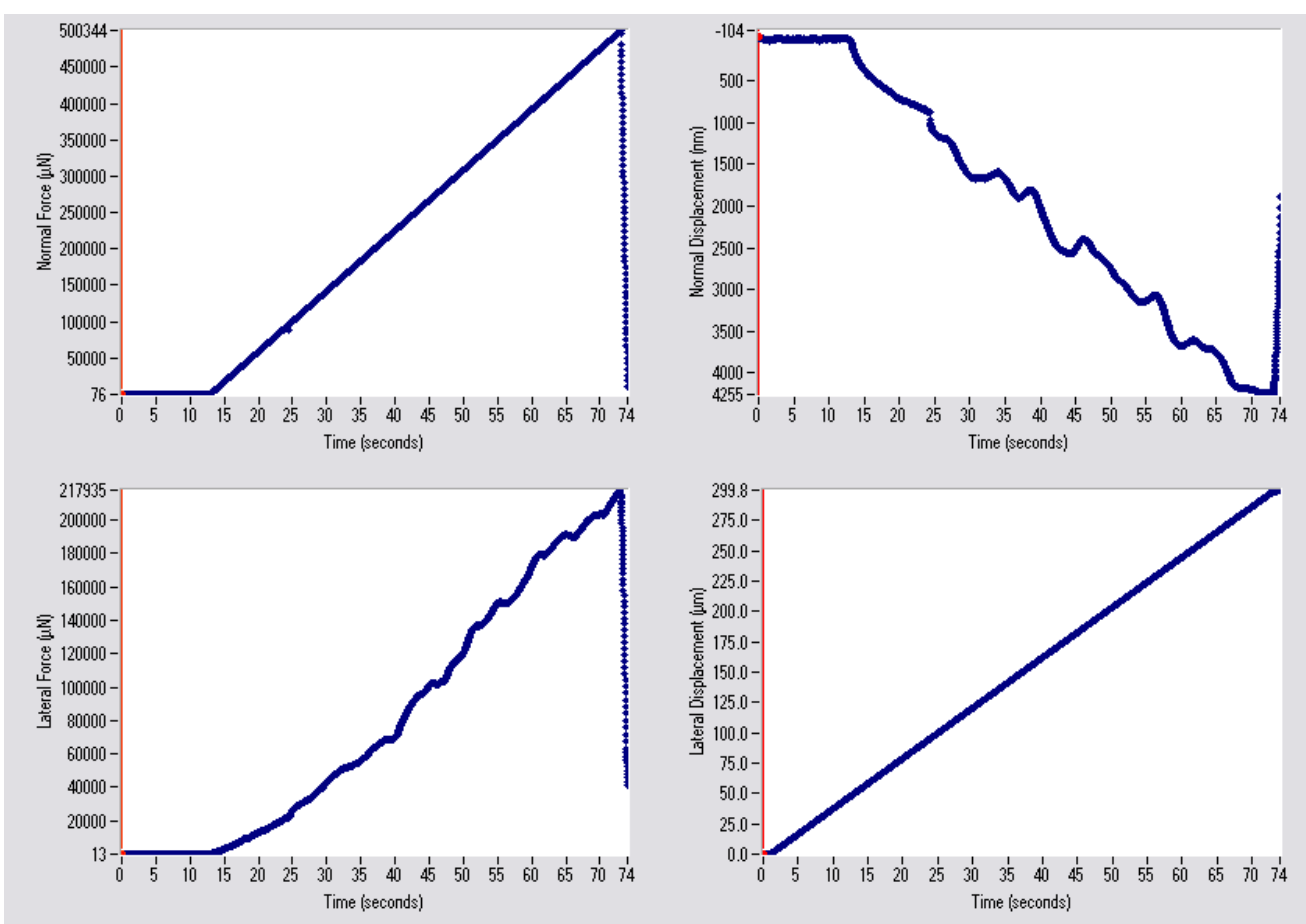

Figure 8.18: Plots of normal force, normal displacement, lateral force, and lateral displacement versus time from a representative $500 \mathrm{mN}$ ramping force scratch test on crystalline NiTi film on mild steel. 

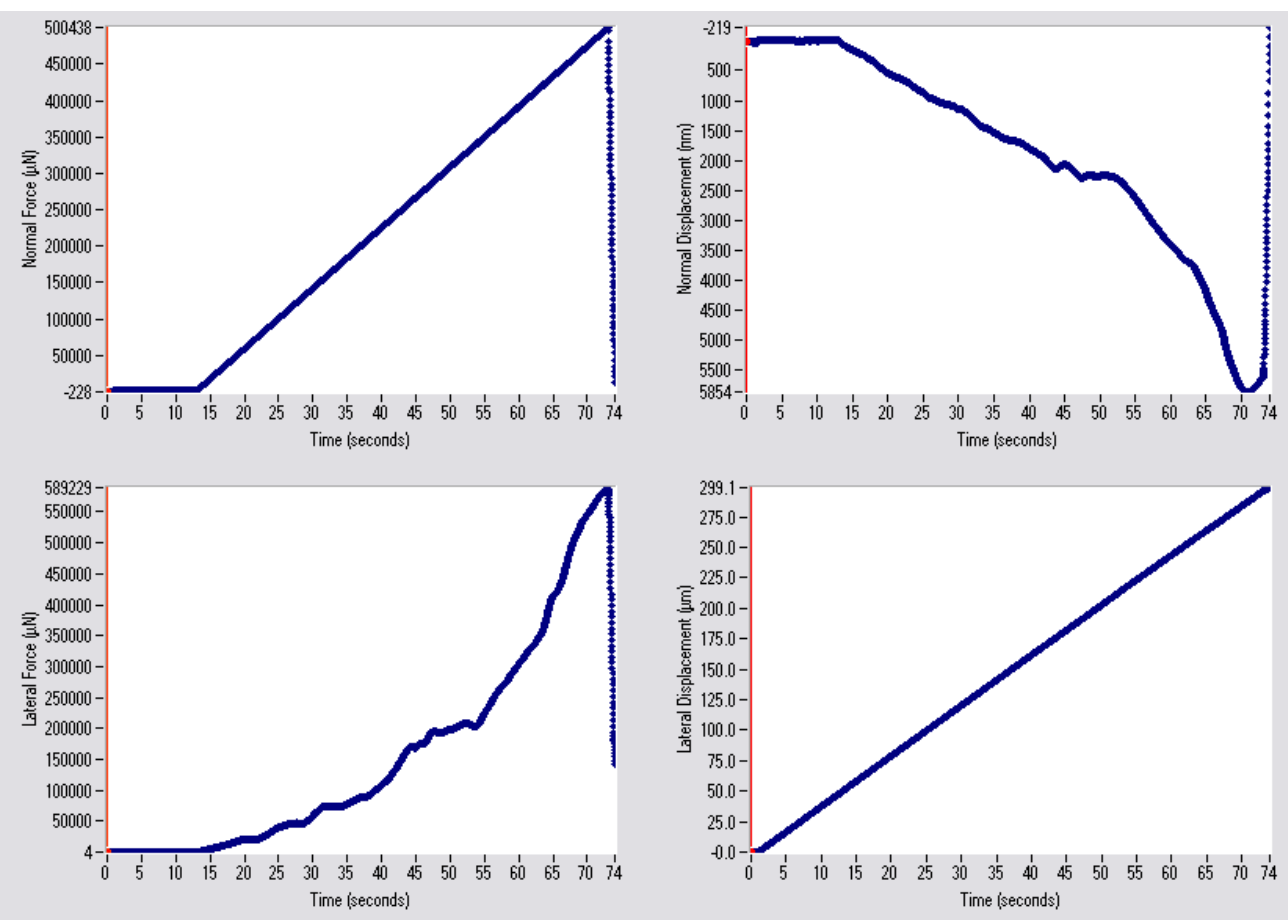

Figure 8.19: Plots of nomal force, normal displacement, lateral force, and lateral displacement versus time from a representative $500 \mathrm{mN}$ ramping force scratch test on amorphous NiTi film on stainless steel.
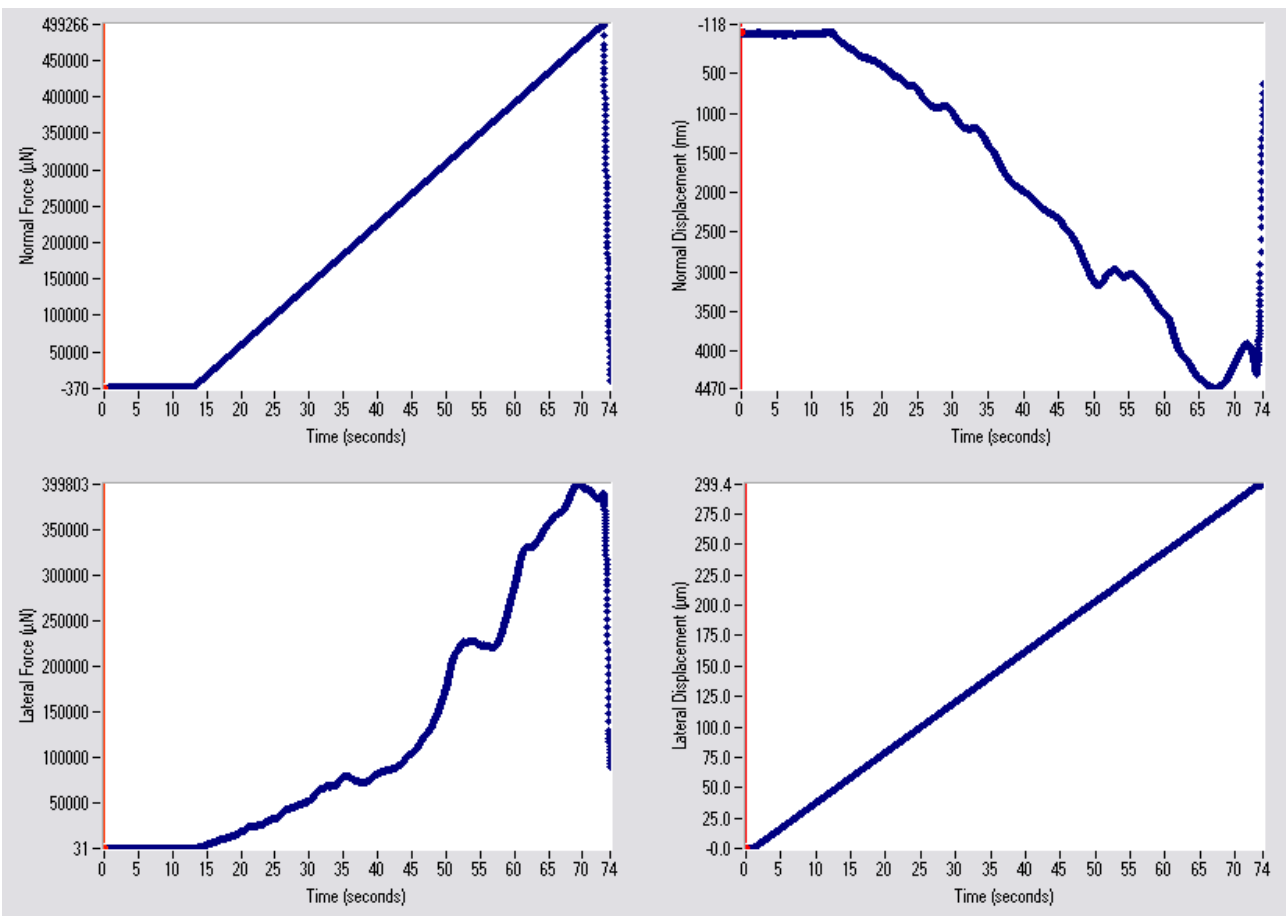

Figure 8.20: Plots of normal force, normal displacement, lateral force, and lateral displacement versus time from a representative $500 \mathrm{mN}$ ramping force scratch test on amorphous NiTi film on mild steel. 
500mN Ramping Force Scratches on Each Sample

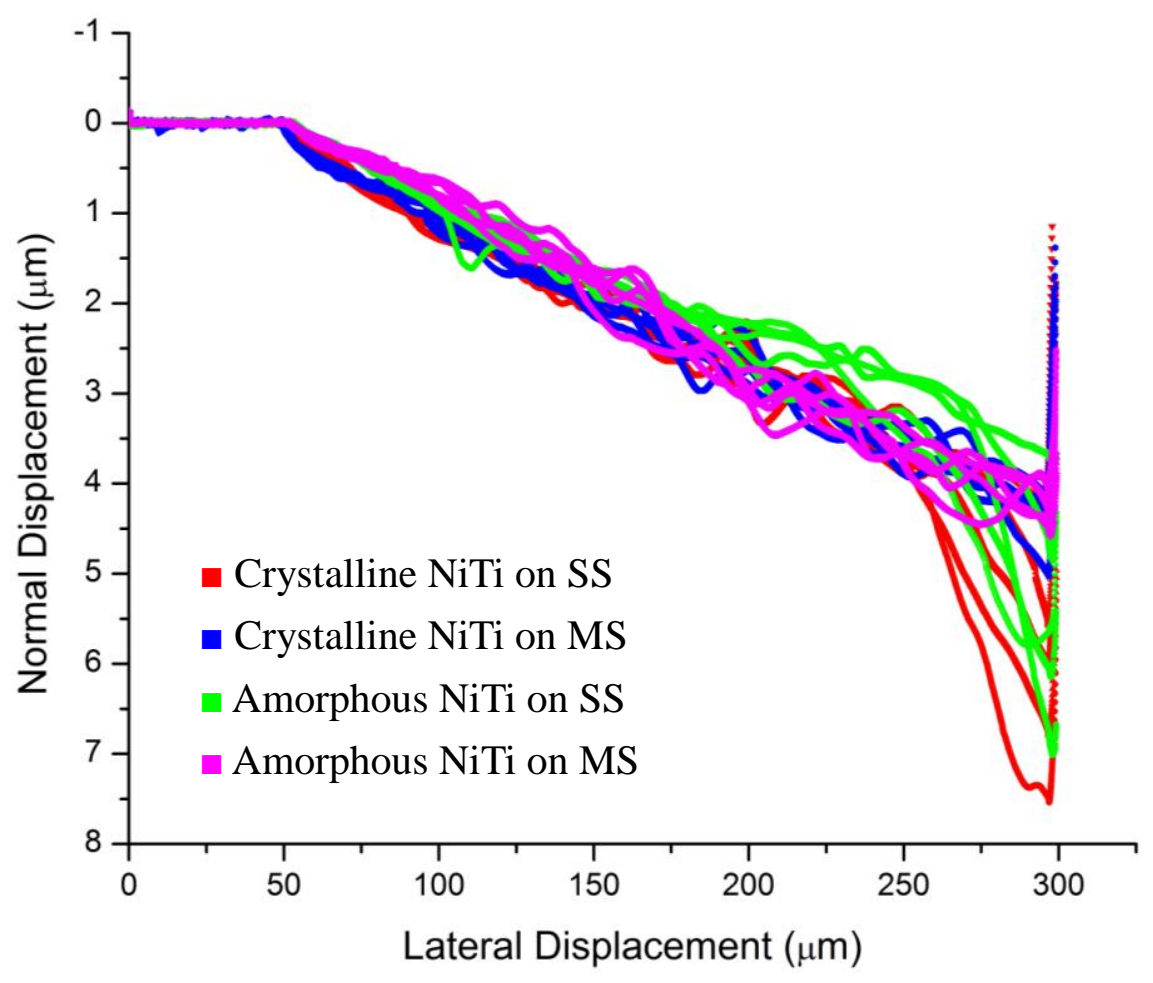

Figure 8.21: A TriboAnalysis ${ }^{\mathrm{TM}}$ plot of normal displacement versus lateral displacement from the $500 \mathrm{mN}$ ramping force scratch tests performed on constrained NiTi films on different substrate materials. 


\section{Chapter 9}

\section{Cavitation Erosion Resistance of NiTi Thin Films}

\subsection{Cavitation erosion resistance of NiTi bulk alloy, austenitic stainless steel and equiatomic NiTi thin films}

Amongst the NiTi thin films with different compositions, near-equiatomic NiTi is expected to show better cavitation erosion resistance than Ti-rich and Ni-rich NiTi because of its room temperature thermoelastic martensitic transformation and lack of precipitates like $\mathrm{Ni}_{3} \mathrm{Ti}$ and $\mathrm{NiTi}_{2}$. Therefore, a near-equiatomic NiTi thin film was first examined for its cavitation erosion resistance and compared with two reference materials, an austenitic 316 stainless steel and a NiTi sample from the target material.

Figure 9.1shows the surface morphologies of the stainless steel, NiTi bulk alloy and near-equiatomic NiTi thin film before cavitation erosion testing and Figure 9.2 displays their surfaces after 4 hours testing. Erosion of the stainless steel is characterized by deep and irregular pitting (Figure 9.2 (a) and (b)), whereas there is no obvious sign of erosion of the NiTi bulk alloy (Figure 9.2 (c) and (d)). The isolated pits shown at high magnification in Figure 9.2 (d) possibly developed from surface pits or large precipitates in the original sample. For the NiTi thin film shown in Figure 9.2 (e), no pits were evident after 4 hours, but surface dimples are present that could have arisen from substrate plastic flow, as the film is less than $2 \mu \mathrm{m}$ thick. The high magnification 
image (Figure 9.2 (f)) shows the surface dents that give rise to the ripple pattern observed at lower magnification.
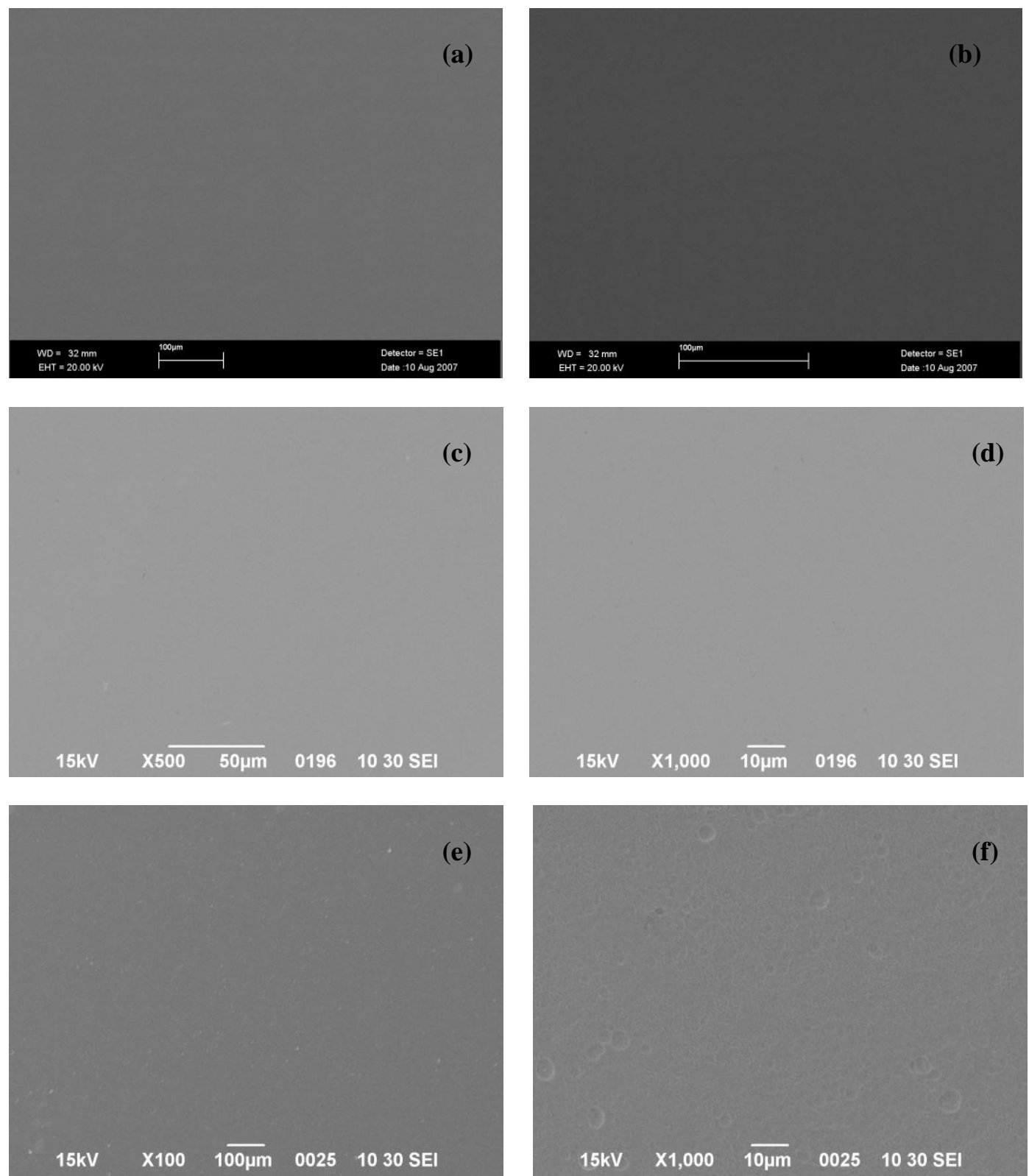

Figure 9.1: Low and high magnification SEM images before cavitation erosion testing. Stainless steel 316 (a) and (b); NiTi bulk alloy (c) and (d); Near-equiatomic NiTi thin film (e) and (f). 

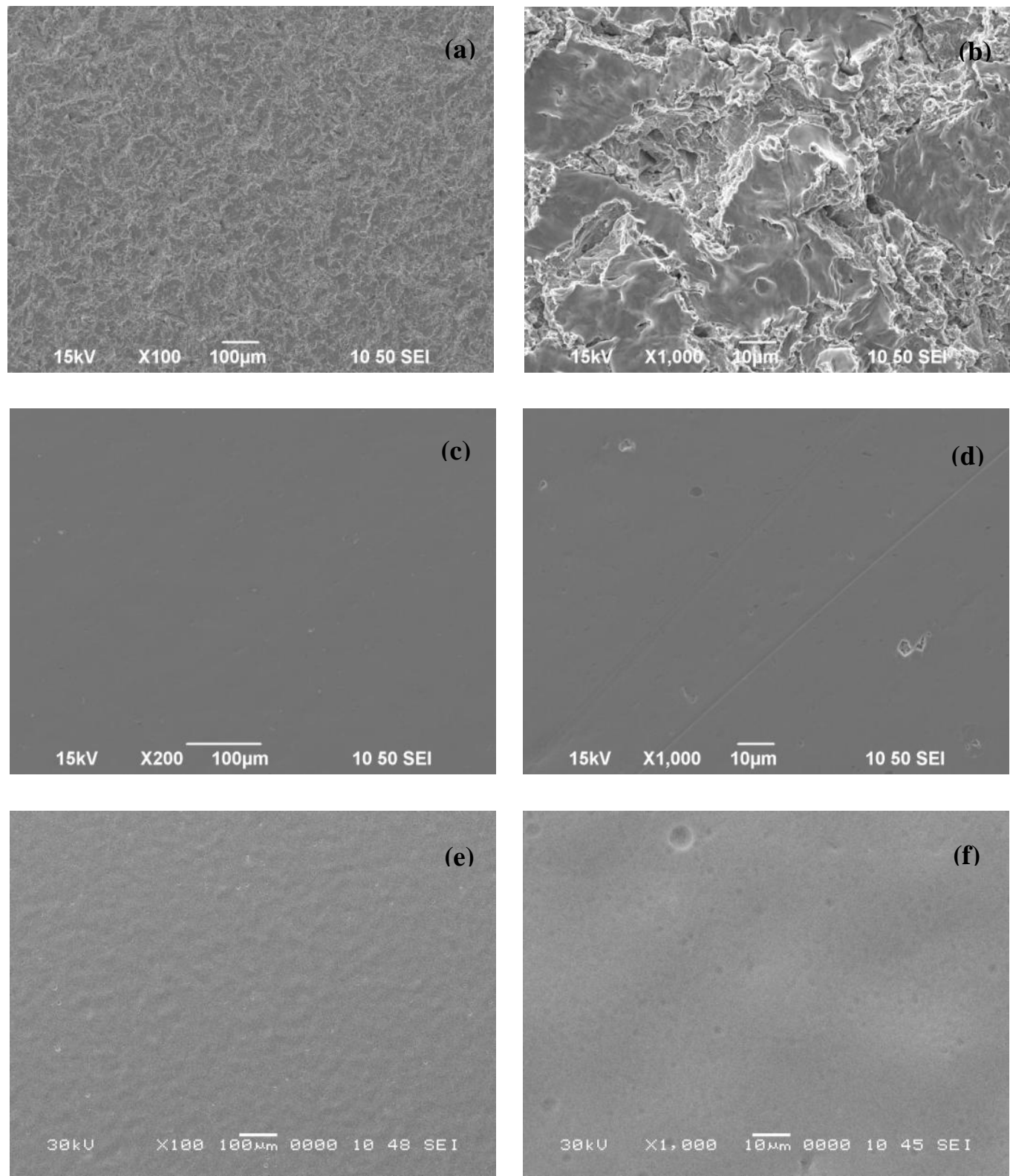

Figure 9.2: Low and high magnification SEM images after 4 hours cavitation erosion testing. Stainless steel 316 (a) and (b); NiTi bulk alloy (c) and (d); Near-equiatomic NiTi thin film (e) and (f).

Figure 9.3 shows the morphologies of surfaces of the austenite stainless steel, NiTi bulk and NiTi thin film on mild steel at the end of 10 hours erosion testing. The surface of stainless steel was eroded severely, showing deep holes (Figure 9.3 (a) and (b)). Localized pits were observed on the surface of the NiTi bulk alloy at high magnification 
(Figure $9.3(\mathrm{~d})$ ). The ripple effect in the thin film sample became more obvious after 10 hours of cavitation (Figure 9.3 (e)) and micro-cracking was found at higher magnification (Figure 9.3 (f)). It is likely that plastic deformation of the substrate under cavitation conditions eventually led to localized cracking of the thin film. Figure 9.3 (g) shows the cross-section of a pit in a NiTi thin film. After the coating was cracked, the substrate underneath was exposed to liquid and eroded by cavitation. It also evident that the NiTi thin film is capable of protecting the substrate from cavitation erosion for a significant period before the thin film is penetrated by erosion.
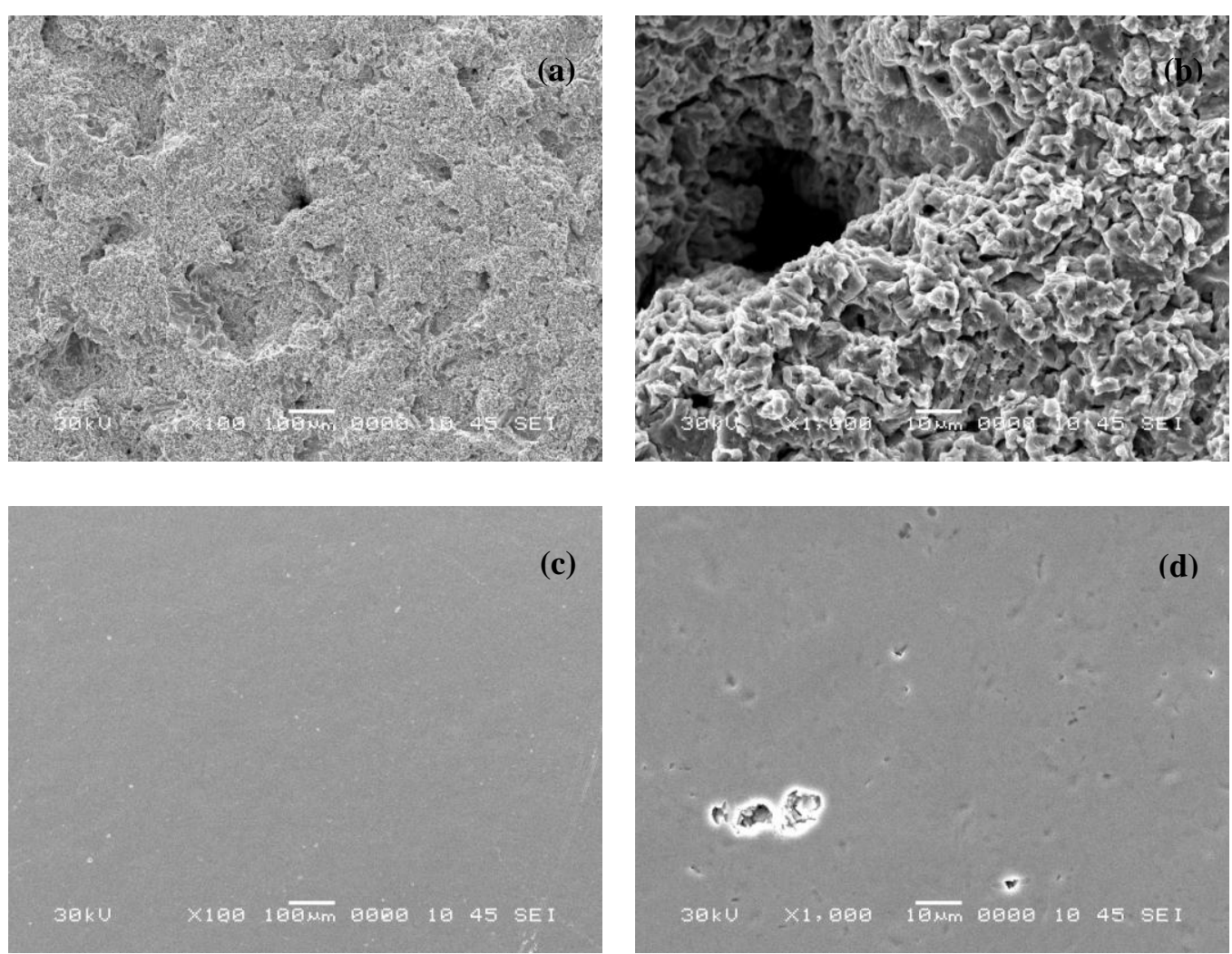

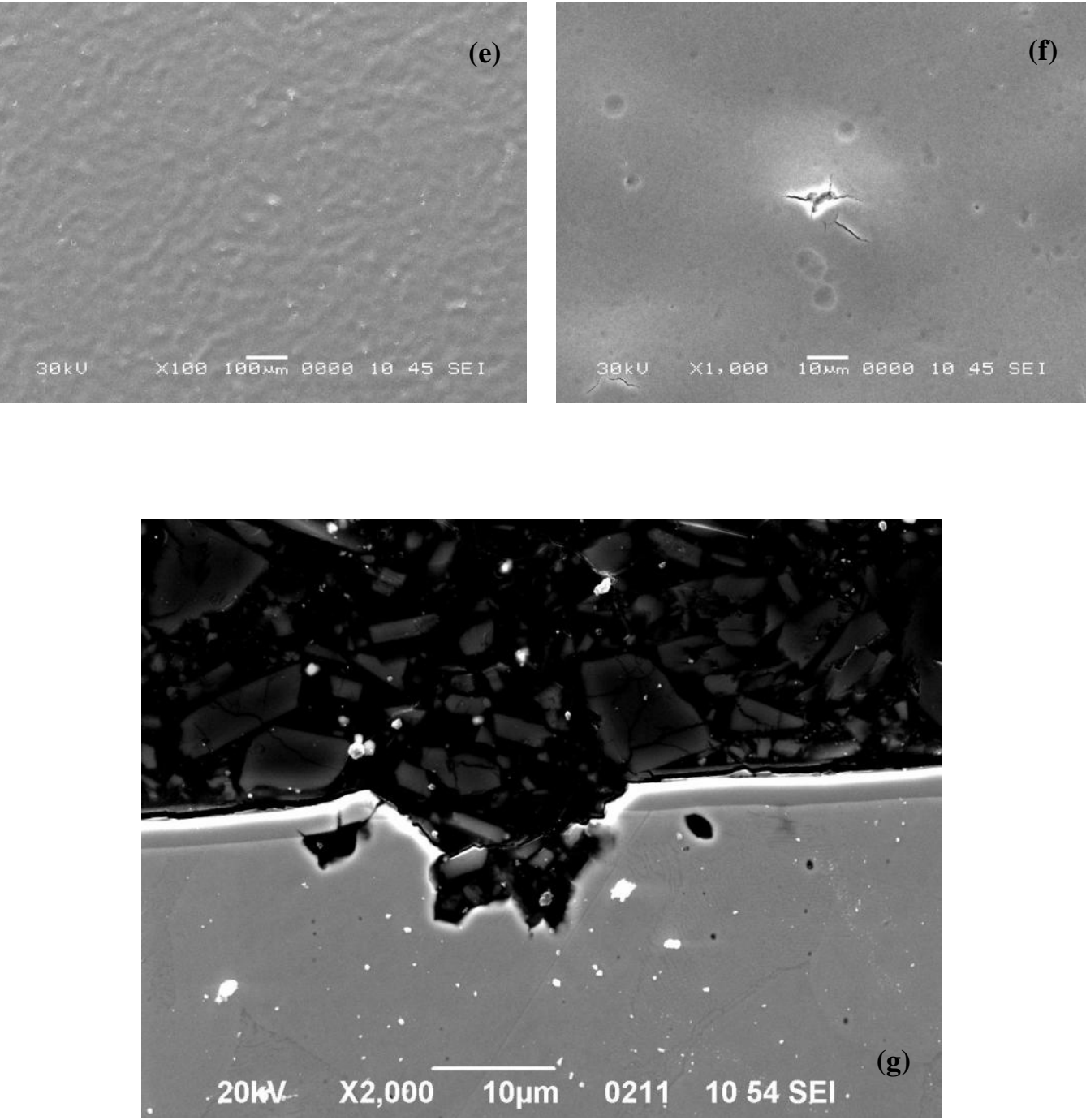

Figure 9.3: Low and high magnification SEM images after 10 hours cavitation erosion testing. Stainless steel 316 (a) and (b); NiTi bulk alloy (c) and (d); Near-equiatomic NiTi thin film (e) and (f); (g) cross-sectional view of a pit in the NiTi thin film that extended into the substrate.

The surface topographies of the stainless steel, NiTi bulk alloy and the near-equiatomic NiTi thin film after 13 hours of cavitation testing are presented in Figure 9.4. Erosion continued on the surface of the stainless steel and deformation ridges started to appear, as shown in Figure 9.4 (a) and (b). Pits in the NiTi bulk alloy are visible at low magnification in Figure 9.4 (c) and at higher magnification in Figure 9.4 (d). For the 
NiTi thin film, more cracks are visible at low magnification in Figure 9.4 (e). It is clear from Figure 9.4 (f) that the micro-crack defects originate in large dimples. Thus, it is inferred that the failure of the NiTi thin film is caused by accumulated plastic deformation of the substrate as a result of loading and unloading effects from cavitation and the associated stressing of the film that results in locailised fracture.
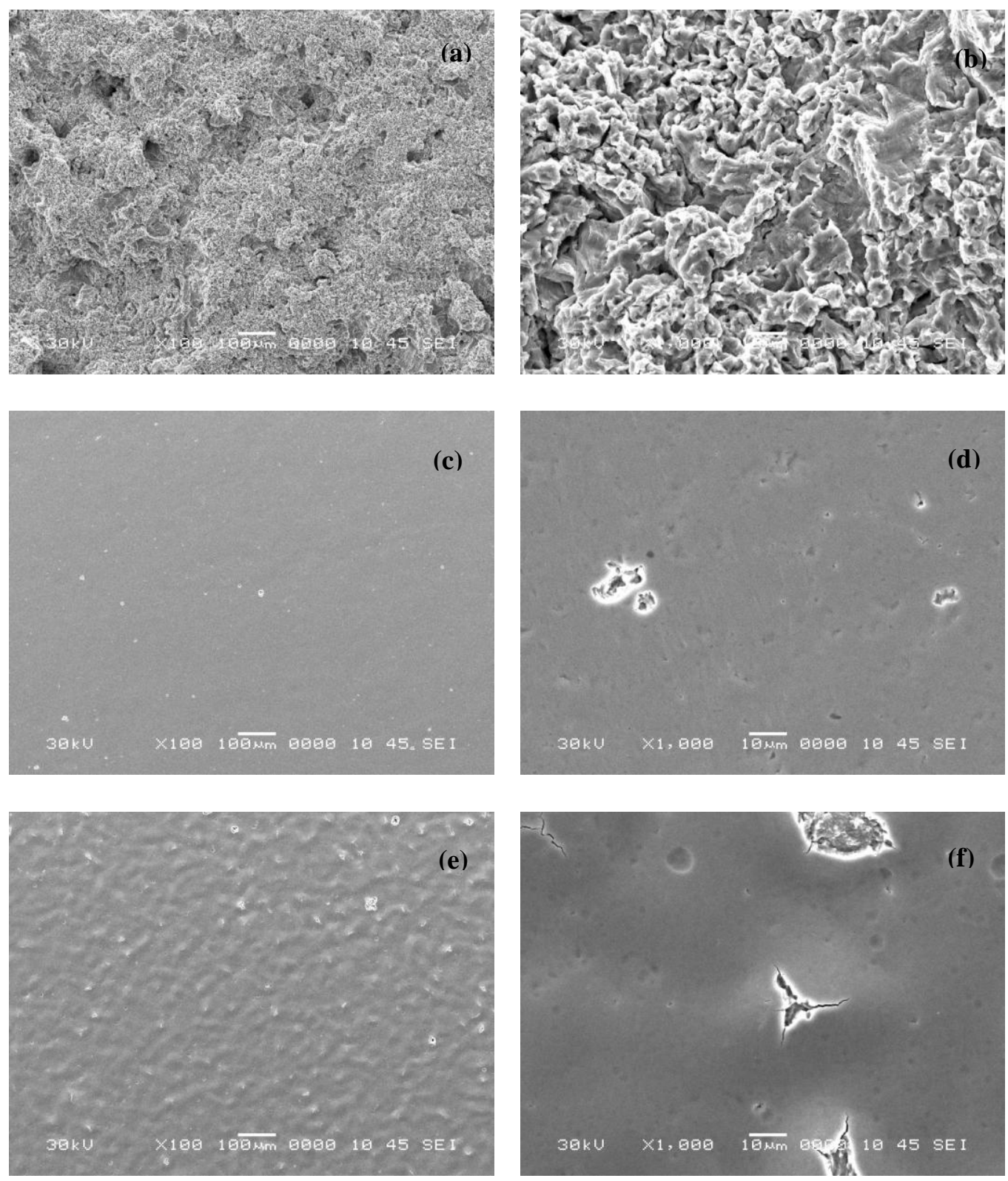

Figure 9.4: Low and high magnification SEM images after 13 hours cavitation erosion testing. Stainless steel 316 (a) and (b); NiTi bulk alloy (c) and (d); Near-equiatomic NiTi thin film on mild steel (e) and (f). 
Figure 9.5 shows SEM images of the eroded surfaces of the NiTi thin film, stainless steel and NiTi bulk sample after 20 hours erosion testing. The 316 stainless steel exhibited a deeply eroded surface (Figure 9.5 (a) and (b)). Small pits are clearly visible on the surface of the NiTi bulk alloy (Figure 9.5 (d)). Pitting of the NiTi thin film increased rapidly, with pits becoming deeper and wider, Figure 9.5 (e) and (f). The cavitation erosion damage increased dramatically around the existing pits, where cavitation bubbles preferentially nucleated and caused accelerated erosion [106]. EDS analysis from the bottom of the pits showed a concentration of $99 \% \mathrm{Fe}$, indicating that the TiNi film had been perforated and that the underlying mild steel substrate was being severely eroded.
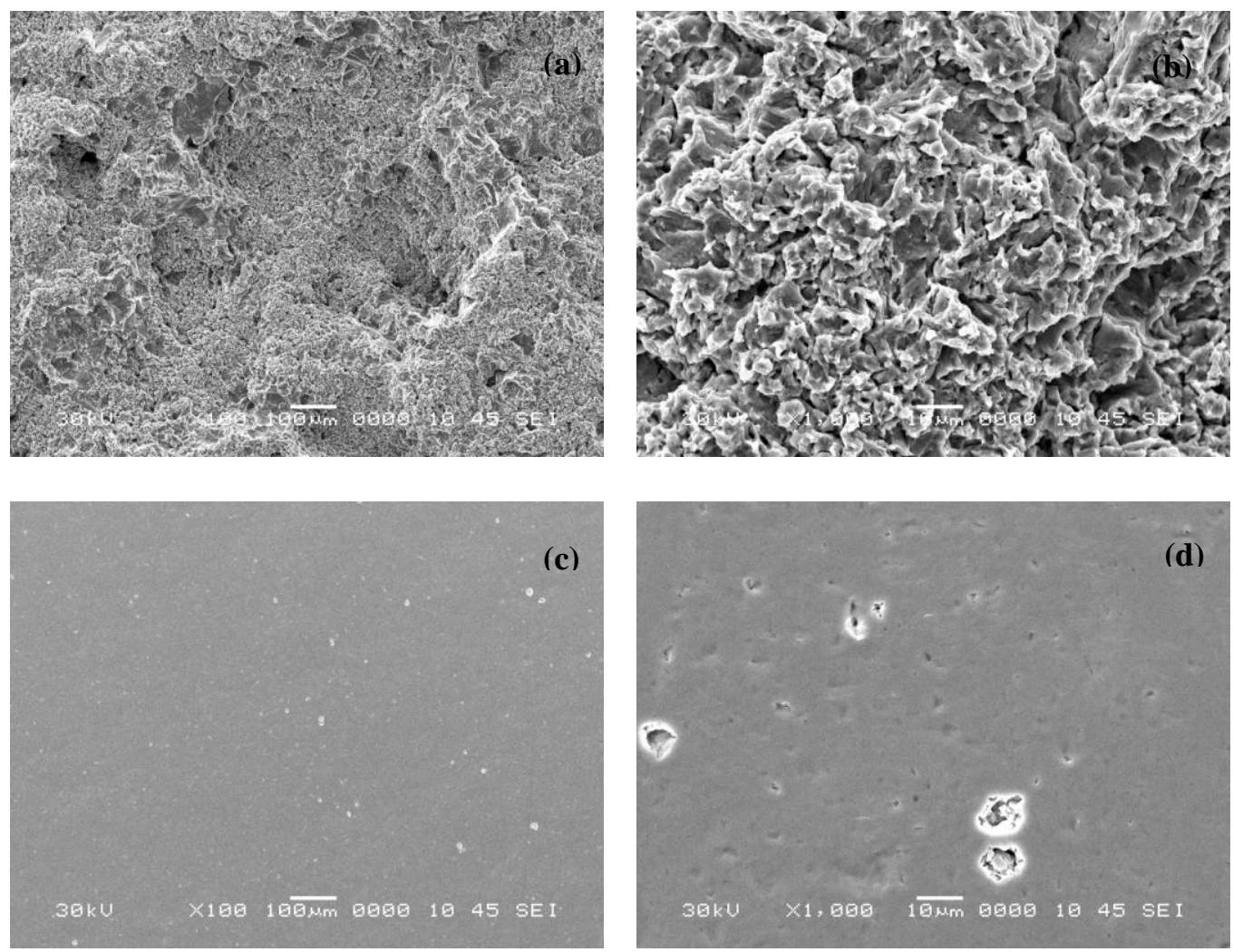

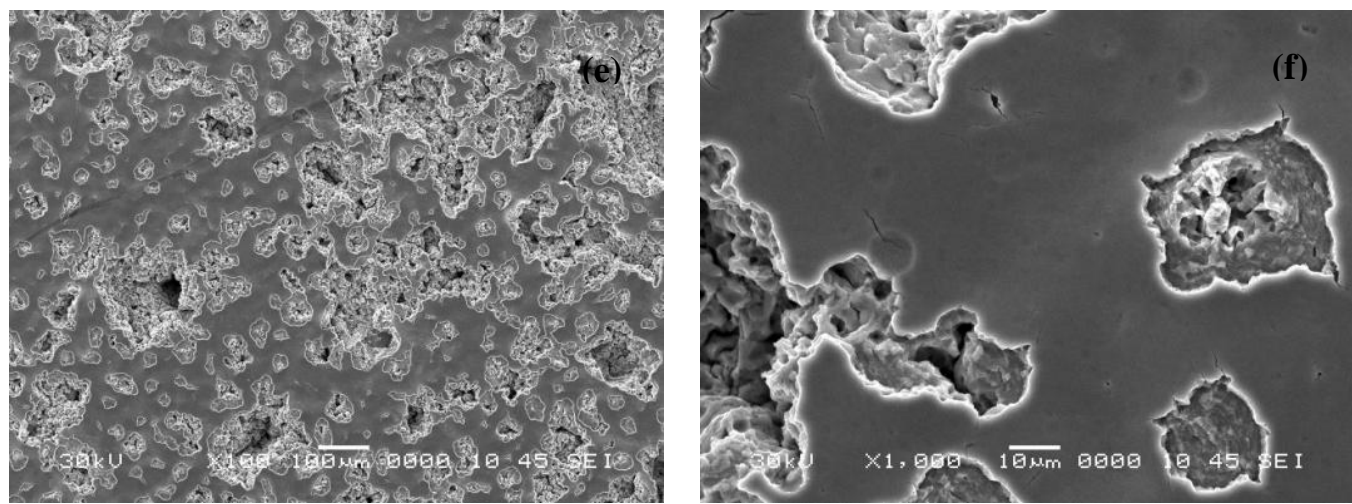

Figure 9.5: Low and high magnification SEM images after 20 hours cavitation erosion testing. Stainless steel 316 (a) and (b); NiTi bulk alloy (c) and (d); Near-equiatomic NiTi thin film (e) and (f).

Figure 9.6 compares the mass loss of 316 stainless steel, NiTi bulk alloy and the near-equiatomic NiTi thin film during testing. In the first three hours, there was no obvious mass loss on all the three samples and this period is usually referred to as the incubation time [106]. After the incubation period, stainless steel started losing mass rapidly, especially after 7 hours, with the erosion rate increasing dramatically. There was a $104 \mathrm{mg}$ loss in mass after 20 hours of erosion testing. In contrast, NiTi bulk alloy showed no obvious cumulative mass loss even after 20 hours although there are minor visible pits on the surface (Figure 9.5 (d)). The mass loss rate of the NiTi thin film was very slow and the film lost only $5 \mathrm{mg}$ at the end of 15 hours. The loss rate increased slowly after 15 hours and the final mass loss was $11 \mathrm{mg}$ at the end of testing. 


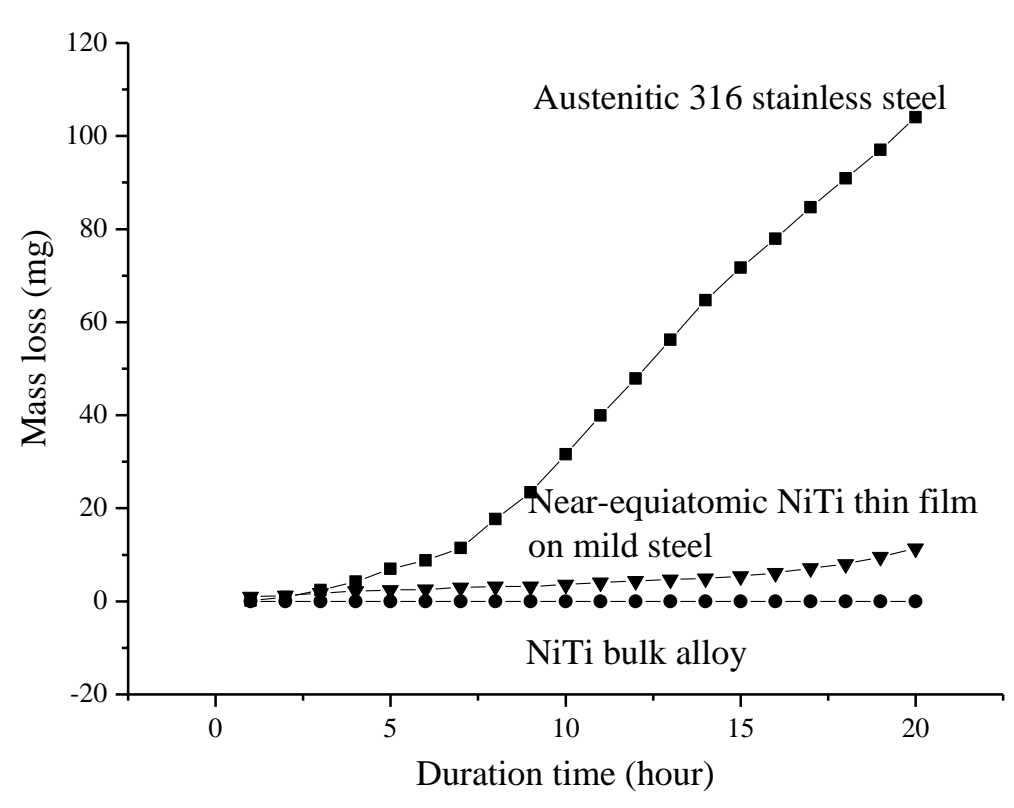

Figure 9.6: Mass loss of NiTi thin film, 316 austenitic stainless steel and NiTi bulk as a function of cavitation exposure time.

It is obvious that the NiTi bulk alloy is highly resistant to cavitation erosion as shown by the exceptionally long incubation periods [107]. However, the high cost and poor machinability [108] of the NiTi alloy exclude its application for most bulk components. Although austenitic stainless steel is widely used in hydraulic systems due to its good corrosion resistance, it still shows relatively poor performance in harsh cavitation erosion environments. Based on SEM analysis and the mass loss measurements, near-equiatomic NiTi thin film deposited by FADS shows much better cavitation erosion resistance than the austenitic stainless steel. Moreover, the NiTi thin film exhibits similar cavitation erosion resistance to the NiTi alloy for testing up to 10 hours. Therefore, it can be inferred that near-equiatomic NiTi thin film possesses similar pseudoelasticity, which is essential for the enhanced cavitation erosion resistance of the 
NiTi bulk alloy.

\subsection{Cavitation erosion resistance of NiTi thin films deposited at different substrate temperatures}

NiTi thin films were deposited on mild steel at different temperatures and subjected to cavitation testing for 4 hours. The surface topography of coatings was observed by SEM and compared at both low and high magnification. As shown in Figure 9.7 (a) and (c), a number of pits are visible in the thin films obtained at low temperature. From the images taken at high magnification, Figure 9.7 (b) and (d), the pits seem to originate from the peeling of relatively large pieces of the film rather than by micro-cracking of the film (Figure 9.3 (f) and Figure 9.4 (f)). The peeling of the film might have resulted from the low adhesion force between the amorphous films and the substrate, as indicated by the scratch test discussed in Figure 8.9. Figure 9.7 (e)-(h) show no pits on the thin films deposited at high temperatures after 4 hours erosion testing. 

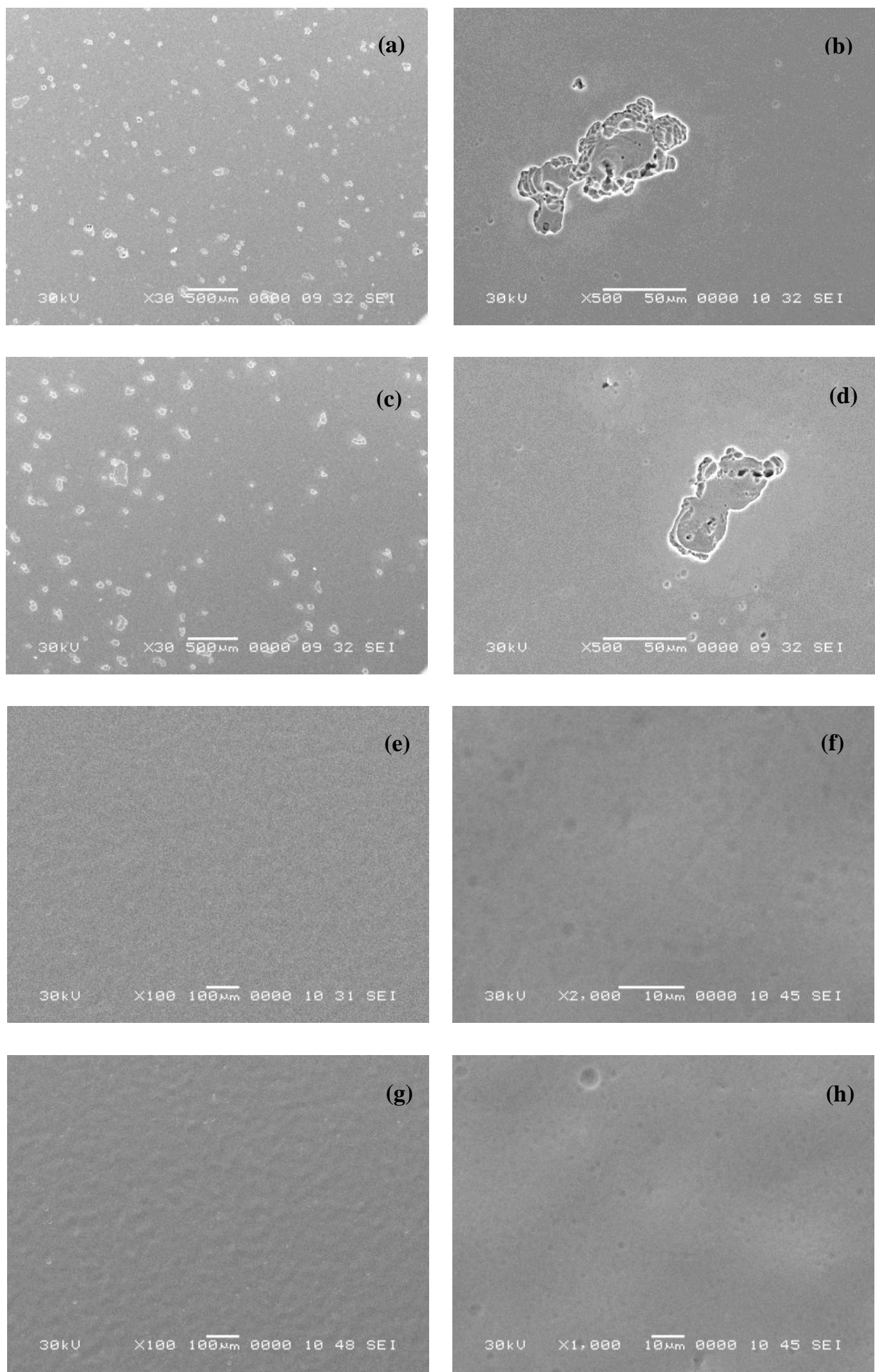

Figure 9.7: Low and high magnification SEM images after 4 hour cavitation erosion testing. NiTi thin film deposited at $130^{\circ} \mathrm{C} \mathrm{(a)} \mathrm{and} \mathrm{(b);} 300^{\circ} \mathrm{C} \mathrm{(c)} \mathrm{and} \mathrm{(d);} 430^{\circ} \mathrm{C} \mathrm{(e)} \mathrm{and}$ (f); and $600^{\circ} \mathrm{C}(\mathrm{g})$ and (h). 
Figure 9.8 displays the surfaces of the thin films at the end of 10 hours erosion testing. As shown in Figure 9.8 (a) and (c), the amorphous thin films obtained at low temperatures contained compact pits, which on viewing at high magnification are large and deep (Figure 9.8 (b) and (d)). The crystalline NiTi thin films deposited at high temperature started to show micro-cracking after 10 hours of erosion testing (Figure 9.8 (f) and (h)), although there was still no obvious sign of erosion at low magnification (Figure $9.8(\mathrm{e})$ and $(\mathrm{g})$ ).
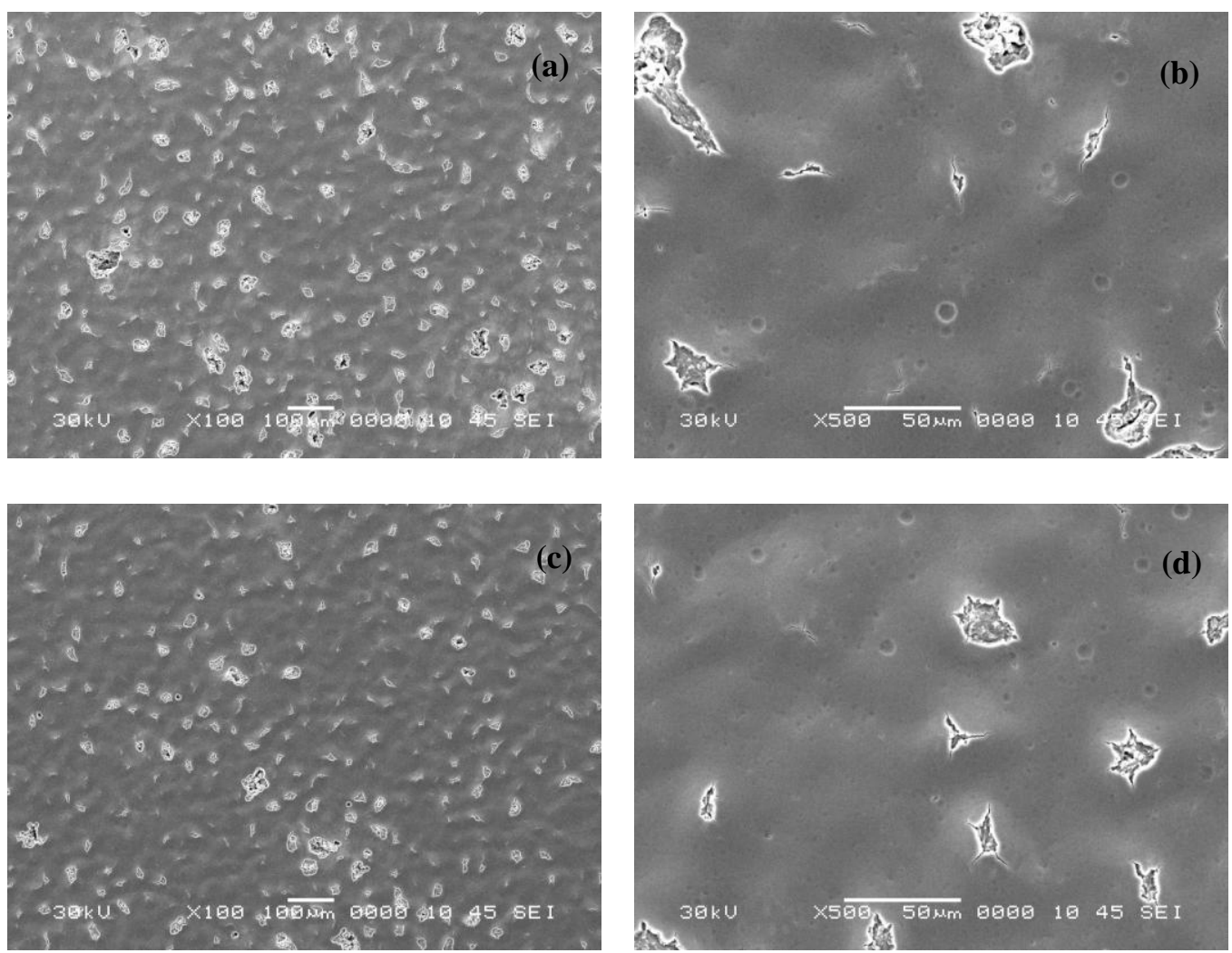

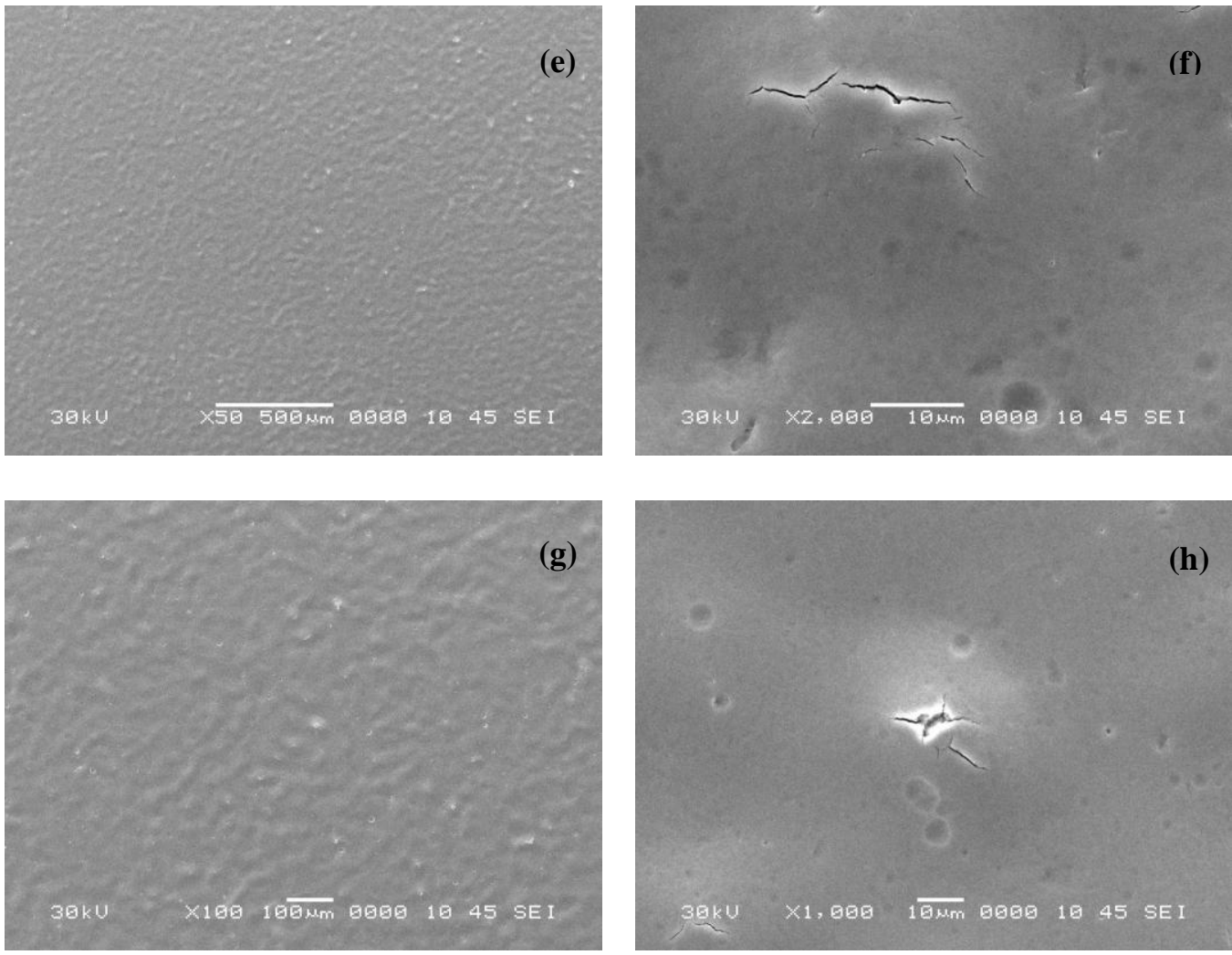

Figure 9.8: Low and high magnification SEM images after 10 hours cavitation erosion testing. NiTi thin film deposited at $130^{\circ} \mathrm{C}$ (a) and (b); $300^{\circ} \mathrm{C} \mathrm{(c)} \mathrm{and} \mathrm{(d);} 430^{\circ} \mathrm{C} \mathrm{(e)} \mathrm{and}$ (f); and $600^{\circ} \mathrm{C}(\mathrm{g})$ and (h).

Figure 9.9 shows the SEM images of the NiTi film surface after 13 hours of cavitation erosion. On the surface of the amorphous thin films in Figure 9.9 (a)-(d), the damaged areas spread out as a result of the further erosion. After 13 hours of erosion, the localized pits became obvious on the crystalline thin films at low magnification in Figure 9.9 (e) and (g), especially on the NiTi film deposited at $600^{\circ} \mathrm{C}$. The defects formed in the centres of dimples or ripples in the film surface, which was resulted from plastic deformation of the substrate. 

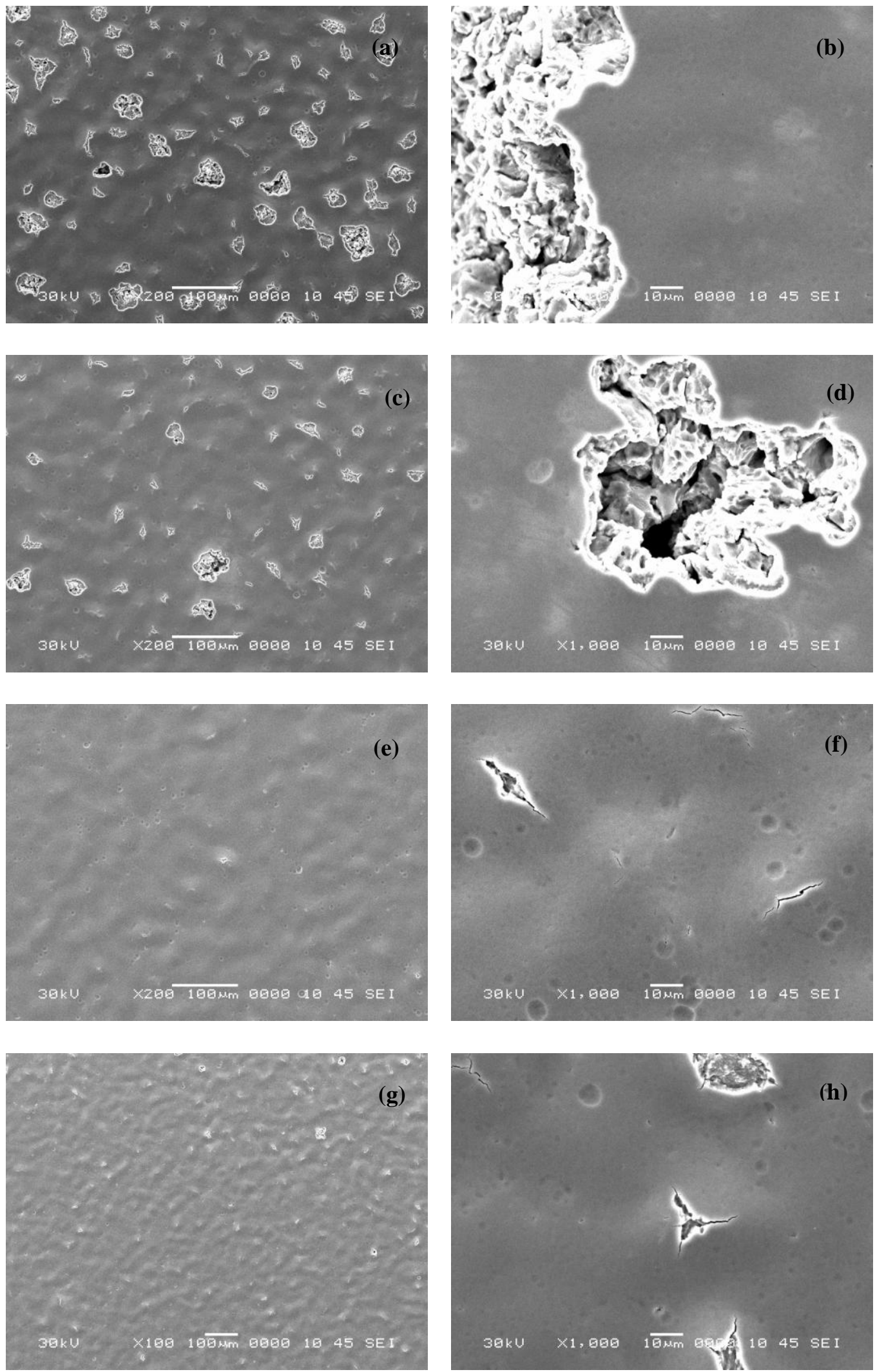

Figure 9.9: Low and high magnification SEM images after 13 hours cavitation erosion testing. NiTi thin film deposited at $130^{\circ} \mathrm{C}$ (a) and (b); $300^{\circ} \mathrm{C} \mathrm{(c)} \mathrm{and} \mathrm{(d);} 430^{\circ} \mathrm{C}(\mathrm{e})$ and (f); and $600^{\circ} \mathrm{C}(\mathrm{g})$ and (h). 
After 20 hours exposure to cavitation erosion, the surfaces of the NiTi thin films deposited at different temperatures are compared in Figure 9.10. Clearly, pits in amorphous thin films (Figure 9.9 (b) and (d)) spread out further and came into contact with each other. Consequently, the whole layer of the thin film was almost peeled away completely by cavitation erosion (Figure 9.10 (a) and (c)). For the crystalline films, the cavitation erosion damage was more severe on the NiTi thin film deposited at the highest temperature of $600^{\circ} \mathrm{C}$ (Figure $9.10(\mathrm{~g})$ and (h)), compared with the film obtained at $430^{\circ} \mathrm{C}$ (Figure 9.10 (e) and (f)). Due to the lower deposition temperature, the NiTi thin film deposited at $430^{\circ} \mathrm{C}$ possess finer polycrystalline B2 and B19' phases compared to the film obtained at $600^{\circ} \mathrm{C}$. The resistance to cavitation erosion increases continuously with decreasing grain size [109]. 

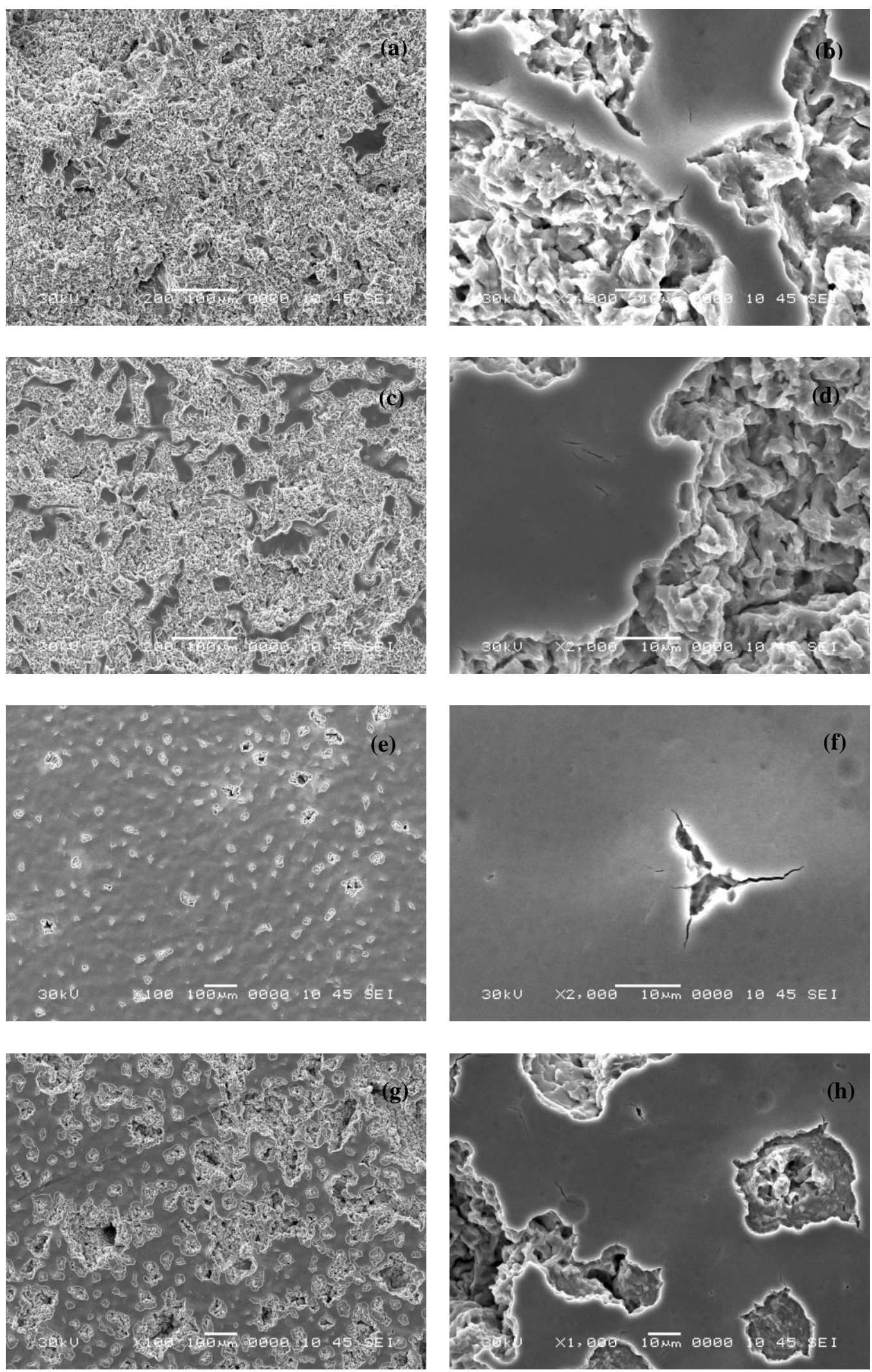

Figure 9.10: Low and high magnification SEM images after 20 hours cavitation erosion testing. NiTi thin film deposited at $130^{\circ} \mathrm{C}$ (a) and (b); $300^{\circ} \mathrm{C} \mathrm{(c)} \mathrm{and} \mathrm{(d);} 430^{\circ} \mathrm{C}(\mathrm{e})$ and (f); and $600^{\circ} \mathrm{C} \mathrm{(g)} \mathrm{and} \mathrm{(h).}$ 
Figure 9.11 compares the mass loss of the NiTi thin films deposited at different substrate temperatures during 20 hours of cavitation erosion. It is clear that the NiTi thin films deposited at low temperatures had a higher loss rate and the mass loss was almost $18 \mathrm{mg}$ after 20 hours of erosion. In contrast, the thin film obtained at $430^{\circ} \mathrm{C}$ lost only around $6 \mathrm{mg}$ and its loss rate remained low during the 20 hours. The mass of the NiTi thin film at $600^{\circ} \mathrm{C}$ began to decrease rapidly after 15 hours and the cumulative mass loss was $11.5 \mathrm{mg}$ after 20 hours. Based on the mass loss curves and the SEM images of the films during the erosion testing, it was found that the sample started to decrease in mass rapidly when the thin film was eroded severely and the dense pits began to connect together under further erosion. After the films were eroded away, the mass loss was mainly from the substrate, which eroded with a significantly higher loss rate.

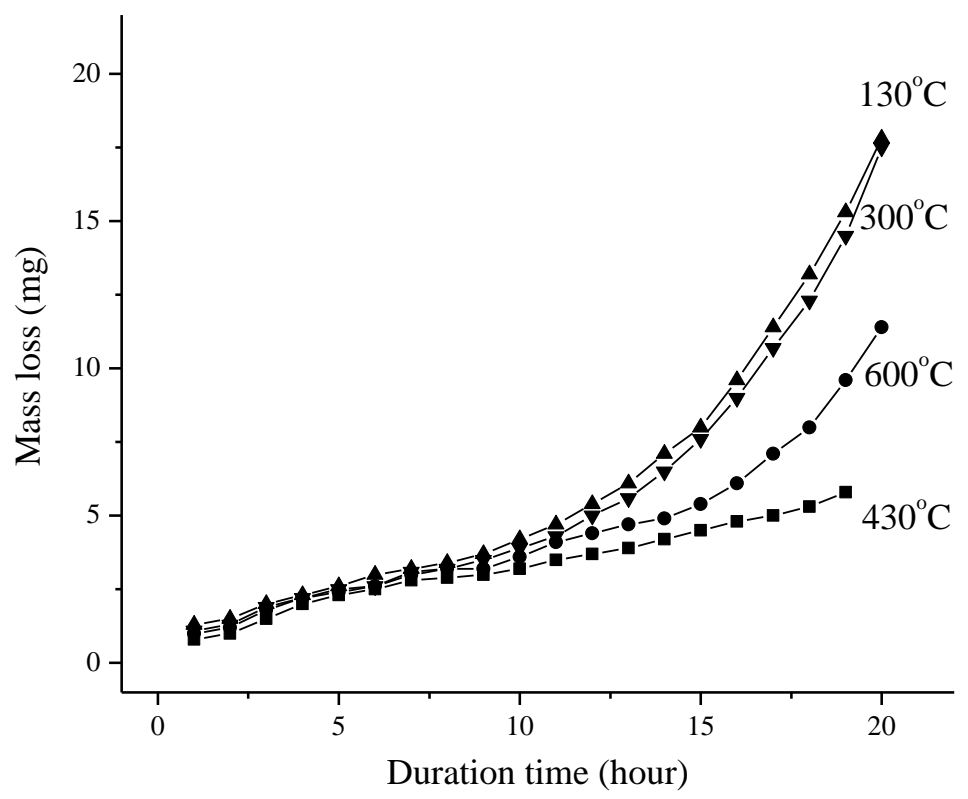

Figure 9.11: Mass loss of NiTi thin films deposited at different substrate temperatures as a function of cavitation exposure time. 
From the SEM results and the mass losses, it can be concluded that the crystalline NiTi thin films deposited at high temperatures possess much more enhanced cavitation erosion resistance than the amorphous thin films obtained at low temperatures. Obviously, the thermoelastic martensite transformation of the crystalline thin films plays an essential role in the cavitation erosion resistance of the NiTi thin films. The thin film deposited at $430^{\circ} \mathrm{C}$ was found to be the most resistant to cavitation erosion compared with films deposited at other temperatures.

\subsection{Cavitation erosion resistance of NiTi thin films deposited at different substrate bias voltages at high substrate temperature $\left(600{ }^{\circ} \mathrm{C}\right)$}

Figure 9.12 shows the surface topography of the as-deposited NiTi thin films obtained at different substrate bias voltages: $50 \mathrm{~V}, 80 \mathrm{~V}, 120 \mathrm{~V}$ and $150 \mathrm{~V}$ at $600^{\circ} \mathrm{C}$. From both the low and high magnification images, it can be seen that all the four thin films are smooth and free of observable defects. 

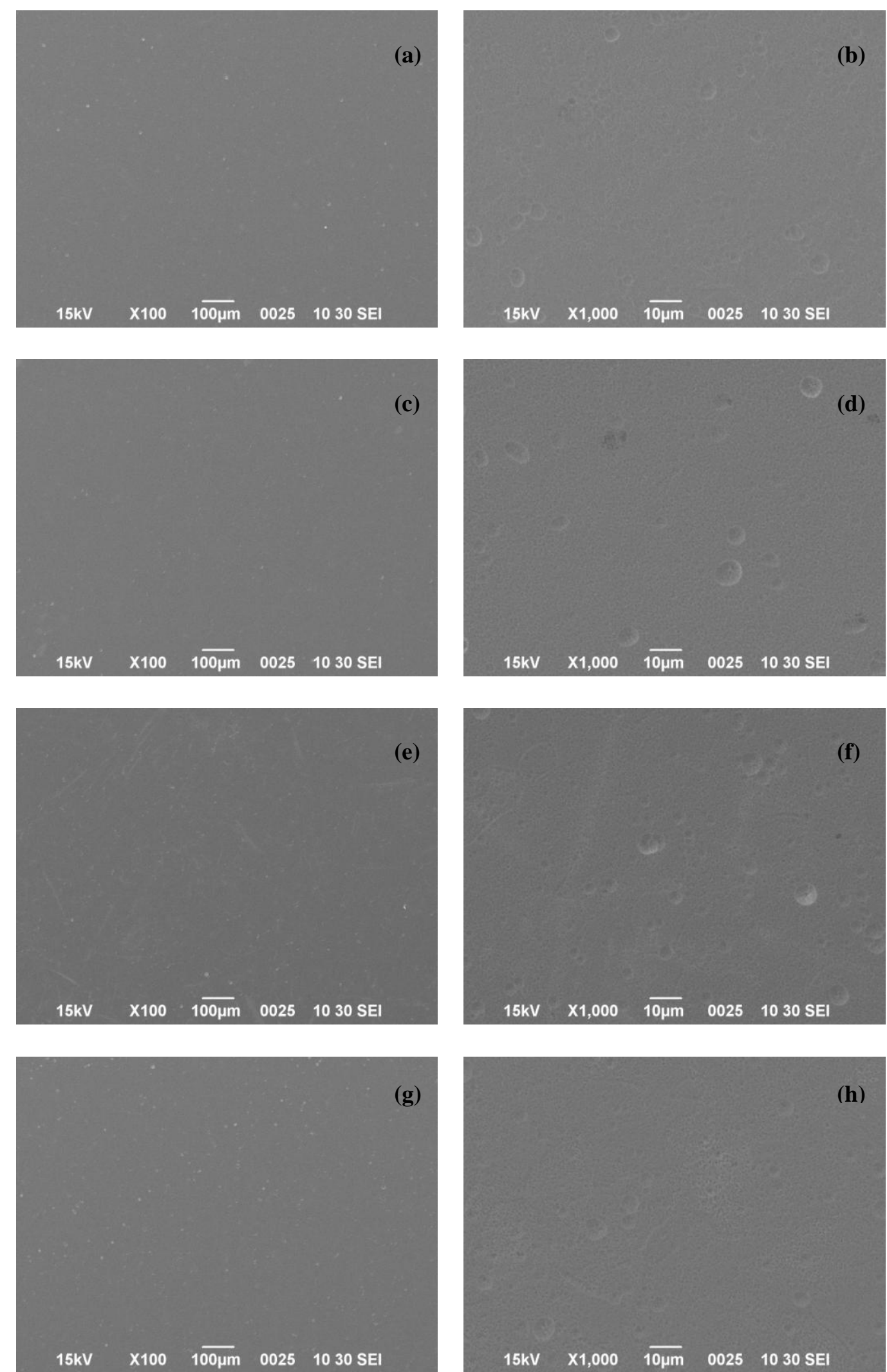

Figure 9.12: Low and high magnification SEM images before cavitation erosion testing. NiTi thin film deposited at $600^{\circ} \mathrm{C}$ with $50 \mathrm{~V} \mathrm{(a)} \mathrm{and} \mathrm{(b);} 80 \mathrm{~V} \mathrm{(c)} \mathrm{and} \mathrm{(d);} 120 \mathrm{~V}$ (e) and (f); and $150 \mathrm{~V}(\mathrm{~g})$ and (h). 
After 4 hours of exposure to the cavitation erosion, it is clear that there were no visible pits on the films deposited at higher substrate bias voltages $(80 \mathrm{~V}, 120 \mathrm{~V}$ and $150 \mathrm{~V})$, Figure 9.13 (b)-(d). However, several pits were evident on the NiTi film obtained at the lowest bias voltage of $50 \mathrm{~V}$ in Figure 9.13 (a). As discussed in relation to Figure 8.14, the adhesion force between the film and substrate is weak for the films deposited at low bias, which probably results in the poorer resistance to cavitation erosion.
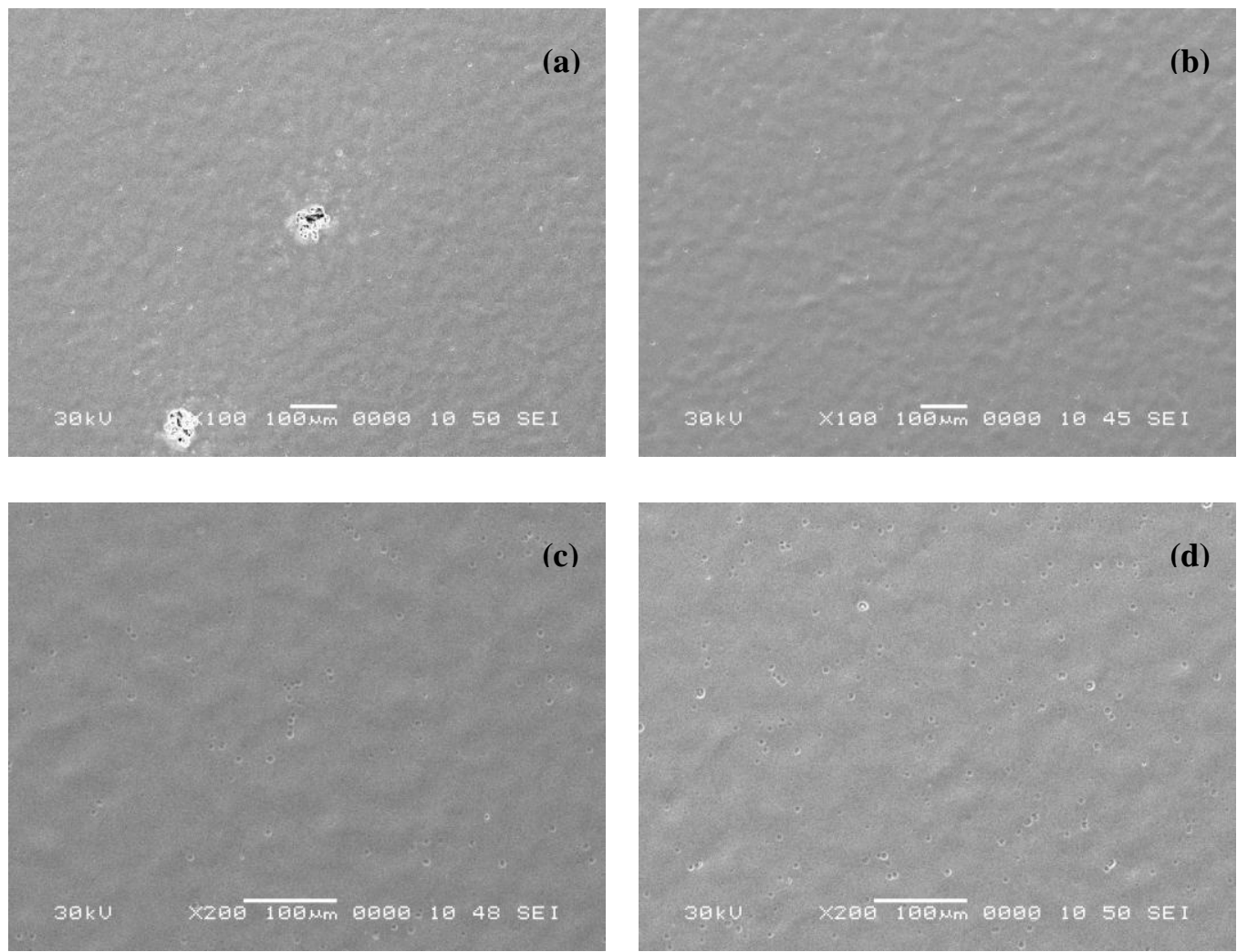

Figure 9.13: SEM images after 4 hours of cavitation erosion testing. NiTi thin film deposited at $600^{\circ} \mathrm{C}$ at $50 \mathrm{~V} \mathrm{(a);80} \mathrm{V} \mathrm{(b);} 120 \mathrm{~V} \mathrm{(c);} \mathrm{and} 150 \mathrm{~V}$ (d).

Figure 9.14 presents the surface images of the NiTi thin films after 10 hours of erosion testing. As shown in Figure 9.14 (a), the pits on the film obtained at $50 \mathrm{~V}$ became wider and deeper due to further erosion. There was still no sign of erosion after 10 hours for 
the film deposited at $80 \mathrm{~V}$ (Figure 9.14 (b)). However, for the thin films obtained at 120 $\mathrm{V}$ and $150 \mathrm{~V}$, surface pits are obvious in Figure 9.14 (c) and (d), especially for the film obtained at $150 \mathrm{~V}$. The relatively poor cavitation erosion resistance of films deposited at high bias voltages could be associated with the consequent high substrate temperatures that results in the large grain sizes.
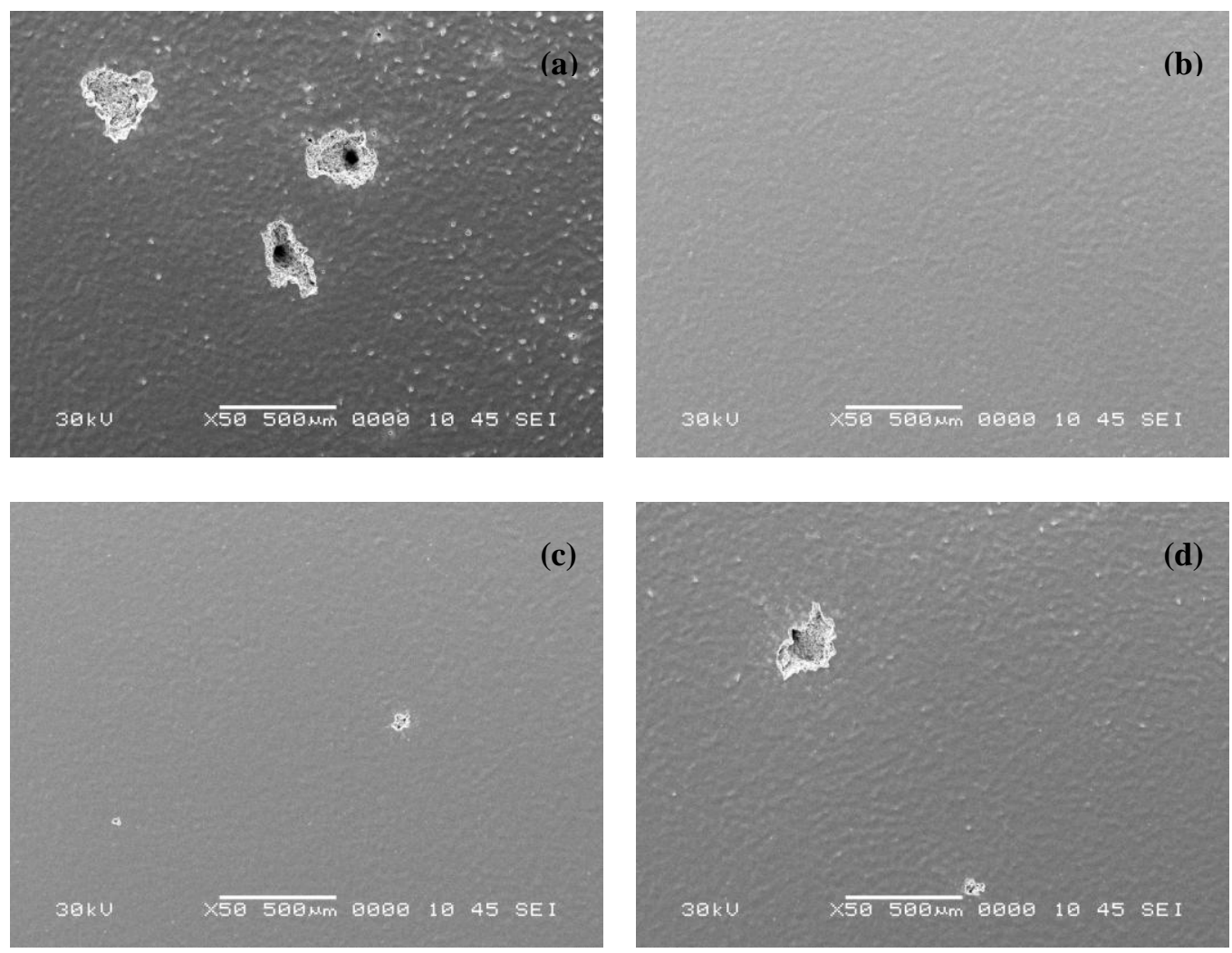

Figure 9.14: SEM images after 10 hours of cavitation erosion testing. NiTi thin film deposited at $600^{\circ} \mathrm{C}$ at $50 \mathrm{~V}(\mathrm{a}) ; 80 \mathrm{~V}(\mathrm{~b}) ; 120 \mathrm{~V}$ (c); and $150 \mathrm{~V}$ (d).

The thin films deposited at different bias voltages were subjected to further erosion testing for 13 hours and their surface topographies are compared in Figure 9.15. It can be seen from Figure 9.15 (a) that the NiTi coating obtained at $50 \mathrm{~V}$ was eroded severely and contained many compact pits. The film obtained at $80 \mathrm{~V}$ started to show small pits after 13 hours (Figure 9.15 (b)). However, relatively large defects were observed on the 
surfaces of the thin film deposited at $120 \mathrm{~V}$ (Figure 9.15 (c)). This may be due to the slightly higher Ni content, which lowers the martensite transformation temperature, as shown in Table 7.3. Thus, a pseudoelastic response to cavitation stresses may be less marked, affecting the resistance to cavitation erosion. A similar pattern was observed on the thin film deposited at $150 \mathrm{~V}$ (Figure 9.15 (d)).
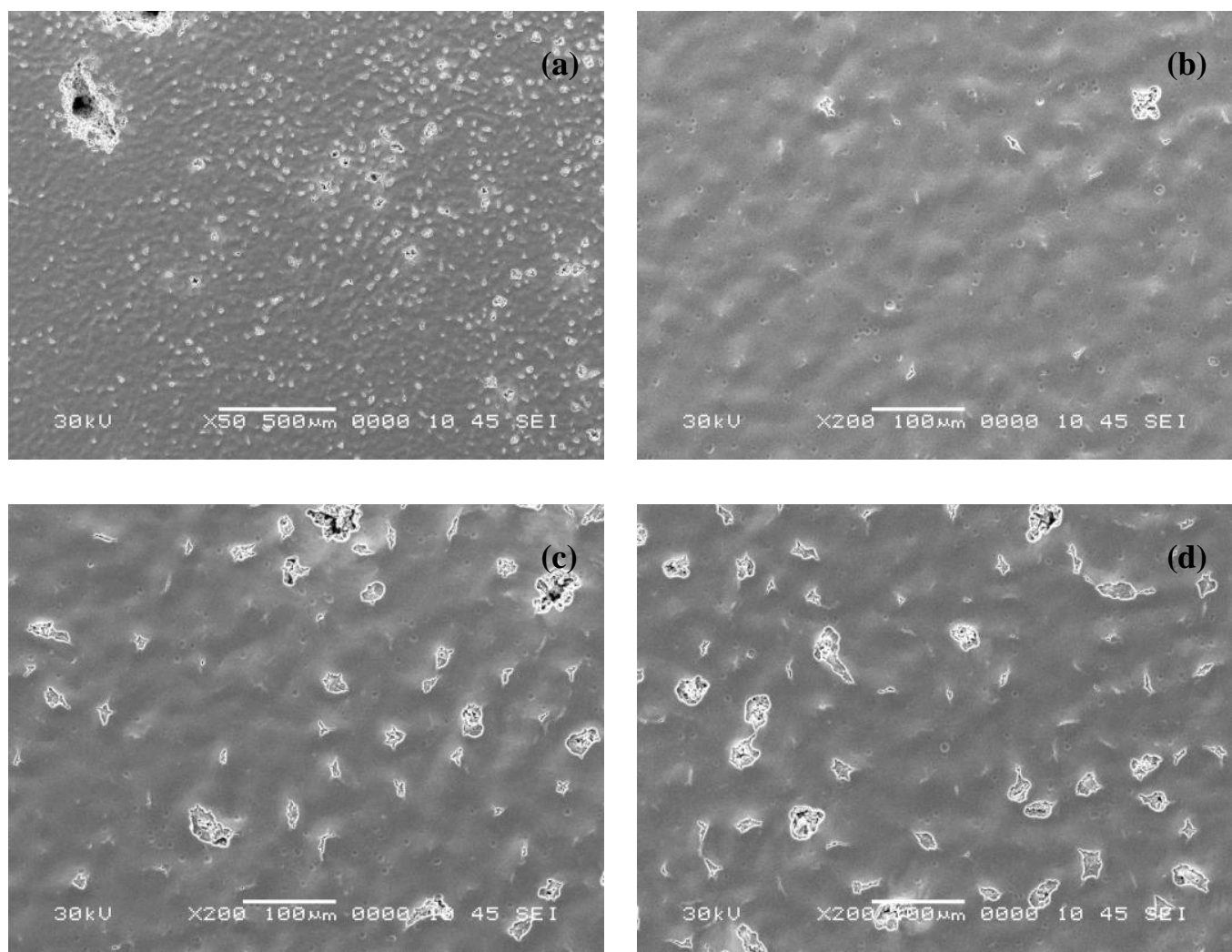

Figure 9.15: SEM images after 13 hours of cavitation erosion testing. NiTi thin film deposited at $600^{\circ} \mathrm{C}$ at $50 \mathrm{~V}(\mathrm{a}) ; 80 \mathrm{~V}(\mathrm{~b}) ; 120 \mathrm{~V}$ (c); and $150 \mathrm{~V}(\mathrm{~d})$.

Figure 9.16 displays the surfaces of the NiTi films after 20 hours of exposure to cavitation erosion. As shown in Figure 9.16 (a), (c) and (d), the surfaces of the samples, which were deposited at $50 \mathrm{~V}, 120 \mathrm{~V}$ and $150 \mathrm{~V}$, were eroded seriously by cavitation, and the NiTi thin film was almost eroded away. The film obtained at $80 \mathrm{~V}$ showed more intact areas (Figure 9.16 (b)) in comparison with other thin films. Therefore, the NiTi 
films produced at $80 \mathrm{~V}$ exhibited the best cavitation erosion resistance after 20 hours testing.
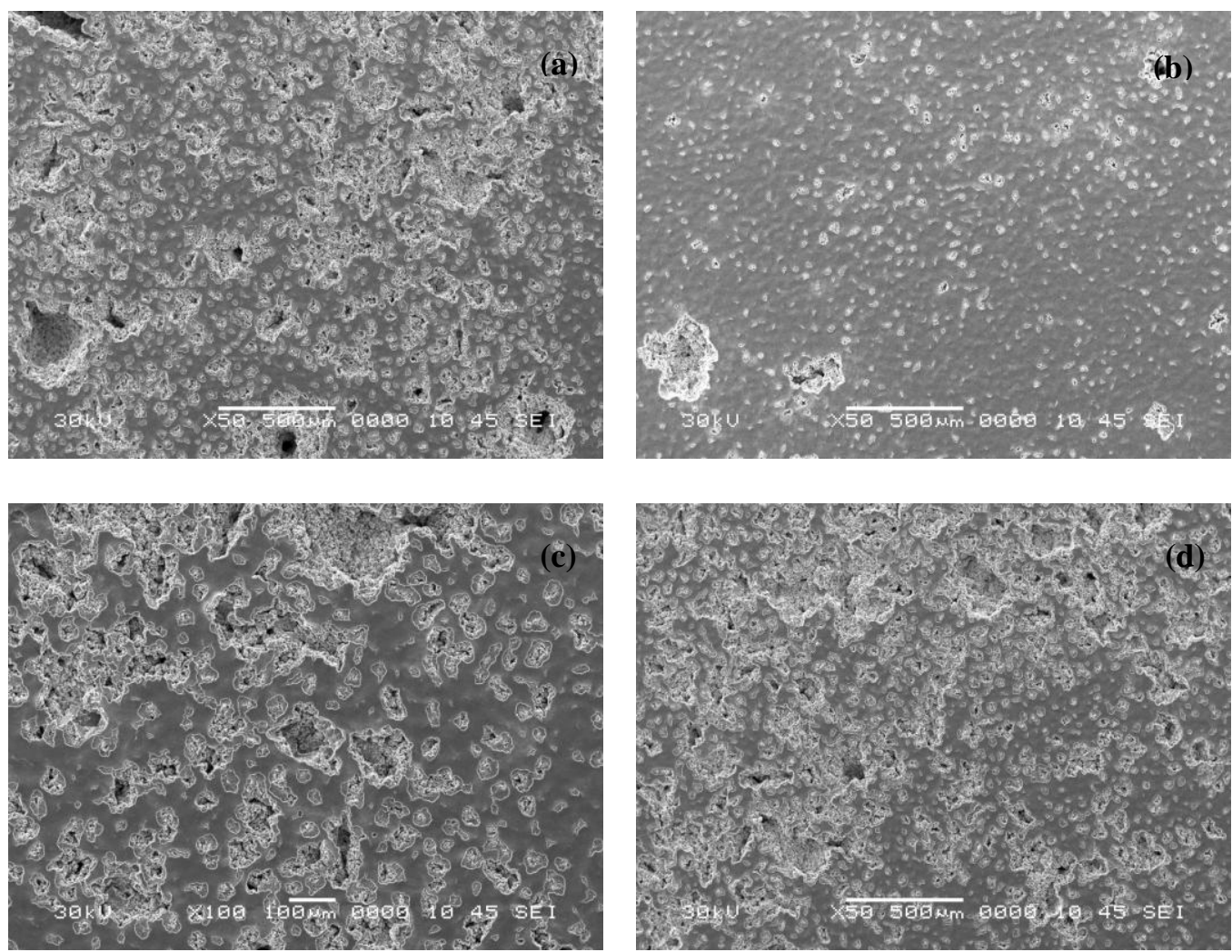

Figure 9.16: SEM images after 20 hours of cavitation erosion testing. NiTi thin film deposited at $600^{\circ} \mathrm{C}$ at $50 \mathrm{~V}($ a); $80 \mathrm{~V}($ b); $120 \mathrm{~V} \mathrm{(c)}$; and $150 \mathrm{~V}$ (d).

Figure 9.17 compares the mass loss curves of the NiTi thin films deposited at different substrate biases. During the first 7 hours, there was no major difference in the mass loss for the four films. The NiTi film obtained at $50 \mathrm{~V}$ started to lose mass very quickly after 13 hours and lost $14.5 \mathrm{mg}$ after 20 hours of erosion. The mass loss rates of films deposited at $120 \mathrm{~V}$ and $150 \mathrm{~V}$ increased sharply after 15 hours and total mass loss is about $10 \mathrm{mg}$. The film produced at $80 \mathrm{~V}$ lost mass at a much lower rate, with only $6 \mathrm{mg}$ lost at the end of testing. 


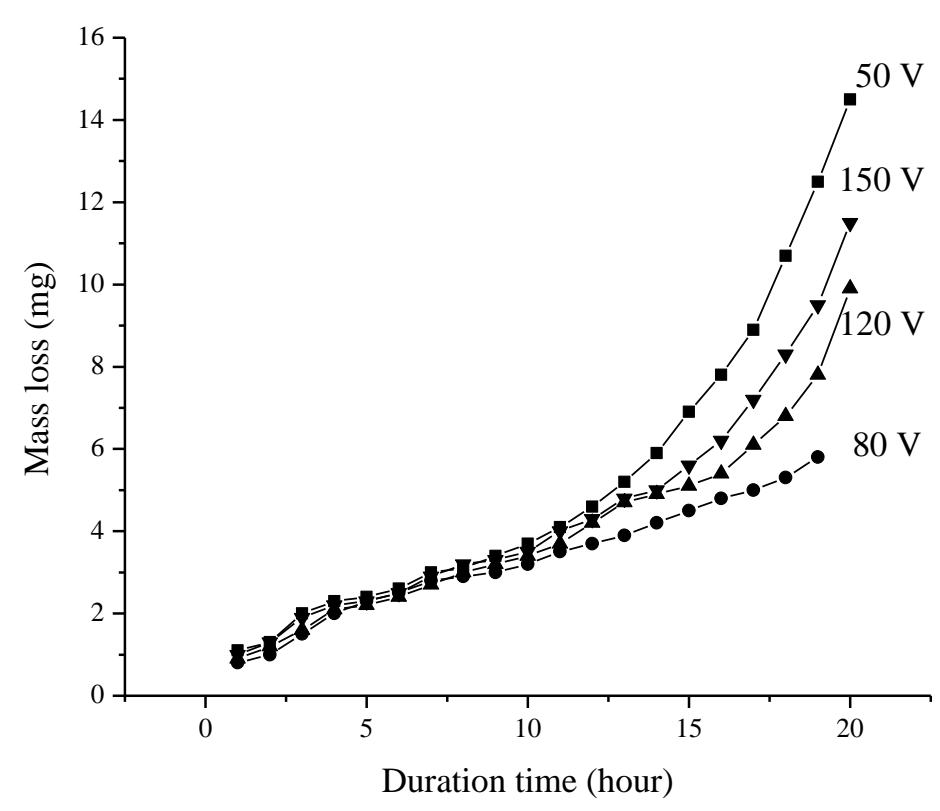

Figure 9.17: Mass loss of NiTi thin films deposited at different substrate biases as a function of cavitation exposure time.

According to the SEM images and the mass loss curves, it is concluded that the NiTi film deposited at the lowest bias, $50 \mathrm{~V}$, showed relatively poor cavitation erosion resistance due to its weaker adhesion to the substrate. The thin film obtained at $80 \mathrm{~V}$ was most resistant to cavitation erosion, which is attributed to the stress-induced thermoelastic martensitic transformation and martensite reorientation. Although the films deposited at $120 \mathrm{~V}$ and $150 \mathrm{~V}$ were also effectively resistant to the cavitation erosion, their cavitation-resistant behaviours were not as good as the film obtained at 80 V. As discussed earlier, a higher bias voltage results in a higher substrate temperature due to the higher impact energy of atoms and ions. The larger grain sizes formed at high substrate temperatures could afftect the cavitation erosion resistance adversely. 


\subsection{Cavitation erosion resistance of thin films on austenitic stainless steel}

Figure 9.18 shows the surface images of the NiTi thin film deposited on an austenitic 316 stainless steel during 20 hours of cavitation erosion. As shown in Figure 9.18 (a), there were some crevices on the surface at low magnification after 4 hours testing. At high magnification in Figure 9.18 (b), the dimple pattern was much more obvious than that on the mild steel shown in Figure 9.2 (f). Due to its lower hardness, the substrate of stainless steel is more likely to deform plastically under the pressure onslaught of cavitating bubbles, leading to rippling of the surface. At the end of 10 hours, film ruptures started to occur due to the plastic flow of the substrate (Figure 9.18 (d)). The film cracks became wider and deeper (Figure 9.18 (f)) due to further erosion at the end of 13 hours. It can be seen in Figure $9.18(\mathrm{~g})$ and $(\mathrm{h})$ that the layer of NiTi coating was almost eroded away by cavitation after 20 hours.
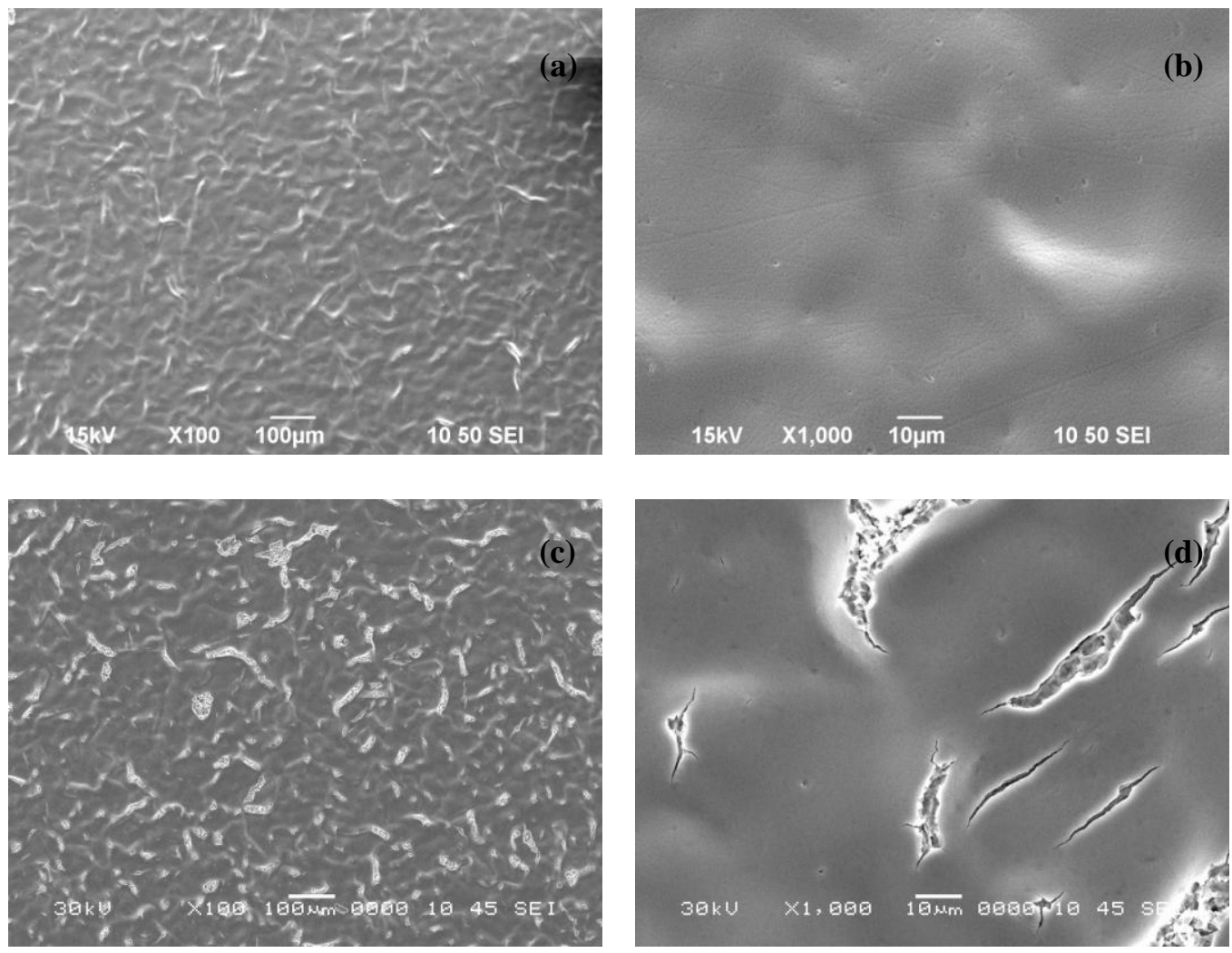

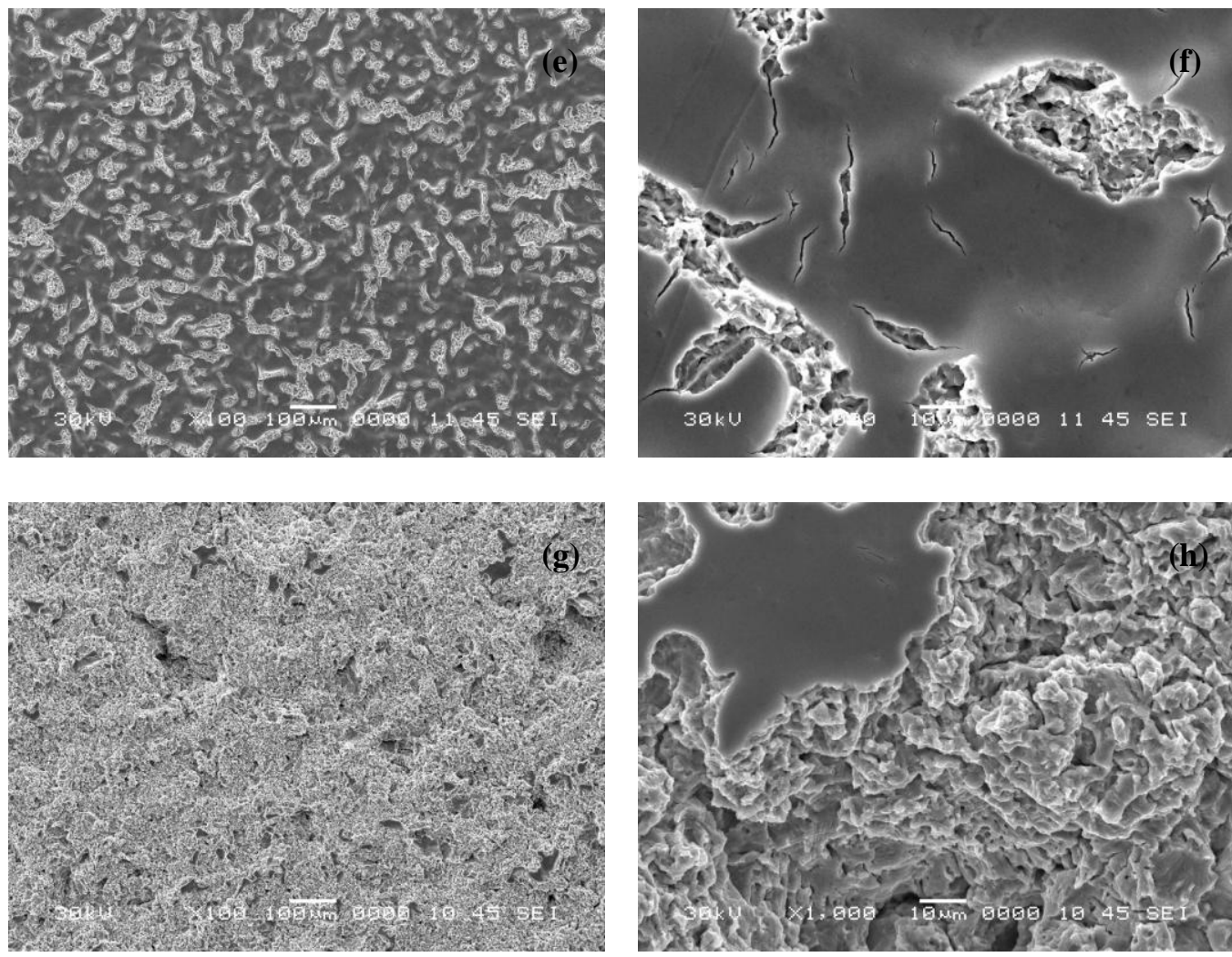

Figure 9.18: Low and high magnification SEM images of the NiTi thin film deposited on austenitic stainless steel after cavitation erosion testing for 4 hours (a) and (b); 10 hours (c) and (d); 13 hours (e) and (f); and 20 hours (g) and (h).

The mass loss of the NiTi thin film on stainless steel substrate during the 20 hours of erosion testing is shown in Figure 9.19. There was no obvious loss in mass in the first 4 hours. The sample started losing mass slowly for up to 10 hours of testing, then the mass loss rate increased dramatically and the cumulative mass loss was $22 \mathrm{mg}$ at the end of 20 hours. In comparison, the NiTi film on mild steel (Figure 9.6) lost mass very slowly during the whole time of erosion testing and only lost $6 \mathrm{mg}$ by the end of the test. 


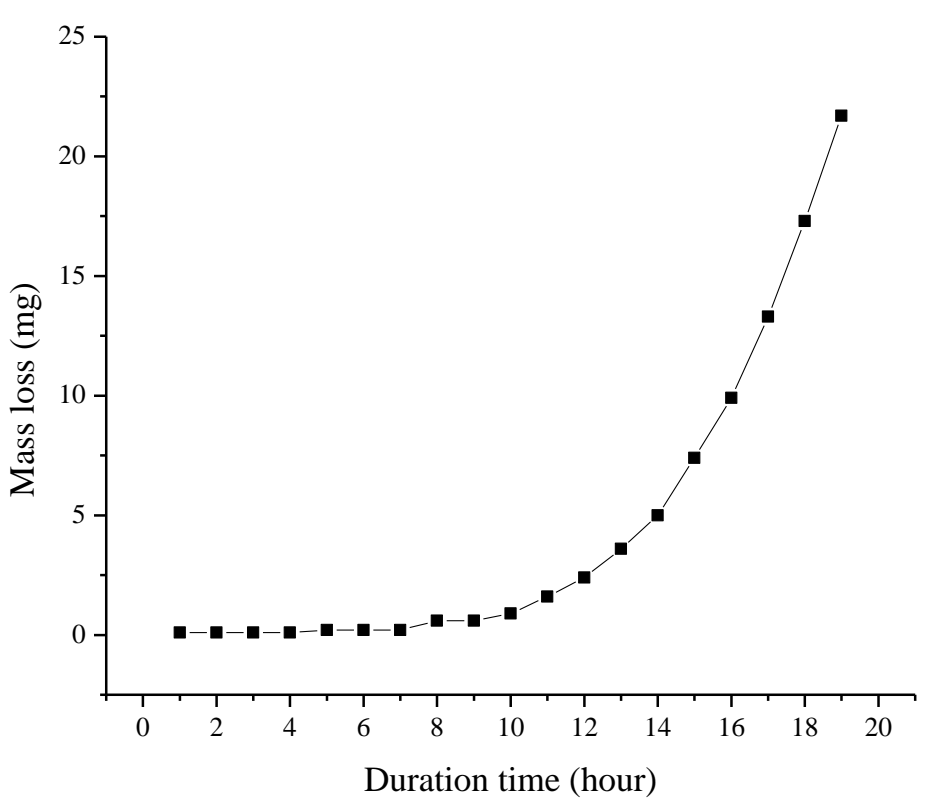

Figure 9.19: Mass loss of the NiTi thin film deposited on austenitic stainless steel as a function of cavitation exposure time.

It is concluded that the NiTi film on mild steel showed more enhanced cavitation erosion resistance than the film on austenitic stainless steel. One relevant factor is likely to be the hardness of the substrate. The mild steel used in the experiment is harder than the stainless steel. Therefore, the mild steel is less likely to deform plastically and to show more resistance to the cavitation stresses. Another reason could be associated with the low thermal conductivity of the stainless steel substrate. The higher temperature obtained during deposition of the stainless steel substrate results in larger grain sizes of the deposited films, which led to degradation of the cavitation erosion resistance of the thin film. 


\section{Chapter 10}

\section{Conclusions and Future Research}

\subsection{Conclusions}

Procedures have been successfully developed to produce adherent and homogeneous polycrystalline NiTi films on mild steel and stainless steel substrates. Control of the process variables enabled deposition of smooth, defect-free films with a nominated composition.

- The Ti content in the as-deposited NiTi thin films increased with an increase in the arc current and decreased with an increase of substrate bias voltage.

- The NiTi films deposited at low temperatures and low bias voltages were amorphous, whereas crystalline films were produced at high temperatures and high bias voltages. The crystalline film had a strong preferred orientation. At the highest temperature $\left(600^{\circ} \mathrm{C}\right)$ or highest substrate bias voltage $(150 \mathrm{~V})$, the obtained films were dominated by B2 parent phase.

- The film roughness increased with increasing substrate temperature.

- The hardness and elastic modulus of the films increased with increasing bias voltage.

- The bonding force became stronger as the substrate temperature or bias voltage increased. 
- The near-equiatomic NiTi thin film shows much better cavitation erosion resistance than the reference alloy of austenitic stainless steel.

The properties and cavitation performance of a range of films deposited on both mild steel and stainless steel substrates have been rationalized in terms of processing variables used in their production and the microstructures of the films. Overall, the research program demonstrated that pseudoelastic NiTi films, deposited by FADS, onto a steel substrate can dramatically increase the cavitation erosion resistance relative to that of bulk austenitic stainless steel. This remarkable improvement was effected by deposition of films of about 2 microns thickness. In particular, equiatomic films containing martensite and residual parent phase showed outstanding cavitation erosion resistance.

\subsection{Future research}

- Although it was inferred that pick-up of $\mathrm{O}$ and $\mathrm{N}$ occurred in the films deposited at high temperature and with high bias voltage, testing of this hypothesis was not included within the scope of the current work. Sensitive compositional analysis of light elements could be undertaken in future work using wavelength dispersive spectrometry (WDS), windowless or ultrathin window EDS or electron energy loss spectroscopy (EELS). 
- The transformation behaviour of NiTi thin films constrained on steel substrates can be investigated during heating and cooling using an environmental scanning electron microscopy (ESEM).

- As-deposited amorphous NiTi thin films on the substrates can be crystallized by heat treatment using a salt bath, so that comparison can be made of the cavitation erosion resistances of crystallized (untextured) amorphous films and as-deposited crystalline (strongly textured) films.

- Effects of heat treatment on the cavitation erosion resistance of crystalline NiTi films can be studied to elucidate the role of precipitates.

- The effect of the thickness of the NiTi film on cavitation erosion resistance can be investigated, with the aim of optimizing film thickness.

- Alloying elements such as $\mathrm{Cu}$ and $\mathrm{Pt}$ can be introduced to modify the microstructures of NiTi-based thin films. Cavitation erosion resistance can be characterized to ascertain whether it can be enhanced by alloying.

- The potential of NiTi thin films produced by FADS for application as microsensors and micro-actuators in the field of micro-electro-mechanical system (MEMS) can be explored. 


\section{References}

[1] Hammitt, F.G. and Heymann, F.J., (1975), Metals Handbook ( $8^{\text {th }}$ edition), vol.10, p160.

[2] Richman, R.H., Rao, A.S. and Hodgson, D.E., (1992), Wear, vol. 157 (2), p401.

[3] Zimmerley, C.A., Inal, O.T. and Hickman, R.H., (1994), Mater. Sci. Eng. A, vol. $188, \mathrm{p} 251$.

[4] Wayman, C.M. and Otsuka, K., (1998), Shape Memory Materials, Cambridge Uni. Press, UK.

[5] Liu, Y., Favier, D. and Orgeas, L., (2006), J. Intel. Mat. Sys. Str., vol. 17, p1121.

[6] Lieberman, D.S., Schmerling, M.A. and Karz, R.W., (1975), Met. Soc. AIME Proceedings, (Ed. J. Perkins), Plenu Press, New York.

[7] Stella, J., Schuller, E., Hebing, C., Hamed, O.A., Pohl, M. and Stover, D., (2006), Wear, vol. 260, p1020.

[8] Ishida, A., Takei, A. and Miyazaki, S., (1993), Thin Solid Films, vol. 228, p210.

[9] Otsuka, K. and Ren, X., (2005), Prog. Mater. Sci. vol. 50, p511.

[10] Kawamura,Y., Gyobu, A., Horikawa, H. and Saburi, T., (1995), J. Phys. IV, vol. 5 (8), pC8.

[11]Chen, X.Y., Lu, Y.F., Ren, Z.M. and Zhu, S., (2002), J. Mater. Res., vol. 17(2), p279.

[12]Makino, E., Uenoyama, M. and Shibata, T., (1998), Sens. Actuators A- Phys., vol. $71, \mathrm{p} 187$.

[13]Mustapha, N. and Howson, R.P., (1998), Vacuum, vol. 49, p75. 
[14] Stanford, N., Huang, S.W. and Dunne, D., (2008), Mater. Sci. Eng. A, vol. 473, p172.

[15]He, J.L., Won, K.W., Chang, C.T., Chen, K.C. and Lin, H.C., (1999), Wear, vol. 233-235, p104.

[16]Hiraga, H., Inoue, T., Shimura, H. and Matsunawa, A., (1999), Wear, vol. 231, p272.

[17]Douglas, J.F., Gasiorek, J.M. and Swaffield, J.A. (1995), Fluid Mechanics, Longman Scentific and Technical, London.

[18]Knapp, R.T., Daily, J.W. and Hammitt, F.G., (1970), Cavitation, McGraw-Hill, New York.

[19]Benjamin, T.B. and Ellis, A.T., (1966), Phil. Trans. R. Soc. Lond. A, vol. 260, p221.

[20]Gould, G. C., (1973). Mech. Failures Prevent. Group Proc., p23.

[21]Margulis, M. A., (1995), Sonochemistry and Cavitation, Gordon and Breach Publishers, Langhorne, USA.

[22]Dular, M., Bahert, B., Stoffel, B. and Sirok, B., (2004), Wear, vol. 257, p1176.

[23]Dular, M. and Osterman, A., (2008), Wear, vol. 265, p811.

[24] Osterman, A., Bachert, B., Sirok, B. and Dular, M., (2009), Wear, vol. 266, p945.

[25]ASTM Designation G32-92, (1997), Annual Book of ASTM Standards, vol. 03(02), p103.

[26]Tang, C.H., Cheng, F.T. and Man, H.C., (2004), Mater. Sci. Eng. A, vol. 373, p195.

[27]Yu, H., Zheng, Y. and Yao, Z., (2009), J. Mater. Sci. Technol., vol. 25 (6), p758.

[28]Reddy, A.V., Sundararajan, G., Sivakumar, R. and Rao, P.R., (1984), Acta Metall., vol. 32, p1305. 
[29] Suh, N.P., Saka, N., (1977), Wear, vol. 44, p135.

[30]Kwok, C.T., Man, H.C. and Cheng, F.T., (1998), Materials Science and Engineering A, vol. 242, p108.

[31]Chang, L. C. and Read, T. A. (1951), Trans. AIME., vol. 189, p47.

[32]Basinski, Z. B. and Christian, J. W. (1954), Acta Metall., vol. 2, p101.

[33]Buehler, W. J., Glifrich, J. W. and Wiley, R. C. (1963), J. Appl. Phys., vol. 34, p1475.

[34]Dunne, D. P., (2000), Mater. Forum, vol. 24, p95.

[35]Taylor, A. and Floyd, R.W., (1950), Acta Crystallogr., vol. 3, p285.

[36] Massalski T.B., Okamoto H., Subramanian P.R. and Kacprzak L., (1990), Binary alloy phase diagrams, ASM Int., Materials Park, OH., vol. 3, p2874.

[37]Otsuka, K. and Shimizu, K., (1970) Scr. Metall., vol. 4, p469.

[38]Buhrer, W., (1982), J. de Phys., vol. 43, pC4.

[39] Knowles, K.M., (1982), Phil Mag A, vol. 45, p357.

[40]Otsuka, K., Sawamura, T. and Shimizu, K., (1971), Phys. Stat. Sol. A, vol. 5, p457.

[41]Ling, H.C. and Kaplow, R., (1981), Metell. Trans. A, vol. 12, p2101.

[42]Wechsler, M.S., Lieberman, D.S. and Read, T.A., (1953), Trans. AIME, vol. 197, p1503.

[43]Lieberman, D.S., Wechsler, M.S. and Read, T.A., (1955), J. Appl. Phys., vol. 26, p473.

[44]Bowles, J.S. and Mackenzie, J.K., (1954), Acta Metall., vol. 2, p129.

[45]Bilby, B.A. and Christian, J.W., (1956), The Mechanism of Phase Transformations 
in Metals, Inst. of Metals, London, p121.

[46] Tadaki, T., Otsuka, K. and Shimizu, K., (1988), Ann. Rev. Mater. Sci. vol. 18, p25.

[47]Delaey, L., Krishnan, R.V., Tas, H. and Warliont, H., (1974), J. Materials Sci., vol. 9, p1521.

[48]Liu, Y., (1990), Shape Memory Behaviour in NiTi, University of Western Australia.

[49]Tan, G., (2005), Thermomechanical Behaviour of NiTi, School of Mechanical Engineering, University of Western Australia.

[50]Hanlon, J.E., Butler, S.R. and Wasilewski, R.J., (1967), Trans. Metall. Soc. AIME, vol. 239, p1323.

[51]Wasilewski, R.J., Butler, S.R. and Hanlon, J.E. (1967), Metall. Soc. J., vol. 1, p104.

[52]Mantovani, D., (2000), JOM-J. Min. Met. Mat. Soc., vol. 52 (10), p36.

[53]Ren, X. and Otsuka, K., (1997), Nature, vol. 389, p 579.

[54]Liang, Y.N., Li, S.Z., Jin, Y.B. and Li, S., (1996) Wear, vol.198, p236

[55]Suzuki, Y. and Kuroyanagi, T., (1979), Tianium Zirconium, vol. 27, p67.

[56]Shida, Y. and Sugimoto, Y., (1991), Wear, vol. 146, p219.

[57]Richman, R.H., Rao, A.S. and Hodgson, D.E., (1992), Wear, vol. 157, p401.

[58]Winzek, B., Schmiz, S., Rumpf, H., Sterzl, T., Hassdorf, R., Thienhaus, S. Feydt, J., Moske, M. and Quandt, E. (2004), Mater. Sci Eng. A, vol. 378, p40.

[59]Miyazaki, S. and Ishida, A., Mater. Sci. Eng. A, (1999), vol. 273-275, p106.

[60]Nomura, K. and Miyazaki, S., (1995), SPIE Proc. Ser., vol. 2441, p149.

[61]Miyazaki, S., No, V.H., Kitamura, K., Khantachawana, A. and Hosoda, H. (2000), Int. J. Plasticity, vol. 16, p1135. 
[62] Johnson, A.D. and Shahoian, E. J., (1995), IEEE Proceedings on Micro Electro Mechanical Systems, MEMS'95, p216.

[63] Kohl, M., Dittmann, D., Quandt, E. and Winzek, B., (2000), Sens. Actuators, vol. $83, \mathrm{p} 214$.

[64]Benard, W.L., Kahn, H., Heuer, A.H. and Huff, M.A., (1997), Proceedings of the 9th International Conference on Solid-State Sensors and Actuators, Transducers'97, p361.

[65]Bunshah, R. F., (1994), Handbook of Dpeposition Technologies for Films and Coatings, Noyes Publications, Park Ridge, N.J.

[66] Hayward, T., (2001), Surface Engineering of Sheet Metal Forming Dies, Department of Materials Engineering, University of Wollongong.

[67]Mathews, A. and Rickerby, D.S., (1991), Advanced Surface Coatings: A Handbook of Surface Engineering. Chapman and Hall, New York.

[68]Rigsbee, J.M., (1989), Surface Modification Engineering, Volume 1: Fundamental Aspects, (Ed. Ram Kossowsky), CRC Rress, Inc., Boca Raton.

[69]T.A. Edison, US Patent 484582 (1892).

[70]Sanders, D.M., (1990), Handbook of Plasma Processing Technology, Fundamentals, Etching, Deposition and Surface Interactions, (Ed. Rossnagel S. M., Cuomo, J. J. and Westwood, W. D.), Noyes Publications, Park Ridge, N.J.

[71] Sanders, D. M. and Anders, A., (2000), Surf. Coat. Technol., vol. 133-134, p78.

[72]Helmersson, U., Lattemann, M., Bohlmark, H., Ehiasarian, A.P. and Gudmundsson, J.T., (2006), Thin Solid Films, vol. 513, p1.

[73]Mesyats, G.A. and Proskurovsky, D.I., (1989), Pulsed Electrical Discharge in Vacuum, Springer-Verlag, Berlin.

[74]Mesyats, G.A., (1995), IEEE Trans. Plasma Sci., vol. 23, p879. 
[75]Beilis, I., Djakov, B.E., Juttner, B. and Pursch, H., (1997), J. Phys., D, Appl. Phys., vol. 30, p119.

[76]Juttner, B., (2001), J. Phys., D, Appl. Phys., vol. 34, p103.

[77] Anders, A., Anders, S., Jüttner, B. and Luck, H., (1996), IEEE Trans. Plasma Sci., vol. 24, p69.

[78]Sanders, D.M., Boercker, D.B. and Falabella, S., (1990), IEEE Transactions on Plasma Science, vol. 18 (6), p883.

[79]Petrov, I., Losbichler, P., Bergstrom, D., Greene, J.E., Munz, W.-D., Hurkmans, T. and Trinh, T., (1997), Thin Solid Films, vol. 302, p179.

[80]Aksenov, I.I., Belous, V.A., Padalka, V.G. and Koroshikh, V.M., (1978), Sov. J. Plasma Phys., vol. 4, p425.

[81] Gorokhovsky, V.I., U.S. patent, 5,435,900 (1995).

[82]Welty, R.P., U.S. Patent, 5,480527 (1996).

[83] Anders, S., Anders, A., Dickenson, M.R., MacGill, R.A. and Brown, I.G., (1997), IEEE Trans. Plasma Sci., vol. 25, p670.

[84] Anders, A. and MacGill, R.A., (2000), Surf. Coat. Technol., vol. 133-134, p96.

[85]Martin, P.J., Bendavid, A. and Takikawa, H., (1999), J. Vac. Sci. Technol. A, vol. 17 (4), p2351.

[86] Martin, P.J., Netterfield, R.P. Bendavid, A. and Kinder, T.J., (1992), Surf. Coat. Technol., vol. 54-55, p136.

[87]Boxman, R.L., Zhitomirsky, V., Alterkop, B., Gidalevich, E., Beilis, I., Keidar, M. and Goldsmith, S., (1996), Surf. Coat. Technol., vol. 86-87, p243.

[88] Voitsenya, V.S., Gorbanyuk, A.G., Onishenko, I.N., Safronov, B.G., Khizhnyak, N.A. and Shkoda, V.V., (1967), Sov. Phys. Tech. Phys., vol. 12, p185. 
[89] Storer, J., Galvin, J.E. and Brown, I.G., (1989), J. Appl. Phys., vol. 66, p5245.

[90]Martin, P.J. Netterfield, R.P., Kinder, T.J. and Descotes, L., (1991), Surf. Coat. Technol., vol. 49, p239.

[91]Wang, X., (2007), Crystallization and Martensitic Transformation Behavior of NiTi Shape Memory Alloy Thin Films, Harvard University.

[92]Tang, W., Sundmann, B., Sandstrom, R. and Quiu, C., (1999), Acta Mater., vol. 47, p3457.

[93] Yang, Y.Q., Jia, H.S., Zhang, Z.F., Shen, H.M., Hu, A. and Wang, Y.N., (1995), Mater. Lett., vol. 22, p137.

[94] Warlimont, H., Delaey, L., Krishnan, R.V. and Tas, H., (1974), J. Mat. Sci., vol. 9, p1545.

[95]Kroger, A., Dziaszyk, S., Frenzel, J., Somsen, Ch., Dlouhy, A. and Eggeler, G., (2008), Mater. Sci. Eng. A, vol. 481-482, p452.

[96]Carroll, M.C., Somsen, Ch. And Eggeler, G., (2004), Scripta Mater., vol. 50, p187.

[97]Nam, T.H., Saturi, T., Kawamura, Y. and Shimizu, K., Mater. Trans. JIM, (1994), vol. $35, \mathrm{p} 103$.

[98] Batallard, L., Bidaux, J.-E. and Gotthardt, R., (1998), Philos. Mag. A, vol 78 (2), p327.

[99]Buckle, H., (1959), Metallurgical Reviews, Institute of Metals, London.

[100] Wang, C.B., Tu, R., Goto, T., Shen, Q. and Zhang, L.M., (2009), Mater. Chem. Phys., vol. 113, p130.

[101] Lee, N.E., Cahill, D.G. and Greene, J.E., (1996), J. Appl. Phys., vol. 80, p2199.

[102] Properties and Selection: Stainless Steels, Tool steels and Special-Purpose Metals, ASM Metals Handbook ( $9^{\text {th }}$ Edition), (1980), vol. 3, p351. 
[103] Tan, L., Shaw, G., Sridharan, K. and Crone, W., Mech. Mater., (2005), vol. 37, p1059.

[104] Cheng, Y. and Zheng, Y.F., (2006), Mater. Sci. Eng. A, vol. 438-440, p1146.

[105] Guruvenket, S., Ghatak, J., Satyam, P.V. and Rao, G.M., (2005), Thin Solid Films, vol. 478, p256.

[106] Wu, S.K., Lin, H.C. and Yeh, C.H., (2000), Wear, vol. 244, p85.

[107] Richman, R.H., Rao, A.S.and Kung, D., (1995), Wear, vol. 181-183, p80.

[108] Wu, S.K., Lin, H.C.and Chen, C.C., (1999), Mater. Lett., vol. 40, p27.

[109] Bregliozzi, G., Schino, A.D., Ahmed, S.I.U., Kenny, J.M. and Haefke, H., (2005), Wear, vol. 258, p503. 


\section{Acronyms}

A: austenite

$\mathrm{A}_{\mathrm{F}}$ austenite finish temperature

$\mathrm{A}_{S}$ : austenite start temperature

AFM: atomic force microscopy

ASTM: American society for testing and materials

B2: TiNi in a body centered cubic lattice structure

B19': TiNi in a monoclinic lattic structure

BCC: body centered cubic

CAP: cathodic arc plasma

DSC: differential scanning calorimeter

EDS: energy dispersive $\mathrm{x}$-ray spectroscopy

FADS: filtered arc deposition system

FCC: face centered cubic

FIB: focused ion beam

$\mathrm{H}_{\mathrm{p}}$ : plastic depth

HPV: habit plane variant

IPS: invariant plain strain

LCL: lower critical load

LCV: lattice correspondence variant

LD: lattice deformation 
LIS: lattice invariant shear

LR: lattice rotation

M: martensite

$\mathrm{M}_{\mathrm{S}}$ : martensite start temperature

$\mathrm{M}_{\mathrm{F}}$ : martensite finish temperature

MEMS: micro-electro-mechanical system

MS: mild steel

Nital: solution of alcohol and nitric acid

Nitinol: nearequiatomic NiTi alloy

PE: pseudoelasticity

PVD: physical vapour deposition

$\mathrm{R}$ : rhombohedral phase

$\mathrm{R}_{\mathrm{q}}$ : Root Mean Square roughness

RLE: rubberlike effect

SE: superelasticity

SEM: scanning electron microscope

SM: shape memory

SMA: shape memory alloy

SME: shape memory effect

SS: stainless steel

Struers OPS: colloidal silica suspension

TEM: transmission electron microscopy 
UCL: upper critical load

UMIS: ultra micro-indentation system

WLR: Wechsler, Lieberman and Read

XRD: X-ray diffraction 